\title{
Cultivating Ownership of Development Aid: The Role of Civil Society in the Pacific
}

\section{Pedram Pirnia}

Student ID \# 300244807

A thesis submitted to the Victoria University of Wellington in fulfilment of the requirements for the degree of Doctor of Philosophy 2016 
Table of Contents

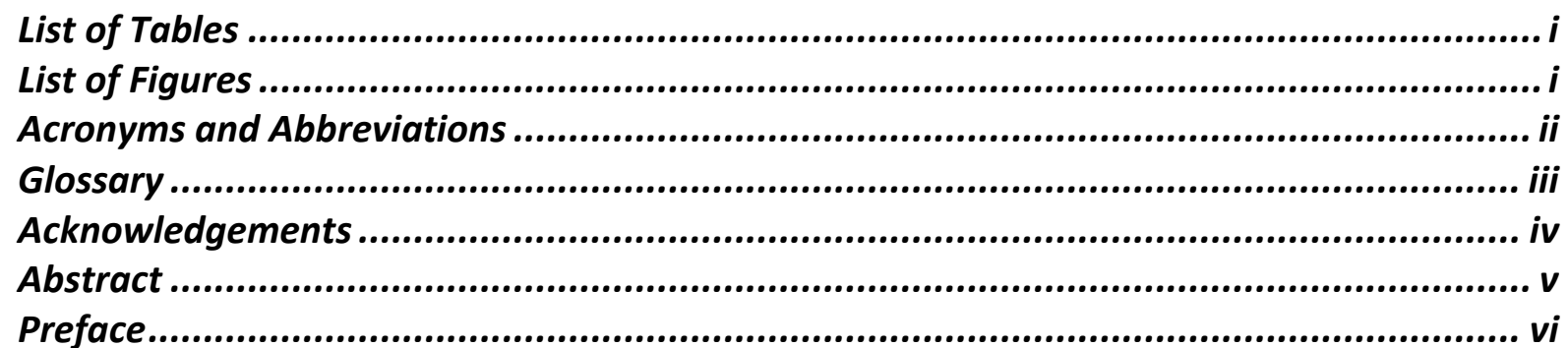

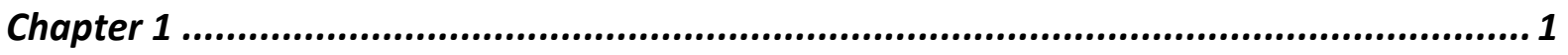

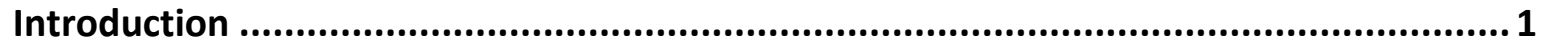

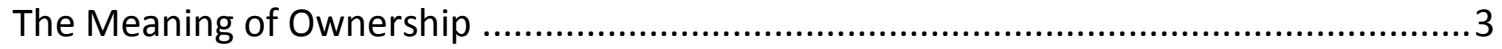

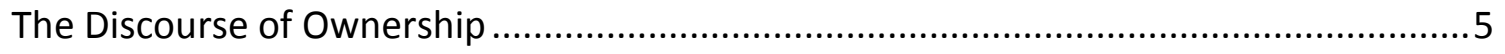

Variables and Characteristics of Ownership ................................................................ 7

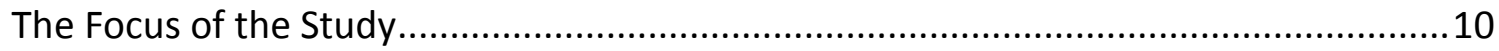

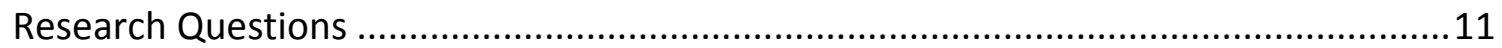

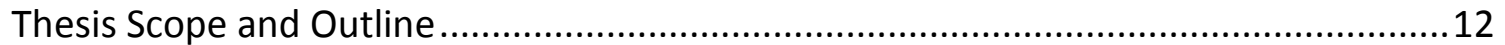

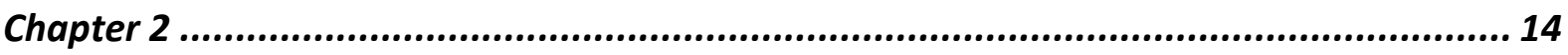

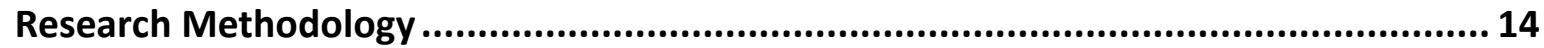

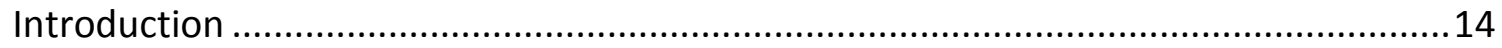

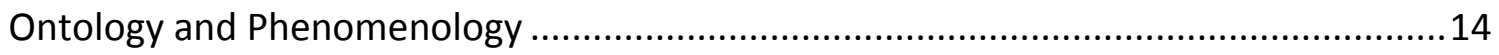

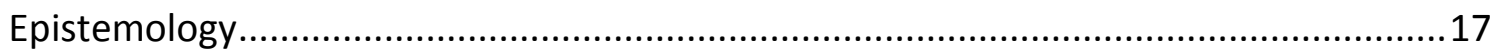

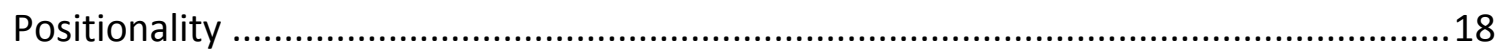

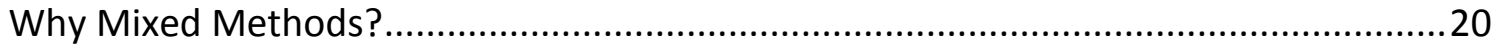

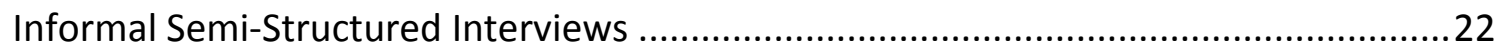

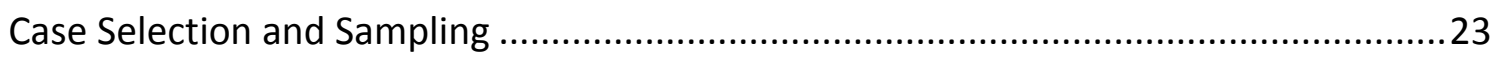

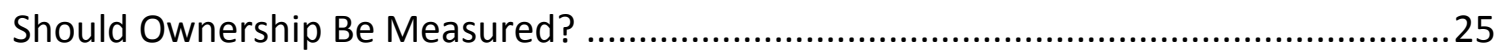

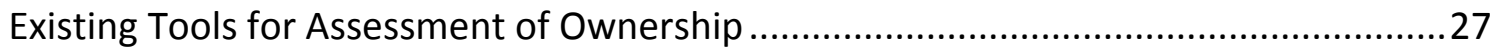

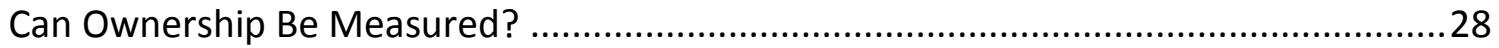

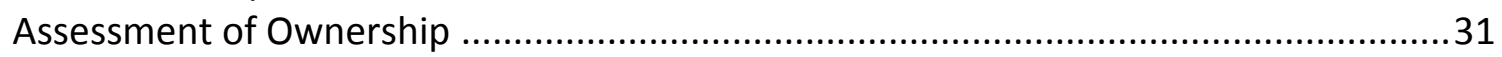

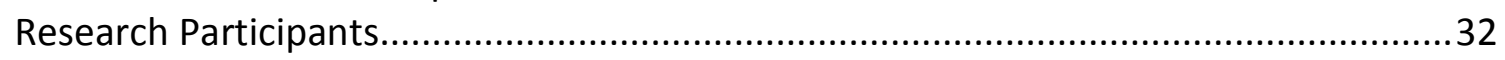

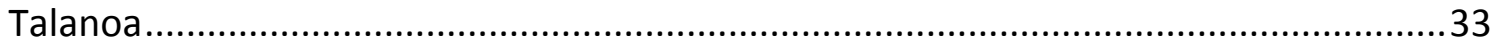

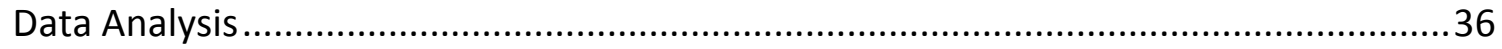

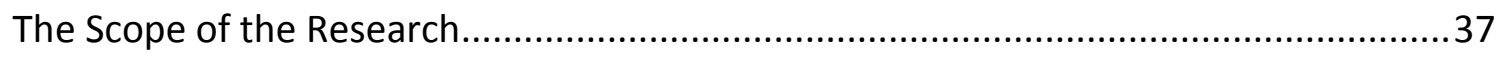

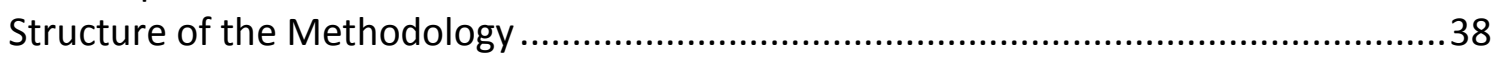

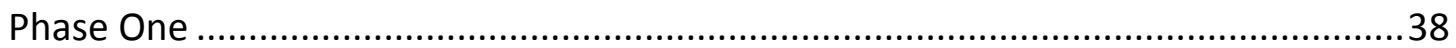

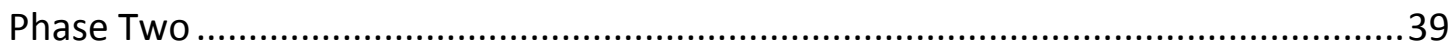

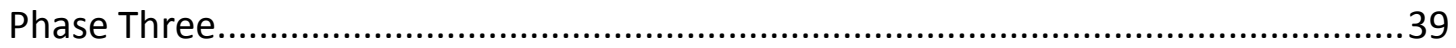

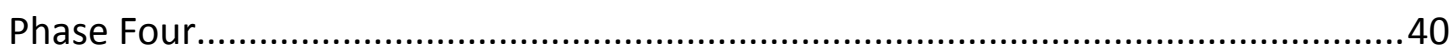

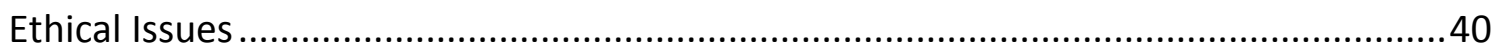

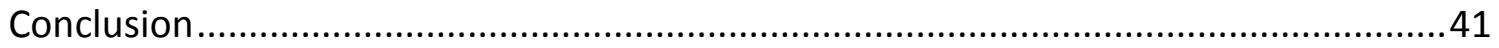




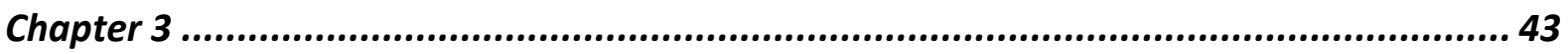

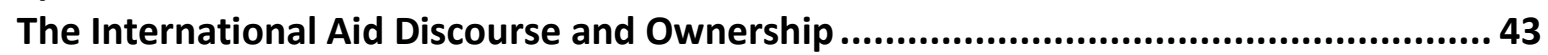

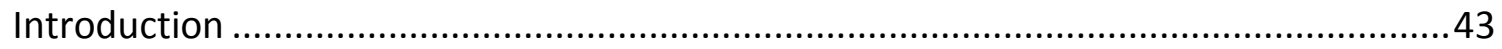

Contextual Background - The Global Aid Discourse .................................................43

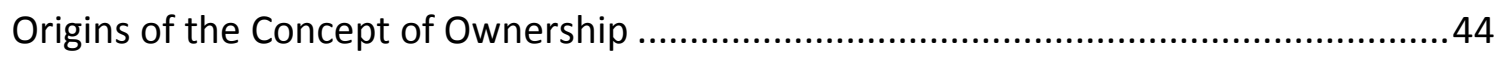

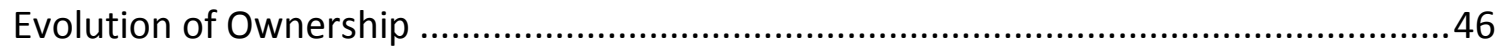

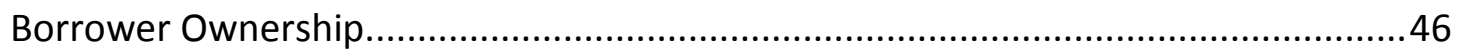

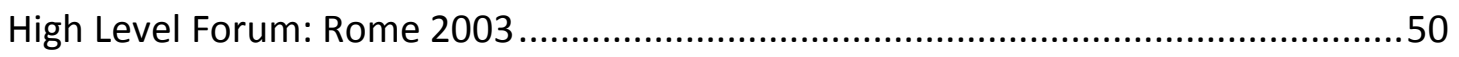

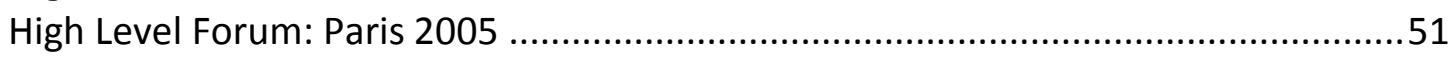

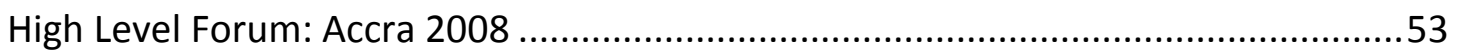

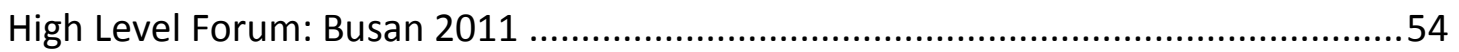

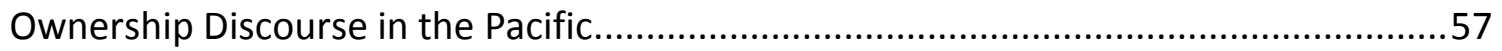

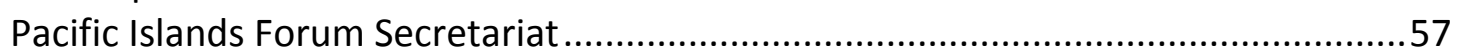

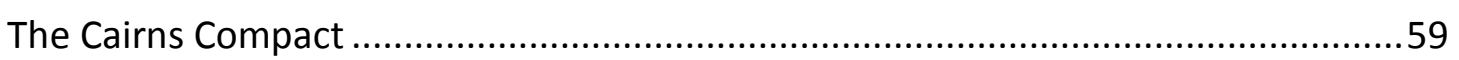

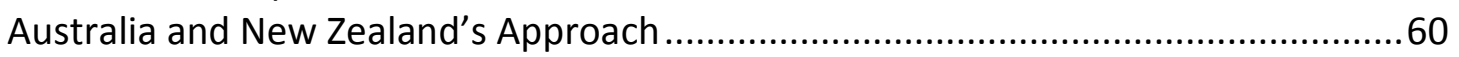

International Aid and Development Organisations in the Pacific ..............................62

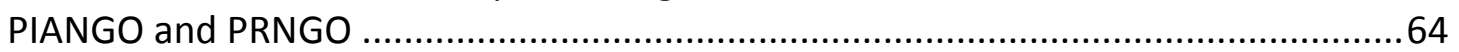

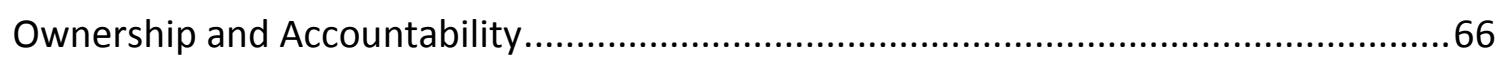

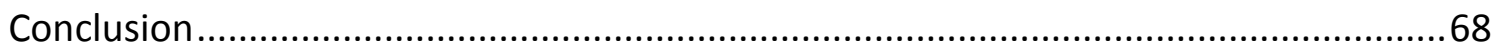

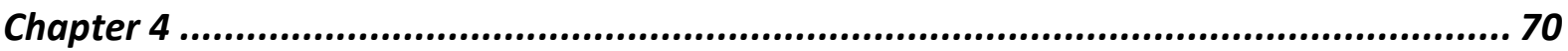

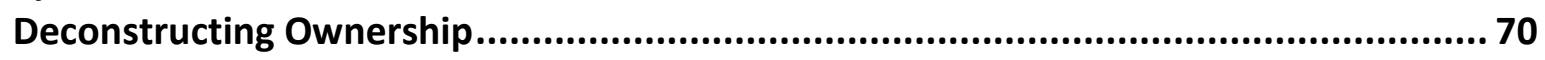

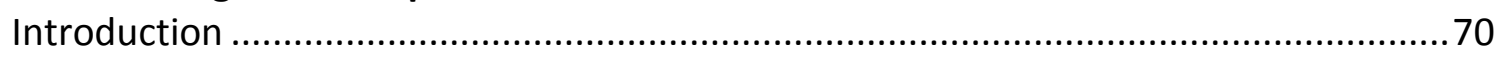

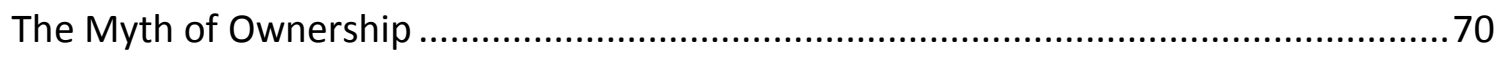

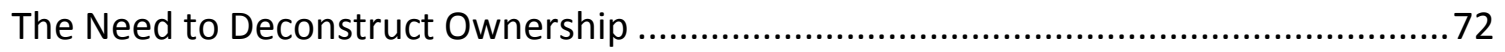

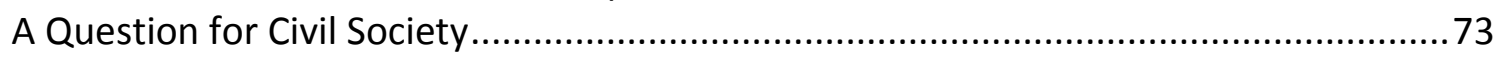

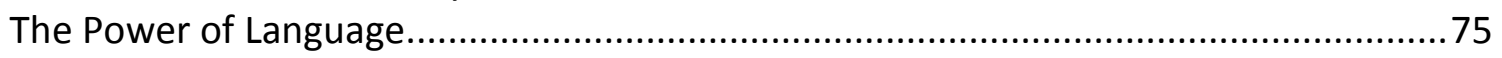

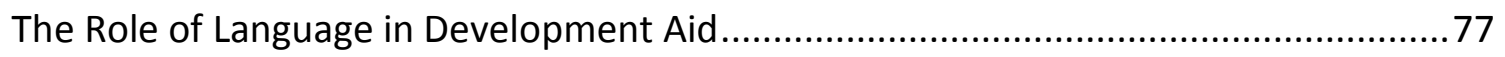

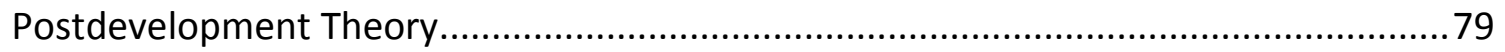

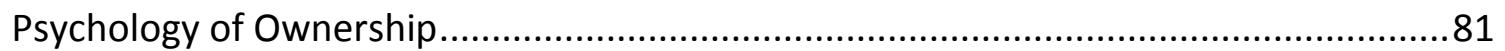

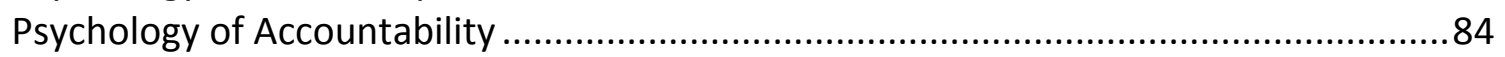

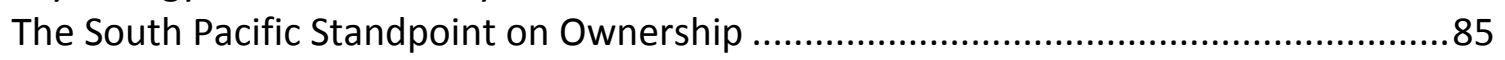

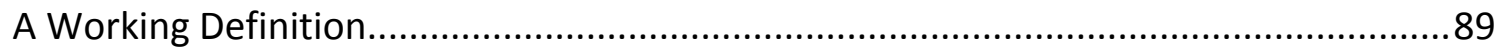

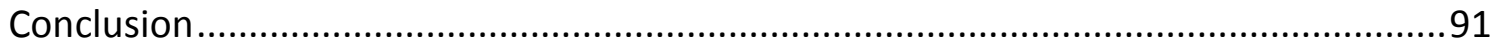

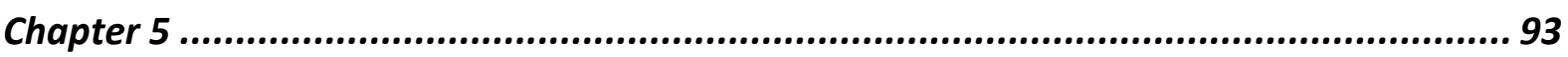

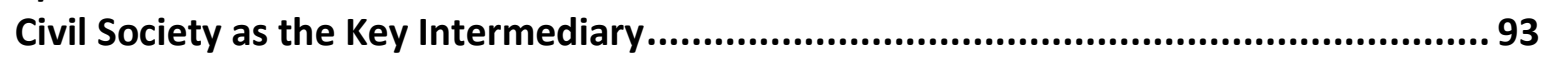

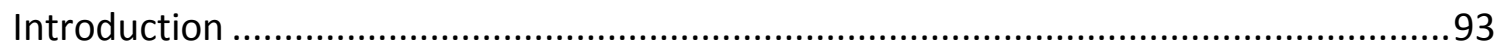

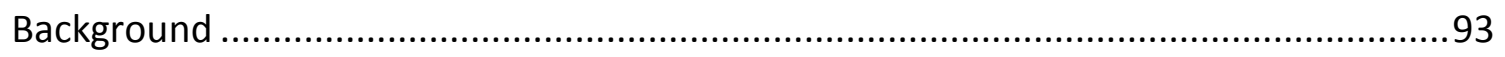

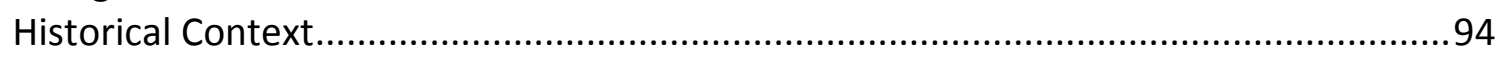

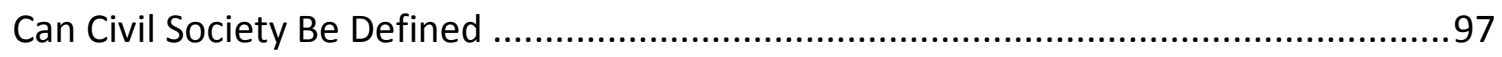

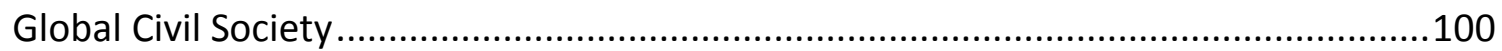

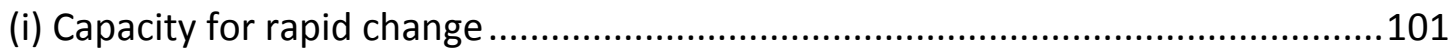

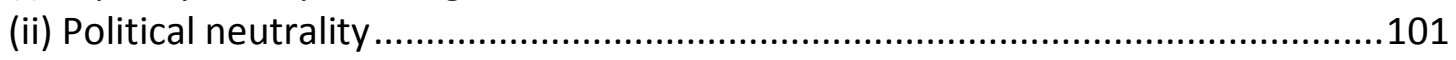

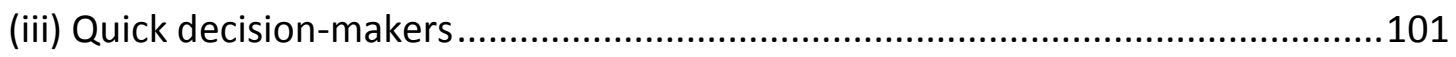




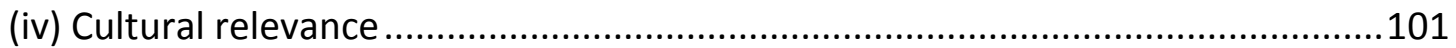

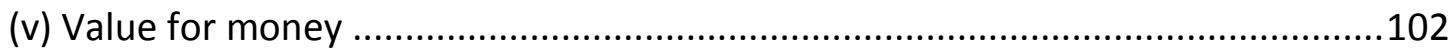

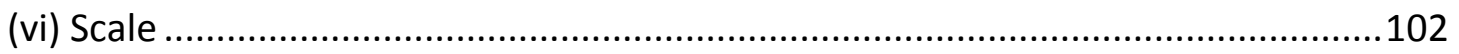

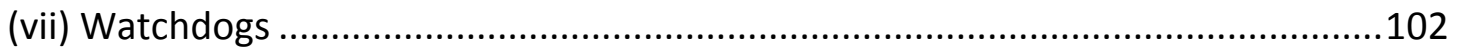

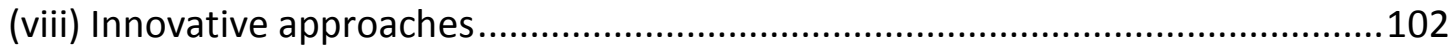

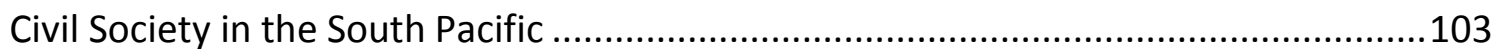

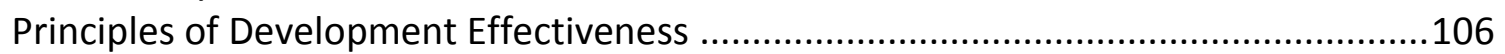

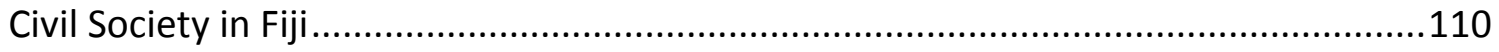

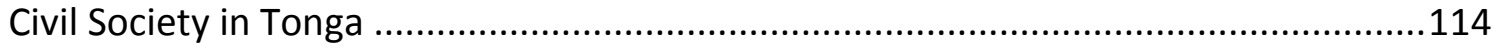

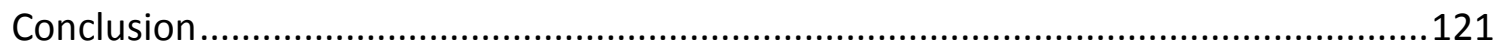

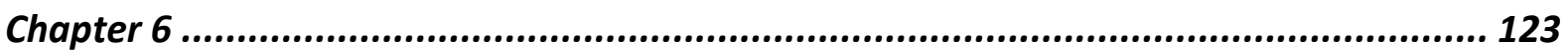

Mainstreaming of Rural Development Innovation Tonga (MORDI) ......................... 123

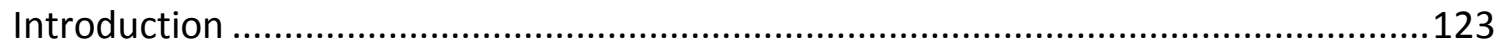

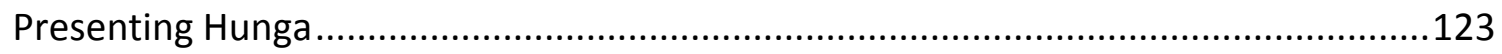

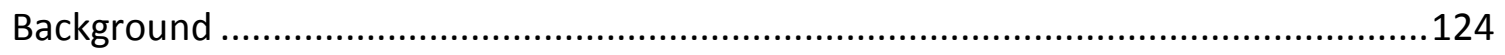

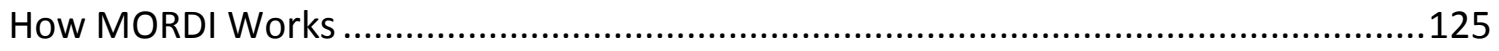

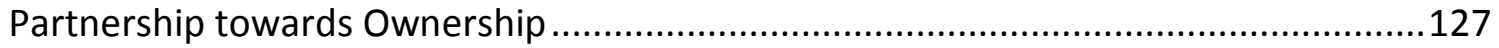

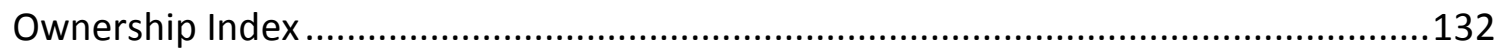

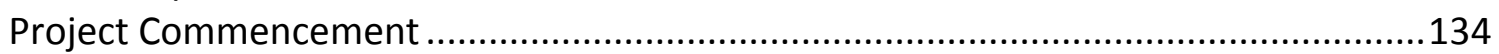

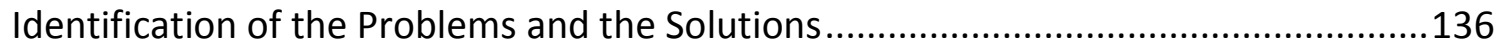

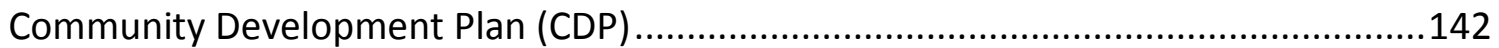

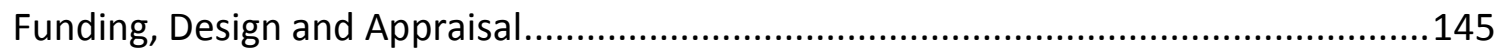

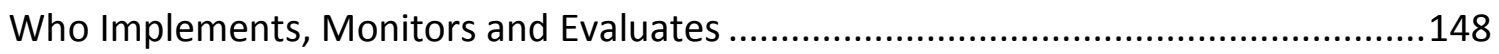

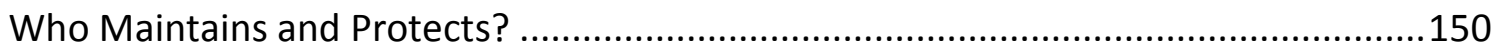

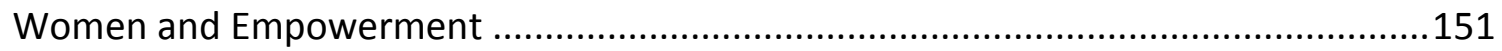

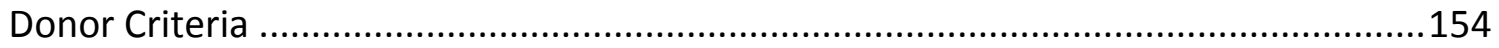

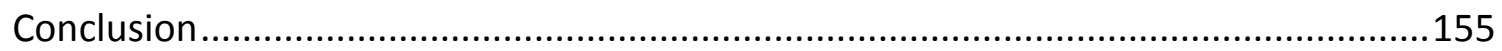

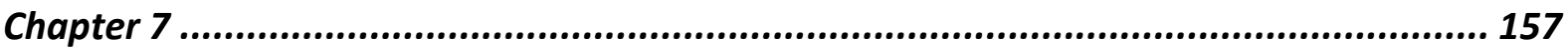

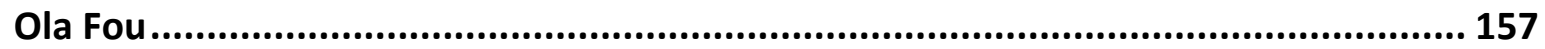

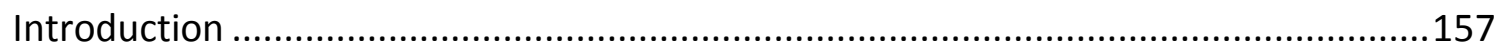

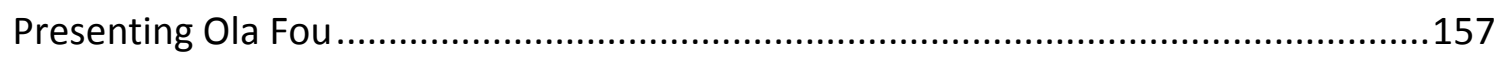

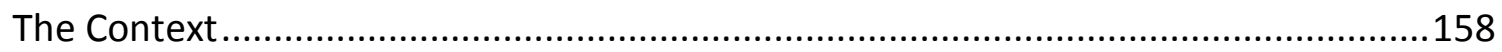

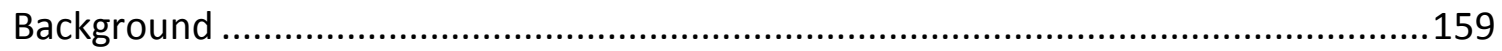

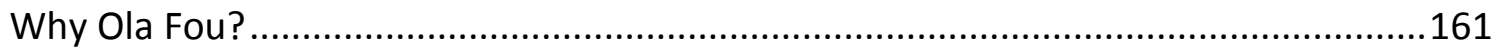

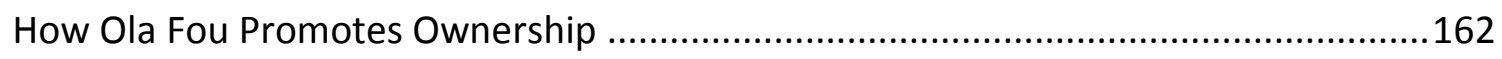

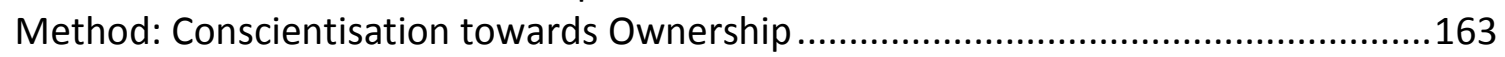

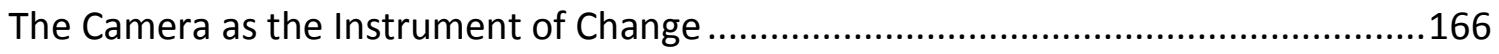

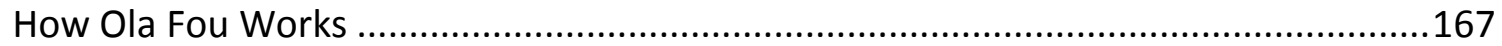

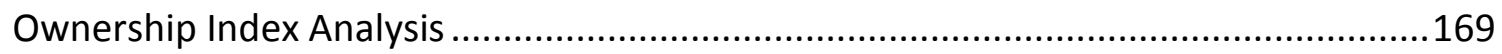

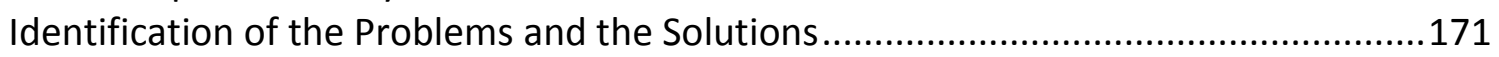

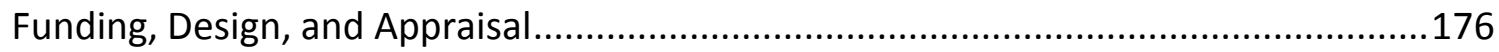

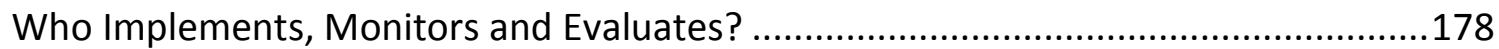

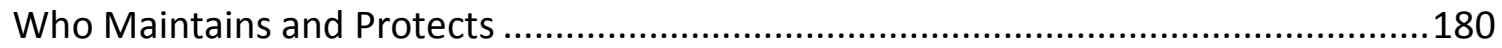

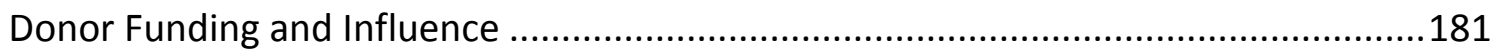

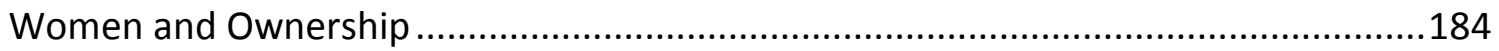


Conclusion

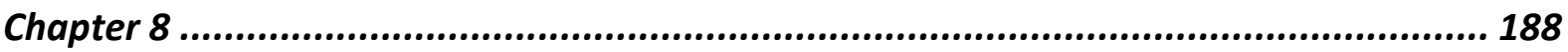

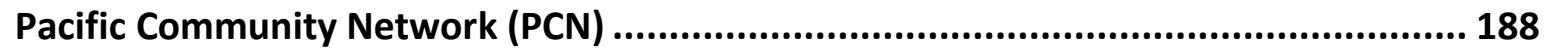

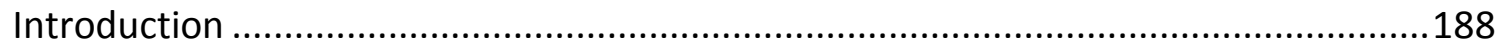

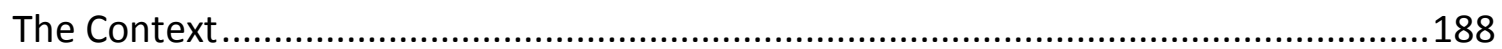

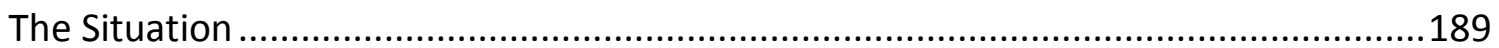

Why PCN?

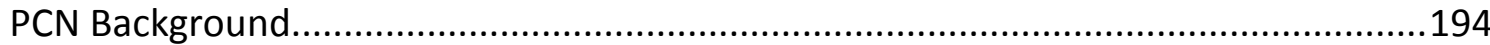

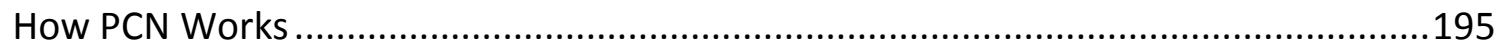

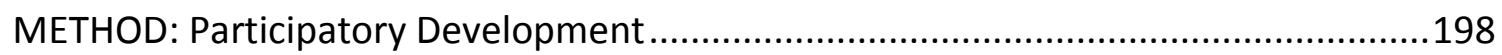

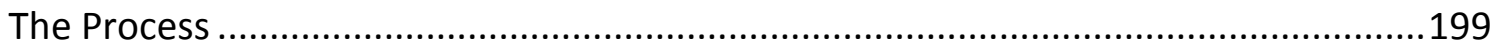

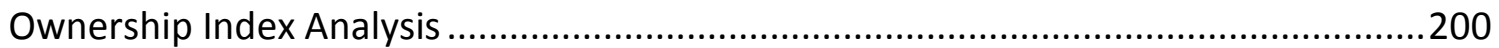

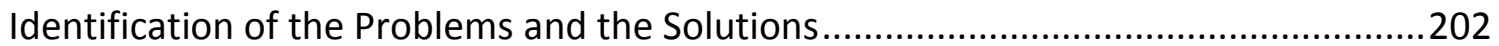

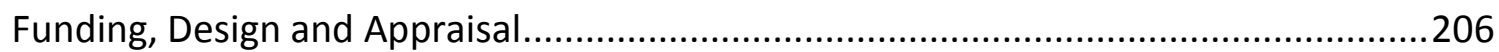

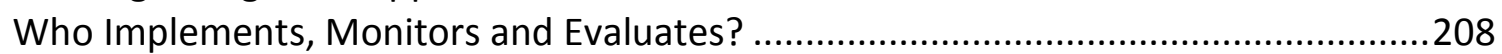

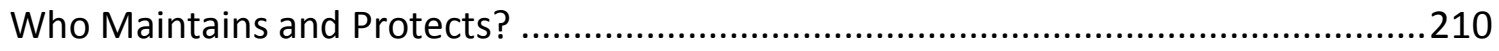

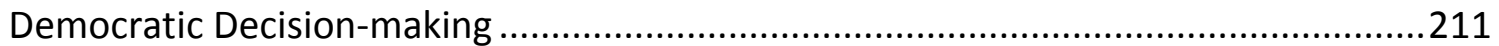

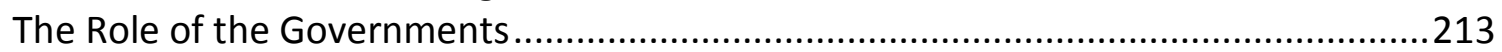

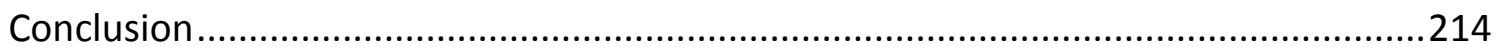

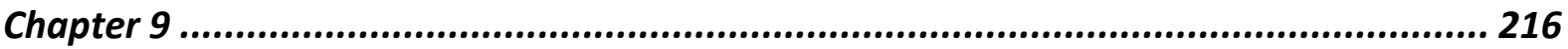

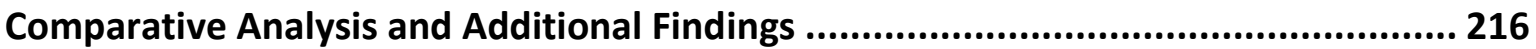

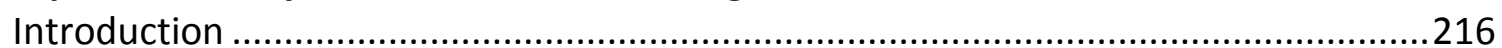

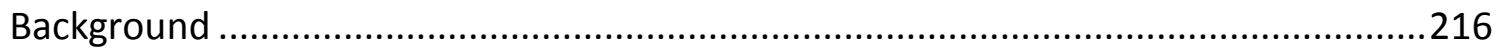

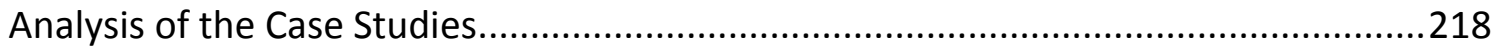

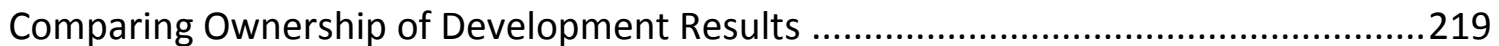

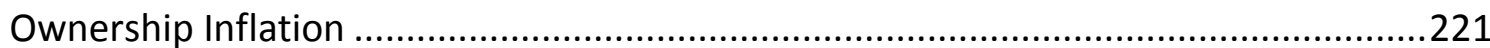

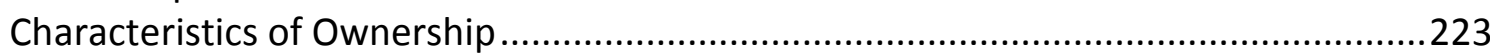

Authentic Participation, and the Critical Role of Women .....................................223

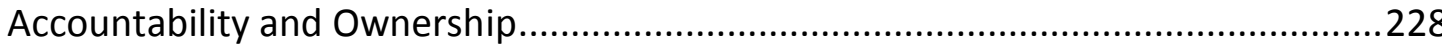

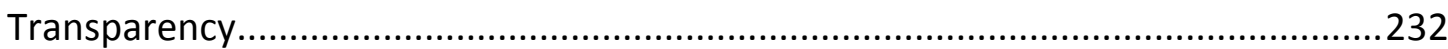

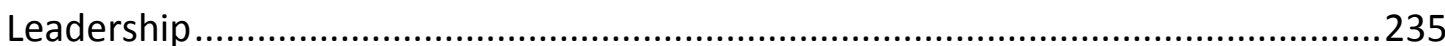

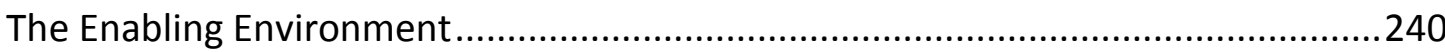

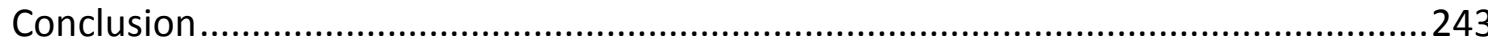

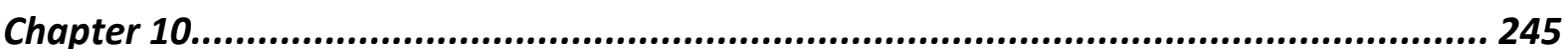

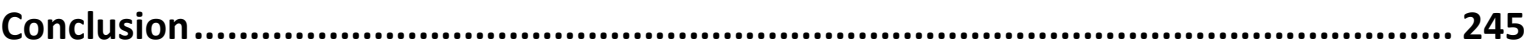

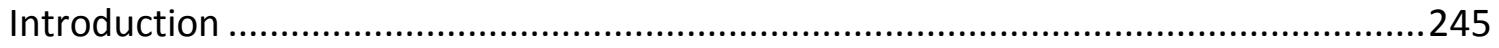

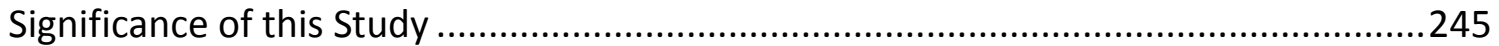

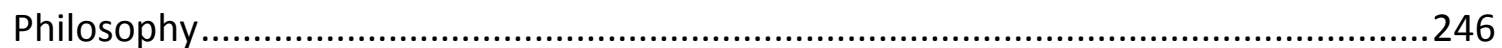

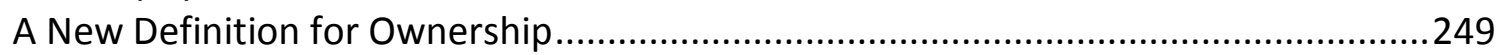

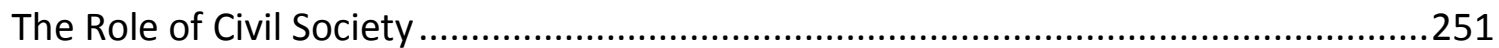

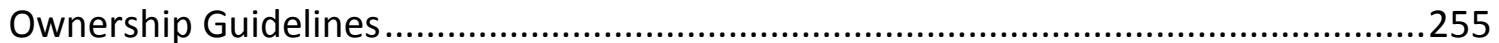

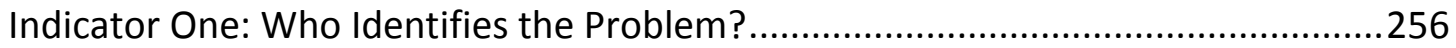

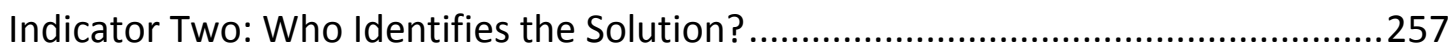

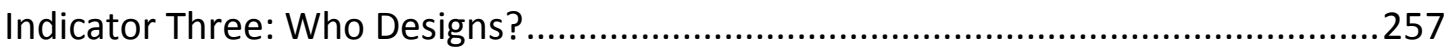




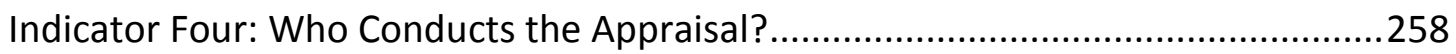

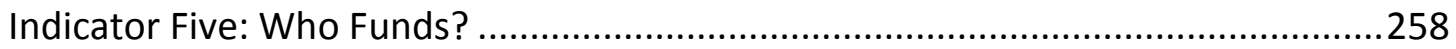

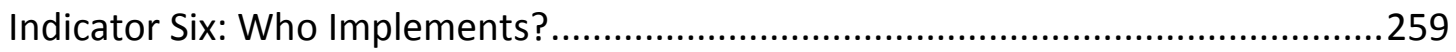

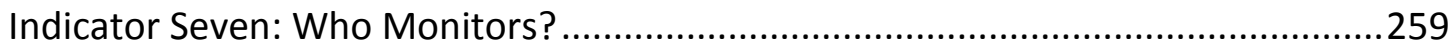

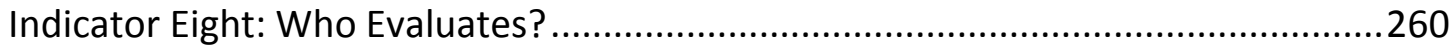

Indicator Nine: Who Maintains and Protects? ......................................................260

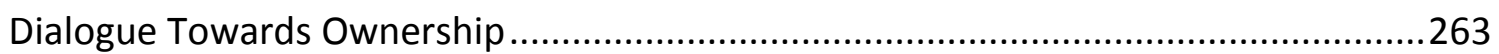

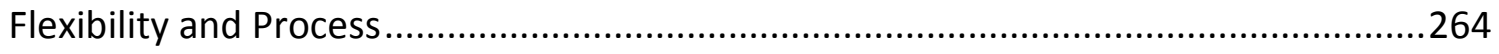

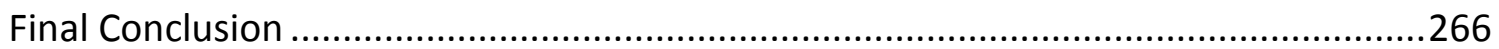

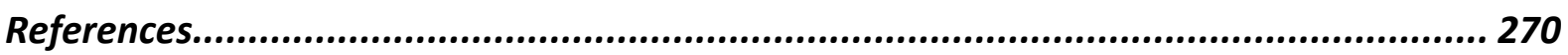

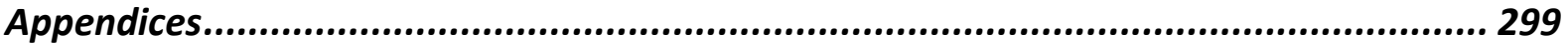

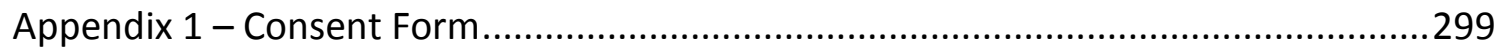

Appendix 2 - Information Sheet for Research Participants ..........................................300

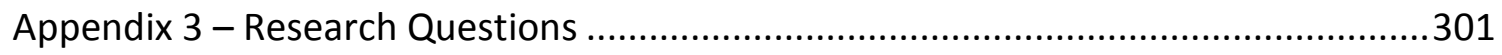

Appendix 4 - Ownership Index Survey: Implementing Organisations .........................302

Appendix 5 - Ownership Index Survey: Project Beneficiaries .....................................305

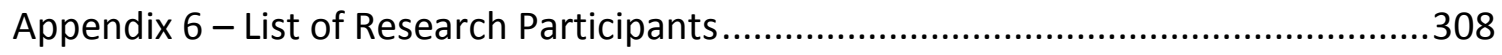

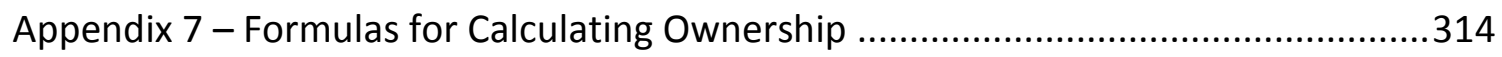

Appendix 8 - Average of Perceived Ownership for the Three Case Studies ..................316

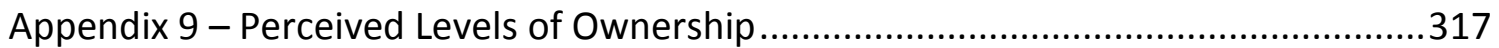

Appendix 10 - The Level of Women's Engagement in Each Case Study .......................318 


\section{List of Tables}

Table 6.1 - Problems and Solutions Identified by the Community .....................................143

Table 10.1 - Effect of Ownership on Development Results 


\section{List of Figures}

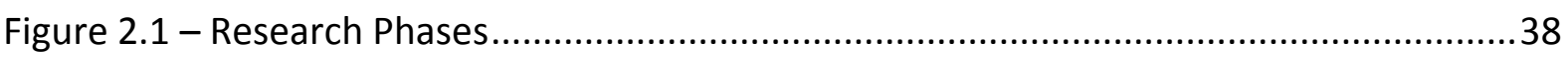

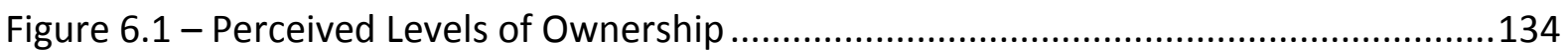

Figure 7.1 - Ola Fou Perceived Levels of Ownership.....................................................170

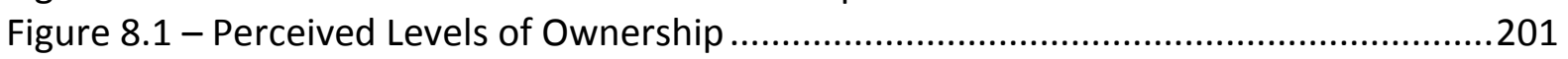




\section{Acronyms and Abbreviations}

- AAA - Accra Agenda for Action

- ACFID - Australian Council for International Development

- ADB - Asian Development Bank

- BOD - Busan Outcome Document

- BINGOs - Big International Non-Governmental Organisations

- CID - New Zealand Council for International Development

- CIDA -Canadian International Development Agency

- CSOs - Civil Society Organisations

- CSFT - Civil Society Forum of Tonga

- ECREA - Ecumenical Centre for Research Education and Advocacy

- FCOSS - Fiji Council of Social Services

- FSM - Fiji School of Medicine

- FSPI - Foundation for the Peoples of the South Pacific International

- FNPF - Fiji National Provident Fund

- FWCC - Fiji Women's Crisis Centre

- GPEDC - Global Partnership for Effective Development Cooperation

- HA-Housing Authority

- HART - Housing Assistance and Relief Trust

- HIES - Housing Income and Expenditure Survey

- HLF - High Level Forum

- IATI - International Aid Transparency Initiative

- IFAD - International Fund for Agricultural Development

- INGO - International Non-Governmental Organisations

- ILO - International Labour Organisation

- IFIs - International Financial Institutions

- MDGs - Millennium Development Goals

- MORDI - Mainstreaming of Rural Development Innovation Tonga

- NGOs - Non-Governmental Organisations

- NLTB - Native Land Trust Board

- NLU - National Liaison Unit (for development CSOs)

- PCDF - Partners in Community Development Fiji

- PCN - Pacific Community Network

- PIANGO - The Pacific Islands Association of Non-Governmental Organisations

- PIAS-DG - Pacific Institute of Advanced Studies in Development and Governance

- PICs - Pacific Islands Countries

- PIFS - Pacific Islands Forum Secretariat

- PRB - Public Rental Board

- PRNGO - Pacific Regional Non-Governmental Organisations

- TNCWC - Tonga National Centre for Women and Children

- UNDP - United Nations Development Programme

- USP - University of the South Pacific

- YWCA -Young Women's Christian Association 


\section{Glossary}

Words mean different things to different people. Here are the meanings of the key words used in this research to make the arguments presented more clear:

- Accountability: the processes through which an individual or an organisation makes a commitment to respond to, and balance the needs of stakeholders in decision-making processes while maintaining an unbiased, just, and financially transparent status.

- Actors: also called stakeholders throughout this research - the individuals or organisations that are most relevant to the issue in question. They include supporters as well as opposing forces that engage with the issue.

- Beneficiaries: all members of a community regardless of sex, age, status, religion, or social standing unless otherwise stated.

- Civil Society: the arena outside the state and the market created by individuals, and their collective actions to advance shared interests.

- Commitment: is a bind or an obligation and refers to a state of being emotionally and intellectually devoted and a willingness to invest time and energy to secure the pledge.

- Community: a group of people living in the same place with particular characteristics in common. In this research it primarily refers to where development project beneficiaries especially women, gather and dwell and benefit from development aid.

- Development aid: 'aid' or 'development' in this thesis implies 'development aid', namely assistance that brings about positive change and improves the well-being of the people.

- Development goal: the highest level of benefit identified.

- Development project: the process and activity of planning, organising, monitoring, and controlling resources, procedures, and protocols to achieve specific goals.

- Discourse: discourse in the context of this research refers to the totality of collated language within the aid and development discipline (written and spoken) used to share information.

- Effectiveness: a measure of the extent to which a development programme or project achieves the specific set objectives.

- Mechanism: either tools or processes, or a combination of the two. Accountability tools refer to devices or techniques used to achieve accountability.

- Ownership: is a complex term and over the years has been defined variably as:

$\rightarrow$ Borrower ownership: a government who represents, barrows, and signs off aid and development funds/loans on behalf of the aid recipient population.

$\rightarrow$ Country ownership: when the partner government is involved in design of development plans and priorities.

$\rightarrow$ Inclusive ownership: when parliamentarians, local authorities, CSOs as well as governments all work together in consultation to identify development priorities.

$\rightarrow$ Democratic ownership: aims to expand 'inclusive ownership' and takes into account the wider population especially the private sector in setting policy.

$\rightarrow$ New definition of 'ownership' offered in this research: when an individual or the community commits to 'maintain' and 'protect' development outcomes.

$\rightarrow$ Ownership Index: a tool for gauging the level of Ownership.

$\rightarrow$ Cultivating Ownership: a deliberate and calculated long-term association for the purpose of nurturing desired change that would be maintained and protected over time by the individual or the community

$\rightarrow$ Owners: are those who can make binding decisions throughout the process for the maintenance, protection, and improvement of the assets.

- Stakeholder: the individuals, groups, and government organisations that are involved in, or may be affected by, the development projects. 


\section{Acknowledgements}

This thesis is a milestone of thinking, work, and research in the South Pacific for over a decade which has been nothing short of a beautiful dream. I felt an unmatched inner peace the first time I laid eyes on the blue Pacific Ocean. I knew I was home at last. Over the years, work and research on the islands of the South Pacific, some very remote, has involved wandering around using all means of transport, and both foreseen and unforeseen unforgettable challenges. I will cherish these memories, especially the people I have encountered on these adventures and I am forever grateful for the open arms and indebted to those who took the time to share their worldview and open my eyes.

Writing a PhD dissertation is a solitary journey; I like to however acknowledge the support and the love of my friends here in New Zealand and those far away who made this odyssey possible. I would like to especially acknowledge and thank my mother and my father who taught me to care and to reason, but especially for their relentless inspiration. I must thank my supervisors Professor John Overton and Dr Andrew Ladley who guided me and helped me sharpen my ideas. Thank you for your guidance, and generous sharing of your knowledge.

This research grows out of the conversations, the friendships and the support of a large number of people on the islands of the Pacific, but I bear ultimate responsibility for the arguments, views expressed and the conclusions that follow, and for any errors and omissions that have crept in. Any appreciation of this research belongs rightfully to you collectively; the errors and mistakes are mine alone.

Over the years, I have observed how there are people who believe in faith and destiny, and then there are those who know that they can shape their own lives; my passion and the purpose of this research lies in creating and formulating strategies that would allow people everywhere to determine and shape their own destinies, and ultimately to take ownership of change in their life. Thus, this research is dedicated to all of the children of the Pacific; my hope is that it will serve future generations as a tool for shaping of the future.

Vinaka Vakalevu and Loloma Levu 


\begin{abstract}
The principle of ownership and the idea that development aid should be owned by recipients has emerged within the last two decades in key statements from a series of international meetings between major donors and partners, most prominently since the 2005 Paris Declaration when 'ownership of development aid' became the first Principle of Aid Effectiveness. The principle was applauded particularly by the governments of rich donor states, but also by their specialist aid agencies and representatives of civil society. However, despite the endorsement and praise of the principle of ownership by all donors and stakeholders, confusion and lack of clarity remains as to what exactly ownership of development aid means especially in terms of policy and practice in the work of development actors.
\end{abstract}

The core proposal of this thesis is that the principle of recipient ownership of development aid, apparently so important at the highest international levels of discussion, must be defined, broken down into relevant ingredients, taken into consideration in terms of policy and practice, and measured. Otherwise, the principle is nothing but empty rhetoric. It is logical to suggest that to have any policy value political concepts should be definable and measureable. Hence, the thesis argues that if one can formulate the relevant ingredients of ownership, one can carefully investigate factors that increase or decrease those ingredients. This is the focus of this thesis.

Field research in the Pacific Islands used a mixed methodology that included gathering data on completed development projects and interviewing government officials, major donor officials, other deliverers of aid - particularly the civil society organisations (CSOs) - and especially the project beneficiaries at the grassroots. Projects where CSOs demonstrated particularly close engagement with the communities and beneficiaries were chosen as case studies. Analysing and deconstructing these mechanics and ingredients of ownership produced a new definition for 'ownership of development aid' and a range of variables for an Ownership Index and for Ownership Guidelines. These combined tools presented in this research should assist professionals to promote, cultivate and measure ownership of development outcomes that project beneficiaries will maintain, protect and improve over time. 


\section{Preface}

The initial spark out of which this research grew sprang whilst I was in Afghanistan (2003/05) working with the Canadian International Development Agency (CIDA). Afghanistan was my first major foray into the politics of development aid. In retrospect, I think I could not have chosen a more fascinating place to experience policy-making, but what I learnt and experienced opened my eyes and profoundly changed my view on development aid.

As the Canada Fund Coordinator in Kabul, I engaged with civil society organisations in Afghanistan and saw first-hand how the aid and development industry works. While in Kabul and back in Ottawa, I spent a lot of time researching and thinking about human rights issues, and how development aid can be more effective. When it comes to tackling issues of poverty, I believe it is important to view problems in a dispassionate way, to put aside politics, and to inform and awaken people to their own capacities so they can think, make the right choices and act for themselves instead of making decisions for them and suggesting the best course of action.

Unfortunately, though hardly surprisingly, while I was in Afghanistan, I witnessed first-hand how decisions and allocations of funding for development aid is donor driven, inherently political and rooted within a particular ideology where an external and paternalist discourse dominates. I witnessed how there was no spirit of educating the local partners and encouraging local actors to think for themselves, to take responsibility and to lead the agenda. Instead, decisions on how development aid is to be allocated in Afghanistan and how injustice and poverty were to be eradicated were often made behind closed doors in Ottawa and were more aligned with Canadian priorities.

My background and my education had not prepared me for all that I encountered. Politics of aid in Afghanistan taught me that ensuring of a non-paternalist discourse and an equal relationship is difficult in practice. Becoming more alert while in Afghanistan and elsewhere in the world over the years, I observed how the rhetoric of development aid is inherently influenced by ideology, and how it is sometimes used as a political tool to frame and construct new realities which reflect the interest of the rich and the powerful. 
What I hoped to see instead was a bipartisan consensual approach that would make foreign aid a double-edged sword to tackle poverty and injustice in the developing world rather than a political tool serving the interest of the few. Thus, my background, work, and research over the years that followed made me particularly attentive to unearthing potential ways that can enhance the role of project beneficiaries in decision-making and to explore how development aid can become more locally driven, effective and more sustainable. As I moved from Afghanistan to a more international arena, and eventually to the South Pacific, I discovered that the aid and development industry is short-sighted globally, and it is failing to formulate policy and change that is maintained and protected by the aid recipients in the long term. Instead I discovered that decisions in regards to development aid are made everywhere by the rich and the powerful in a curious blend of ideology and politics, and are most often grounded in special interests.

Engaged and involved while observing the challenges for ensuring sustainable development aid, I became interested in how people (project beneficiaries) can take ownership and determine the changes they want to see and play a greater role in moulding their own future. The current research topic developed out of this interest.

The question of self-determination and the idea of 'ownership' of change and inclusive decision-making in development aid, has emerged for me time and time again over the last decade while working in the South Pacific with the New Zealand Ministry of Justice on indigenous rights as an analyst, and working with the New Zealand Council for International Development (CID) as a senior policy and research officer. Through CID I became engaged with the mobilisation of the global civil society, the Open Forum and the conception and formulation of the Pacific Development Effectiveness Principles which lead to formation and endorsement of the Principles of Development Effectiveness in Busan, South Korea at the Fourth High Level Meeting on Aid Effectiveness in 2011.

Over the last 10 years I have travelled extensively in the Pacific region and have particularly developed an intimate knowledge of Vanuatu, Kiribati, Fiji, and Tonga. Thus, my work over the past decade has centred on the mechanics of self-determination and ownership of development change and I had worked around most of the issues I will discuss in this thesis before I returned to University to complete this research. 
I am fascinated by the Pacific Islands, the captivating indigenous traditions and ways of life and how dominant, rich and powerful countries of the world and their ways of thinking and ideologies have influenced and shaped the islands and their people. This thesis is hence rooted predominantly in my own experiences within the aid and development industry of the Pacific region. At the same time, I have aimed in this research to primarily offer the 'voice' of the people of the Pacific and especially the development experts in the region, particularly women.

My hope is that this research will prompt a debate around the important question of selfdetermination and ownership of development aid by the project beneficiaries, not only within the academic arena, rather by those tackling poverty and injustice and especially by civil society and those whose lives are affected by the decisions around the systems of delivery of development aid as this research is about them and the people's right to shape their own destiny.

Thus, I have aimed in this research to capture the debate around the question of ownership of development aid and am putting forward a new definition and practical tools to cultivate and measure the concept. More debate and research is however needed on the questions posed and the conclusions made in this thesis which I believe will surely lead to greater selfdetermination, better policies, and better results and development change that is desired and maintained by the people. 


\section{Chapter 1}

\section{Introduction}

Between 2003 and 2011, a series of High Level Forums (HLF) were held by the Organisation for Economic Co-operation and Development (OECD), 'aid donor' countries and 'stakeholders'. The stakeholders included states that were recipients of development aid and (by 2011 at least), Civil Society Organisations (CSOs), banks and representatives of the private sector involved in the delivery of aid. The broad goals of these forums were to reframe the objectives and key principles that should guide the provision (and receipt) of development aid in the new millennium. One important concept that emerged from these meetings is the subject of this thesis - namely that 'recipient ownership' should be a critical ingredient in development aid.

Why might recipient ownership be relevant to this whole field? As I explore in this thesis, a logical but completely unstated 'theory of change' lies within the concept, summarised in two simple propositions:

- that development aid can positively change recipient behaviour (institutions, local communities, individuals); and

- such change is more sustainable if the recipients 'own' the aid process.

Putting this in development aid terms, the proposition is that "development effectiveness requires partner ownership".

This shows the risk of a circular argument about concepts and causation: ownership is important because development aid expects change that requires recipient ownership of the process. Such circularity is extremely common in this field and is hard to avoid, even in this thesis. Still, the logic is intuitive, illustrated by simple examples. If I come up with an idea to do something (say, to learn to tie my shoelaces) and I am closely involved in the learning process (including practising it myself), I am surely more likely to learn how to tie 
my laces, and the learning is more likely to be permanent, than if I am told I must tie my laces and someone ties them for me.

In development terms, if an institutional recipient of aid is expected to undertake some change (say, to eliminate corruption in state expenditure), that result seems more likely to occur if the recipient organisation identifies the solutions in consultation with the people, understands the key drivers of corruption, addresses the causes, manages the aid process through inclusive dialogue, and takes responsibility for the results.

Seen this way, ownership appears to mean quite a lot of things, all to do with recipients 'being involved with' the process, and engaged in the dialogue before the problems and the solutions are identified and throughout the project cycle at each phase. Logic again suggests that there might be degrees of involvement, from 'being consulted' to 'being in charge' all the way to 'being offered'. These are not the same thing, obviously. So does the degree of involvement affect the core causation proposition? In other words, is aid less likely to be effective if a recipient is merely consulted on the proposed aid, compared with being fully in charge? Or more starkly, is aid less likely to be effective if the process does not even enter onto the spectrum; that is, aid is delivered without even consulting recipients?

For both donors and recipients, these might be important questions affecting the entire aid process that must be taken into consideration. These questions were posed and addressed at the High Level Forums (HLF) (2003-2011), and it has been suggested and agreed universally that they matter deeply. At its simplest, attempting to answer them requires some way of defining and measuring the various ingredients that might make up the concept of 'recipient ownership' in this field. That is the core objective of this thesis.

The search for measurement tools for difficult concepts is not in itself new. Where they are important to public policy (or how to achieve goals by state action) measures have been produced for concepts such as happiness, state fragility, and the rule of law (BaliamouneLutz \& McGillivray, 2011; Skaaning, 2010; Wang, Wu, Hsieh, Liou, \& Chen, 2014). The common strategy in indices is to break up the concepts into component parts and find some way to assign a form of measurement to each part. 
That approach is adopted in this thesis. But unlike the above examples, the attempt here was not to produce state-wide measurements to answer questions in the aid context that might be equivalent to: how does the rule of law/index in Mexico compare with that in Canada? That will have to be the subject of further research. Rather, the objective was to focus on finding a tangible definition for ownership as well as identifying its components and how they can be promoted and documented from the bottom up of the aid process at the grassroots, at the project level, and to search for practical examples in the South Pacific, particularly Fiji and Tonga, where a range of donors, particularly Civil Society Organisations (CSOs) work with local communities using development aid to achieve some form of positive change. In other words, the focus was on how ownership might be relevant to deliverers, predominantly CSOs, and recipient partners (people within local communities) in specific examples.

\section{The Meaning of Ownership}

The term 'ownership 'of development aid has become a key concept within the aid and development discourse. The word is fashionable and adopted by all manner of government, civil society, and even private sector groups to describe modes of organisational relationships with people. The complex debate is divided between people's diverse needs and desires, their right to self-determination, and the government and donor agenda, but there are no common definitions for 'ownership' that everyone agrees on. Traditional donor governments, the Development Assistance Committee (DAC), the BRIC countries (Brazil, Russia, India and China), as well as civil society at the global, regional and the national levels all refer to ownership, but there is lack of agreement between all of the stakeholders as to how the principle is defined, measured, and put into practice within the aid and development industry ${ }^{1}$. Furthermore, the aid and development industry is skewed because there is a lack of genuine ownership of the development programmes by the people (project beneficiaries) and "donors continue to provide considerable personnel inputs, to ensure control" (Hansen \& Tarp, 2000, p. 145).

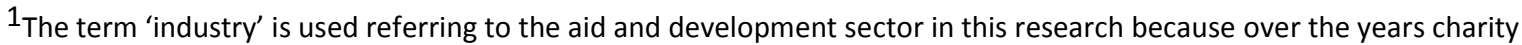
and philanthropy has become "an important branch of economic activity" (De Haan, 2009, p. 3).
} 
Ownership of change demands interaction, process, and dialogue between internal and external actors as development aid is more effective and sustainable when stakeholders participate, ask the questions, and identify the problems and the change needed themselves (Smillie, Helmich, Randel, \& German, 2013). As it will be discussed in the following chapters, perspectives on the principle of ownership today fall within a spectrum from idealism, to realism, and finally to pessimism. As will be discussed in Chapters 3 and 4, there are various constraints at each level (global, regional, local) and within each sphere of the aid and development industry making ownership more of a 'policy ideal', and a 'myth' as there is no consensus amongst aid and development actors as to what ownership means in practice and how it can be measured (Kim \& Lee, 2013). This thesis will therefore dissect the anatomy of the phenomenon of ownership within the aid and development discourse to understand its components and will question the existing structures and approaches that foster ownership. It also asks further questions about how the existing structures can be improved.

Ownership evokes many diverging interpretations as it is a policy ideal, though a vague technical term and difficult to define and promote both analytically and operationally. The concept of ownership and its components are also directly associated with other related and perceptible concerns that need to be taken into consideration but which are beyond the scope of this research. However, they are highlighted and discussed because they constantly surfaced in the interviews for this research: namely how technical terms such as ownership are defined within the aid and development arena, and how the term is translated into partner languages, and incorporated into policy and practice.

The debate on the question of ownership is side-tracked by so many important and mainly political challenges, such as partner legitimacy, capacity, lack of resources, and funding, which complicate further the already complex bureaucracy, as will be revealed through the case studies in Chapters 6, 7, and 8. Ownership of development aid is essentially a political question, and because donors are reluctant to ask the important questions and tackle ownership and accountability (Riddell, 2014), it does not mean that these questions should not be posed. In fact, these are exactly the questions this research poses and, as it will be revealed in the following chapters, promoting ownership and accountability does make aid more sustainable and more effective, and brings people to the centre of the debate, and 
ensures greater involvement of each community, especially women, in making decisions that influence their lives and ensures change that is desired and maintained by the beneficiaries.

\section{The Discourse of Ownership}

Ownership of aid by the recipients is a popular concept and it is frequently talked about. Aid and development actors agree that "ownership does make aid more effective" (Theisohn, 2013 , p. 293), yet ownership remains a vague and evolving term in the development context.

As discussed, it is unclear as to what exactly ownership means in terms of policy and practice to different development actors and partners, especially to the CSOs and how they are to promote and cultivate the phenomenon. There are no agreed definitions, consensus, or measures to promote, ensure or to measure ownership of development aid by the people within the civil society arena.

At the same time, the $21^{\text {st }}$ Century has marked a massive shift in the language and culture of development aid. Aid levels have fluctuated and the discourse has constantly changed. The "language of development has become English" (Chambers, 2013, p. 68), and rich countries and donors keep introducing new technical terms to the industry to improve the system and these terms are frequently translated into partner languages, but much is lost in these linguistic interactions and most of these important concepts that are being promoted among partner countries are still vague in policy and practice. At times it is challenging to translate some of the concepts and to find equal meaning for the sometime ambitious and often technical terms suggested, especially when the concepts are already puzzling and unclear in their origin in English, and are simply used by policy makers and rich donor countries as political and "cosmetic rhetoric" (A. Cornwall, 2008, p. 18) to appeal to the people. This politicisation of development aid can be primarily addressed in my view by targeting the ambiguity of legal and technical terms such the concept of 'ownership'. "Clarity must be achieved through specificity" (J. M. Cohen \& Uphoff, 1980, p. 218) if development aid is to become more effective and sustainable. 
This research early on encountered what is more obvious to non-English speakers: namely that ownership in development aid discourse is an English language term, but the actual delivery of aid and its grassroots effect finds its reality in different languages, and in different cultures and perspectives, which are sometimes difficult to translate and convene. The equivalent of this phenomenon in research methodology terms might be regarded as 'standpoint theory' -grounded in social constructivism, namely that how one views the world simply depends on where one stands (Hartsock, 1998)and is influenced by socially constructed conceptions and norms. This issue will be further discussed in detail in this thesis.

Numerous technical terms and principles other than 'ownership' have been debated over the years within the aid and development sector. They provide good examples of how sometimes the language in the aid and development sector is political, and how it can be a barrier and refers to high ideals and concepts that are challenging to define (Cheah \& Phau, 2012), such as the terms 'accountability', or 'partnership' (Sachs, 2010), all of which surfaced during interviews and research on the question of ownership.

The paradox is that "the words that work in projects of world-making are those that lend themselves most to being filled with multiple meanings", (A. B. Cornwall, 2005, p. 17) and so it is suggested that it is high time to pay greater attention to the language of development aid and to demand greater clarification of the meaning of the words and concepts used, and how they are interpreted into partner languages.

The development agenda is often still finding Northern solutions and donor technical terms, and often without exact conversion of the concepts into local partner languages and identification of local ways as to how these concepts are to be incorporated into policy and practice. Some of the development terms used are still vague in English to start with and are confusing and have not found their equals in other languages. The argument put forward in this research is that the technical terms used are often political, vague, never neutral, and are often attached to funding (money) and that these expressions must be illuminated and clarified, especially in partner languages and seriously discussed and taken into consideration because they have a direct impact on the effectiveness of development results. 
During the past decade, civil society around the world has taken the lead in strongly influencing governments (Mawdsley, Savage, \& Kim, 2014), demanding that the principle of ownership be more precisely defined and taken more seriously into consideration. Although rich countries and donor governments have highlighted the importance of the principle of 'country ownership', its meaning has constantly changed at each HLF, and there is an ongoing debate as to what ownership exactly means, how it is defined, and how it can be shaped into policy and practice, especially by the CSOs (Kindornay \& Samy, 2012). As will be discussed in Chapters 3 and 5, ownership has been the subject of the aid and development discourse since the end of the $20^{\text {th }}$ Century but, if anything, the debate over the concept of 'ownership' has masked its implications and there is still no consensus amongst stakeholders as to what the concept of 'ownership' actually means in policy and practice.

However, an apparent positive change is occurring within the discourse and 'ownership' has surfaced in the rhetoric of aid and development effectiveness. Complex development terms and principles are being talked about more than ever before, but it will take time before these sometimes-ambitious concepts can be defined, agreed on, translated into partner languages and formed into policy.

The political and commercial interests of donors matter greatly. "The politics of aid remains central to any discussion of whether and how aid works" (Riddell, 2014, p. 106), and political interests are often well disguised in the language used. Although more just rhetoric is being discussed globally, a lack of clear definition for some of these development terms in partner languages means that change is slow, the development agenda is still donor driven, often ineffective and that the language used is often confusing and a barrier. As research on the question of ownership in the following chapters reveals, words sometimes mask the reality and are empty vessels and puzzling if they are not accurately described.

\section{Variables and Characteristics of Ownership}

Research on the question of ownership, especially the analysis of the case studies discussed in Chapters 6, 7, and 8 will reveal that 'ownership' has a direct impact on the sustainability and effectiveness of development results. Case studies also revealed the numerous ingredients of ownership of which nine indicators have been acknowledged as potential variables that must be taken into consideration when cultivating and assessing ownership of 
development results. This thesis will reveal that the nine indicators of the Ownership Guidelines and the Ownership Index formulated for this research can assist both the development actors to cultivate ownership of development outcomes by the project beneficiaries, and that these indicators can equally be used by the community members to assess and to obtain an estimate of the quality of engagement and ownership of development results.

Analysis of the global, regional and national discourse son ownership, especially the case studies, were valuable in unearthing the ingredients of ownership. Interviews with development experts working in the Pacific were especially revealing. The case studies undertaken and close examination of how ownership can be cultivated demonstrated other issues that are directly relevant to ownership and that they must be also taken into consideration if ownership is to be promoted. These important features of ownership are essential, but they are not so easily measured. Governments, donors, and especially CSOs need to take these characteristics of ownership seriously into consideration if they are to demonstrate greater legitimacy and to cultivate ownership of results by the project beneficiaries and ensure more effective and sustainable development aid. These crosscutting features of ownership are complex, but research revealed that they have a direct impact on effectiveness and sustainability of results. They surfaced in almost all of the discussions and the interviews. In addition to the variables mentioned above, which will be discussed in detail, research revealed the following characteristics of ownership to be vital if ownership of development aid is to be cultivated:

- authenticparticipation, notably the role of women;

- accountability;

- transparency;

- leadership; and

- the enabling environment for CSOs.

As with the principle of ownership there is no consensus on policy, and practice amongst stakeholders as to how these key cross-cutting concepts are defined and promoted in 
practice, although they are constantly referred to within the discourse and aid and development actors, are drawn to them as an expression of solidarity that goes beyond financial aid flows. As research advanced, however, what became apparent is the contradiction between the development discourse and development outcomes. What aid and development actors know they should do to cultivate sustainable and effective change, and what is actually achieved in the field is often quite different.

While aiming to deconstruct the concept of 'ownership' it became apparent that "the concepts of 'accountability' and 'partnership' are also buzzwords" (A. B. Cornwall, 2005, p. 4) and political terms often used as slogans and catchphrases. As it will be argued throughout this thesis, technical terms need systematic clarification if aid and development are to become more effective and sustainable, and that the time has come to unpack these complex political concepts and to integrate them effectually into policy and practice.

The above-mentioned characteristics are especially distorted by the funding processes, and most development actors have no choice but to form stronger partnerships and be more accountable to their funders. Most CSOs examined in the South Pacific context have much closer partnerships with donors than they do with the people they serve which influences their legitimacy. The literature does tackle the issue, highlight this inequity and distinguish between 'upward accountability' and 'downward accountability' (Bendell, 2005), but these important questions must be more profoundly debated to safeguard and promote effective development. Upward accountability refers to relationships where a more powerful actor (such as a donor government) demands and influences the actions of a less powerful actor such as a local CSO. Downward accountability is similarly associated with power and relationships, where a less powerful actor (such as an intended beneficiary) can use accountability mechanisms (if available) to influence the actions of a more powerful actor such as an implementing CSO, but there is no consensus yet as to how civil society in particular is to ensure accountability downwards to the people.

Some of the CSOs examined for this research highlighted their upward accountability obligation to their funders for reporting and the need to keep the donors satisfied for continued funding, which drains their energy and fosters an environment where aid and 
development actors, especially CSOs have "more solid partnerships with their donors than to the people and the communities they serve" (Ebrahim, 2010, p. 117).

This process of cultivating ownership through partnerships and within a healthy enabling environment discussed throughout this research is about enhancing accountability, ensuring more lasting partnerships that are inclusive and how these concepts translate into ownership and improve the legitimacy of the stakeholders and safeguard effectiveness of development results. The key challenge is ensuring an enabling environment and a development aid structure where the voices of the people at the very grassroots within the developing communities are not overshadowed by the interests of the donor governments and more powerful stakeholders.

\section{The Focus of the Study}

The main argument of this thesis is that development aid is not as effective as it can be. It has the tendency to be driven by the donors (Knack, Xu, \& Zou, 2014), it lacks authentic long-term participation and especially accountability downwards to the people. The thesis argues that there is room to improve the effectiveness of development aid by ensuring greater engagement and ownership of change by the aid recipients. Hence, this thesis will explore the anatomy of ownership at the global, regional, and national arena in Fiji and Tonga with a focus on civil society and how development CSOs define, promote, and cultivate ownership. It will assess ownership and unearth its various ingredients, particularly how development actors, especially CSOs in the South Pacific context, are promoting this principle. To understand the complexities of ownership, this research will focus on three effective CSOs as case studies that have been successful in promoting and cultivating the principle of ownership. However, it is essential to clarify why this research was conducted, what problems it intends to address and how.

The 'why' of this research is concerned with possible solutions for improving the effectiveness of development aid. The 'how' of this research clarifies the epistemological approach and questions the effectiveness of the aid and development efforts, while the 'what' is the ontology, and is concerned with the outcomes of development aid and various meanings and components of ownership. Finally, the 'how' offers a new definition for ownership of development aid and a series of indicators as a tool for measuring and 
assessment of the ownership. The ontological and epistemological position adopted for this research helped frame the overarching aim of this research. The questions asked, all the information obtained, and how the results were analysed all contribute to this philosophical framework and understanding of the complexities of ownership.

Civil society of the South Pacific is a fertile ground to explore donor partner relationships, and to search for remedies to improve the effectiveness of the aid and development agenda. The culture of the South Pacific Islands, the people, the history of aid and development in the region, and the concern and willingness of Pacific Islanders to understand and safeguard ownership of the development agenda and their destiny makes the Islands a very fertile ground for research.

\section{Research Questions}

The main question this thesis poses is what ownership within the aid and development arena actually means and how it can be defined, cultivated, and potentially measured. A cluster of initial inter-related questions surfaced as research advanced, all relating to the central question, including:

- How do development actors at different levels (global, regional, national, local deliverer, local recipient) define ownership?

- Whose ownership is the concern?

- What might be the main ingredients of ownership and can these components be measured? And, used to cultivate ownership?

- If ownership is 'shared' (e.g., between donors, deliverers, and recipients), is it reflected in any measures (such as accountability)?

Development effectiveness is fast becoming a dominant lens for viewing progressive change in aid politics. It is hoped that the outcome of this research will empower the people and provide aid and development actors, especially CSOs, with strategies to improve downward accountability to the people and ownership of more effective and sustainable development outcomes. 


\section{Thesis Scope and Outline}

The thesis is organised into10 chapters. Chapter 2 presents the methodology adopted for this research. In essence, this was background research on published materials, followed by field research mostly using semi-structured interviews, and qualitative assessments, concluding each interview with the Ownership Index questionnaire.

Chapter 3 outlines the international aid and development discourse that is the backdrop for this research, including the big picture statements from the HLFs noted above and relevant equivalents from regional organisations in the Pacific.

Chapter 4 attempts to deconstruct ownership of development aid and to untangle the linguistic and psychological complications of the term before presenting a new working definition for the concept. Unsurprisingly, perhaps, analysis of the discourse around the concept of ownership reveals how the concept is a policy ideal, but that breaking down a technical term, as such, and clearly identifying the desired outcome of ownership is timely and necessary and will enable aid and development efforts to be more effective and sustainable.

As alluded to above, the field research early on revealed that the key intermediaries, or deliverers, of development aid are CSOs. Chapter 5thus will explore the capacity of civil society as a global force. It will examine the role of civil society historically, globally and within the South Pacific region with a focus on Fiji and Tonga.

These four chapters are the basis for the case studies that form the empirical core of this thesis, in Chapters 6, 7, and 8. These studies reflect extremely close partnerships between the CSOs and the communities they serve in Fiji and Tonga and how these accountable partnerships have translated into high levels of ownership of development aid.

In Chapter 9, I present a comparative analysis of the findings based on the information obtained through the mixed methods approach. In this chapter, I will present the research findings, including the characteristics of ownership and other insights revealed through more than 180 in-depth qualitative semi-structured interviews. Finally, Chapter 10 presents the conclusions, including the Ownership Guidelines, a series of deductions and an overview 
and analysis of the role of the civil society and how ownership can be cultivated and assessed to improve effectiveness and sustainability of development aid. 


\section{Chapter 2}

\section{Research Methodology}

\section{Introduction}

The first task for this research was to consider and choose a method that would allow a meticulous analysis and study of the principle of ownership within the aid and development arena and how it can be cultivated and measured. This chapter will present the epistemology of this research, the positionality of the researcher and the scope and details of the mixed methodology adopted to collect data. The different phases of the research, will be also discussed as well as the advantages and the disadvantages of measuring ownership and its rating formulae before it concludes by way of offering a brief note on the limitations and ethics of research in the Pacific.

\section{Ontology and Phenomenology}

It became apparent early on in this research that there are many divergent perspectives and viewpoints about the question of ownership. Thus as the research progressed the ontology for this study was shaped and moulded from various standpoints and philosophical perspectives.

How one views the world depends on where one 'stands' (Harding, 2004). Therefore, as a researcher (and a complete outsider) I aimed to put myself in the place of the research participants, looking at the world and researching the phenomenon of ownership from their perspective, trying to understand what ownership might mean from different perspectives and 'standpoints'. As a result, the philosophical framework of this research was both 'objective' and 'subjective' (Schopenhauer, 1844), and aimed to capture a perspective as wide as possible. At the same time I am aware that any answer found for any question posed cannot be concrete and permanent (Fenner, 2006), and that the answers and the solutions offered here are a reflection of the realities of the Pacific Island states today, and predominantly my ideas and viewed from my standpoint.

While travelling in the islands of the South Pacific, as an outsider I was aware of my background and my limited understanding of the cultural settings. In this vein, this research 
was shaped equally by my own personal philosophical standpoint and the possible meanings I might have attributed to the local concepts, subjects, and their perceptions. At times my particular perspective and standpoint may not have been typical of the population, but I believe this difference in perspective helped me understand the underlying complexities, given the familiarity of my gaze with similar issues I have witnessed during work and travel elsewhere in more troubled corners of the world. Therefore, a phenomenological outlook was adopted for this research, from which the world is viewed as subjective, and the researcher is part of what is being researched, and when possible "placed in the place of the subject" (D. E. Gray, 2013, p. 24).

The ontological and epistemological positions of the researcher often frame the overarching aim of the research - what questions are asked, the manner in which they are asked, and how the results are analysed. Given reality is both objective and subjective, the so-called real world is therefore perceived and shaped by each perspective and each individual's experience. How each individual views the world is important and allows us to "pay attention to both subjective and objective realities of our world" (Olson, 1977, p. 116).

This research thus aimed to capture the perceptions of a diverse and varied group of participants inspired by the ideology of Kaupapa Māori (Pihama, Cram, \& Walker, 2002; G. H. Smith, 1997), pondering important questions regarding who is this research conducted by, and who is it for? Whose interests does it serve, who will benefit from it, and who will be using the results? These questions were omnipresent throughout this research and ultimately shaped the results, keeping in mind the diversity of possible standpoints, perspectives, and the endless angles from which one can observe any phenomenon and aim to frame the so-called 'truth'.

As a researcher I tend to strongly agree with the 'standpoint theory', which supports the notion that a more objective account of the world can be created if we agree that the world is viewed from different perspectives (standpoints): and that we each see the world and the 'truth' from where we stand. Each standpoint determines both what one focuses on as well as what is obscured, and it is always different and changing. Depending on one's background, perspective, and where one stands, one's standpoint often varies from that of another individual who may be of a similar status. Hence, an individual or a community's 
perspective is shaped by their cultural experience, their social group and construct, as well as the angle from which they see the world from.

Standpoint theory is aligned with the theory of social constructivism which is concerned with the nature of knowledge and how we create meaning with language and mainly through cognitive processes and socially accepted norms. Constructionists view knowledge and truth as created, not discovered by the mind, which makes so-called 'reality' questionable and socially defined (Andrews, 2012; Cobb \& Yackel, 1996).

Such theorists argue that our identity originates not from within but in reaction to the world outside and from our social interaction and the environment we grow in. Socialisation and character formation takes place through significant others who mediate the objective reality of society and render it meaningful, and in this way it is internalised. It is important to note though, that the most effective tool for shaping identity and social construction and development is language (Burr, 1998).

Burr (1988) commented that within social constructionism language is problematic, but it is our only means by which we can share and transmit thoughts and feelings. In other words, it is language that highly influences our thoughts and our actions and permits cultivation of higher ideals and concepts such as justice, freedom or ownership. Language provides the means to structure development results that are maintained and protected over time. At the same time, it is important to note that meaning and understanding is shared and there are certain concepts and technical words that are hard to pinpoint in language and convey or precisely define, and ownership of development aid is certainly on this list and its meaning taken for granted.

The way we look at the world is always influenced by the languages we know and how they have influenced us, and the angle from which we see the world. Neutral and impartial research is an ideal. While some researchers believe that neutral and value-free research is possible, others subscribe that "researchers can never be objective" (Snape \& Spencer, 2003 , p. 13). Our perspective of the world is thus always tainted by our background, education, and the window from which we have observed the world. 
The challenge for me as a researcher has been to leave my standpoint behind and to observe without judgment, maintaining an unbiased position. My background and positionality demanded that I be conscious and mindful at all times. Thus, I assessed my approach, my questions and my observations at each step, making sure that I am accountable to every participant in my research and that I am able to see the world from their perspective and standpoints.

\section{Epistemology}

Semi-structured, in-depth interviews conducted in Fiji and Tonga allowed me to explore and grasp an understanding of the 'local' knowledge and perspectives and to learn about the meanings and the feelings around the question of ownership and how stakeholders make sense of the phenomenon based on their own particular experiences (Spratt, Walker, \& Robinson, 2004; Tashakkori \& Teddlie, 2010).

It is important to highlight the fact that knowledge about ownership is not separate, objective, or strictly quantifiable making the epistemology of this research socially constructed. People make and give meanings to phenomenon such as ownership of development aid in different and particular social and cultural contexts. Although I have tried hard to remain neutral, I am conscious of constructivist philosophy, and I am aware of my own beliefs and values and how they influence my outlook on the world and the findings for this research. Thus, underlying this thesis is the assumption that research, particularly research in the social sciences, is a subjective undertaking in which the researcher and research participants cannot be separated from the cultural, social, political and historical processes and that the so-called knowledge produced is socially constructed.

Meaning is constructed through lived experiences, understanding of different cultures, social and political norms and histories. While positivism and rationalism assume an independent reality, and thus an independent truth, social constructivism raises awareness of the way different context, and cultural and social norms shape reality and produce versions of the truth (Law, 2004; May, 2011). Consequently, the epistemology adopted for understanding the complexity of ownership and the role of the civil society in the South Pacific Islands required reflexivity, self-awareness, and "mindfulness" through engagements (Haskell, Linds, \& Ippolito, 2002). 
The so-called "real story" and knowledge around ownership gathered and presented in this research hence is a social construct (Schank \& Abelson, 1995) and predominantly the result of some 180 interviews and the bringing together of a range of local perspectives in the South Pacific Islands. At the same time, I acknowledge that my own interests, my experiences and my background have also influenced my choice of topic and the way I have approached this research. Hence, I often use the first person given I have drawn heavily on my own experiences and the understanding of the individuals who participated in this research.

\section{Positionality}

Consistent with the epistemological approach of this thesis, it is necessary to explicitly locate myself in order to acknowledge the ways in which my positionality influences this research. Our identities are subjective, unstable, dynamic, and change according to relationships we form with different people in different places and at different times. This is why our positionality is never fixed or static and changes over time and can produce potential bias (Denscombe, 2010; England, 1994; Roberts, 2001). Recognising this reality can have a direct impact on research outcomes and shape our views and our interpretations of the world around us because a researcher's position has a direct impact on the form of interactions made and eventually the findings of the research (Hartsock, 1998; Higgs, Horsfall, \& Grace, 2009).

A reflexive consideration of how knowledge is produced in interview situations is important as qualitative assessments can be highly susceptible to subjective biases from the researcher and the findings are always explicitly and implicitly informed by a researcher's individual experiences, aims and values (Miles, Huberman, \& Saldaña, 2013; O'Leary, 2004).

Relationships in research can be complicated, and must be thoroughly reflected upon to avoid misinterpretations and value judgements as the complex interaction of people and the coming together of the worldviews (standpoints) has a direct impact on the perception, motives and the information participants exchange and the formation of knowledge (Ritchie, Lewis, Nicholls, \& Ormston, 2013). 
Hence it is important to acknowledge that my knowledge is situated, and that my positionality has shaped the responses that I have induced and the way I have filtered and displayed information. I hold three citizenships and have lived and worked in the aid and development industry on three different continents. Both New Zealand and Canada are home to me, while I still recognise and value my Persian, Iranian origin. I am a male researcher, and the freedoms and experiences this entails has also influenced this research because being a male of my background must have naturally influenced my attitude to respondents and their responses to my questions.

Most of the research participants directly asked and referred to my background and ethnicity. It was interesting to note how my positioning and Persian/Iranian background often placed me as a fellow member of the conflicted and complicated geographic positioning. Some interviewees referred directly and constantly to the world of politics and my background.

I acknowledge feminism and secularism as influential in my worldview and the methodologies I have adopted for this research. I am aware that it is impossible to know how others viewed me (Vanderbeck, 2005) but my background and the many places I come from was somehow strange and most often amusing to some of the research participants. In general terms, I was often welcomed while some participants told me that they feel they can speak to me about certain frustrations because of where I am from, but I was more often treated as a stranger. Some people evidently "other"ed (Sultana, 2007) me, and I can confidently say that I never became an insider on any of the islands I visited in the Pacific, but being the 'other' and from a historic and revolutionary place like Iran, sometimes opened up discussions which were mind-opening, especially for me.

I respected everyone and made an effort to build on commonalities and at times I felt that by time I was able to blend in more effectively and managed to develop a degree of trust, openness, and honesty which allowed a surprising space for sharing, and mutual support and learning during which knowledge for this research was produced. Nevertheless, I am also aware that despite my aims to be self-reflexive, who I am, and how I am perceived were constantly being shaped by the relationships with others, always evolving and never being able to be fully grasped (Whelan, Huber, Rose, Davies, \& Clandinin, 2001). 
Finally, I must admit that my past and my personal experiences working within the aid and development industry have most likely influenced this research most. Throughout this study, I mainly drew out of my understanding and the professional connections I have built over the years. These professional connections I have formed over the years assisted me in approaching and accessing development experts who are well respected and are key people within the aid and development arena, especially in the South Pacific.

The development projects selected for this research are not chosen at random. They are the result of local expert recommendations and consultations with local communities and are best examples of CSOs which reveal the obvious and prominent insights into how ownership of change can be cultivated. This way I have succeeded in giving project beneficiaries and the Pacific development experts 'voice' to share their insights.

Having examined the epistemological approaches that have informed this thesis, as well as my motivation and position within it, I will now aim to shed some light on the mixed methods used to conduct this research.

\section{Why Mixed Methods?}

Methodology tends to define the rules, the tools for conducting research, and the paradigm that underpins research (Higgs et al., 2009). The terms 'method' and 'methodology' are Latin in origin and refer to the process of data collection. Methodology means "the science of finding out" (Babbie, 2013, p. 4). There is a rivalry between different methods of research, each claiming to be more accurate. Mindful of the numerous methods of research, I opted for a unifying methodology accommodating different approaches to ensure more accurate and reliable conclusions but also aimed to go further and to formulate new methods to assess ownership as it will be discussed further in this chapter.

Qualitative research is a common method of research in social sciences, but it resists the tendency to fix meanings and instead draws inferences about meaning (Ritzer, Zhao, \& Murphy, 2001). Because there are multiple meanings, 'standpoints' and perspectives on each phenomenon, including ownership, there are naturally multiple interpretations of ownership. As this research advanced, it became apparent that there is no single definition or account on the question of ownership which is more accurate than another and that all 
standpoints on ownership, although vague, are equally important. Thus, a qualitative method alone tends to add to the confusion regarding ownership rather than clarify it.

There is a multiplicity of definitions and a range of different perspectives on what ownership means. At the same time, there are no existing tools to cultivate ownership, or assess and to document the different perspectives and to report the complexities of the phenomenon. These factors gave rise to the arguments put forward in this research that ownership must be defined, cultivated, measured and assessed.

In a sense, as research advanced it became apparent that the questions of understanding and observing the levels of ownership and promoting ownership are a methodological challenge because of the existing vagueness of the meaning of the concept and a general misreading of the process, in that development partners do not document the levels of ownership 'felt' each time a project is complete. Instead, as it can be observed and is a common practice, development partners often rely on self-assessments and evaluations conducted based on the expected outcomes, or word of mouth, and the plausibility of the development results to judge the levels of ownership. Conclusions, as such, seemed just inadequate for this research.

Semi-structured interviews thus seemed insufficient on their own, and more detailed information was needed to record, analyse, and compare the phenomenon of ownership. An Ownership Index was thus formulated once the ownership variables were identified, and tested to suggest more detailed qualitative assessments as research advanced, especially through examination of the case studies and the ownership 'ingredients' identified. The semi-structured interviews and the qualitative assessments consequently enriched the research findings and provided a much sharper picture and better understanding of the complexities of ownership.

A number of methods were then considered and a mixed-methods approach was designed for this research, largely inspired by Gupta and Ferguson who call for and encourage pioneering and innovative practices of "fieldwork that transgress the disciplinary boundaries" (Gupta \& Ferguson, 1997, p. 13). This combining of different methods was thus framed and conveyed which matches the trajectory of information sought on the complexities of the principle of ownership. 
Research thus explored the meaning of ownership of development aid using a range of different methods and in four phases. Initially the global discourse was explored and what ownership means within the international aid and development discourse, how the debate around the question of ownership has unfolded since the turn of the century, how ownership has been incorporated into policy and how the international agreements and forum outcome documents have referred to the concept. Next, I focused more closely on the regional interpretations of the concept and how regional organisations in the South Pacific uphold the principle of ownership and how they have incorporated the phenomenon into their work. Finally, I examined and analysed the national structures and embedded myself in the communities and amongst the project beneficiaries on the selected Pacific Islands, making sure their perspective and understanding of ownership is documented and shared. These different phases will be further discussed in this chapter.

A new mixed-methods approach helped to overcome the limitations and biases of a single method approach (Johnson \& Onwuegbuzie, 2004; Walsh \& Downe, 2005), and the end result was a rich data source. Although untested, the methods designed and adopted for this research ensured substantiated findings and provided a multiplicity of perspectives and a rational balancing of strengths and weaknesses and facilitated the emergence of a 'third paradigm' (Teddlie \& Tashakkori, 2009) and ultimately a new 'standpoint' on the question of ownership.

\section{Informal Semi-Structured Interviews}

Semi-structured interviews are in-depth interviews and are often referred to as a 'conversation with a purpose'. This method was adopted predominantly given the vague nature of the question of ownership, and allowed a balance between flexibility and control to be maintained throughout the interviews. Semi-structured interviewing is believed to be one of the most effective techniques used in qualitative research; this is especially so in the study of people's knowledge and experiences (Drever, 1995; Mikkelsen, 2005). A preplanned set of questions guided the interviews (see Appendix 3). It must be said that I did reflect on the order of questions before each interview and rearranged the questions depending upon who was being interviewed and the time available. 
Visits to numerous development projects, and informal conversations with project beneficiaries were particularly helpful; I was able to see and follow the thinking of the research participants and better understand the challenges they were facing. The individuals and stakeholders involved in design, implementation and evaluation of the aid and development industry were first selected and interviewed. At the same time, I strengthened my network within the communities triangulating the information. This double-edged approach provided a wealth of information to record and analyse.

Each interviewee was given as much time as they needed to answer each question. My aim was to listen. Sometimes participants got 'off track', given the vagueness of the term 'ownership', but they were carefully steered back to the subject under discussion. My interviewing style changed as the research progressed and, with time, my questions around the concept of ownership were sharpened and contextualised.

\section{Case Selection and Sampling}

One of the methods adopted was to seek out the most effective and community-driven CSOs in the South Pacific as case studies and to put them under the microscope. Using the method of 'purposive sampling', some sixteen CSOs were initially identified by the people and selected based on their level of engagement with the communities they serve and their legitimacy and success as mediators for translating partnerships into ownership through respect for dialogue and process. After further, more detailed examination, three were shortlisted that were revealed to be the most effective amongst the CSOs examined, which are presented and discussed in Chapters 6, 7 and 8 .

This method of 'purposive sampling' is also known as judgment sampling, and is built on deliberate choice of inquiry based on the qualities these CSOs possess. Purposive sampling is an effective technique that does not need underlying theories, but that permits the researcher to decide what needs to be known, and who can provide the information by virtue of knowledge or experience and word of mouth (Tongco, 2007).

Purposive sampling is especially exemplified through engaging of appropriate and knowledgeable case studies and research participants, which was relatively easy to identify given the size of the Pacific Islands and the strong sense of community which is prevalent. 
Numerous important questions, however, constantly hung in the air as research advanced. The questions I constantly faced were how to gather more information which is accurate, and how to sample the population efficiently. How many people should be involved? Which organisations should be sampled? What sampling technique should be used to assure the sample is the best in its category and representative? How should I analyse the data? Is this learning replicable (Vogl, Vogl-Lukasser, \& Puri, 2004)?

While in the field, I constantly communicated with my supervisors back in Wellington, and sought their guidance, making sure that the sampling and the methods adopted were the most suitable. Purposive sampling can be used with a number of techniques. A study may be started with a survey, then purposive sampling conducted based on the survey (Tongco, 2007), which is how this research was completed. At the same time, the most important challenge I faced with this method was the reliability and competency of the informants. This is why I had to conduct as many interviews with as many development experts as possible to verify the findings (see Appendix 6) and to make sure that the data obtained was accurate. I was of course always alert and assumed predispositions on the part of the research participants, and reflected often on how to ask appropriate questions that would bypass the biases of the research participants and draw out accurate information.

As time advanced, and mainly because of the local guidance I received and continued reflection, I learnt how and who to engage to provide the level of analysis necessary on the question of ownership of development aid. Having worked within the aid and development industry in the Pacific, I managed to engage credible local informants on the islands who guided me on my path and made me see the complexities of the questions posed. Purposive sampling thus proved to be a practical and efficient tool for understanding ownership and unearthing methods that would improve the sustainability and effectiveness of development aid.

Conducting in-depth research in unknown territories can be a rich experience and the analysis of case studies examined in such settings, revealing and powerful (Berg \& Lune, 2004; Siggelkow, 2007). The few case studies adopted and examined were therefore very useful in unearthing the ingredients of ownership and demonstrating the strong role CSOs can play as intermediaries when they are accountable and legitimate. It can be safely 
concluded that the case studies selected "illuminated the general by providing the opportunity to observe the particular" (Denscombe, 2010, p. 53).

Many scholars view a case study as the most suitable research method, and argue that the 'how' and 'why' of the research determines the suitability of a case study approach, and that "a case study can be on any topic" (Yin, 2010, p. 160). However, the case study must present some empirical (qualitative and/or quantitative) data". But a case study method is not always effective and also has its critics; some common objections to using the case study approach are that (Flyvbjerg, 2006; Yin, 2010):

- case studies are often biased;

- they have a narrow basis for generalisation;

- thorough investigation of a case study takes too long; and

- they are difficult to conduct.

Having mentioned these shortcomings, it must be said that adopting case studies is a common standard in development discipline and practice. Robert Chambers notes that "case studies illuminate the dark corners and often stimulate and inform more than statistics" (Chambers, 2014, p. 64). Thus, as it will be observed in the following chapters, the case studies adopted proved to be worthwhile as they permitted close observation of the phenomenon and obtaining of data from both sides of the spectrum of development (donor to beneficiary) and accumulation of valuable information for further analysis.

\section{Should Ownership Be Measured?}

As research advanced, it became clear that if the research findings on the question of ownership are not contributing to knowledge in any meaningful way, then the usefulness of information gathered on ownership can be questioned. It became apparent that more tools are needed to identify and better understand ownership, how it is cultivated, and whether ownership is actually a beneficial and a desired development result.

Research participants often referred to ownership as a 'feeling' which complicated the research, as feelings are always hard to measure. Yet, this 'feeling' nonetheless had to be documented, equated, analysed, and measured for more in-depth understanding of the phenomenon. Early on in the research, it became apparent that the qualitative and 
participatory research on the question of ownership, although very actual and valuable, cannot be exclusively relied on because the basis of data gathered is simply grounded on multiple accounts of ownership offered by each research participant, and although each 'standpoint' and perspective offered on ownership is legitimate, there is no existing method that would permit comparison of the assessments, and to indicate which account of ownership is more valuable.

Without any additional assessments or any attempts to capture, record, measure and compare the experience of ownership and the differences felt, the conclusions obtained would constitute just another collection of 'feelings' and account of ownership, and, as such, the information obtained cannot be further discussed, compared and analysed.

As it will be explained in the next section, two surveys were then formulated using a Likert Scale (Spratt et al., 2004). These two surveys form the basis for the Ownership Index; one survey evaluates the levels of ownership felt among project beneficiaries and the other survey assesses the levels of the ownership assumed by the project implementers (see Appendix 4 and 5). The information recorded is then triangulated and the ratio of ownership partially measured. The two surveys were tweaked and finalised over time as different case studies were examined. Data and evidence was thus gathered on the details of the engagements which resulted in detection of a tangible definition for the Principle of Ownership and creation of an Ownership Index and Guidelines.

Research revealed that both the Ownership Index and the Guidelines presented in this research are practical tools that can assist in cultivating ownership and strengthening of the effectiveness and sustainability of development outcomes and can be of use both to the project implementers (CSOs) and to the project beneficiaries. Research revealed that the ownership definition and the indicators identified in this research must be taken into consideration from the start, injected into the development process and assessed from both ends of the spectrum as development aid unfolds, capturing the perception of both the project beneficiaries and the project implementers.

Observing and understanding the variables of ownership and how each stakeholder feels as projects unfold thus made the use of the Ownership Index logical for this study and 
understanding of the phenomenon of ownership. The information obtained with the support of the index are rendered into graphs in chapters 6, 7 and 8.

The qualitative assessments conducted with the support of the Ownership Index should not, however, be solely relied on as the information is partial, but the data gathered is valid enough to reveal that an Ownership Index is highly beneficial and can assist development experts to:

- gather evidence;

- document/record the development process;

- provide a rapid and overall diagnosis of development projects for future assessments towards more effective and sustainable development outcomes;

- support and facilitate comparative analysis;

- assist in creating points of discussion between partners; and

- promote the role of project beneficiaries in the development process ensuring that development results are maintained and protected by the project beneficiaries.

Scales and indices are often more criticised than used and have their own strengths and weaknesses but it must be highlighted that it is not the tools that are imprecise and often the problem, rather who is using the tools and to what political end.

\section{Existing Tools for Assessment of Ownership}

How can ownership be defined, cultivated and measured? To address these key questions, I researched the existing, definitions for ownership of development aid. Definitions offered for ownership are vague and numerous, as will be discussed in Chapter 4, and there are no tools, as such, to measure or to assess the concept. The most effective tool found is called the Capacity Development and Results Framework (CDRF) (World Bank, 2009)and is created by the World Bank Institute (WBI), which over the past decade has aimed to provide a systematic guide for measuring and exploring the value and feasibility of the bank's development interventions.

I explored the CDRF as a tool for dissecting ownership of development projects in the field, but CDRF soon demonstrated its limitations, as it depends exclusively on the analysis of Project Appraisal Documents (PADs) without engaging all partners inclusively at the 
grassroots; therefore, in my view, it fails to take into consideration the perspective and the level of ownership of the project beneficiaries. The CDRF simply measures:

\section{- Strength of stakeholder ownership prior to project implementation}

The formal and informal political, economic and social forces that determine the CSO Strategy, and ways it engages the community and the government

\section{- Efficiency of policy instruments}

The administrative rules, laws, regulations, standards, (Guidelines, Toolkits) and other formal incentives and

\section{- Effectiveness of organisational arrangements}

The systems, rules of action, processes, and other resources to achieve a development goal.

These criteria help assess the risks involved and strengthen approaches, but neglect various other conditions and principles throughout the project cycle (before and during the project) that, if taken more carefully into consideration, can highly enhance the effectiveness of development aid. Further research and more careful analysis of the CDRF also revealed that the definition of ownership provided by the World Bank is questioned by stakeholders as it will be discussed in Chapters 4 and 5 and that there is ample room to improve the CDRF, and to actually formulate a simple, tangible and measurable definition for the important principle of ownership.

\section{Can Ownership Be Measured?}

The Ownership Index formed and tested in this research to document the qualitative assessments of the research participants is inspired by close analysis of various existing tools: The Bhutan's Happiness Index, the Rule of Law Index, the Peace Index, the Four-Part Aid Effectiveness Agenda of the Canadian Development Agency (CIDA) 2007, and the CDRF mentioned above.

"Existing indexes are highly critiqued and often useless" (V. Naidu, Interview, May 2013, Fiji), but the development organisations generally agree that an "index does more good, than harm in the long run" (J. Murdoch, Interview, June, 2013, Fiji). Thus, as it will be 
observed in this research, presenting a new definition for ownership and aiming to measure the principle can be problematic, but can also address a major, long-standing weak point within the aid and development arena, namely the role of the project beneficiaries.

The Ownership Index designed for this research documents the perception of stakeholders and ownership of the process in identified stages of the project cycle through qualitative assessments. The index and the questions for the survey were formulated over time through successive experiments as research advanced. Twenty-three measures of ownership were identified throughout the project cycle 2 (See Appendix 4), and eventually eight of the twenty-three measures that play a critical role were selected as the prime indicators, due to their importance and relevance (See Appendix 7 for detailed discussion on the ownership ratings and the ownership formulas). The last indicator is grounded in the definition offered for ownership in this research and is regarded as a desired outcome.

Each measure offers not only insight into the complexities of each phase but also how any development project can be made more effective and sustainable by taking the maintenance and protection of the outcomes into consideration at these points of interval. The first two indicators are concerned with the problem identification and problem solution which can have a major impact on the process and development outcomes as will be observed through the case studies and is further discussed in Chapters 9 and 10. The last indicator measures the desired outcome being the question of commitment to maintenance and protection of results.

In addition, recall indicators were used to verify accountability and transparency of the endof-project evaluations and the direction of reporting (i.e. upwards to donors vs. downwards to communities), as well as particular approaches to information sharing (see both sets of Survey Questionnaires for CSOs and project beneficiaries in Appendix 2).

\footnotetext{
${ }^{2}$ The word 'project' and 'project cycle' used in this research, should be interpreted as broadly as possible as it simply refers to the collection of related activities to meet a specified objective.
} 


\section{The following are the Ownership indicators:}

1. Who identifies the problems (idea of the project);

2. Who identifies the solutions (knowledge);

3. Who designs the project (writes);

4. Who convenes the project appraisal;

5. Who finances the project (percent by the community + governments + CSOs);

6. Who implements the project;

7. Who monitors the project;

8. Who is involved in the project evaluation; and with whom are the findings shared (reporting upwards or downwards?)

9. Who (owns) or maintains and protects the outcomes?

Research participants then gave a score to each of the variables on a scale of 1 to 10 :

$$
\text { 1------2------3------4------5-----6-----7------8-----9-----10 }
$$

\section{0 indicating the highest level of engagement}

The Ownership Index is an additional tool for documenting the qualitative assessments of both the project implementers and the project beneficiaries, providing two sets of data that can be compared, further analysed and discussed - the perception of ownership of development outcomes by the project beneficiaries; compared and contrasted to the perception of the aid and development actors who implemented the project.

The index presented here and the Ownership Guidelines which will be discussed in Chapter 10 appear linear, but that is an over-simplification of the reality as development is much more complex and the element of flexibility must always be taken into consideration. It is important to note that the Ownership Index revolves around the 'process', and views the process of development as the 'product'. Cultivation of ownership or documenting of the progress is not necessarily linear, as the relationships between the stakeholders are complex and there are other interdependencies that need to be taken into consideration as development projects advance. 


\section{Assessment of Ownership}

To obtain a more accurate insight the ratings are expressed as percentages, and they do not add up to a whole. The ratings are an expression of how strong the ownership is, with $0 \%$ being no ownership at all, and $100 \%$ being the highest possible level of ownership. $A$ distinction is also made between community ownership, as reported by the community itself, and that reported by the project implementers. Because there is a variance between these two ratings as will be discussed in Chapter 9, the final ownership rating is the average of the two. This is determined with this proposed formula:

\section{$\mathrm{Oo}=(\mathrm{Oc}+\mathrm{Os}) / 2$}

where $O o$ is the final ownership rating, $O c$ is the community-reported ownership rating, and Os is the CSO staff reported ownership rating for the community based on the Survey questions.

Upon examining numerous CSOs and comparing the qualitative assessments with the Ownership Survey ratings, a partial threshold for ownership of development aid was adopted for this research at $70 \%$ to $75 \%$. This rating is naturally based on purposive sampling of high rating CSOs adopted for this research (see Appendix 7).

Both the Ownership Guidelines and the index are new and experimental tools that have been designed for this research as additional methods which have proved effective. They permit creation of a scaffolding that would allow cultivation and assessment of development results that are maintained and protected by the project beneficiaries.

The Ownership Index formulated in this research is an experimental tool and aims primarily to capture the levels of ownership felt, but it is important to highlight that the information is partial and 'quasi-quantitative' (Jiobu \& Lundgren, 1978; McKeown, 2004), and within the genre of 'mixed methods'. The information obtained with the help of this new method permitted documentation and a range of additional in-depth analysis and comparison of data towards more effective development outcomes that the people would want to maintain and protect over time. 


\section{Research Participants}

A wide range of research participants and perspectives was included to obtain a diverse, rich and accurate picture of ownership. Research participants included community members, development leaders, staff of CSOs, politicians, and academics. Project beneficiaries and grassroots interviews were particularly informative and educational.

I travelled by boat and small planes when possible to the outer islands of the South Pacific to obtain a grassroots and Pacific perspective of the impact of development aid. I also focused on residents of some of the poorest squatter settlements and other marginalised groups on the islands as will be discussed in Chapter 8. Many expressed their desire to be quoted for they felt that self-determination and ownership of development aid is an important issue. In Suva and Nukualofa, I connected with civil servants, academics, politicians, the UNDP staff, the UNDP Head of Delegation, as well as aid and development representatives from China, Japan, Australia, New Zealand, EU, ADB, and the World Bank. Finally, Fiji's ex-vice-president, and ex-prime minister, as well as numerous members of the parliament in Tonga also participated in this research. Obtaining some of these interviews was not easy, but I was persistent.

While in Fiji and Tonga, I based my research at the National Liaison Office for CSOs engaged in development aid. Their directors and staff helped me reach out to a wide range of CSOs, and their project beneficiaries, sometimes on very remote islands. I also engaged with faithbased CSOs, human rights CSOs, and development CSOs, and explored their policies and strategies for promoting ownership.

I particularly sought the perspective of women of the Pacific and their standpoint on the question of ownership and how development aid in their view can become more effective. I spoke with the community members as well as women leaders and youth leaders when possible. The information obtained from all these interviews shaped my understanding and standpoint and guided this research in untangling the complexities of the questions posed.

It is important to highlight the fact that the majority of interviews conducted were not specific to the case studies discussed in Chapters 6, 7 and 8, but highly relevant, and some 
of these additional interviews are directly quoted in Chapters 4,5 , 9and 10 , to reveal specialist perspective and local and indigenous understanding.

\section{Talanoa}

Another method used was a Pacific research method called talanoa which is becoming more popular amongst Oceanic researchers in recent years. Talanoa is a traditional Pacific method of exchanging information. It is a Tongan word at its origin, literally meaning: 'talking about nothing', 'chat' or 'gossip' (Farrelly \& Nabobo-Baba, 2014, p. 318). It is within the cultural milieu of talanoa that knowledge and emotions are shared and new knowledge is generated. 'Talking about nothing', or talking to a great extent about the same topic is the way by which decisions are made within the indigenous South Pacific context (David Robinson \& Robinson, 2005; Vaioleti, 2006a). Talanoa when conducted authentically has the power to remove the distance between researchers and participants and it is inspired by the Pacific way of life which "is based on oratory and verbal negotiations that have deep historical and traditional roots in Pacific cultures" (Vaioleti, 2006a, p. 25). Talanoa is a culturally appropriate tool of investigation because it has synergy with the Pacific people's way of life, and can be used as a method to cultivate ownership within the Pacific context, but there are few complications as further research revealed which I will briefly discuss here.

I used talanoa when appropriate, especially when engaging with the local indigenous participants who were willing. Talanoa is not formal and it suited my approach. It is subjective, collaborative, and is resistant to rigid institutional hegemonic control. Talanoa operates from a constructivist perspective, whereby knowledge is socially constructed through social oral engagement and dialogue between the partners during the development process which is the basis for cultivating ownership as it will be observed in the case studies and concluded in chapter 10 . Using talanoa, however, did help at times to bridge cultural differences, and provided a glimpse into the indigenous epistemology as proposed by Gegeo (1998) and is essentially a cultural group's way of thinking which can be a critical tool in the understanding of a people.

Talanoa is equivalent to the Western concept of 'discourse'. The word 'discourse' has IndoEuropean roots according to the Oxford English Dictionary; in its Latinate form, dis means 
"in different directions," and currere means "to run". It refers to the ongoing dialogue needed for understanding the truth; as there is no permanent meaning of the phenomenon; and if there is 'truth'; it is always changing, and thus the so-called 'truth' from this standpoint is a 'process' (Nietzsche, 1887/1992). Consequently, talanoa, in my view, is similar to this Western concept known as 'discourse', which according to Foucault is vital and refers to all forms of cultural life. What is important to note is that it is language that makes this unfolding and exchanging of knowledge or otherwise known as 'discourse' possible. At the same time, what is often neglected is how language is also a barrier to discourse and especially translation of cultural, technical, and developmental concepts can mislead and deceive the less informed populations.

In Western schools of thinking, it is Foucault who largely based his standpoint on the question of discourse within the polity and links the concept to different theories of power and state and their limits. Similarly, talanoa within the Pacific context avoids immediate and final conclusions and demands that the conversation be continued about the questions posed over time, in peace, and with pleasure and understanding, which is why kava is normally served. Discourse similar to talanoa has no boundary, it includes everything that we know and that can be said about any specific topic, keeping in mind that everything is constantly changing including the so-called 'truth'.

The 'truth' is therefore a process and is always evolving, ever-changing, and its limits are simply unknown. Talanoa captures this worldview. A talanoa, very much similar to the Western concept of 'discourse' informs us through ongoing dialogue, makes us conscious of how we can view the same phenomenon from different angles and opens our eyes through ongoing and inclusive discussion.

Ensuring active and meaningful talanoa while building authentic partnerships and constantly engaging in dialogue throughout the development project cycle will no doubt enhance the effectiveness of development outcomes and will result in ownership of development outcomes as the case studies will reveal in this research. It is due to the power of dialogue and talanoa; or 'discourse' as Foucault puts it, that positive change and so-called 'progress' and 'development' is arrived at. As with any culture, language is the means by which a society is shaped, and dialogue the method by which Pacific cultures and activities 
are built on (Keppel, Morrison, Watling, Tuiwawa, \& Rounds, 2012), but careful attention must be paid to the language used and the interpretation of any phenomenon, especially of social and cultural theories as well as scientific terms. A new word like 'ownership' can bring about a new world, but it can also cloud the vision and dilute understanding if misinterpreted and misunderstood.

I engaged in talanoa when research participants wanted to and when I felt it was appropriate. I often sat around in traditional settings with the men of the communities as it is the tradition in the Pacific. I listened and slurped the sacred and bitter kava that was often prepared and served by the kind women of the community and enquired about the effectiveness of development aid and ownership of change.

Although the knowledge and tradition of talanoa enlightened me, I felt that I need to concentrate more on other methods more aligned with my background and the epistemology of this research for numerous reasons, primarily because I felt conscious of being the 'Other', and my lack of capacity to speak any of the local languages and the fact that I am not familiar with the details of the cultural norms. Most importantly, as time advanced, I observed that talanoa tends to exclude the perspective of women and demands that they remain silent in traditional settings.

\section{Authentic talanoa can only be conducted in local indigenous languages and demands a good understanding and respect for the local cultural norms. The difficulty with talanoa in traditional settings is that women must remain silent in the presence of the men. (Dr. Ana Taufe'ulungaki, Interview, July, 2013)}

This is predominantly why talanoa was not adopted for this research. I wanted to know and to incorporate what women think in regards to ownership of development aid and I sought their perspective every chance I had. I did not have the time unfortunately to engage in an 'ongoing conversation' about the effectiveness of development aid, and 'to no-end' as talanoa methodology demands. I wanted concrete, inclusive, and sound conclusions, so I relied on a range of different methods. 


\section{Data Analysis}

Pilot interviews were conducted with development experts in New Zealand before the field mission was undertaken to assess the calibre of questions and structure of the interviews. Once on the field, I conducted 180 interviews of which 118 research participants signed the consent forms and agreed to be quoted (see Appendix 5). The rest of the interviewees informed me extensively and generously, but decided to remain anonymous due to the nature of their partnerships and their fear of losing funding. Their participation, however, was critical as they anonymously helped shed light on the complexities of ownership.

For ethical reasons, I visited the case studies selected and other completed development projects often with the research participants who work with the implementing CSOs. I would explain my research to the project beneficiaries and would then engage informed and interested individuals. All of the interviews were recorded for a second inspection and a more detailed analysis. More than 200 hours of recorded conversation were listened to and analysed after the field research was completed.

Each interview generally lasted approximately 45 minutes to one hour. At the end of each interview, participants were asked to complete a qualitative assessment survey with the support of the Ownership Index (see Appendix 3, 4, \& 5), which took around 5 to 10 minutes to complete and provided ample additional information.

There are no standard methods prescribed for analysing recorded semi-structured qualitative interviews. While the central task of interview analysis rests with the researcher, some general approaches to the analysis of qualitative material do exist (Miles et al., 2013; Saldaña, 2012). I followed the following steps to generate meaning during and after the interviews:

- careful listening;

- noting hidden meanings, patterns;

- categorising;

- contrasting and partitioning variables; and

- building a logical chain of 'evidence'. 
Each of the methods selected had its own strengths and logic and was used to address different questions and purposes (Spratt et al., 2004; Tashakkori \& Teddlie, 2010; Teddlie \& Tashakkori, 2009).

\section{The Scope of the Research}

Fiji and Tonga were chosen carefully because of their contrasting aid and development structures. Since 2006, aid to Fiji has been primarily disbursed through civil society, because of the consequences of political instability in recent years. Fiji has a dynamic civil society and a solid coalition of CSOs active in various capacities. The CSOs in Fiji have historically been active and have played a crucial role in Fiji's development. The CSOs in Fiji, as elsewhere in the South Pacific, have been particularly active in areas where the government is failing (Fraenkel, 2013; Hegarty, 2013; Lal, 2013; Sahlins, 2013). Close observation of their conduct (as discussed in Chapter 5) revealed that CSOs have played an excellent role in informing and connecting the 'local' to the 'global' and mediating between external donors and the community.

Allocation of aid to Tonga, by contrast, is centralised. It is channelled through the government of Tonga in compliance with the Paris Declaration of Aid Effectiveness, and the Aid Effectiveness Agenda. Donor funds in Tonga are primarily allocated to the Ministry of Finance, which then channels the funds to development partners including the Tonga's NLU for CSOs, and other selected CSOs aligned with the country's development plans.

Development aid in Tonga has been directed to projects that increase the capital assets of the nation, recent examples being harbour developments, airport expansion, and road improvements. Tonga provided an excellent opportunity to closely observe the challenges associated with the principle of country-ownership, and compliance with the 2005 Paris Declaration of Aid Effectiveness.

With communities dispersed over some 180 remote islands, Tonga is one of the most vulnerable countries in the world according to the Commonwealth index (Secretariat, 2014) and thus a very interesting research topic for understanding the complexities of development aid. Tonga is exposed to human-induced and natural disasters, and the outer island communities are often completely neglected and are vulnerable to natural calamities. 
CSOs are often the only organisations active on remote islands as the Government of Tonga does not have the capacity and the resources to reach out to all the remote islands.

Finally, Tonga and Fiji were selected for this research because they represent the opposite ends when it comes to the question of sovereignty; Fiji is the first in the Pacific to cede its sovereignty, and Tonga is the only country among the Pacific Islands that has never lost its sovereignty to a foreign power (Crocombe, 2001).

\section{Structure of the Methodology}

The diagram below sums up the four phases of the research process:

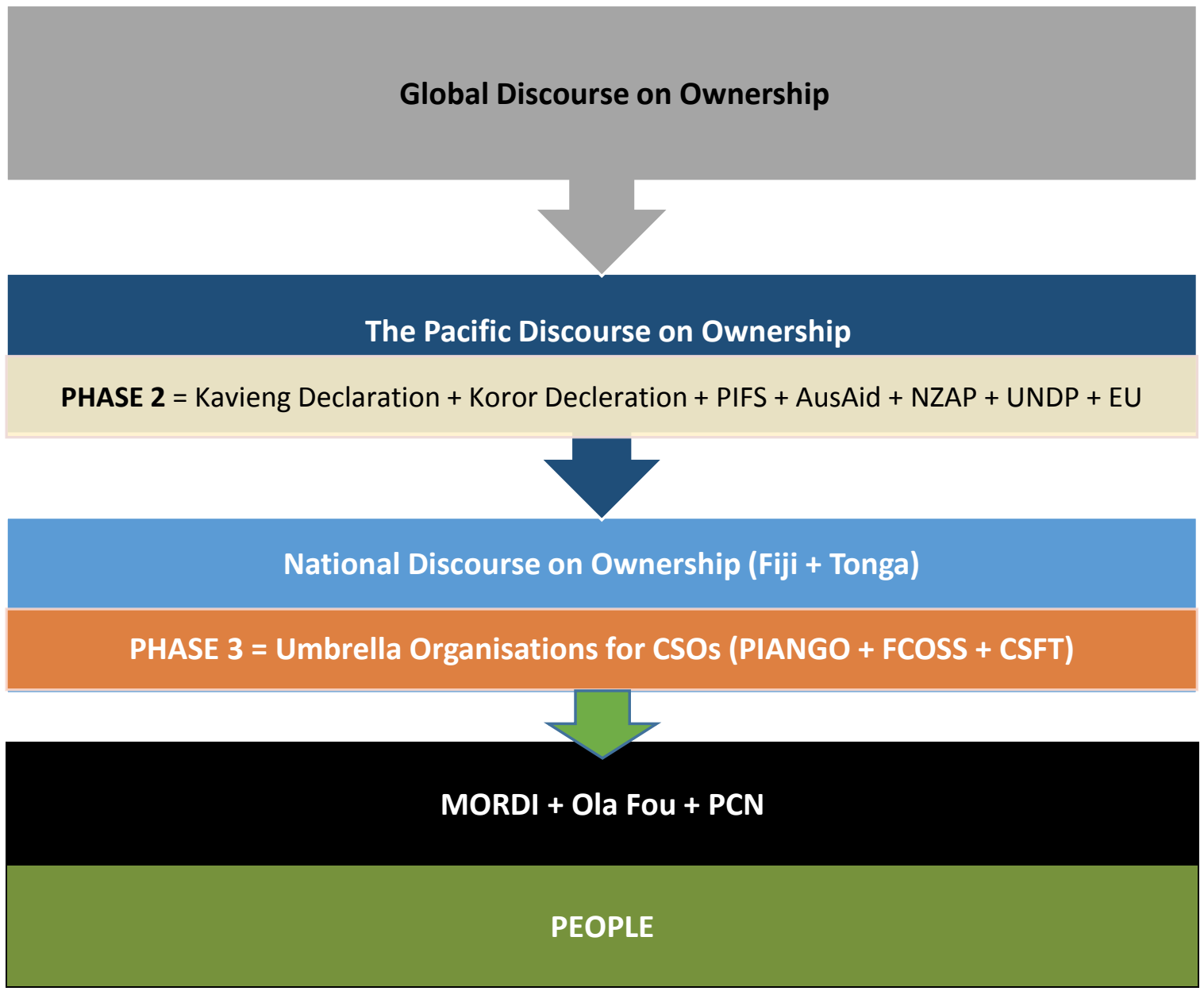

Figure 2.1 - Research Phases

\section{Phase One}

During this first phase I researched the international discourse on local ownership, donor government policies, and the outcome statements of international meetings on aid and development effectiveness. I methodically examined all existing documents, particularly 
those relating to the definition and meaning of the term ownership, and how the term is incorporated into policy and practice. 'Ownership' is a key word used in all of the Aid Effectiveness outcome documents, but research revealed that the concept is a policy ideal, unclear, and it has been described differently at each High Level Forum (HLF) meeting over the years. The term has gone through a major shift in meaning. Chapter 3 discusses these findings and the Global Debate and the evolution of the term 'ownership' within the international discourse.

\section{Phase Two}

Regional organisations as grand mediators were the target of the second phase of this research. At this stage, the meaning of ownership was explored further, along with how it is defined within the policy framework of a number of organisations in the Pacific region such as the Pacific Island Secretariat (PIFS) ${ }^{3}$, the United Nations Development Program (UNDP), the European Union (EU), New Zealand Aid Programme (NZAP), the Australian Aid Programme (AusAid), the Pacific Island Association of Non-Governmental Organisations (PIANGO) $^{4}$; and the National Liaison Units (NLUs) for civil society in Fiji and Tonga. I was determined to understand how, as key players in the region, these organisations of such scale and reach define ownership, and what policies and strategies are in place to safeguard ownership of development aid by the project beneficiaries. I also carefully examined the Koror as PIFS recognised response, and Kavieng Declaration (2008) on Aid Effectiveness as an example of country-level adaptation of the principle of ownership.

\section{Phase Three}

The two umbrella organisations for civil society in both Fiji and Tonga played a key role at this stage of the research. Fiji's Council for Social Services (FCOSS) and Civil Society Forum of

\footnotetext{
3 PIFS plays a role in ensuring the participation and presence of all stakeholders in formation of policy and promotion of ownership. PIFS is a political grouping of 16 independent and self-governing Island states in the Pacific region and is also mandated to coordinate the implementation of the Pacific Plan for strengthening regional cooperation, development and integration. PIFS also brings together nine of the main regional civil society organisations in the Pacific region including the University of the South Pacific, Pacific Island Development Programme, and the Pacific Aviation, Fisheries and Power Associations.

4PIANGO is an important and well-connected Pacific network that has aimed to strengthen and influence the impact of development civil society organisations in 22 Pacific Island countries, mainly working with NLUs across the Pacific. PIANGO has been active since 1991 and has assisted NGOs in the region to work collaboratively with other development actors. PIANGO is the regional umbrella organisation of all the national umbrella organisations.
} 
Tonga (CSFT) were both very helpful and supportive of this research. The directors of both FCOSS and CSFT shared their assessments of the civil society sector in the Pacific and concerns around the question of ownership.

The civil society sector in Fiji and in Tonga is broad. To better understand strategies and approaches of the sector for promotion of ownership, it was suggested by both Directors that I explore the most effective and community driven CSOs. Thus, with their guidance, a number of CSOs were selected that are most renowned for implementing community-driven projects. I then approached these particular CSOs, visited their development projects, and engaged their staff and project beneficiaries in semi-structured interviews.

\section{Phase Four}

To unearth the ingredients of ownership, and to understand the process and how it is promoted, I narrowed down the area of research even further. In this next phase, to counter-balance criticisms and to prevent possible errors, I focused on sixteen selected CSOs, and then carefully chose three case studies based on research I conducted in the community and expert advice. The CSOs selected and discussed in Chapters 6, 7 and 8, have the reputation for implementing development projects that are highly sustainable and maintained by the community. Observing their work, their organisational structure and the approaches they have adopted to engage with their project beneficiaries forms the basis for most of the conclusions made in this research.

\section{Ethical Issues}

While conducting this research I aimed to leave my biases and beliefs aside but "researchers cannot conveniently tuck away the personal behind the professional, because fieldwork can be very personal. As researchers, we are positioned by our gender, age, race, and so on, as well as by our biography, all of which may inhibit or enable our research in the field" (England, 1994, p. 249).

To overcome these biases, I aimed to fairly and accurately represent the concerns and opinions of the participants, and I have quoted participants at length, word by word, rather than using their comments as 'sound bites'. I hope this has enabled the context of their perceptions to overshadow my own opinions. Furthermore, I stopped working at the 
Council for International Development where I worked as the Senior Policy and Research Officer and became an independent researcher. I started each of my interviews by telling the participants about myself and this research. I made sure that each research participant understood the issues around my research questions, and what this research aims to achieve. I aimed to listen, understand and obtain a balanced perspective from each standpoint. I took every opportunity to confirm information obtained, verify and validate data, making sure that it was accurate.

Victoria University of Wellington requires consideration for ethical implications of research. In accordance with this requirement, I provided the research participants with an information sheet and a consent form before each interview (see Appendix 1). By signing the consent form, participants acknowledged that they had been informed and that they were willing to take part in this research although some did chose to be anonymous while they gave their verbal agreement to participate. I have taken the issues of confidentiality in regards to the research participants into consideration throughout this research and have done all I can to minimise any potential harm to participants.

\section{Conclusion}

Almost two decades ago Wesley-Smith wrote, "Pacific Islanders are among the most studied people on earth" (Wesley-Smith, 1995, p. 115). This exhaustion is taken beyond its limits today, but as I travelled across the South Pacific as another researcher it became apparent to me that Pacific Islanders are not necessarily tired of research; rather, they are eager to take 'ownership' of research, to pose their own questions, and to use their own methods of investigation. They want to maintain and protect their own traditional ways of investigation and knowing, instead, of relying on research methods and questions proposed by outsiders.

In this chapter, I have sketched an outline of the mixed methods adopted for this research, and the research methods and structure. Finding the appropriate methods for this research was not easy given the nature and complexity of the research questions. Thus, I designed my own mixed methods but constantly sought local, indigenous and professional perspectives, and adjusted my approach and the methods adopted as the research progressed. 
Keeping in mind the limitations faced while conducting this research, I prefer to think of the specific new and experimental tools formulated for this research as just the beginning of a much larger and much-needed inquiry into the question of ownership. In the next chapter, I will study the origins of the concept of ownership, and will review the literature on the evolution of the concept as a principle of aid and development effectiveness and explore the meaning of the theory of ownership in other disciplines. 


\section{Chapter 3}

\section{The International Aid Discourse and Ownership}

\section{Introduction}

In this chapter, I will examine the concept of ownership within the international aid and development discourse in line with the research methodology adopted and discussed in Chapter 2. Ownership is a relatively new phenomenon within the international aid and development discourse. The concept is complex, multi-layered, and is still being debated amongst international aid and development actors. In this chapter, I will discuss and analyse the evolution of the term and how international, regional, and national development organisations define ownership of development aid and put the principle into practice.

\section{Contextual Background - The Global Aid Discourse}

There is a 'strong will' around the world to end poverty, but efforts have not been as fruitful as expected (Dichter, 2012). Numerous meetings are being held annually by the rich donor countries around the same old issues of poverty and how the mechanics of the industry can be improved. Ownership has been one of the main topics of most of these meetings over the last decade. It is today commonly regarded as a "precondition for sustainable results of development cooperation" (Edgren, 2003, p. 9), and a "key factor for sustainability" (M. Edwards \& Gaventa, 2014, p. 3).

Country ownership was hailed as the first Principle of Aid Effectiveness in 2005 by the OECD in Paris (Foresti, Booth, \& O'Neil, 2006) but what exactly does ownership mean? Should it be measured? Can it be measured? Unfortunately, while the concept of ownership of development aid has been valued especially by developing countries and the global civil society, the understanding of the word and the meaning of the principle remains perplexing.

The aid and development arena is becoming more populated and complicated with the increase in the number of CSOs and greater interest and engagement from new donors. Despite the financial crises of the last decade, donors are allocating more funds to aid and development (Hsu, Pitt, Greco, Berman, \& Mills, 2012). 
There are new actors and more debate on the question of ownership, but no consensus yet as to what the concept means to the different stakeholders in terms of policy and practice; no detailed rules or guidelines exist to promote the phenomenon. Furthermore, the private sector has also joined the sector, but how these diverse new partnerships are going to be better formalised and all these factors taken into consideration is yet to be seen (Eyben \& Savage, 2013).

The new generation of talks on aid and development effectiveness is now named the Global Partnership for Effective Development Cooperation (GPEDC), and it follows the High Level Forum (HLF) meetings. In April 2014, at the last meeting on aid and development cooperation, some 1,500 aid and development delegates from 161 countries flew to Mexico City. With this many participants present, it is difficult to assess the effectiveness of a twoday meeting (Janus, Klingebiel, \& Mahn, 2014). According to the Institute of Development Studies, the success of these new global meetings will depend on the degree to which the traditional donors and governments are prepared to 'listen', and to engage with the new aid and development actors. New donors, such as China, are becoming increasingly more important and they bring their own approaches. The challenge is to produce common goals that all actors can agree on (ODI, 2014).

The new donors naturally have their own agendas to think about and they are not necessarily attracted to the old principles of aid and development effectiveness set previously by the old colonial powers and traditional donors. There are no 'gains', so to speak, for the new donors such as China, in signing the previously agreed principles of aid effectiveness and other documents promoted by the traditional donors. All this, however, has a direct impact on the delivery of development aid and on ultimately people at the grassroots.

\section{Origins of the Concept of Ownership}

The concept of ownership in development aid has a long past but a short and vague history. Overall, there is a gap in the literature and the perception of the idea is hard to trace and is relatively new. The philosophical approach of the concept of ownership, however, can be traced back to the whole notion of 'participation' and the debate that Robert Chambers spearheaded in the 1990s (Chambers, 1994a). During the past decade, however, and since 
the 2005 Paris Declaration, the concept of ownership which is inspired and rooted in the concept of participation of stakeholders, has come to the forefront of development effectiveness discourse, but arguably ownership has become less of a populist and more of a managerial concept as it will be observed in the following sections.

A successful example of the connection of the two concepts of 'partnership' and 'ownership' are the methods promoted by Robert Chambers, such as the Participatory Rural Appraisal (PRA) and the Participatory Learning and Action (PLA). Both methods have been widely used in development programmes since the late 1990's and have become synonymous with the extensive work of Robert Chambers. These methods are primarily concerned with providing tools that allow and encourage communities to develop their own practices and processes for more effective development aid which, as case studies in Chapters 6, 7 and 8 will reveal, have a wide range of impacts on sustainability of development outcomes if they are properly conducted. There are multiple strengths that combine to create the participatory recipe inherent to the individual and the collective (Chambers, 2002), and evidence reveals that they tend to lead to ownership of the outcomes by the project beneficiaries.

What can be observed at the core of successful effective participatory methods, making it relevant and similar to the philosophy of ownership, is the reaction to the top-down, external, expert-led processes. Chambers went as far as claiming that participation is the new paradigm of development (Chambers, 1994b; Jennings, 2000; Pretty, 1995), however, "there is in general a lack of evidence that participation is actually working" (Cooke \& Kothari, 2001, p. 57), and as effective as it is claimed to be.

The failures of development are often attributed to recipients' lack of self-sufficiency and responsibility. Development has not been conceived in such a way that the partners and target groups are both made responsible for the projects. Instead, "development aid has assumed a culture of independence and passivity in the recipient countries" (Baaz, 2005, p. 124). It is this lack of ownership and assumed passivity and dependence that this research aims to combat.

Ideally "local partners lead development while external actors back their efforts to assume greater responsibility for their own development" (Crewe \& Harrison, 1998, p. 70) but creation of a non-paternalist discourse and an equal relationship has proven difficult in 
practice. While there are numerous studies that theorise the problem of partnership' (Sachs, 2010), the obvious factor is that these concepts and many others "are used as political slogans to hide motives, and to mask other goals" (Baaz, 2005, p. 7). As a result, concepts such as 'national ownership' or 'country ownership' have become important 'buzzwords' (A. Cornwall, 2007) and in my view are political myths and slogans used to manipulate the agenda, although there is ample goodwill at their conception. The main problem is that development aid actors refer to the concept of 'participation' or 'ownership' within the sector, but no development organisation is obliged to incorporate the principles into their practice and there is no consensus yet among the actors as to what these principles actually mean in policy and practice.

What is interesting to note is that the concepts of 'participation' and 'ownership' were initially adopted and endorsed by the World Bank and the International Monetary Fund in the late 90s, being the two most important international financial institutions. Both concepts were initially highlighted in Poverty Reduction Strategy Papers. In other words, adoption of participation and ownership approaches were encouraged as financial managerial devices to shift responsibility to the partner governments, but not power. So, the question posed in this research is whether the origin of the concept of ownership is another populist policy as the sceptics would argue (Cooke \& Kothari, 2001; Sachs, 2010), or whether both concepts of participation and ownership finally gain more standing and can be incorporated more firmly into policy and practice.

In the following sections, I will analyse the evolution of the concept of ownership and the definitions offered for the theory in-depth, and will discuss why none of the definitions offered have yet gained traction, before I offer a new and practical definition for the concept of 'ownership'.

\section{Evolution of Ownership}

\section{Borrower Ownership}

The term 'ownership' within the aid and development discourse was first used in reference to financial loans. Observing the evolution of the word 'ownership' within the literature reveals that the term was officially coined by thelnternational Financial Institutions (IFIs) 
after the end of the Cold War when the developed countries shifted their economies towards privatisation (Bank, 2002). To a great extent, this initiated the beginning of a new era of 'financial interventionism' (Kahn \& Winton, 1998) as IFIs began to further strengthen their grip on the economies of developing countries, and as funding for aid increased to assist economic growth, but also to fight corruption and to improve effectiveness.

The term 'ownership', however, gained more momentum within the aid and development arena towards the end of the last century when banks started to seek more credible and accountable signatories for the loans allocated. The concept of ownership is introduced by the banks in this era as a financial and legal term and is used often in documents drafted by the IFIs, in cooperation with developing partner governments, and those responsible for signing off the financial loans on behalf of the people in developing countries. To fight corruption in aid recipient countries and to enhance effectiveness of aid delivery, donors and governments embarked on identifying 'owners' for the loans offered, making sure that the funds allocated were safely signed off and that the officials in developing partner countries were signing financial agreements that are legally binding. What was desperately needed, and is still an issue, was accountable governments that would lead, and officials within the developing partner countries that would be capable of making commitments on behalf and with the people when they received funds from the donors.

Review of the literature also permits us to trace the roots of the concept of ownership in the Washington Consensus and the Structural Adjustment Programmes (SAPs) (Soederberg, 2001; Williamson, 2000). The end of the Cold War initiated the beginning of a new era of greater economic opportunities around the world for rich countries. The private sector, and particularly the banks, instigated a financial takeover of the developing world in a 'new form of colonialism' (Soederberg, 2004). This meant that the private sector and banks entered a new era. They played a more important role than ever before, pressuring, dictating, and seriously influencing their own governments as well as the governments of partner countries (Gurtner, 2010).

An awkward series of failed cases of structural adjustment attempts, supported by the World Bank and International Monetary Fund (IMF) (Dollar \& Svensson, 1998), was largely attributed to lack of 'ownership' on the part of the borrowing countries. Developing 
countries wanted to borrow from the rich countries (and IFIs), but the ruling governments were often not the true representatives of the people and did not always understand the implications and the commitments to the reforms that condition the loans (Devarajan, Dollar, \& Holmgren, 2001, p. 571). The entire SAP approach was therefore criticised and it failed over time, because of the coercion of the World Bank and IMF through conditionality. The SAP approach failed because the loans were administered by corrupt officials in developing countries who signed the contracts without consulting people at the grassroots (Mohan, 2000), while the bailouts forced countries to agree to reforms that they did not want. In short, the SAPs worsened the conditions of the poorest and most marginalised groups, because of negligent and corrupt officials and governments (Edigheji, 2005, p. 18) that are in most cases still in power.

Therefore, aid and development was ineffective to some extent because of the weak institutions involved, lack of accountable governments, and lack of respect for the rule of law (Bourguignon \& Sundberg, 2007). What the process lacked more than anything else was credible signatories who would take 'ownership' of the loans needed on behalf of the people in developing countries.

As the success stories have revealed, allocation of funds to developing partner countries needs responsible and accountable 'owners' who will take charge and make the right decisions on behalf of the people (Booth, 2012; Kim \& Lee, 2013). Important questions must be posed very early on; who is the owner of the loan(s), and funds allocated? Who is borrowing the money on behalf of whom, and who will ensure that the funds are properly used? The thinking behind this approach at the start of the ownership debate was that increasing local government participation would increase ownership of the loan programmes and thus ensure more secure lending of the funds and better fiscal policy.

Thus, the concept of 'ownership' at its conception had nothing to do with the role of the people and development project beneficiaries. Instead, it referred to 'owners' of the loans, and "borrower's ownership" (Gilbert \& Vines, 2006, p. 178) simply referred to the signatories of the loans. According to the World Bank, funds allocated had to become more secure. Hence, the challenge was to ensure that the 'owners' (borrowers of the loans and the recipients of aid) were accountable and capable, and had 'the ability to implement'. 
The debates at the World Bank around the need for greater accountability and "borrower ownership" initiated the start of the big push at the end of the $20^{\text {th }}$ century towards greater 'participation' of the governments of the partner countries, enforcing the rule of law, and 'ownership' of the development aid agenda. This shift in thinking and approach at the World Bank was no doubt highly influenced, in my view, by Robert Chamber, the father of 'participation' in development discourse, and his surprising engagement with the World Bank. The Director of the World Bank, Wolfensohn, made a historic and unexpected comment in 1998 when he stated that "at the World Bank we should never stop reminding ourselves that it is up to the governments of partner countries and their people to decide what their priorities should be" (Wolfensohn, 2005, p. 117).

Over the years, however, unfortunately the only apparent ownership the poor in developing countries have managed to obtain is ownership of the financial loans. Hence, much more work and reflection and debate is still needed on how the system can be improved and how development aid can become more effective.

The term 'ownership' thus became formally recognised and standardised by all financial institutions that provided loans for development aid. In 1999, a new and anticipated direct reference was made to the concept of ownership in the World Bank's Comprehensive Development Framework (CDF), which stressed that developing and borrowing countries are encouraged to formulate "development plans jointly with donor organisations, CSOs to ensure that the development objectives are comprehensively covered, [...] and that local ownership' of funds are maximised" (Gilbert \& Vines, 2006, p. 77). This, in a way is the moment in history when 'borrower ownership' became a precondition for the World Bank before loans were allocated, and has since left the partner governments with a range of responsibilities, including the weighty obligation of the partner governments to engage the civil society in design of development policy. An approach in which the majority of partner governments have failed.

In 2002, SAPs underwent a complete transition, and the rules of the game were changed by the IFIs and the World Bank. A new agenda was introduced that replaced SAPs. The new strategy is more effective and demands partner countries write their own Poverty Reduction Strategy Papers (PRSPs). The PRSPs demand that country strategies be 'country-driven', with 
an emphasis for the first time on ownership of development plans by the partners. What the PRSPs neglect to elaborate on is how a 'country-driven' strategy is to be achieved, and ownership of development outcomes by the people be cultivated.

As a result of PRSPs, a more flexible and creative approach to policy creation has been implemented at both the IMF and the World Bank, and the system has become more accountable as more loans are secured. To increase the borrowing country's ownership and involvement, developing countries are encouraged to draw up and 'own' their PRSPs, which essentially have taken over the SAPs. Unfortunately, the content of PRSPs is very similar to the original content of bank-authored SAPs. Critics argue that the similarities show that the IFIs and the countries that fund them are still overly involved in the policy-making processes, and it is the donors that make the final decisions (Dijkstra, 2011) when it comes to development plans. However, the PRSPs, although imperfect, have initiated new approaches for lending money to low-income countries based on accountability and greater security and ownership of the loans by the borrowing partners and the recipients of development aid.

In 2003, OECD/DAC initiated and organised a series of HLF meetings that lasted for a decade, bringing all of the donors and other stakeholders together to address these abovementioned aid delivery challenges and to improve the effectiveness of aid. These meetings, for the following decade, served as focal points for debate on reform of the international aid system and how development aid can be more effective (Kang, 2012). At each of these meetings over a decade, the question of ownership of aid and development has been debated with no concrete definition offered, especially as to what ownership means for civil society and in policy and practice.

\section{High Level Forum: Rome 2003}

The Millennium Development Goals (MDGs) ${ }^{5}$ were signed in 2000. However, it took three years for the signatories to come together again to assess the slow progress towards the

\footnotetext{
${ }^{5}$ The MDGs are eight international development goals that were established following the Millennium Summit of the United Nations in 2000. One hundred and eighty-nine United Nations member states at the time committed to help achieve eight Development Goals by 2015.
} 
Goals and to rethink strategies, mainly financial, with the IFIs and the partner countries towards achieving the Goals. A meeting was called in 2003 in Rome and the OECD countries and stakeholders were invited. The meeting aimed to harmonise donor activity and to align their work.

The first generation of meetings held in Rome (2003) sealed the deal on the 'borrower ownership'. Donors resolved to ensure harmonisation in activities (finances), and agreed to provide country-led support, and pledged to expand efforts to review and identify ways to adapt country-led policies (Martini et al., 2012).

Civil society organisations, widely absent from the meeting, highly criticised the Rome Outcome Document and argued that the document was narrow and too focused on the technical aspects and government-to-government financing (Hayman, 2009). The Rome Meeting and the Declaration fuelled the debate around the MDGs and other challenges: most importantly, the need to ensure country ownership. Equally the need to speed up the agenda to meet the MDG targets was highlighted. What was neglected in Rome was the roles of civil society and especially the project beneficiaries in the process (Tujan Jr, 2012).

\section{High Level Forum: Paris 2005}

In order to address the challenges of achieving the MDGs, their slow progress, and the shortcomings of Rome, the second generation of HLF Meetings was held by the OECD in a historic meeting in Paris (2005). "Unlike the Rome Declaration, the Paris Declaration introduced specific principles and a strong monitoring component" (M. L. Lawson, 2010, p. 7). The High-Level Forum in Paris was of a different calibre and, in retrospect, signing of the Declaration was a leap forward especially within the aid and development discourse. Paris Declaration in my view is a major shift in aid paradigm and development thinking.

For the first time in history, country ownership and accountability were shifted to the top of the aid and effectiveness agenda, and proclaimed as two of the five most important principles of aid effectiveness. Donors prescribed the five simple but essential principles for aid effectiveness to the partners, with country ownership as the first principle of aid effectiveness, followed by harmonisation, alignment, managing for results, and mutual accountability (Correll, 2008, p. 12). 
The most remarkable aspect of the Paris Declaration, in my view, is its attempt to measure the progress of the principles of aid effectiveness with indicators, timetables, and targets along with an evolving agenda for implementation and monitoring, which has failed over time to meet its targets, but is unique. "With all its shortcomings, there is no doubt that the Paris Declaration is a historic document and is valuable because of its new approach and method of delivery, even if it has largely failed" (Booth, 2011, p. s23).

The Paris Declaration was criticised by CSOs around the world from the day it was signed. They argued that it failed to take into account and address a large number of issues, such as the inclusion of "human rights, gender equality, decent work and accountability towards the people" (Nowaczyk, 2011, p. 12). The Paris Declaration overlooks development effectiveness issues around the impact of development aid on the ground and, most importantly, the role of other stakeholders, such as the civil society within the national setting, and the impact on the role of the people in the process.

The Paris Declaration placed country ownership at the forefront of the aid effectiveness debate and called it essential, but the term 'ownership' within the Declaration remains broad and it has become problematic. Some scholars argue that the term 'ownership' is critical, but that currently it is nothing but a distracting pleasant buzzword used in the donor rhetoric. In a paper submitted to the World Bank, Buiter (2007) accurately summed up the challenge of endorsing a multifaceted slogan and catchphrase such as 'country ownership'; Buiter highlighted the fact that 'ownership' refers to the financial interests of donors, the loans by the partner countries and aid recipients (borrower ownership) and has no direct impact on the lives of the people at the grassroots. "The concept of country ownership has been used and abused in so many ways, he argued, that it now is at best unhelpful, and at worst misleading and confusing. The statement 'this program is country-owned' means no more than 'this program is supported by the people who run and own the country'. It is time to purge it from our vocabulary" (Buiter, 2007, p. 4) - and to adopt a more appropriate and inclusive, applicable term.

The points Buiter raised about the importance of properly defining what ownership means have been ignored since. It is here and within this perplexing framework that this research is imbedded and evolves. 


\section{High Level Forum: Accra 2008}

In an attempt to address the limitations and the shortcoming of the Paris Declaration, donors decided to come together again. This time, civil society was invited into the arena and the HLF was more inclusive. The third generation of discourse around effectiveness of aid was initiated in Accra in 2008. The third HLF discussions focused on what each of the Paris Declaration Principles meant in practical terms. What made Accra different, however, was that, for the first time, CSOs were officially invited by the donor government to participate in the debate (Poverty, 2014).

CSOs were disorganised and were not as prepared as expected because this was the first time that they were invited to the donors' tent and obliged to unite their voices. The main challenge was to create a united strategy amongst all of the civil representatives at the conference at the last minute, which was impossible due to time constraints. Different CSOs took the microphone during the meeting and talked about the challenges they were facing and the solutions they envisioned, all of which made them appear disorganised in the eyes of the donors and governments, as they had not reached consensus amongst themselves before the meeting. However, they did manage to influence the process, and question many vague aspects of the aid architecture, especially the question of ownership of development aid and how accountability systems downwards to the people could be improved (Tomlinson, 2011).

The Accra Agenda for Action ( $A A A)$ is a significant milestone and a unique evolution in aid and development discourse. It brings to the table new issues, most importantly the views of civil society on development effectiveness. The document, although signed by OECD members, was never implemented into policy and practice by rich donor countries, but it did reveal to the CSOs that they can influence policy on a grand scale if they unite.

'Country ownership' and its meaning and implications was especially challenged by the CSOs at ACCRA, and donors and governments present agreed to improve the language. The term 'country ownership' was changed by donors to 'inclusive ownership' and it was agreed that there must be a greater and more inclusive dialogue between governments and stakeholders for aid to be more effective and sustainable (especially with CSOs) (Atidegla, 2011). 
The AAA was a success for civil society, as it ensured a more inclusive partnership and dialogue between stakeholders, but it again neglected to elaborate on how this new principle of 'inclusive ownership' was to be adopted in policy and practice. The AAA defined ownership as "integration of all stakeholders into the formulation process of the development agenda" (Di Vinadio, Sinha, \& Sachdeva, 2012, p. 4) and demanded that focus should be given to increasing partner-country ownership of development aid, recognising the diversity of approaches needed in aid for the different types of countries involved, and delivering and accounting for development results (Atwood, 2011). What the AAA unfortunately failed to address was a solid and practical explanation as to who these stakeholders are, what 'ownership' refers to, and most importantly how all these goals are to be achieved (Wallace, Bornstein, \& Chapman, 2007).

At the same time the AAA also failed to establish what exactly this "integration of all stakeholders" actually means or how donors are to move away from tied aid and aid conditionality. However, the most significant feature of the AAA is its recognition of the need for other development stakeholders - notably civil society and parliaments - to be involved in the formulation and implementation of development policies (Steinle, 2009).

\section{High Level Forum: Busan 2011}

The fourth and last HLF was held in Busan, South Korea, in December 2011. I flew in amongst delegates from all corners of the world. Different meetings were held in different hotels around the city and joint positions were formed. Delegates from China, Mexico, Brazil, Russia, and South Africa were the newcomers at this HLF meeting in Busan.

The Busan Outcome Document extended the offer of partnership to fight poverty to a wider range of development actors, including emerging economies, the civil society, but especially to the banks and the private sector, which was a surprise, but also the result of the 2008 financial crisis. The Outcomes Document framed a new agenda for aid and development effectiveness, at least on paper, and offered another definition for ownership. The language used in the Busan Outcome Document and how the principle of ownership is defined was discussed before the HLF meeting amongst CSOs and finalised just before the main event. Civil society delegates demanded clarification from the rich countries and donors as to what 'ownership' meant, and how donors were going to ensure it was applied. The difficult 
questions posed almost halted the meeting, but the civil society delegation coordinated better than the previous HLF meeting and made firm decisions on "when to walk out of the meeting and when to stay" (Open Forum and BetterAid, 2012, p. 15) if their demands were not met. Donors, under pressure by the unity of the global society, agreed to enhance and expand the meaning of 'ownership' and it is under such circumstances that the fourth generation of the term 'ownership' was presented and named 'democratic ownership'.

The idea behind this fourth wave of ownership and the new language adopted in Busan was to advance and improve the previous terminology of ownership and ensure a more inclusive approach and decision-making procedure. The new term introduced, however, has confused the rhetoric even further. As observed, the term evolved from 'borrower ownership' to 'country ownership' (2005), and then to 'inclusive ownership' (2008). The new term 'democratic ownership' (2011) does nothing but cloud the discourse even further while it has succeeded, to some extent, to foster a more inclusive dialogue between donors, recipient countries, civil society, and the private sector to participate and work in partnership for the design and implementation of more development outcomes, ensuring that the best and the most sustainable results are ensured. What the Busan Outcome Document neglects and fails to address again, as with the previous HLF meetings is how this principle of ownership, so revered, is to be cultivated, and how democratic ownership is going to be translated into policy and practice?

The Busan Outcome Document, as highlighted, was effective in achieving one goal and that was the bringing together of the new aid and development actors and to demand greater accountable participation and "democratic representation in policy-making processes as a strategy to make development more effective" (Hauck \& Land, 2011, p. 2). The concept of ownership in its new form of 'democratic ownership' continues, however, to remain a vague concept, although endorsed and hailed time and time again over the past two decades. The concept is a plausible idea and does inspire aid and development technocrats to seek a broader participation of stakeholders in any development activity. But how is this going to be done is the question.

In my view as a participant, the Busan meeting was a disappointment given the lack of consensus on so many fronts and the volume of compromises made with the private sector 
and the new donors, especially China. The Chinese delegation played a dominant role, and proposed to endorse the Busan Outcome Document only after downgrading it to a purely "voluntary" arrangement. China openly proclaimed on the first day of the meeting that it would not sign the document unless a paragraph was added clearly stating that the signatories of the Busan Outcome Document were free from endorsing the content of the document, and that embracing of the principles of aid and development effectiveness was simply a 'voluntary' act (Mawdsley et al., 2014).

The voluntary option introduced by China inevitably weakened the document from the outset. In reality, the Busan Outcome Document became ineffective because many donors and governments present did not sign even the watered-down version of the document, and followed the Chinese lead. The only country that signed and officially volunteered to endorse the document was the host country, South Korea. Some go as far as calling Busan a "failure" (Mawdsley et al., 2014, p. 34), but I tend to see it as a 'failed success', mainly because of the way global society united their voice in their opposition to donors and governments for the first time, and because of the formulation and inclusion of the Principles of Development Effectiveness, which are unprecedented and put forward the objectives and the aspirations of development CSOs around the world for sustainable development.

With so many stakeholders present, so many different interests, and only two days of meetings, it is no surprise that no firm and meaningful agreement amongst the new and traditional donors was reached in Busan. In addition, presence and inclusion of the private sector as a new player within the aid and development arena raised many eyebrows because no comprehensive guidelines were thought of or drafted "around accountability and policy frameworks to hold business to account" (Mawdsley et al., 2014, p. 34), which added greatly to the confusion.

The numerous waves of ownership and the evolution of the concept from 'borrower', to 'country' to 'inclusive' and finally now 'democratic ownership', has made the principle of ownership and its definition perplexing. As observed, ownership has evolved over the years, but the actual meaning of the concept and its implication continues to remain vague. In the next section, I will review the evolution of the concept of ownership within the Pacific 
region and will discuss how the international discourse discussed above has influenced policy and practice within the Pacific region.

\section{Ownership Discourse in the Pacific}

\section{Pacific Islands Forum Secretariat}

The Pacific Islands Forum Secretariat (PIFS) is an inter-governmental organisation in the Pacific that aims to enhance cooperation between the independent countries of the Pacific Ocean (16 members). It plays a key role in coordinating the aid and development agenda and strategies of the island states.

To initiate research on the question of ownership within the Pacific context, it seemed sound to start with the PIFS, given its engagement with the HLF meetings over the years and the international discourse on aid and development effectiveness. The PIFS is a key development organisation in the Pacific region with the mission "to enhance the well-being of the people of the South Pacific by fostering cooperation between governments and between international agencies" (The Pacific Island Forum Secretariat, 2014). The PIFS also aims to harmonise regional positions on various political and development policy issues.

The Pacific Plan is the guiding development plan for the PIFS. It was drafted in 2005 when the leaders of the Pacific island states came together and agreed to a common strategy for development (Morriss, 2009), according to the PIFS Advisors who participated in this research, the main objective of the Pacific Plan is to guide and strengthen regionalism and to enhance and stimulate economic growth, sustainable development, good governance and security for Pacific countries through regionalism, but:

The difficulty with the Pacific Plan is that it was introduced by Australia and New Zealand and that it was never 'owned' by the Pacific Islands. Rather it was prescribed by donors and imposed (A. Shuster, Interview, July, 2013)

Since 2005, the PIFS has been active and engaged with HLF meetings and has endorsed Accra Agenda for Action (2008) and the Busan Outcome Document (2001). However, when interviewed, advisors working with the PIFS admitted that ownership and its meaning is still 
being debated within the Pacific context and that there is ample room to clarify its meaning and implications in policy and practice.

Interested in the findings of this research and the question of how ownership might be defined and promoted, I was invited by the PIFS to participate in the 2013 Pacific Island Countries Development Partners Meeting to further explore and research the notion of ownership. Participants included delegates from 22 countries, the Secretariat of the Pacific Community, and the University of the South Pacific. There were also some new member states that are now more active in the Pacific region, namely India, Israel, and China, as well as other Suva-based International and Regional Organisations such as the OECD, PIANGO ${ }^{6}$ and $\mathrm{PRNGO}^{7}$. The objective of the meeting was to foster an inclusive regional dialogue and to strengthen effective development cooperation. I was given free and open access by PIFS to interview the delegates and to conduct research on the question of ownership during the two-day meeting.

Most of the Pacific Island representatives claimed that the 'Pacific Plan' is not a plan that was formed by the people; it was proposed by the donors, especially Australia and New Zealand, rather than desired and decided by the people of the Pacific and their respective governments. Therefore, the stakeholders do not feel that they own the strategies adopted, and this has had an impact on the effectiveness of the plan.

There is in general a lack of ownership of the plan which was drafted first by Australia, and submitted to PIFS for feedback and endorsement. The challenge for the future of the PIFS is to address the question of ownership of the Plan at the country level ensuring that stakeholders are better engaged. (A. Shuster, Interview, July, 2013)

The 10-year Pacific Plan primarily promotes economic growth, sustainable development, good governance and security (Huffer, 2006). Some argue that:

The Pacific Plan and the target areas identified are more aligned with the thinking and strategies of donors especially the government of Australia

\footnotetext{
6 The Pacific Islands Association of Non-Governmental Organisation

7 The Pacific Regional Non-Governmental Organisations
} 
and New Zealand than they are with the needs of the people of the Pacific (A. Shuster, Interview).

The plan was reviewed and revised in $2013 / 14$ by the committee members of the PIFS to address some of the above-mentioned challenges and boost regional cooperation. The PIFS is now undertaking reforms based on recommendations from this audit and has discussed and offered the development of a strategy to address the particular needs of each island state.

The Pacific CSOs are to monitor its success and its impact on the lives of the people. It is acknowledged within the plan that its success depends on the participation and support of partners and stakeholders, and the building of strong national 'ownership' of development plans and encouraging civil society to observe its progress, but;

The Pacific Plan does not elaborate on how 'national ownership' is going to be ensured, and how CSOs and other stakeholders at the national level are to be engaged in the process. (M. Penjueli, Interview, July, 2013)

\section{The Cairns Compact}

The other important regional agreement with reference to the importance of ownership in the Pacific context, is the Cairns Compact on Strengthening Development Coordination in the Pacific. Adopted at the 2009 Cairns Forum Leaders Meeting, the Cairns Compact has since intended to lift the economic and development performance of the region. The Compact aims for more effective coordination of available development resources among Pacific Island Countries and donors, in order to achieve real progress against national development goals and the MDGs.

After the Pacific Plan, the Cairns Compact is the second key donor-driven document in the South Pacific that leads and aligns the aid and development agenda. The reason it is highlighted here is because numerous research participants argued that:

"Similar to the Pacific Plan the Cairns Compact was initially drafted by Australia and New Zealand and submitted to member states across the 
Pacific just two weeks before the meeting was held" (A. Shuster, Interview, July, 2013).

Pacific leaders were then asked to provide feedback on the draft within the very short given timeframe before it was signed off at the end of the two-day meeting in August 2009.

This method lacked input and ownership of the development issues and of the process by stakeholders, especially civil society in the partner countries. The Cairns Compact intended to revive the Paris Declaration within the Pacific context by encouraging and "enhancing the governments of partner country's sense of ownership of its development process" (Negin, 2010, p. 4), but neglected to take into consideration the importance of other stakeholders and the process.

Both the Pacific Plan and the Cairns Compact encourage aid effectiveness through private sector-led growth, but;

"the people and the civil society of partner countries were not engaged, and consulted in drafting of the plan" (A. Shuster, Interview, July, 2013).

As argued throughout this thesis, when development plans are offered or dictated, they are barely effective in the long term. For development aid to be sustainable and effective it must be owned by all the stakeholders, and the project beneficiaries must be engaged in identifying the project and making informed decisions throughout the process. The case studies in Chapters 6, 7 and 8 will reveal that the more involved the project beneficiaries are in identifying the development agenda, the higher their perception of ownership and the more effective and sustainable the outcome of development aid.

I next engaged both the New Zealand and Australian Governments and their aid representatives in Fiji and Tonga in an attempt to better understand donor approaches and regional policies adopted to promote ownership.

\section{Australia and New Zealand's Approach}

Both Australia and New Zealand were amongst the leading voices to condemn the Bainimarama coup in 2006, and both countries immediately placed sanctions on Fiji, reducing their aid and allocating funds to the CSOs instead of channelling the funds through 
the country-level systems as embraced by the aid effectiveness agenda in Paris (2005) (McGhie, 2013).

The Acting High Commissioner of New Zealand in Fiji, Mr Phillip Taula, acknowledged that promoting and ensuring ownership of development results is complex, and that Fiji is an excellent example of how country ownership is not always a practical policy. The Paris Declaration emphasises the importance of aligning aid with the recipient government's priorities, delivering aid through government systems, but the situation becomes complex when donors are dealing with a government that is not democratically elected or does not represent the 'voice' of the people.

Meetings with the Australian Counsellor for Development Joanne Choe, and the Australian Minister-Counsellor John Davidson were also informing, as both high-ranking Australian delegates to Fiji confirmed that the 2005 Aid Effectiveness Principles, and the principle of country ownership are the guiding principles adopted by Australia, but:

\section{Ensuring the Paris Principle of 'country ownership' has been a very complicated undertaking. Hence Australia has not even gone beyond Paris to attempt to draft policy on Busan Principle of 'democratic ownership' which could potentially imply a new, and even more complicated set of rules and regulations that will entangle the current aid and development system even further. (J. Choe, Interview, July, 2013)}

To better understand the Australian approach, I decided to dig the surface deeper and examined the work of the Fiji Community Development Program (FCDP), which is a relatively new arm of Australian Aid (AusAid) extended to work solely with the civil society in Fiji. In the past few years, Australia has mainly channelled its funding through civil society in Fiji instead of via government and in-country systems. Through the FCDP, Australia is allocating millions to exclusively enhance the capacity of civil society in Fiji over a five-year period (FCDP, 2014).

To my surprise, research and interviews revealed that the FCDP has no policy or guidelines to promote ownership, and there is not even a reference to the principle of 'ownership' of development outcomes by the people on its website or in its organisational policy. The 
Australian Government provides practical assistance and capacity building services through the FCDP to support the work of CSOs in building community resilience. However, it has no policies for promoting ownership of development results by the project beneficiaries. The Director of the FCDP Michael Brownjohn stated;

\begin{abstract}
Australian aid to the civil society in Fiji does not have a general strategy or policy to cultivate ownership of development aid by the people, and does not demand CSOs to ensure 'ownership' by their project beneficiaries although that is a given criteria and it is expected. (M. Brownjohn, Interview, July, 2013)
\end{abstract}

Mr Brownjohn talked about the interconnectivity of Results Based Management approaches and how the need for greater emphasis on evaluation and reporting in the past decade has, in his view, made development more effective. The Australian Government today demands:

More reporting, greater accountability systems, and transparency from development NGOs and although this means more work for NGOs; it has made the sector more effective. (M. Brownjohn, Interview, June, 2014)

Thus, as evidence reveals, neither Australia nor New Zealand have any guidelines or policies in place to ensure ownership of development aid by the project beneficiaries nor do they actively promote the principle of democratic ownership recognised by both countries in Busan (2011). Both countries are committed to the 2005 Paris Declaration and have taken clear steps rhetorically towards the principles of aid effectiveness and ensuring country ownership of their development aid and strengthening of partnerships between governments (B. Wood et al., 2011). What remains unclear still, is what policies can be adopted and how ownership of development outcomes can be cultivated.

\title{
International Aid and Development Organisations in the Pacific
}

To further understand the complexities and challenges of the principle of ownership at work within the Pacific region, I approached the United Nations Development Programme (UNDP), the European Union (EU), and engaged and interviewed aid and development representatives of USAID (Peace Corps), Germany, Japan, and China in both Suva and Tangatapua. I accompanied their staff when possible on numerous monitoring missions and 
visited their development projects on the outer islands where I engaged their project beneficiaries in this research.

The staff of the UNDP in both Suva and Nukualofa, especially the UNDP Regional Director Garry Wiseman and the UNDP Programme Specialist Janet Murdoch, were instrumental in providing access to documents and facilitated interviews with key stakeholders. The principle of ownership is highlighted by the main regional donors. The EU and the UNDP both mention its importance and refer to 'country ownership' and the need for the partner governments to identify areas of priority and development plans in their policy document and strategic frameworks. What remains unclear is how partner governments are to engage with other stakeholders especially civil society in the recipient country before identifying national development plans and how they go about cultivating ownership throughout the development process.

Interviews with UNDP and EU staff revealed that in the view of major donors, promoting and ensuring ownership of aid and development outcomes is the responsibility of the aid recipients. The staff of the UNDP, and the EU also admitted that they have no concrete policies on democratic ownership as endorsed in Busan and that:

There are no organisational guidelines yet at UNDP or within the civil society that promote ownership or encourage project beneficiaries to take charge and lead the change. (G. Wiseman, Interview, July, 2013)

According to J. Murdoch:

The UNDP expects partners and aid recipients (governments and CSOs) to do their homework and to ensure ownership of the results by the people adopting their own strategies. (J. Murdoch, Interview, July, 2013)

Women are especially under pressure because of traditional barriers and norms(Fulu et al., 2013). Youth struggle with limited access to education and lack of access to opportunities on the islands (Lim, 2011). The important question is how people at the grassroots, especially women and youth who are to benefit from development aid can better engage in decisionmaking processes, and take ownership of development change. Evidence indicates that lasting "change within any society must come predominantly from within" (Collier, 2010, p. 
3). People must make the development aid decisions themselves. They must determine the changes and the areas of priority for development themselves, but as it stands project beneficiaries are not sufficiently informed or engaged from the start with identification of development projects and

Donors assume they know. (J. Murdoch, Interview, July, 2013)

There are also the hurdles of bureaucracy and the need for donors to disburse funds within the allocated timeframes, which often forces donors and the CSOs to bypass most obvious concerns:

At the end of the day, the quality of aid and development delivered depends on the capacity and the ability of the officials, and the staff of the aid recipient organisation. (G. Wiseman, Director, UNDP, Interview)

Transnational organisations such as the EU and the UNDP each have their own organisational priorities that they need to comply with, but they do their best to align their work with national Poverty Reductions Strategy Papers (PRSPs) and the national development plans of their partners, however:

Sometimes they have no choice but to dictate the agendas to their partners and enforce development plans respecting their own mandates, i.e. issues related to women's rights, as partner governments are not always proactive to promote and address human rights issues. (G. Wiseman, Director, UNDP, Interview)

What is important to note is that the Paris Declaration is largely endorsed in the Pacific region; and while country ownership of development aid as endorsed by Paris Declaration is important, it must be stressed that it is not enough.

\section{PIANGO and PRNGO}

The next stage of the research examined Pacific civil society umbrella organisations. I interviewed the Director of PIANGO, Emele Duituturaga and the director of PRNGO, Maureen Penjueli. PIANGO is based in Suva; it coordinates and represents the civil society of 22 countries in the Pacific. The core mission for PIANGO is to bring together the civil society 
across the Pacific together and to strengthen their capacity and to give 'voice' to the people living on 22 island states (PIANGO, 2014), but the organisation is under-staffed and has gone through major financial challenges in recent years.

Information on PIANGO members is scarce and the Directors of civil society umbrella organisations in both Fiji and Tonga (H. Khan and S. Ilolahia) claimed that PIANGO is not as effective as they hoped it would be due to its lack of capacity. This is an issue that Emele at PIANGO openly talks about. According to Emele, PIANGO does not even have enough funds to pay her a salary, but she has been active all the same and has been very effective as a volunteer in connecting the local debate to the international discourse on aid and development effectiveness:

PIANGO does not have the resources to connect and to strengthen the capacity of members across the 22 island states, and is unaware of member strengths and weaknesses due to geographical barriers, lack of capacity and lack of funding. (E. Duituturaga, Interview, June, 2013)

Distance is the most prevalent obstacle for PAINGO, although in recent years the Internet is breaking the barriers and is better connecting the islands to one another and to the world. Accurate information is, however, lacking about the details of activities of the CSOs on the island countries and the needs and challenges of the people. At the same time PIANGO does what it can with its limited capacity to align the various perspectives amongst the CSOs across the Pacific Islands and has acted as the voice of the Pacific region for civil society. It has shared information on issues of concern, especially at the HLF Meetings (PIANGO, 2014), which will be discussed in detail in Chapter 5. According to the Director of PIANGO, none of its member organisations across the Pacific have any written policies or strategies in place that would define or promote 'democratic ownership' of development aid, and it is, in general, unclear in terms of policy and practice how CSOs are to cultivate ownership of the outcomes of their development projects.

In the past few years, PIANGO has worked very closely with PRNGOs as it is the umbrella organisation for larger CSOs active in the Pacific. There are currently 13 transnational CSOs that form PRNGO. Given their size and scale PRNGO members are some of the most influential regional organisations in the region and their partnership with PIANGO as the 
representative of national CSOs has been fruitful. I contacted these organisations for this research and conducted an enquiry on the approaches they have in place to ensure ownership.

According to the Director of PRNGO:

Ownership and accountability go together hand in hand. Large regional organisations tend to align their work with their donors as they primarily feel accountable to their funders. However, donor criteria, especially the reporting, tends to be laborious. It drains capacity and leaves no room for flux, and organisations that receive funding have no choice but to primarily meet donor demands and to align their work with donor policy and criteria. (M. Penjueli, Interview, June, 2104)

Therefore, what needs greater attention is how ownership and accountability downwards to the project beneficiaries can be enhanced at different levels of the aid industry, which, in effect, is the shortcut to safeguarding effective and sustainable development aid.

\section{Ownership and Accountability}

In recent years, CSOs and their lack of adequate downwards accountability to the people they serve has been highly criticised. It is obvious today to any researcher that civil society tends to align its activities with the criteria of donors, and is quick to change policy and modify its activities with funders. According to some of the research participants:

Large CSOs are very good in maintaining donor pulse; i.e. Oxfam, WWF and World Vision to name a few. They know how to speak the language of the donors. They know how to report, and have adopted successful business approaches for delivering development aid. They have become corporations and function primarily to keep the business alive. $(\mathrm{H}$. Khan, Interview, June, 2014)

Scholars such as Banks and Hulme equally critique CSOs and claim that CSOs, especially large transnational organisations "have lost their way becoming bureaucratic, depoliticised organisations responding primarily to governments, donors and their agendas rather than 
being the autonomous, grassroots-oriented, and innovative organisations that they once were" (Banks \& Hulme, 2012, p. 31).

The above sentiments capture the perspective of many of the research participants at the grassroots level across the South Pacific. Accountability constantly surfaced in every interview and was revealed to be an issue at stake, while research revealed that currently there are no Codes of Conduct in Fiji and Tonga, or any consensus amongst CSOs as to what accountability downwards to the people means and how CSOs should demonstrate accountability to the people while some CSOs have started to conduct self-assessments to avoid criticism.

Many of the research participants alleged that ownership and accountability are interrelated and that the more an organisation is accountable, the more it will reflect on sustainability and ownership of the project outcomes. Therefore, accountability, as will be discussed Chapter 4and especially in Chapters 9 and 10, surfaced at every corner and is evidently an essential pillar and a strong characteristic of ownership.

The Director of the Tonga NLU expressed her concerns:

There are no guidelines for 'accountability' to the people or for promoting 'ownership' of development outcomes in Tonga, Fiji or any of the South Pacific island countries; while both accountability and ownership of development results are the key pillars for ensuring effective and sustainable development aid (S. Ilolahia, Interview, July, 2013)

It seems all too obvious that 'accountability' can transform the aid industry if taken more seriously into consideration. It can have a significant impact on the quality and the quantity of development aid "yet accountability is simply and generally assumed, ignored and predominantly linked with monitoring, evaluation and producing reports" (Jump, 2013, p. $5)$.

Both accountability and ownership have been endorsed at each of the four HLF meetings, in the Paris Declaration they were highlighted as two of the most important principles of aid effectiveness. Yet, a decade later there is still no consensus amongst the signatories and other stakeholders, especially amongst the CSOs, as to how these very important pillars of 
effective aid are defined, how they can be potentially measured and how they can be better integrated into policy and practice.

\section{Conclusion}

As observed in this chapter, the global debate on effectiveness does address the importance of ownership within the aid and development arena, but the meaning of the concept of ownership is still unclear and evolving, and most donors and governments are reluctant to define the concept. The future of aid and development, however, will remain bleak unless the language of the industry is demystified and complex principles such as 'ownership', 'accountability' and 'partnership' are clearly deconstructed, understood by the partners and agreed on amongst the stakeholders.

Although the international discourse on aid and development effectiveness is perplexing, it represents a shift in thinking and it is influencing the aid and development agenda around the world as the case of the Pacific Island countries demonstrates. As discussed, there is still no consensus on the meaning of technical development terms such as ownership, but the fact that important questions such as ownership of development aid are being posed by the stakeholders and debated is a success in itself. It is simply a matter of time before these concepts are clarified, and their implications known, which is what this research aims to prompt.

It is only since 2005 that the question of ownership has surfaced at a global level. Steps have been taken since then, and partners are more engaged in drafting their own development plans, but much greater attention must be paid to the issues of accountability and especially the role of women in decision-making, as the case studies will reveal, if ownership of development aid is to be cultivated. Arriving at a consensus among stakeholders on these concepts, however, and agreeing on appropriate policy can take time.

It is easy to be critical of the donors and the CSOs in the face of such slow progress, especially when one observes the power games behind the scenes and the political nature and heavy and costly bureaucracy of the aid and development industry. It is, however, important to note that there is ample goodwill within the sector and that change will occur only gradually and that the ultimate solution is an inclusive and ongoing dialogue, and 
emphasis on improved accountability, making sure that people are informed and that women are empowered and engaged in making the decisions that influence their lives and the future of their communities. It is, of course, challenging and problematic to assess and arrive at a concrete definition and formulate tools to measure a complex and multidimensional concept such as 'ownership', but it is possible as the case studies in this research will reveal, and it is critical.

In the next chapter, I will plunge deeper into the relevant literature and will explore the concept of ownership within other disciplines and will reveal that ownership is not as complex as it is assumed and that it is in fact a desired outcome that can be cultivated through authentic partnerships based on mutual accountability, and respect for dialogue and process. 


\section{Chapter 4}

\section{Deconstructing Ownership}

\section{Introduction}

As observed in Chapter 3, the exact meaning of the term 'ownership' is confusing and still being disputed within the global discourse. There is a pressing need, however, for the concept to be precisely defined, claimed by the aid recipients, and cultivated, because research reveals that ownership is an imperative principle of aid and directly related to effectiveness and sustainability of development outcomes. The aid and development industry is complex, expanding, and evolving. New technical words, sets of goals and principles are presented each year to improve the system. These new words and principles for improving the effectiveness of the aid and development outcomes can sometimes be confusing, especially when the terms used at their origin are political, unclear and refer to concepts that have no equal counterparts in partner languages.

In this chapter I will dissect the anatomy of ownership based on the review of the literature and analyse its multidimensional nature with the aim of understanding its psychological roots and implications. The main argument presented in this chapter based on research findings is that accountability is a proxy of 'ownership' and that 'ownership' is a desired outcome, can be defined, and has obvious ingredients that can be identified, cultivated and partially measured. I will then present a new working definition for ownership of development aid that can break through cultural and geographical barriers and serve as a useful and simple gauge for cultivating sustainable and effective development aid.

\section{The Myth of Ownership}

Ownership has become a common term and a widely-held principle of the aid and development effectiveness agenda within the last decade. The literature, however, is full of idealistic, yet inconsistent, language when referring to the phenomenon of ownership. These diverse perspectives within the discourse reveal the complexities of the concept, and how ownership is an ambiguous political concept in need of being accurately defined. 
No policies or guidelines currently ensure or demand ownership of the development outcomes by the project beneficiaries, although there are international regulations aligned with the Paris Declaration (2005) discussed in Chapter 3, demanding 'country' and 'democratic' ownership of aid, which stress mainly on partner governments' ownership of the aid and development agenda. However, as observed in Chapter 3, 'country ownership' or 'democratic ownership' is too narrowly defined, and it focuses primarily on ownership of aid by the national governments: "irrespective of whether the ruling government is capable or legitimately elected or representative of all segments of society which makes country ownership questionable" (USAID, 2012, p. 17).

At the same time, research and evaluation of findings conducted by the United Nations Development Programme (UNDP) and the World Bank reveal that "programmes commanding a greater sense of ownership by the people (development target groups) and stakeholders have better outcomes" (Fukuda-Parr \& Lopes, 2013, p. 14). This research in the context of the South Pacific equally revealed that all aid and development actors agree on the importance of the principle of ownership but that currently there is no agreed definition, especially amongst the CSOs, as to what ownership means and how it is to be promoted and measured. Research also revealed that ownership is directly related to development results that are more effective and sustainable.

None of the CSOs and regional larger transnational CSOs such as Red Cross, WWF, and Oxfam examined for this research have written policies or guidelines for promoting and ensuring ownership of development outcomes by their project beneficiaries. Larger CSOs tend to take the national development plans inspired by the Paris Principles of Aid Effectiveness (2005) into consideration, and tend to be engaged with the global and regional debates and agendas. However, research also revealed that the concept of ownership is vague in meaning, and that different development actors have different definitions for the concept and that there are no guidelines or procedures in place to cultivate ownership of development outcomes by project beneficiaries while donor governments "despite their commitment to 'country ownership' still determine the direction of aid and development" (Mfunwa, 2006, p. 19). 
The word 'ownership' of development aid by the project beneficiaries, although highlighted and revered as a principle within the discourse, is generally absent in organisational policy of all CSOs examined in the context of the Pacific, and was referred to as a policy 'ideal' or a 'myth' by some of the research participants, which highlighted all the more the need for debate on the topic.

Ownership of development aid is a 'myth'. Donors, and often CSOs talk about the importance of ownership but development projects frequently tend to tumble after donors leave, making ownership an ideal. (R. Joni Madraiwiwi, Interview, June, 2013)

Alan Dundes defines myth as a "sacred narrative" (Dundes, 1984, p. 21). Bruce Lincoln claims that a myth is an "ideology" (Lincoln, 1999, p. 147). Both definitions offered are very relative to the concept of ownership as the term has become idealised, while it is still vague and somewhat a hallowed narrative upheld by donors and CSOs that needs serious clarification.

Classifying ownership as a myth or labelling it as an ideology is an overstatement, but the point to be made here is that the concept of ownership is highly valued within the sector, yet ambiguous in nature, while evidence reveals that ensuring ownership of aid is directly related to more sustainable and effective development results.

\section{The Need to Deconstruct Ownership}

Some scholars point out that the politics of aid and inequality will always exist and that concepts such as ownership of development aid are simply ideals and hard to realise given the political motivations, lack of equality, and the hidden agendas that often influence partnerships. What is certain, according to some scholars, is how political dimensions of aid will always remain central to understanding of both the giving of aid and its impact on the recipient (Riddell, 2007). Money and power stain relationships, and financial relationships for partnerships are often imbalanced and rarely based on common objectives or shared interests (Ahmad, 2006), and this is why donors naturally "tend to link aid to their own interests" (Browne, 2006, p. 1). 
At the same time, it has become apparent that cultivating ownership of development aid can be a remedy for this problem in the long term and a shortcut to more effective outcomes, as the phenomenon of ownership is about initiative, self-sufficiency and "selfconfidence, without which there can be no leadership, and self-determination. Ownership is about expansion of recipients' capabilities, involving enhancement of choices and freedoms and as such is not only a means but an end in itself" (Fukuda-Parr \& Lopes, 2013, p. 76).

The ongoing debate on the question of ownership is thus crucial, because the concept and the language of ownership is confusing and funding constantly tilts the debate. What is needed is fostering of accountability, and ongoing and inclusive dialogue. Although the meaning of 'ownership' is still imprecise within the global discourse on development aid, the recognition, renegotiation and donor attempts over the last decade to improve 'ownership' is a great achievement on its own, and it is an acknowledgement that the term 'ownership' is being questioned and evolving. Further clarification is, however, required as to what 'democratic ownership' actually means in policy and practice, especially to the work of donors and governments. Equally, CSOs must enhance their downward accountability to their project beneficiaries and improve the role people, especially women, play in decisionmaking at each stage of the development process.

Grandiose idealistic development terms need demystifying and more pragmatic and practical understanding. The more and better these technical concepts are clarified, the easier it will be to translate them into partner languages, because developing partner communities "often speak a language other than English, and do not have the time or priority for long and complex analyses even if the subject matter is pertinent to them' (Ferguson, 2005, p. 48).

\section{A Question for Civil Society}

As argued, the word 'ownership' is a policy ideal and a technical buzzword. The concept of ownership is multi-dimensional, and defined differently by different actors within the hierarchy of development aid (A. Cornwall \& Brock, 2005). There are no policy implications for cultivating ownership, especially within the civil society sector, while there is a knowledge gap and lack of consensus amongst aid and development actors as to how ownership can be defined and incorporated into policy and practice. 
The review of the literature, especially the Development Assistance Committee (DAC) and the UNDP reports, indicates that partner countries are drafting more comprehensive national development plans and are taking greater charge of the development agenda, but who authors the national development plans is the question that comes to mind. Transnational civil society organisations and major donors equally follow the global forum outcome documents, such as the HLF statements discussed in Chapter 3, but from observing civil society in Fiji and Tonga, it becomes apparent that the implications of country ownership strategies are still irrelevant to the work of CSOs and to their partnerships with project beneficiaries and the people they serve at the grassroots. Ensuring 'ownership' is an important issue and must be addressed sooner, rather than later, because the sooner the concept is more sharply defined and cultivated, the sooner aid will become more effective and more sustainable.

Civil society is well placed to lead this agenda and to better articulate the role of the individual and the community, and to align the thinking of the donor governments with that of the people (M. Edwards, 2009). As will be revealed in the following chapters, evaluating and analysing the work and impact of civil society has been highly informative for understanding the question and complexities of ownership, and for formulating a new definition for ownership presented later in this chapter.

However, before a new and practical definition for ownership of development aid is presented based on the research findings and analysis, it is necessary to briefly explore both the role of language in the aid and development arena and the psychology of ownership, as these aspects have no doubt a direct impact on what ownership means in practice.

Language is a powerful human tool through which knowledge is transmitted, and plays an important role in aid and development industry. Without language as a tool to transfer knowledge, cultivating ownership of development aid will be complicated. Language is an effective tool for development aid, but it can also be misleading, and sometimes even confusing. Language is a powerful instrument, but it also produces philosophical and sometimes intangible and idealistic words such as 'accountability', 'partnership' or 'ownership' which can be misleading if not properly understood. 
The challenge for civil society as mediators between the people at the grassroots and the donors and governments is to untangle these complex terms within the discourse of development aid with regards to cultural diversity and to make sure that partners know the exact meanings and the implications of these technical terms in policy and practice. Translation of such complex technical words into partner languages is always challenging, especially when the roots of the concepts are unclear in their language of origin. As watchdogs, however, civil society can play a critical role to make sure that exact meaning is conveyed and that these theories are not lost in translation (A. Cornwall \& Brock, 2005).

Research revealed that language of development aid can be highly effective and useful, but that it can be also a serious barrier and a tool for political manipulation. What does ownership mean to different partners? How can we arrive at a consensus? How can cultivating ownership be incorporated into our rational and cognitive conduct? Is ownership a 'signpost' to an emotion referring to a higher psychological state? What mental functions underline its cognitive and intellectual functions, and how can they be refined to cultivate greater self-determination?

\section{The Power of Language}

The power of language, in my view, is seriously underestimated in development discourse, especially in translation of technical development concepts and transformation of knowledge and method from culture to culture. There are references and ample evidence of the success of language and its unlimited capacity and potential to bring forth development, but it is essential that development 'language/discourse' be more precise so that it is not diluting knowledge or confusing the development process. Language is a vital instrument for sharing our thoughts, visions and aspirations and the ultimate tool by which we can shape our internal and external realities.

Humanity and numerous civilisations have evolved because we have been able to think, envision, dream, and to name each experience and use language to convey our understanding. We turn our thoughts into words and our words into actions. We give our ideas words and use language to share them. If the words are vague, inaccurate or misleading, then the process and the results achieved tend to be diluted. If the language is 
clear and the words used are precise, then the results achieved are more aligned with what we were initially thinking (Bandler, 1985).

"To be human is to exist in language. In language we bring forth and create our world" (Chambers, 2013, p. 185). Through language we have in the past, we will again, in the future, give names to our ideals and aspirations. We first conceive the 'idea' (in our mind), then give it a name, a 'word', and then bring the 'word', our 'idea', into the world through action. The term 'ownership' is a good example of how a technical development idea can be translated and transformed into action.

Robert Chambers is a pragmatic scholar who addresses the problem of language based on years of experience working within the aid and development arena in different countries. Chambers states that words can be confusing and are often used by the powerful as a political tool to divert the aid and development agendas (Chambers, 2013).

Chambers particularly indicates his concerns about a single/dominant approach to development aid that can be potentially attributed to the challenge of dealing with technical buzzwords such as 'partnership', or 'ownership'. What is obvious, he points out, is the need for accuracy when it comes to the use of technical terms. It is crucial that we take the idea of interpretations of the concepts and translation of 'ideas' seriously into consideration. Words are our vehicles; they help us visualise our goals and they are the means for achieving our development results, but we need to keep in mind that words also tend to simply express the mind-sets and values of a certain linguistic group.

The discourse of international development and the diverse range of meanings given to the concept of ownership as discussed in Chapter 3, is inherently confusing. Ensuring effective development aid becomes much more complicated when words/signposts are inaccurate, vague and lack equal counterparts in partner languages. It is fascinating to note how the term 'ownership' means different things to different cultures and people (d'Souza \& Wills, 1998). It was interesting to hear research participants trying to describe 'ownership' from their different standpoints. The challenge for this research was to understand all existing standpoints and to bring these different cultural viewpoints together. 
The problem of language in aid and development arena becomes even more apparent when we notice that scholars cannot even agree on the meaning of 'aid' or 'development'. Different schools of thinking and academics, such as Sen (2000), Sachs (2005), Collier (2007) or Moyo (2009), each have a different take as to what 'aid' or 'development' means. What this indicates is that diverse perspectives on each phenomenon must be taken into consideration keeping in mind that each standpoint is valid. Terms such as 'partnership' and 'empowerment' are other good examples (A. Cornwall \& Brock, 2005) of how grandiose and ambitious words can become popular, inspirational and widespread even though they tend to be somewhat vague in meaning. The more precisely words and concepts are defined, deconstructed, and spelled out, the more useful they can become as potential leverages.

So, the question this research grapples with indirectly is the power of language and the need for clarity when a new inspirational and technical word is introduced, such as 'ownership'. How do diverse stakeholders around the world, especially CSOs, define and respond to the concept of 'ownership', and more importantly how is the concept being promoted? The point argued is that the term 'ownership', along with many other development terms, is a loaded concept and multi-definitional and it is vital that technical terms as such are clarified before they are used.

\section{The Role of Language in Development Aid}

It could be argued that language is the most critical and decisive tool for development aid. We capture our experiences and knowledge in words and then use language to transfer what we know. Words can change us. With the right words we can change the world around us. Words can hurt us, and yet they can inspire us, and shape us. Words can console us, heal us, help us. Words can connect us and aid us in development.

The twentieth century is especially important in the history of human development as scholars begin to understand and highlight the role and the importance of words and language. Ludwig Wittgenstein identifies 'language' as the main problem of philosophy. In his book titled Tractatus Logico-Philosophicus, Wittgenstein reminds us that language is the very reason why there is confusion in thinking and philosophy. He refers to 'words' as 'signposts' and views every word as a destination. This can be observed in terms such as 'justice', 'freedom' or the very concepts of 'empowerment', 'partnership', or 'ownership' 
within the aid and development discourse. These ideals and 'philosophical destinations' are envisioned by one individual, or dominant group and then a certain language, often foreign for the target group, is used to map out the journey and to provide the directions for partners to arrive. This process, however, can be very confusing because there is always more beyond a known map. Language is the tool, as Wittgenstein reminds us, by which we can share the pathways we know of, new areas we discover and to bring about desired development. Words and their exact meaning must thus be seriously taken into consideration if we are to shape the world around us (Wittgenstein, 1921) and to bring about change that we would want to maintain and protect over time.

Words have the power and the potential to advance our ideals and goals. In Wittgenstein's view, words also have the capacity to falsely fabricate and dilute our vision and reality. Language, he emphasises, can be both perplexing and enlightening. The better we identify what we mean when we use a word, the better we place our signpost on the road to our targets, and the faster we will arrive at our destination (Burbules \& Smeyers, 2002; Malcolm, 1989; Mulligan, 1997; Patterson, 2006; Wittgenstein, Anscombe, Wright, Paul, \& Bochner, 1969).

At the same time, the number of words we have for a given idea demonstrates our understanding of the phenomenon (Chomsky, 1986); a good example is how the Inuit 8 have more than a dozen words to refer to snow. Essentially, the more we know and understand a concept, the more words we have for it. The problem arises when a concept is unknown in a partner language and when there is no word for it. The first challenge for me in this research was to find an equal term for ownership in other languages, especially in the context of the South Pacific. How is ownership of development aid conveyed in other languages? If there is no exact word for ownership in a partner language, then how is the concept introduced?

Language is a living organism, and it is evolving constantly (Jiang, 2000). New words are coined to capture, encapsulate and communicate observed phenomenon, and to point to new goals and development objectives. New words are then translated into other

\footnotetext{
${ }^{8}$ The Inuit are the aboriginal inhabitants of the North American Arctic, from Bering Strait to East Greenland, a distance of over 6000 kilometers. As well as Arctic Canada, Inuit also live in northern Alaska and Greenland, and have close relatives in Russia.
} 
languages, but lose their meaning in translation if they are not properly defined or understood at their origin. Words capture thoughts (Heidegger, Gray, \& Wieck, 1968); they capture experiences and are the foundation of change in human development. In other words, the uniqueness of being human lies in our ability to think, give our thought a word and to connect all the words we know through language. Words can also be solitary, they can be unclear, or they can die. Words are living entities, they can change meaning or become perplexing especially when translated into different languages (Baker, 2011).

\section{Postdevelopment Theory}

Postdevelopment thinkers have very clearly identified the problem of language in aid and development practice, and the role of words for obtaining power and influence. They argue that language is often used by the powerful to achieve political ends. They indicate how development terms and concepts such as 'development', 'poverty', 'aid', 'recipient', or 'partnership' tend to posit an unequal relationship, but are used by the dominant group as a tool to mobilise and involve people in a range of struggles for attainment of the goals identified by the powerful (Sachs, 2010). One can equally envision the frustration of the postdevelopment thinkers with concepts such as 'ownership' or 'accountability' within the aid and development discourse.

Thus, it has been important for postdevelopment thinkers to critique development aid as a discourse, and to analyse and understand the power of words and the intentional framing of important political concepts such as 'partnership' and how the so-called 'truth' is constructed through discourse. In 1992, Wolfgang Sachs co-authored and edited a book called The Development Dictionary: A Guide to Knowledge as Power which contributed greatly to the compilation of postdevelopment literature. Many postdevelopment thinkers including Arturo Escobar contributed to this collection. In Rahnema's contribution to that volume, he asks if we can get around the development gridlock of language, and how development terms are evidence of this framing in which economic progress along Western ideals is the benchmark for development. Rahnema admits that it may be true that a large majority of people, whose lives are in fact difficult, do want change and development. But development, he suggests, cannot be dictated or given. Rather people everywhere must 
think for themselves, identify their own goals and find their own development solutions (Sachs, 2010).

As with other terms within the aid and development discourse, the conventional frameworks and definitions of ownership are limited. This limitation and obscurity of meaning deepens the confusion and permits the powerful to exercise their will, because power is exercised rather than possessed, and it must be understood as a prerequisite for action and influence, because power is simply everywhere (Foucault, 1982). It exists in the way we structure our societies and especially in how language is shaped and controlled by the powerful. In Foucault's view, power is "present throughout a complex web of discourses, practices and relationships that position some subjects as more powerful than others" (Cahill, 2008, p. 298).

Postdevelopment thinkers, however, do tend to get carried away, in my view, and tend to ignore the positive aspects of power and development such as improved rates of child mortality of the developing countries and other positive influences. They also tend to view and categorise the people of the developing world to be completely submissive to the Western structures of thinking and power (Kiely, 1999), whereas a deeper study, observation and analysis of the world history and current affairs reveals a different reality. Finally, postdevelopment thinkers are also criticised for "offering no concrete or constructive solutions" (Pieterse, 2011, p. 238) to the struggle of the people's everyday lives, while they constantly highlight the shortcomings of development efforts.

Keeping some of the valid criticisms of postdevelopment thinkers in mind, the goal of this research has been to go beyond this deconstructive analysis when it comes to examining power and development aid and to pursue new practical paradigms. I think everyone agrees today, that it is time that the language of development aid is taken more seriously into consideration, and that the technical terms are especially illuminated, clarified and properly translated into partner languages. What must be emphasised here, however, is that the post development discourse is valid and words are at times used to hijack the agendas, but language is also an extremely powerful and positive tool which has had an unparalleled influence on human development and can be one of the most effective tools for ensuring positive change. 
The question this research wrestles with along the same lines, is whether the term 'ownership' is, as postdevelopment thinkers argue, another development jargon that has been hijacked by the powerful or whether it is possible for the concept to be revived, revitalised and used as an impetus for transformative change.

\section{Psychology of Ownership}

Ownership has a dual psychological dimension. Conventional wisdom suggests that people will take better care of and strive better to maintain and protect the outcome of their actions if they make the decision and identify the changes needed and if they are involved throughout the development cycle. People who make decisions tend to stand by their decisions and own the outcome of the choices they have willingly made. To better understand this logic, I decided to research how and what triggers this 'feeling' of ownership, and what happens to an individual psychologically when the 'feeling' of ownership initiates.

The most prominent explanation offered for ownership in psychology literature is: "an individual's awareness, thoughts, and beliefs regarding the 'target' of Ownership" (Pierce, Kostova, \& Dirks, 2003). "When people have a sense of ownership, psychologically they experience the feeling of connection between themselves and the tangible or intangible 'target', and do their best, to maintain and protect the 'target', or otherwise the subject of ownership" (Avey, Avolio, Crossley, \& Luthans, 2009, p. 174). The term 'target' in psychology is quite broad, but in general it refers to whatever the object of attachment represents to an individual or a group (Avey et al., 2009). Targets may be something as small as ownership of a preferred colour or a pen, or, as is the case of inquiry for this research, ownership of a development project within the community.

The Theory of Psychological Ownership (Pierce et al., 2003) suggests that ownership is simply the control over and intimate knowing of the target, along with investment of the self into the target. Pierce and his colleagues define psychological ownership as that state where an individual feels as though the target of ownership or a piece of that target is "theirs", or the target has a close connection with the self, being a part of the "extended self" (Belk, 1988). 
Therefore the state of ownership is psychologically based mainly on feelings of possessiveness and being psychologically tied to an object (Van Dyne \& Pierce, 2004). As time advances and as we engage further "what is mine becomes a part of me" (O'Driscoll, Pierce, \& Coghlan, 2006, p. 394) and this trivial, yet profound, theory can have a major implication if viewed from an aid and development standpoint.

Furthermore, based on literature pertaining to what constitutes possession and ownership, (O'Driscoll et al., 2006) conclude that:

- ownership occurs towards both tangible and intangible (targets); and

- ownership has positive emotional, attitudinal and behavioural effects.

The emotional behaviour and generally positive feeling of ownership develops over time, and it is the result of a combination of attitudes such as self-determination, engagement, self-expression and self-reflection, as well as proper use of language and dialogue throughout the development process. Congruently, other scholars argue that ownership and self-identity are interrelated and that people engage in certain behaviours to defend outcomes of decisions they have made in the past as a form of safeguarding their identify (Avey et al., 2009).

Interviews and case studies also revealed that project beneficiaries who felt a strong sense of ownership of development outcomes often mentioned the importance of accountability, and identified ownership as the result of a feeling of trust towards development partners and the desire to ensure longevity and maintenance of the outcomes. As case studies will reveal, the more a CSO is accountable, for example, the more it is concerned with more effective development and ownership of the development outcomes by the project beneficiaries (Lloyd David Brown, 2008). In other words, unsurprisingly the responsibility and assurance of accountability during a partnership (development cycle) is a useful proxy for discussion of ownership. The greater the sense of accountability of an individual or an organisation; the greater the feeling of responsibility for cultivating ownership and ensuring the sustainability of the results they have.

Research in psychology has clearly identified that "accountability nurtures a feeling of freedom, and control of one's destiny and actions that result in feelings of self-efficacy 
(Bandura, 1994). Accountability promotes and naturally stimulates a sense of ownership concerning a particular target and a "sense of responsibility" (Kaler, 2002). It follows that the more trusted, responsible and accountable an individual or an organisation is, the greater is the level of ownership of project outcomes by the project beneficiaries.

The Ownership Guidelines and the Ownership Index formulated for this research are both centred around these psychological findings. It is argued, by some scholars, that "ownership is a feeling of belonging" (Kohler \& Huber, 2006) and engaging. From this perspective ownership within the aid and development discourse is closely related to, and a result of, engagement, which is undeniably important. It entails the intention of being actively involved and engaged in the development process, and the emergence and development of the feeling of 'ownership' as the project advances instead of just being a passive recipient or an observer. Many research participants mentioned how ownership of development projects (as the case studies will reveal) has a direct impact on their emotions, their attitudes and behaviour. It is simply a positive feeling in our psyche which tends to cultivate a sense of striving for accomplishment and success.

When we have the feeling of ownership, "we tend to want to 'protect' and 'improve' the object of ownership" (Avey et al., 2009, p. 173). This aspect of ownership was particularly obvious in all the successful case studies examined for this research. The concept of 'ownership' is also described as a cognitive-affective construct defined as the state in which individuals feel as though the target of ownership or a piece of that target is theirs, and reflects their awareness, thoughts, and beliefs (Pierce et al., 2003), which also was observed in this research every time a project outcome was examined that people felt they owned.

An individual or the community thus feels ownership when they desire to maintain, protect and improve the 'target', being the outcome of development aid in the case of this research. The higher the level of ownership, the higher the desire of the individual or the community to willingly contribute to the maintaining and the protection of the development outcomes. This is a critical finding and underpins the hypothesis of this research.

Furthermore, as will be demonstrated in Chapters 6, 7, and 8, the more people engage with the process, the more they feel they own the outcomes as they tend to improve the process and direct the project towards outcomes they desire. As a result, the person or the 
community absorbs the project as it advances, and becomes "one with the target" (Pierce \& Rodgers, 2004, p. 597) and 'owns' the results. Research participants who claimed high levels of ownership of development projects in their community reported that the process was crucial and that they immersed themselves within the project as the project was advancing. The more engaged they became with the development process, the more they 'felt' ownership, because they were working towards targets and development outcomes they desired.

There is an objective reality to ownership, as Etzioni (1991) suggests. The feeling of ownership is a strong feeling, and it is "real and tangible" (Etzioni, 1991, p. 465). The target of ownership can be felt, and touched. Ownership is a psychological experience, and it is a 'thought' and a 'feeling', and exists in the mind and in the heart. Although limited, there is empirical evidence which suggests that all forms of ownership have an effect on the individual Pierce \& Rodgers, 2004), and hence on the outcomes of development aid.

\section{Psychology of Accountability}

Accountability is a pillar of ownership, and is in many ways synonymous with ownership. It is the product of appropriate engagements and "clear accountable systems" (Fukuda-Parr \& Lopes, 2013, p. 141). Scholars have expanded the research on psychology of ownership by examining accountability, and posit that the two concepts of ownership and accountability are interconnected, and that accountability is in fact an additional psychological dimension of ownership (Avey et al., 2009). Building on the theoretical psychological model of Avey et al. (2009) it is suggested that psychologically "accountability is a sense of shared responsibility" (Olckers \& Du Plessis, 2012, p. 2590) between partners and should be considered as an additional dimension of ownership.

Accountability can therefore be defined and referred to in psychology as the implicit or explicit expectation and the right to hold oneself and others accountable (Lerner \& Tetlock, 1999). Accountability, thus, is directly related to the question of ownership and synonymous with 'accepting responsibility' and 'demonstrating transparency' and 'answerability' and that is, of course, willingly (J. A. A. Wood \& Winston, 2007). 
There is no common agreed definition of accountability downwards to the people or consensus as to how accountability downwards is defined and how it is to be practiced. "Accountability is a buzzword" (Lerner \& Tetlock, 1999; J. Wood \& Winston, 2005). There is no consensus or agreed codes of conduct that uphold the principle. At the same time, similar to the concept of ownership, it has become evident over the years that "accountability tends to enhance results" (Seidenfeld, 2001, p. 1066).

The study of ownership in psychology is limited (Van Dyne \& Pierce, 2004), but what can be concluded from the limited literature and the research in the field is that ownership is a feeling, related to maintaining and protecting development outcomes; and that the project beneficiaries will ensure the sustainability of the development outcomes and will feel psychologically tied to the development outcomes when they are engaged in decisionmaking processes and are in partnerships that are accountable.

Very similar to the phenomenon of ownership, accountability, especially downwards to the people, needs serious attention from within the civil society sector and consensus amongst stakeholders as to what it means and how it can be promoted. Research in Fiji and Tonga revealed that civil society is seriously lagging behind in demonstrating accountability downwards to the people and cultivating ownership of change. CSOs must take ownership and its proxy accountability into serious consideration if they are keen to improve the effectiveness of their work and development results. It is obvious that there will be two immediate positive outcomes if CSOs take accountability into consideration. Firstly, and most importantly, cultivating ownership and demonstrating accountability downwards to the people will secure further funding from donors to do more, and, secondly, accountability will strengthen the legitimacy of the civil society, who are, after all, the watchdog over governments and the private sector.

\section{The South Pacific Standpoint on Ownership}

It was fascinating to hear the diverse Pacific perspectives on the question of ownership. Participants discussed ownership from a variety of different standpoints but as research advanced it became apparent that ownership is generally viewed as a 'feeling' and a commitment. 
The meaning of the term 'ownership' in the South Pacific context is complex and, for the average person on the islands, the concept of ownership triggers a range of questions. These mainly surround traditional forms of communal ownership and decision-making processes, as well as land ownership, which is unique to the Pacific in that it includes a diverse range of practices. Most of the indigenous Polynesian research participants referred to the importance of ownership of tradition and the Pacific customs and the fear of losing these aspects of their culture in the face of rapid development and foreign interventions. They talked about the need for the people to be better informed and the principle of ownership and self-determination to be debated and better understood within each community, especially before development projects are chosen or implemented. Most of the indigenous Polynesian research participants especially talked about ownership from a traditional Polynesian perspective and the need to take ownership of development change and to especially keep the old customary values alive.

In Fiji, vanua is an essential cultural concept. In Tonga, fanua holds the same meaning, and both terms uphold the principles of ownership in a South Pacific context. Both vanua and fonua refer to land or country and are generally translated in English as "land", but these indigenous concepts encompass a number of inter-related meanings equally hard to translate (Crocombe, 2001; Linnekin, 1990; Williksen-Bakker, 1990).

When speaking in English, Polynesians refer to vanua, or fanua, depending on which island they come from, rather than using the English equivalent. According to Fijian academic Asesela Ravuvu, the concept of ownership from a South Pacific perspective commonly refers to and encompasses the three dimensions of land, people and custom (Williksen-Bakker, 1990) referring to the 'land we belong to', but also the people, their traditions, customs, beliefs, values, and the various other formal processes to make decisions and to foster harmony, solidarity and prosperity within their particular social context on the islands. The concept of ownership from the traditional perspective of the South Pacific, cultivates a sense of belonging and generates a particular identity (Ravuvu, 1988, 1991); the people of the South Pacific feel a sense of "profound loyalty to their traditions and their common heritage, identity" (S. Lawson, 1996, p. 113). 
A Fijian or a Tongan individual is inseparable from the traditional ways and customs, and her relationship with her family. Living on an island shapes the standpoint and the outlook of any individual on to the world (Sienkiewicz, 1999). Most of worldviews cherished have been maintained and protected over centuries and rest on the intricate web of connected, and on-going relationships. These unique Pacific perspectives ultimately shape the character of each individual and the community (Ravuvu, 1988). The ultimate purpose of the individual in this context is to uphold the vanua, or fanua, through reverence for 'harmony' (Reuter \& Reuter, 2006).

The question and concept of ownership of development aid was often repudiated and mixed up with traditional understanding of ownership as these different meanings of ownership oppose one another, as discussed, and had to be differentiated;

People within the Pacific paradigm perceive ownership as a responsibility. They feel responsible for preserving their community, the land and the ocean for the future generations. Individual, the community and the land are all one, and no individual can 'own' the land, rather 'ownership' from the Polynesian perspective is about sharing responsibility and it is communal. (A. Taufe'ulungaki, Interview, July, 2013)

Most indigenous Pacific islanders who participated in this research claimed that there is no equal and precise word for the term 'ownership' in their languages (Fijian or Tongan), given the complexities of the concept of 'ownership' and how it refers to a diverse range of issues. I was often told by the research participants that the idea of ownership is foreign to the traditional Polynesian worldview:

Despite the lip service regularly paid to the concept of ownership of development aid, it is unclear as to what it actually means to the people and how it can be secured-ownership of development aid is a complex and confusing Western concept and must be appropriately defined. (F. Tevi, Interview, July, 2013)

The Speaker of the Tongan Parliament was particularly frank about the challenges of understanding and upholding the traditional norms of ownership of land and tradition in 
one hand and the principle of ownership of development aid in the other. It is particularly challenging, he elaborated, within the context of the Tongan Parliament while dealing with donor governments;

The technical terms that donors use are often ambiguous and the term ownership is a good example of how language is used as a political tool to manipulate the agendas. Donors give the impression that development is not motivated by their self-interest, that aid is not political or motivated by other factors, and that we must take ownership but when it comes to Tonga's national development plan; our government has no choice but to match its development plans with donor criteria to receive development assistance. (Lord Fakafanua, Interview, July, 2013)

Thus, ownership can provoke a spirited debate in the South Pacific context given the history, the culture, and the life-long struggle and dealings of the people with colonialism. Pacific Island people are proud and have a fierce desire to maintain their identity and their traditions, the interconnectivity of the society, and the strong communal bonds, (Ravuvu, 1988; Ward \& Kingdon, 2007) but all this is bound to eventually change.

The debate around the question of ownership of results by the aid beneficiaries is lost in the long list of needs. Ownership of development aid is not embraced by the donors and the civil society to the extent it should be. "The first challenge is to clarify the language" (Fukuda-Parr \& Lopes, 2013, p. 14), as there is "a dire need for unbundling the concept of ownership from rhetoric to reality" (Fukuda-Parr \& Lopes, 2013, p. 128).

The structure for maintaining and protecting old stories, customs and especially traditional knowledge in the South Pacific is highly complex. As with land and material goods, these non-physical and spiritual aspects of cultural attributes are owned by more than one individual in the form of a 'public good', and in Fiji and Tonga they have been preserved through oral traditions over the centuries (Ward \& Kingdon, 2007). Customs, beliefs, stories, etc in Fiji and Tonga are maintained and protected orally and learnt through language and upbringing. It is the responsibility of each generation to guard them and to share them, making sure that the next generation does the same. (A. Smith, Reitsma, Van Den Hoven, Kotzé, \& Coetzee, 2011; Zipes, 2005). 
Close examination of the Pacific and its indigenous outlook and understanding, as the case studies will reveal, highlights the need for a shift in thinking, especially the safeguarding of women's proper engagement in decision-making processes. It seems as though the time has come for most of the old rules and traditional values to be re-examined, re-evaluated and reformed, because no matter how valuable or sacred they are, they are not producing sustainable and inclusive development results that the people, especially women, of the Pacific today want to maintain and protect.

\section{A Working Definition}

In this section, I will present a new definition for 'ownership' of development aid, given the preceding discussion about the complexities of the concept, the psychology of ownership, and the need to define the concept as a strategy to ensure more effective delivery of development aid.

Ownership of development aid is a complex phenomenon. The table below presents the four existing broad definitions offered by donor governments at different international meetings which were discussed earlier in this chapter and are referred to as the four waves of ownership.

\section{Four Waves of Ownership}

\section{8}

Borrower ownership:

governments (officials) who represent, agree, barrow, and signs off aid and development funds on behalf of the aid recipient population.

2005

Country ownership:

partner governments are involved in design of development plans and priorities.

2008

Inclusive ownership:

integration of all stakeholders into the formulation process of the development agenda

$$
2011
$$

Democratic ownership:

aims to expand 'inclusive ownership' and takes into account the wider population especially the private sector in setting policy.

\section{Figure 4.1 - Four Waves of Ownership}

The above approaches for ensuring ownership stated at different international meetings, although a step forward, are vague, unclear, and do not precisely indicate how ownership is 
to be promoted and cultivated in policy and practice and what it means as an outcome. They are broad political statements made in regards to strategies that must be adopted to ensure the delivery of aid, but have no serious implications in development policy and are often circumvented.

In addition, there is no consensus as to how civil society is to contribute and safeguard ownership of its development work, given the important part the sector can play and its role as the intermediary and a reliable partner for donor governments and potential project beneficiaries. The important question then that needs to be taken into consideration is how project beneficiaries, the people at the grassroots and the communities can be better informed and engaged inclusively and accountably in the development process at each phase of the development process towards more effective and sustainable development outcomes that they would want to maintain and protect.

Thus, based on the examination of the international discourse, the existing definitions of ownership and the research findings and consultations with development experts, I hereby present a simple and new definition for the principle of ownership.

Ownership of development aid occurs: when people make the commitment to maintain, and protect development outcomes

\section{Maintenance}

Refers to the obligation of the person or the community to willingly contribute, in part or in whole, to maintaining the development process, outcomes and the results.

\section{Protection}

Protection applies to the aid and development outcomes of the project beneficiaries, and the community. Protection equally encompasses all activities aimed at ensuring full preservation of the project outcomes and results, with respect for human rights.

\section{Commitment}

Commitment is a pledge, a bind, or an obligation and refers to a state of being emotionally and intellectually devoted and a willingness to give time and energy to something we believe in.

\section{Figure 4.2 - Proposed Working Definition of Ownership in Development Aid}

As it will be observed from close examination of successful CSOs that have managed to cultivate ownership in Chapters 6, 7 and 8, people must be invited to inclusively and 
accountably engage with development projects from the start, and throughout the project cycle at every stage of the development process. The success of any development project depends on the quality of the partnership, accountability of partners, legitimacy of development actors, and the authenticity and consistency of the dialogue. As the case studies will reveal, particular attention must be paid to the role of marginalised stakeholders, especially women and youth, and strategies must be adopted to ensure their appropriate engagement throughout the process.

\section{Conclusion}

In spite of the widespread use of the term and emphasis on the principle of ownership, it is apparent that long-term ownership of development outcomes are often lost to short-term priorities. Sustainability and effectiveness of development results are being risked because of economic and political interests, while accountability downwards to the project beneficiary is frequently brushed off.

The language used in the aid and development arena around the important questions of 'ownership' or 'accountability' is misleading, and needs more in-depth discussion and clarification, given the ample psychological evidence that accountability is a proxy to ownership and the most vital factor for ensuring more effective and sustainable development outcomes.

Development target groups are not informed or sufficiently encouraged prior to project identification and project design to reflect on results and ownership of development outcomes and change that they would want to maintain and protect. The language of aid and development is confusing and sufficient dialogue between partners lacking, while partnerships are often political, one-off and aid and development agendas unclear, narrow, and donor driven.

In short, there is fragmentation and confusion within the aid and development discourse. The system and the language is no doubt improving, but there is ample room to advance efforts and to make development aid more accountable, and thus effective and sustainable.

The first step, as observed in this chapter, is to create consensus amongst the stakeholders, especially amongst the rich donor governments, as to how ownership of development aid or 
accountability to project beneficiaries can be best defined or planned and incorporated into the project cycle, which is a void that this research challenges. Safeguarding and ensuring sustainability and ownership of development results is not as complex as it appears and, as discussed in this chapter, ownership can be defined but it must be depoliticised, inclusively negotiated, clarified, and agreed on by stakeholders before it can be integrated into development policy and planning. 


\section{Chapter 5}

\section{Civil Society as the Key Intermediary}

\section{Introduction}

As alluded to throughout this thesis, civil society organisations (CSOs) are key intermediaries and deliverers of development aid and are well placed within the aid and development industry to cultivate ownership of development aid by the project beneficiaries. In this chapter I will examine their role, and the strategies they have adopted as a sector worldwide to enhance the role of project beneficiaries in decision-making. The aim of this part of the research is to assess civil society and the strategies adopted by the sector to cultivate change that is owned by the people, and better understand how it contributes to more effective delivery of development aid.

\section{Background}

Civil society as a sector is dynamic, quick to address injustice, or to rebel for a cause, yet "civil society today is undervalued" (H. K. Anheier \& Toepler, 2009, p. 56) despite the fact that it has gained more prominence than ever before. People around the world are effectively coming together within the civil arena, organising themselves to rise against injustice, and to create change. The sector has become the "buffer zone, strong enough to keep both state and market in check, therefore preventing each from becoming too powerful, dominating or corrupt" (H. Anheier, 2013, p. 20).

As observed in Chapter 3 and 4, a top-down and donor-driven approach to policy and governance is dominating the aid and development industry. A greater emphasis on, and empowering of, the people at the grassroots and the strengthening of individual voices is demanded if development aid is to become more effective. Given the special place civil society occupies between the citizens and the state, the question posed in this chapter is whether civil society is actually capable of being that agent on the ground to cultivate ownership of development results amongst the aid recipients and to promote people-driven change. 


\section{Historical Context}

Civil society has become a popular concept in recent decades and it has been explored by a range of scholars such as (Banks \& Hulme, 2012; M. Edwards, 2009; Steinle, 2009; Tester, 1992; Van Rooy, 2013). It is not my intention to repeat their work here, but I will briefly review some of the more radical historical and philosophical perspectives on civil society to simply direct the reader as to why civil society is the focus of this research and important to the question of ownership of development aid. I will then focus on the effectiveness of civil society in the South Pacific and the role CSOs play in Fiji and Tonga to promote ownership of change desired by the people.

The 'state' and 'civil society' have historically remained in opposition to one another "although this opposition is seen more as a dialectic" (Hann \& Dunn, 1996, p. 82). They have each influenced the existence of one over the other and have tried to hold each other accountable. The term 'civil' refers to a 'just society' where the 'good' of the people is primarily valued (Griffith \& Ferrari, 2000). As democratic institutions have evolved in the Western political states, the 'state' became more dominant over the 'civil'. Some scholars, like Hobbes (1588 - 1679), viewed civil society as an entity against the state very early on as modern statehood was developing, because they viewed civil society as an entity that often embodies personal interests and is backed with monetary affluence (Rogers, Filmer, Lawson, Bramhall, \& Clarendon, 1995).

In contrast to Hobbes, Hegel $(1770$ - 1831) viewed civil society as necessary and a unique space as well as "the intermediate between the family and the state" (Kaldor, 2003, p. 7). Hegel famously proclaimed that civil society is one of the greatest "achievements of the modern world [. . . ] civil society is where there is room for every idiosyncrasy, every talent, every accident of birth and fortune, and where waves of passion gush forth, regulated by reason" (Comaroff \& Comaroff, 1999, p. 3).

At approximately the same time as Hegel, on the other side of the Atlantic Ocean Alexis de Tocqueville, a French nobleman, examined civil society in North America in the midst of what he termed the 'age of individualism'. De Tocqueville travelled across the American continent between 1835 and 1840 and observed and analysed civil society as a sphere of free enterprise where citizens are able to bring forth their personal desires, which he 
viewed as being often self-centred and independent from the 'good' of all. De Tocqueville's observations and questions are somewhat relevant today: have we gained polity at the price of real freedom? Has the pursuit of happiness (wealth) caused separation amongst citizens?

Describing eloquently the free and vibrant state of America, de Tocqueville asked a very important question based on his observations around the importance of civil society, and associated life. The question he posed which is valid even today, is whether this growing need for individualism in the form of civil society is dangerous, and whether individuals must find some context in which they might be fulfilled together, instead of each individual or group simply pursuing their 'own' freedom and happiness. The following statement captures his thoughts precisely: I see an innumerable crowd of like and equal men. Each of them withdrawn and apart, like a stranger to the destiny of all the others: his children and particular friends form the whole human species for him; as for dwelling with his fellow citizens, he is beside them, but he does not see them; he touches them but does not feel them; he exists only in himself and for himself alone (de Tocqueville, 1835, p. 494).

Civil society has come a long way since de Tocqueville and has evolved over the years, but it is interesting to note the diversity of perspectives on the concept, how it has evolved, and the evolution of the idea of the public versus private debate. Responding to de Tocqueville, many including Karl Marx (1818 - 1883) questioned the validity of pursuit of the individual happiness, wealth, and freedom and concluded that money and personal motives are the main obstacles for the prosperity of the people and the state and that personal motivations are the reason why individuals, civil society and states become corrupt. Civil society hence, in the view of Marx, ironically is "synonymous with a self-interested and egotistical society" (Van Rooy, 2013, p. 10).

Marx greatly rejected the positive role of the civil society and actively advocated for crushing the sector. He proclaimed that civil society is simply "bourgeois", and a terrible lie that "puts man against man preventing the community of all men" (Tester, 1992, p. 18). For Marx, as for de Tocqueville and Hegel, civil society was the domain where the individuals fulfilled and advanced their personal interests, and were thus often harmful to the society as a whole. 
Civil society as we know it today was first imagined by Antonia Gramsci (1891 - 1937), an Italian theoretician, who some claim is "single-handedly responsible for the 'revival' of civil society in its modern sense" (M. Edwards, 2009, p. 8). As a political activist, Gramsci was sentenced to 20 years of prison by Benito Mussolini's fascist regime in 1926 and wrote extensively while in jail. He was inspired by Marx, but he was not entirely convinced. Gramsci the thinker and the revolutionary is renowned to be amongst "the first Marxists who separated his thinking from the mainstream Marxism, challenged Marx, and generated his own conception of civil society" (J. L. Cohen, 1994, p. 142).

Gramsci, unlike anyone before him, argued that civil society can and should be the sphere where new ideas and beliefs are shaped and tested. He viewed civil society as the site of the counter-hegemonic problem-solving, rather than 'the problem' as Marx or some other prominent thinkers viewed it previously. His views of civil society over the consecutive decades heavily influenced and shaped the fabric of our modern world. Gramsci's revolutionary picture of civil society was best captured during the cold war and how Western democracies used civil society as means to give 'voice' to the people at the grassroots and influence despotic rule as in, for example, Czechoslovakia and Poland (Bernhard, 1993; J. L. Cohen, 1994; Kaldor, Anheier, \& Glasius, 2003).

Gramsci saw civil society through a very new and different lens and suggested that civil society is the space where the information is freely shared, logic rules, intellectual develops and freedom is secured from dominant forces, a positioning that has been echoed since. In Gramsci's view civil society is a necessary tool and the most civilised form of challenging the dominance of unjust authoritative states (Gramsci, 1995). As a result, civil society in its $20^{\text {th }}$ Century context became, and still remains, the base for struggle against authoritarianism, corruption, and the shortcomings of governments (Howard, 2003).

The concept of civil society received increasing attention during the Cold War as it proved to be an effective tool for influencing despotic governments. This was especially in relation to the move from authoritarian regimes to multi-party democracies. Since the end of the Cold War (1991), strengthening civil society has become the key approach to fostering democracy as it has proved its capacity (Heinrich \& Fioramonti, 2007) to stand against despotic governments and to bring about positive change desired by the people. 
Civil society has gained much more momentum and value in recent decades. Today, scholars like Jürgen Habermas and Robert Putnam argue that civil society is at the heart of a vibrant democracy. Habermas goes as far as claiming that civil society within a modern state is a kind of procedural rationality, where equal participants take part in a cooperative search for truth (McAfee, 2000).

In Putnam's view, civil society is important because it facilitates an understanding of the interconnected nature of society and the diverse interests within it (Edwards, Foley, \& Diani, 2001). Thus, civil society has proven to be a critical pillar for a healthy state as it has demonstrated its capacity to build social capital, bring together shared values, and transform the political sphere and eventually the state. Civil society has become the foundation for social capital "networks, norms and social trust that facilitate coordination and corporation for mutual benefit" (Edwards et al., 2001, p. 43).

Therefore, civil society has evolved enormously and has become a dynamic, ubiquitous and much needed pillar of any liberal and progressive society today. It is the arena where people come together to advance their shared goals. Civil society is where people unite, whether formally or informally, to reflect and act on mutual objectives. Civil society is the very space where individuals or a group of like-minded people can come together, share ideas, unite voices and shape their own destiny, influence the society as a whole, and bring about change that they desire.

\section{Can Civil Society Be Defined}

Civil society is hard to define but not hard to understand. Logically, progress of research demanded that a definition for civil society be formulated as it is a broad concept and the sector has a diverse range of definitions. Governments around the world, major donors and scholars each have their own definition for civil society and the variety of available definitions and standpoints on civil society is overwhelming. Here, I will present the most noteworthy definitions that surfaced as research progressed, before I present the broad working definition I framed for this research.

The Centre for Civil Society at the London School of Economics offers a sound definition for modern civil society that captures the dual nature of the phenomenon and is a good starting 
point: Civil society is that set of diverse non-government institutions which is strong enough to counterbalance the state and, whilst not preventing the state from fulfilling its role of keeper of the peace and arbitrator between major interests, can nevertheless prevent it from dominating, and atomising the rest of society. (Gellner \& Hamilton, 1994)

Gellner argued that civil society is a "Western phenomenon and the foundation and underpinning of capitalism and bourgeoisie democracy" (Gellner \& Hamilton, 1994, p. 27).

Alan Fowler, a prominent activist and academic, defines civil society as: The voluntary actions of citizens who organise themselves to achieve collective purposes. Structurally, civil society may be thought of as a set of people's organisations that are neither managed by the government nor oriented towards profit (Fowler, 2000b).

Civil society is a broad phenomenon and has various definitions and even various names, such as the Third Sector (H. K. Anheier \& Seibel, 1990), the 'third system', the 'third realm' (Huang, 1993), the 'third wave' (Huntington, 1993), the 'non-profit sector' (Salamon \& Anheier, 1997), and the 'voluntary sector' (Clark, 1995), mistakenly sometimes used synonymously.

To clarify the muddy waters of civil society and in search of a more comprehensive definition, I looked up to see how the Organisation for Economic Co-operation and Development (OECD), and the United Nations Development Programme (UNDP) define the concept. The OECD defines civil society as: "The multitude of associations around which society voluntarily organises itself and which represent a wide range of interests and ties. These can include community-based organisations, indigenous peoples' organisations and non-government organisations" (OECD, 2009), while the UNDP defines civil society as: "Together with state and market, civil society is one of the three 'spheres' that interface in the making of democratic societies"(UNDP, 2004).

It is natural that definitions of civil society are varied depending on where one 'stands' and that the definitions offered are not absolute, since civil society is dynamic, constantly changing and is rapidly growing around the world. Recent upheavals in the Middle East, namely the so-called Arab Spring or better referred to as the Arab Awakening, for example, reflect the unprecedented growth and value of civil society and the impact the sector can 
have in influencing the whole of the society and the governments. This is the result of a rise in power of a more educated population with access to internet. Information technology has given rise to a new social order online in the Middle East, in my view, which now forms a new genre of virtual civil society. This virtual and civil society is effecting the politics of the region and the whole world, including the most remote islands of the Pacific, and will have a long term impact on the lives of the people and especially on how decisions are made in the future.

Review of the literature shows that all existing definitions of civil society are contestable, owing to the diversity of cultures and contexts, making civil society "unsuited to a singular definition" (Corry, 2010, p. 11). Some scholars go as far as labelling civil society as a "loose and baggy monster" (Foley \& Edwards, 1996), others see it as the remedy for a sound polity, and this "diverse range of definitions" makes the selection of one comprehensive definition challenging.

However, for the purpose of this research, I formulated my own simple definition stimulated by the CIVICUS $^{9}$ definition ${ }^{10}$ and all other definitions examined, and have broadly concluded that: civil society is the enabling space outside the state and the market, created by individual and collective actions to advance the good of all.

The term 'civil society' referred to in this research is synonymous with the nongovernmental organisations (NGOs) and international non-governmental organisations (INGOs) and refers to all organisations outside the market and the government. It includes advocacy groups, faith-based organisations, social movement agents, and other actors explicitly involved in promoting justice and advancing human rights. The definition formulated for civil society in this thesis is deliberately kept simple, fluid and dynamic as is the nature of civil society itself.

In the next section, I will explore why civil society can be the key intermediary and the preeminent interface for promoting and cultivating ownership, before I focus on civil society in the South Pacific context.

\footnotetext{
${ }^{9}$ World Alliance for Citizen Participation: http://civicus.org/index.php/en/

10 "The arena, outside of the family, the state, and the market, which is created by individual and collective actions, organisations and institutions to advance shared interests."
} 


\section{Global Civil Society}

History, in my view, shows that governments worldwide cannot always be trusted to exercise power justly and fairly. The history of Fiji is one example of how governments can be sometimes oppressive and unjust. Thus, it is in the best interest of citizens to ensure effective ways to hold governments accountable. Civil society can play a strong role in this process, and has proved itself capable of shifting paradigms, promoting justice, and creating positive change. Civil society, however, is often muzzled, although next to the press it is the ultimate pillar of democratic state and can hold both the market and the government to account if it is informed and accountable (Fox \& Brown, 1998).

Civil society plays a delicate role and acts sometimes for and sometimes against the state. It can be a force for positive change or it can waste donor funds and resources. Civil society can lose its civility; equally, it can be corrupt and/or promote religious intolerance or ethnic division (Hanafi, 2002). The impact of civil society and its strength is dependent on its accountability, the quality of inclusiveness of the debate it upholds and the space it occupies (Boomsma, O'Dwyer, \& Georgakopoulos, 2010). It is the government that nourishes its ability and the 'enabling environment' it is nurtured within. Michael Edwards suggests: "the goal is not having a strong civil society but rather a society that is civil" (Edwards, 2009).

The case studies presented in Chapters 6, 7 and 8 will show how civil society is ideally imbedded within the community and how it can bridge the gap between the donors, governments, and the grassroots. CSOs all over the world aim to occupy this unique space: a space where they can cultivate self-determination and promote Ownership of positive change and development aid.

There is a lot of uncertainty about CSOs and what they can do and how they can potentially complement the work governments do. In 2010, as the Policy and Research Officer of the New Zealand Council for International Development (CID), I conducted research and drafted a discussion on what civil society can do that governments are not able to do. Research at the time revealed that the following eight features are areas that CSOs work compliment that of the governments. 


\section{(i) Capacity for rapid change}

The capability of donors and governments to change policy, address concerns quickly, and connect strongly and swiftly with the development project beneficiaries is restricted by the complexity of their funding criteria, political motivations and other factors. Civil society, however, often works directly in the field and is able to quickly adapt or rapidly change environments and go where donors and governments are not able to. Development CSOs are above all agile, alert and can move fast because of their scale, their often-neutral political status and devoted staff.

\section{(ii) Political neutrality}

Often civil society is active in places in the world where donor governments prefer not to intervene. Fiji, between 2006 and 2014 provides a good example of how a state labelled as not legitimate by rich and more powerful neighbouring countries like Australia and New Zealand was isolated and aid and development was restricted. When there are political disagreements, official aid channels are blocked and civil society is much more capable of bypassing such stakes, delivering development aid, and connecting to the people (Pegus, 2013).

\section{(iii) Quick decision-makers}

Due to their smaller scale and de-centralised functions, CSOs can be more efficient compared to donors and governments because the decisions they make are more informed by the knowledge of grassroots conditions. Continually changing environments require flexible and adaptable informed responses. CSOs are, in general, well connected to grassroots, and have the knowledge and capacity to link with the communities and make development aid more effective and sustainable (Clayton, Oakley, \& Taylor, 2000).

\section{(iv) Cultural relevance}

Understanding, ongoing dialogue and taking into consideration the role of culture are essential for effective development and for cultivation of ownership of change. It is necessary to view cultural diversity resources and a diversity of viewpoints and languages as

a plus, not a barrier. Local CSOs have the pulse of the people (Mati, 2008) and the 
communities they serve, and because of their flexibility they can bypass these obstacles smoothly and rapidly.

\section{(v) Value for money}

CSOs have a range of skills and expertise that provide excellent value for money. The ability of CSOs to tap into local community and provide cost-effective grassroots support is unmatched by any other intermediary. Equally, their overheads and the cost of operations are much lower (Clayton et al., 2000; Steinle, 2009).

\section{(vi) Scale}

Due to their nature and size, CSOs worldwide are able to reach out and interact on several different levels with project beneficiaries and to connect the global to the local and vice versa (De Haan, 2009). They are able to provide cost-effective grassroots support, and often address the needs of individuals at the local level through sponsorship of small projects (i.e., MORDI Case Study, Chapter 6). The most obvious and positive factor of their scale is their ability to make decisions promptly based on their capacity and motives.

\section{(vii) Watchdogs}

Civil society can act as a watchdog to oversee, monitor, and demand accountability from governments and private sector. In playing this role, civil society must first safeguard and promote its own legitimacy through emphasising and demonstrating accountability. The world needs independent, accountable and legitimate organisations that can act as just and unbiased watchdogs. Global civil society is an important advocate for human rights, especially women's rights and good governance, and thus is well situated to encourage greater engagement and control of development aid by the project beneficiaries (Fioramonti \& Kononykhina, 2014) and cultivate ownership of change.

\section{(viii) Innovative approaches}

Civil society worldwide continues to engage and lead projects aimed at tackling poverty through innovative community-driven and grassroots approaches. Local innovative initiatives are best explored by CSOs and often lead to strong localised solutions and local commitment. 
As observed above, the eight features of CSOs mentioned compliments that of the governments, making the sector more capable and connected to the citizens in certain areas. Both the UNDP and the OECD have publicly recognised that CSOs are valuable partners in the development process through the Paris Declaration (2005) and Accra Agenda for Action (2008), which demand donor and government commitment worldwide to recognition of CSOs as actors in their own right.

\section{Civil Society in the South Pacific}

As discussed in Chapter 2, this research examined the global, regional and national discourses around ownership, but mainly focused on civil society in the South Pacific, and particularly the civil society of Fiji and Tonga, to better understand the complexities of ownership at work. According to the UNDP, civil society is a progressive and positive force that has played a significant role in shaping and transforming the islands of the South Pacific (UNDP, 2012). Civil society in the South Pacific has been particularly effective as it has demonstrated that it can advance people's rights, improve the standard of living within communities, tackle government policies and initiate changes desired and 'owned' by the people.

The Pacific is a very diverse region, and so are the nature of civil society in the Pacific Region and the challenges it is facing. The 24 separate island states are spread over the vast Pacific Ocean. The island countries of the Pacific have been colonised by Europeans and many Pacific institutions and laws emanate from the Western colonisers. Traditional indigenous authority exists alongside modern government systems (Crocombe, 2001). The relationship between the Western and traditional governance sometimes creates tensions and affects Pacific values, which are based on a holistic world view, that is, respect for the natural environment, mana ${ }^{11}$, hospitality, ritual practices and communal life (David Robinson, 2012). There are numerous examples of CSOs' positive influence in the Pacific such as the women's movement (George, 2011; Harcourt, 1994; Leckie, 2002), the anti-nuclear weapon testing movement (Gusterson, 1998; Power, 1986), the environmental movement (Haynes, 1999) and various other movements such as the indigenous peoples' and sovereignty

\footnotetext{
11 'mana' is a Polynesian noun referring to an impersonal and sacred supernatural power which can be transmitted or inherited.
} 
movements. All are good examples of how people at the grassroots can mobilise through civil society and lead the changes they desire.

The family and the community is at the heart of Pacific Island society (Oliver, 1989). This has made the Pacific Islands a fertile ground for CSOs. Some scholars suggest that the concept of civil society is narrow and that it should be widened to include kinship, family and kin relations, which play a more vital role in the South Pacific and especially in developing countries and within more traditional contexts (Lewis, 2001). The family unit and the web of connections between the people on the islands make the Pacific unique. The principles of sharing and sense of belonging to the community prevails at the centre of their thinking and way of life. The traditional values and principles uphold unity and harmony in the face of accepted taboos and cultural prohibitions. Therefore, in many ways, civil society in the South Pacific is, in practice, the extended family (Swain, 1999). From a South Pacific context, it can be observed and argued that civil society is not a new phenomenon and that it revives around traditional forms of mutual assistance which have existed historically (Crocombe, 2001; Douglas, 1979; Edmond, 1997).

Some research participants thus contested the notion of modern civil society and its role altogether. Mr Fe Tevi, an advisor at the International Union for Conservation of Nature (IUCN), voiced his concerns:

The Pacific context and people's motives, culture and history is often ignored by development institutions and donors. Globalised approaches often get imposed without respect for the Pacific ways of life, culture and without people of the Pacific being properly informed and engaged in the process. (F. Tevi, Interview, July, 2013)

Major donor representatives present in Suva who participated in this research such as the Governments of Australia, New Zealand, the OECD, and the UNDP when asked about lack of engagement of the people at the grassroots alleged that this is not their responsibility entirely and that, while they are of course concerned, it is the responsibility of their partners, being the governments of the aid recipient countries or the organisations they work with and fund, to engage the people at the grassroots, but that time is an obstacle in this process as well as a range of other issues, because their main objective is to disburse 
the funds within the time limits to appropriate and accountable partners. Civil society organisations are thus spending millions of donor funds on the islands of the Pacific, but the development outcomes are not sustainable or owned by the people and most development projects are rushed, short term, and quick fixes that tend to fall apart when donors leave.

Aid flows to CSOs are questionable and the allocation of funds are not as transparent as they are expected to be (Feeny \& Donahue, 2014). In general, there is lack of accountability and a great deal of data manipulation on aid flows and it is often hard to trace and compile accurate information on donor funding, although the reports are well written and presented and every dollar seems to have had a major impact. All this leaves ample room for debate around the question of effectiveness, sustainability and ownership of development aid and the need to address the existing questions around the problem of accountability and legitimacy of CSOs, donors, and transparency of aid flows, and "the disagreements about trends and patterns" (Wallace et al., 2007, p. 49).

The situation is critical and there is ample room for discussion and consideration of how delivery of development aid can be improved, and how people (project beneficiaries) can be better engaged and encouraged to lead. Some argued that:

Millions of dollars are spent annually by donors, but the people in whose name the money is spent are not sometimes even consulted or involved with the process and that development architecture in the Pacific has become predominantly political and donor driven. (F. Tevi, Interview, July, 2013)

Donor constraints and funding criteria further complicate the situation and often tilts the relationship processes and influences development results. There is plenty of room to better understand these complexities and to improve greater downward accountability systems and partnerships. People can and must be better engaged, they must be brought forth, especially women, to participate in decision-making and encouraged to lead and bring about the change and development they seek.

In most cases, it is not the people that lead the aid and development agenda. People in the communities, especially women, are not even encouraged to take part in decision-making 
processes or to participate in the process. Rather, people are led by external actors because the problems they are facing are too obvious, and donors assume they know:

Aid and development, across the world and in the South Pacific has become an industry, and CSOs are working within this industry and doing their best to tackle the apparent challenges, but also to abide with donor rules and regulations so they can survive. This is why CSOs listen to donors first and do everything they can to primarily meet donor demands because they have to secure the flow of funding and ultimately their own funding to be able to operate. (F. Tevi, Interview)

In recent years, CSOs have had to deal with increasingly complex issues, as well as growing demands on their services. This has meant that CSOs have had to broaden their skills to address additional issues such as climate change, fair trade, human rights, and economic development (UNDP, 2012).

As the case studies will reveal in the following chapters, civil society is a capable and effective player within the aid and development arena. But there is room to improve its decision-making structures, management of financial flows and the sector's accountability to stakeholders, especially downwards to the people, so that it can attract greater trust and more funding and act as a legitimate actor on the ground. These issues and a range of solutions offered by research participants are further discussed in the last two chapters, but for now it is important to dig deeper and to share some of the other findings and observations in regards to the civil society within the South Pacific context.

\section{Principles of Development Effectiveness}

As discussed in Chapter 3, donors, and recipient governments overlooked consultation with civil society in drafting of the Paris Principles of Aid Effectiveness. This was largely because the aim of the Paris Declaration was to reach agreements between donors and recipient governments regarding the dispersal of aid revenues through modalities such as SWAPS and general Budget Support. Hence, the Paris Declaration at its origin was primarily a statecentred agreement and that is why other actors, especially the CSOs, were not invited to the negotiating tables. However, once the agreement was signed, some donor governments 
realised that they should have involved and invited other stakeholders, especially the civil society, to the meetings, because of the important role they can play in delivering development aid.

Thus, donor governments felt obliged and formed a temporary multi-stakeholder on Civil Society Advisory Group (2007) to bring together the voices of the sector from around the world. This Advisory Group created a formal link with CSOs, including the CSOs in the Pacific through PIANGO, with the goal of highlighting the importance of development effectiveness and complementing the Paris Principles of Aid Effectiveness (Atwood, 2011).

With financial support of the donors and guidance of the Advisory Group, The Open Forum for CSO Development Effectiveness was formed in 2008. The Open Forum was assigned the task of bringing civil societies around the world together under the same tent to consult with all stakeholders and to identify the most critical development effectiveness principles in response to the Paris Principles of Aid Effectiveness. From 2008 to 2011, civil societies around the world united under this umbrella named the Open Forum and embarked on a unique journey to accomplish this task (Tujan Jr, 2012).

The Open Forum consulted with thousands of CSOs across the globe on different continents within a three year timeframe to list the principles of development effectiveness for civil society (Martini et al., 2012) and strategies that can be adopted to improve the delivery of development aid on the ground. The umbrella body of CSOs in each country reached out to all their members and their governments to instigate the process. While contexts were very different, broad engagements and the international disputes were constructive.

In New Zealand, I was responsible for moving the mandate forward at the Council for International Development and formed a Development Effectiveness Committee bringing together civil society leaders, academics and government officials to encourage dialogue. In collaboration with Fijian and Tongan CSOs, I represented the New Zealand civil society at the Open Forum's $1^{\text {st }}$ and $2^{\text {nd }}$ Global Assemblies in Prague and Siem Reap and the High Level Forum on Aid Effectiveness in Busan South Korea. Throughout this engagement, I kept the New Zealand civil society informed by promoting accountability, by highlighting the need for a Code of Conduct for civil society in New Zealand and by maintaining a "watching" brief over development effectiveness issues in New Zealand and around the world. Most 
importantly, I conducted workshops and consulted with development experts in Auckland, Wellington and Christchurch on the question of development effectiveness, and voiced the concerns of the New Zealand civil society to the Open Forum main office in Brussels.

The Open Forum cultivated strong relationships between diverse and culturally varied CSOs from around the world. The worldwide process created a global dialogue amongst CSOs. It also helped surface the complexities of aid delivery and possible options to make development more effective.

After three years, thousands of pages of feedback and comments were submitted to the Open Forum around potential strategies that could be adopted. Recommendations from more than 70 countries, including New Zealand, were amalgamated to synthesise and to produce the eight Principles of Development Effectiveness. I was responsible to bring together the New Zealand CSOs engaged in international development and to unite their voices with the rest of the CSOs in the Pacific Islands and to list and submit their development priorities to the Open Forum. It was a costly endeavour but it resulted in a historic document for the first time that articulates what needs to be seriously taken into consideration for development aid to be more effective on the ground. Here are the principles highlighted by CSOs as key doctrines for more effective development aid (Open Forum, 2011):

- commitment to human rights;

- gender equality and equity;

- democratic ownership and participation;

- environmental sustainability;

- accountability and transparency;

- equitable partnership and solidarity;

- commitment to mutual learning; and

- commitment to realising positive sustainable change.

The above Principles for Development Effectiveness were then presented to donors and governments in Busan (2011) on behalf of the global civil society. They were subsequently negotiated during the three-day Busan meeting between the stakeholders as discussed in Chapter 3, and incorporated in the Busan Outcome Document. Arriving at a global 
consensus on this scale is a unique achievement for civil society, but further work is still needed to define these principles and to make sure that they are incorporated into policy and practice.

As discussed in Chapters 3 and 4, the development CSOs examined in Fiji and Tonga who collaborated in formulating these principles have no formalised approaches or agreed agendas as to how the Development Effectiveness Principles are going to be safeguarded in practice. Almost all development leaders, including the PIANGO Director and the National Liaison Unit (NLU) Directors in both Fiji and Tonga, admitted that:

The Principles for Development Effectiveness are idealistic, but highly relevant to the work of CSOs. However, there are no policies and guidelines yet agreed on amongst the CSOs in the Pacific as to how they can be put to practice. (E. Duituturaga, Interview, June, 2013)

The Director of Fiji NLU, Mr. Khan, expressed his concerns by identifying the fact that maybe the Principles for Development Effectiveness are neglected because of how they were formulated:

The Open Forum and the formulation of the Principles of Development Effectiveness is another donor-driven agenda. Millions of dollars were spent. Hundreds of development experts travelled around the world over three years to ensure the formation of these principles, but the consultations were faulty. Not all the countries in the Pacific region were involved and not all the CSOs within the selected countries participated. The consultations were flawed, and the results lack ownership by the stakeholders. (H. Khan, Interview, June, 2013)

The main problem in my view is that donor governments who supported this initiative and funded the consultations and the formulation of the principles of development effectiveness have not even formally recognised the outcome document. More time and research, I assume, is therefore needed to better understand how these principles can be better highlighted, adopted, and implemented. In addition, as discussed in Chapter 3, there is also lack of clarity and some of the language and the technical concepts referred to in the 
outcome documents, although valuable, are vague in policy and practice, such as 'partnership', 'ownership' or 'accountability'.

In the next section, I will present the research findings on the civil society of Fiji and Tonga to draw a general picture of the complexities of the sector. I will then narrow the focus of this study onto the case studies and the selected CSOs who have managed to establish accountable partnerships with the communities they serve and to incorporate the principles of development effectiveness into their work and cultivate ownership of development outcomes by the communities they serve.

\section{Civil Society in Fiji}

The first wave of CSOs in Fiji and Tonga, as elsewhere in the Pacific, that started humanitarian work were faith-based. Churches in Fiji constitute some of the oldest providers of aid and development (Crocombe, 2001). They have been widely involved in assisting the communities through crises and in building hospitals, schools, and other development projects, addressing some of the primary needs of the communities (Ernst, 1994).

Over the years, the Fijian civil society has expanded and has become dynamic, diverse, and vibrant. This is mainly due to the women of Fiji who are at the heart of the sector and have played a dynamic role in its evolution. They have actively used civil society as leverage to mobilise, advance their rights, influence government, and challenge traditional norms. Lack of equal status and power, as elsewhere, which women of Fiji have dealt with over centuries, has been carried over into the $21^{\text {st }}$ Century and is still debated, but much has changed in recent years and the credit goes to civil society chiefly.

The "constitution in Fiji favours males and reinforces discrimination by formally recognising the customary law" (Reanda, 2001, p. 56). Despite their priceless contribution to Fijian society and the great advances women have made in Fiji, they are not treated equally, and, as other places in the world, there is a long way to go before equality and power-sharing between men and women is balanced. Indigenous women have more rights and access than the Indo-Fijian women, but overall women are under-represented in the political scene and especially within the Fijian Parliament (George, 2012; Reanda, 2001). To address these 
challenges, women in Fiji have always united within the civil society arena. Their unique and exemplary engagement goes back to the 1960s and has been going on ever since. Organisations like Soqosoqo Vakamarama (the Fijian women's organisation) and the Fiji Catholic Women's League (primarily Fijian) were amongst the very first wave of active CSOs founded "on the basis of ethnicity and gender" (George, 2012, p. 24).

According to George (2012), before the first coup in Fiji in 1987, women's groups were the first and the most active in Fiji to address the question of human rights. Since the coups, however, there has been a mushrooming of rights-based organisations to address the importance of the rule of law, social justice, conflict resolution, and peace building.

Among the CSOs that participated in this research the Fiji Women's Crisis Centre (FWCC) and Young Women's Christian Association (YWCA) based in Suva are good examples of the oldest and most dynamic (est. 1961) CSOs in Fiji. Over the years, YWCA and FWCC have fought for women's rights, initiated historic changes and are still active despite many obstacles. The YWCA, in particular, has become a significant advocacy organisation in Fiji, fighting the injustices inflicted on women, and has involved itself in both local and regional politics (George, 2012).

Fiji's civil society has expanded rapidly on a healthy scale over the last thirty years, and it has played a critical role in addressing most of the shortcomings of the government (UNDP, 2012). At a national level, Fiji has seen the number of registered NGOs rise from less than 100 in 1980 to over 800 in 2013 (Mohanty, 2008). This unique expansion of the civil society sector is not exclusive to Fiji. This is a global phenomenon. Worldwide, $90 \%$ of registered CSOs were formed between 1970 and 2004 (Edwards, 2009). At no other time in history has there ever been such a significant increase in the number of CSOs.

Civil society in Fiji has changed from its early days, but remains vibrant and active. It faces a challenging 'enabling environment' and a difficult relationship with the Government of Fiji in the face of the coups and the strong role it has played in addressing human rights abuses by the military government of Bainimarama (Llewellyn-Fowler \& Overton, 2010). The history of civil society in Fiji is an excellent example of how change can be initiated at the grassroots and how people can take ownership of issues they are facing and influence governments 
and inform, empower, and encourage individuals to take actions needed to cultivate positive change.

After the coup in 2006, external donors who fund the CSOs in Fiji shifted their attention from the government and the Paris 'country ownership' approach and focused more on civil society (Bhim, 2010). As a result, there are greater funding opportunities for the CSOs and they have flourished and have become better informed, engaged, and more effective. In cutting ties with the government, donors increasingly looked to local civil society to be a "key ally, both in supporting development work and in providing advocacy for human rights against the illegitimate military regime" of the time (Llewellyn-Fowler \& Overton, 2010, p. 833).

Over the years, the political upheavals have fractured and divided the CSOs. Some supported the 2006 coup from the start and have affiliated themselves with Bainimarama and his agenda, while other CSOs have maintained a stance against the government or have tried to remain neutral. Nonetheless, CSOs have expanded in Fiji despite the division and the sector is more active than ever before. However, civil society has never been properly engaged in development planning and CSOs have in general followed donor agendas. As a result, there are CSOs who barely survive, because they do not meet donor criteria and are unable to match the needs of their community with donor conditions. At the same time, there are CSOs such as the Foundation for Rural Integrated Enterprises \& Development (FRIENDS) who have managed to access unprecedented sums of funding from donors given the shift in donor policy and the focus on civil society.

Most civil society leaders who participated in this research were very careful with what they said about the Bainimarama regime of the time and mostly avoided expressing their views about the politics of the day. Note that the interviews with CSOs in Fiji took place before the so-called democratic elections in 2014 , which gave Bainimarama apparent legitimacy. Fiji's former Deputy Vice President, Ratu Joni Madraiwiwi, took part in this research. As an indigenous iTaukei and as a human rights lawyer and a traditional chief, his insights and participation in this research were very valuable. Civil society, according to Ratu Joni, has been a vital part of modern Fiji, although its accountability to the people has been under question over the years; 
The sector has managed to speak out against the injustices inflicted by the governments during and after each coup and to reach out to the people. Civil society has played a vital role in Fiji in terms of addressing human rights issues, especially promotion of the rule of law. (Ratu Joni Madraiwiwi, Interview, June, 2013)

Following each coup in Fiji, and infliction of injustices (sometimes by the government) it is civil society that has reached out to the people first. Ratu Joni mentioned how in his view:

"Civil society has grown rapidly, but has become less accountable and more political in recent years than ever before. (Ratu Joni Madraiwiwi, Interview, June, 2013)

Interviews with UN and EU staff confirmed Ratu Joni's reflections as the UNDP Director stated that:

Donors always have their own agendas, including even UN, such as 'rule of law', 'good governance' or 'women's rights' issues, which are not always proactively promoted by partner governments. Civil society, however, promotes these donor foreign agendas and thus aid and development political games begin. (G. Wiseman, Interview, July, 2013)

On the same note, the directors of the most prominent CSO umbrella organisations in Fiji, FCOSS, PRNGO and PIANGO, each spoke about the existing divisions within civil society and the general lack of alignment and harmonisation of activities within the sector.

Disappointed with the impact and the effectiveness of CSOs and comparing the funds they have received to what they have achieved in the past 20 years in Fiji, the Director of the FCOSS stressed:

In most cases, CSOs have formed stronger partnerships with their donors rather than with their target groups. This lack of downward accountability of CSOs to the people they serve and lack of ownership of issues within the communities is the reason why aid and development is not as effective as it can be. (H. Khan, Interview, July 2013). 
Research revealed that CSOs are in a challenging position and it is the funding structures and the need for donor cash flows that tilts the relationships. CSOs have no choice but to align their activities with donor criteria to secure funding:

"Most development projects are replicates and development fast-foods, and often do not penetrate deep enough to address the concerns of the people and the diverse cultural and social sensitivities. This has over time resulted in an enormous waste of resources and the disengagement of local populations. (G. Wiseman, Interview, July 2013)

Any observer of civil society in Fiji can appreciate that civil society is effective in addressing injustice. CSOs play a critical role in personal and community development in Fiji because of their scale, their accessibility, flexibility, on-the-ground relationships, and their proximity to the donors as highlighted earlier in this chapter. They are a dynamic force especially for safeguarding human rights, women's rights and the rights of other marginalised groups, but there is ample room to reform civil society, especially its accountability and to improve the effectiveness of development aid.

\section{Civil Society in Tonga}

Tonga is a Polynesian kingdom of many uninhabited islands with white beaches, coral reefs and the deepest point in the ocean $(10,882 \mathrm{~m})$, known as the Horizon Deep. Similar to the rest of the Pacific Islands, Tongan culture is highly influenced by Christianity, and is home to a diverse mix of denominations, each with their own particular interpretation of the Bible.

The civil society sector in Tonga is small, diverse, fragmented, and is highly dependent on foreign funding to maintain its modern standards of living. The sector has a relatively healthy enabling environment, but could benefit from greater support from the government, better alignment of activities and harmonisation.

Most of the CSOs in Tonga collaborate very closely with the government and have managed to find their niche within the overall National Development Plan, and focus on the government's commitments to development, vis-à-vis national, regional and international commitments. Several local and transnational CSOs as well as the Tongan Government participated and guided this research. 
According to local development experts and the communities who participated in this research, the Tongan Women and Children Crisis Centre (WCCC) is by far the most effective CSO in Tonga and has had major positive impact on the people, especially women and youth. The Director of WCCC, Ofa Likiliki, agreed to participate in this research and played a key role in guiding and informing it. Violence against women is one of the most prevalent issues across the Pacific and especially in Tonga. According to Ofa:

\section{It has been estimated that between 5,000 and 10,000 women in Tonga are victims of intimate partner violence each year, a prevalence of between $30 \%$ and $60 \%$ of women; and, despite this statistic, most denominations prefer not to acknowledge and to speak-out against the existence of such wrongdoings formally. (O. Likiliki, Interview, August, 2013)}

As in Fiji, women's participation and representation in the decision-making processes at both informal and formal levels of decision-making are restricted legally and traditionally. Although governments of Fiji and Tonga have made several commitments towards the advancement and empowerment of women, there are only very few CSOs like WCCC that cultivate self-determination and reach out to the women and encourage them to voice their concerns and take ownership of change.

Similar to Fiji, women lead the civil society in Tonga and they have done a remarkable job in coordinating, harmonising, and managing the sector. Women in Tonga, as elsewhere in the Pacific, however, suffer primarily because of traditional, cultural and especially religious norms. Women do have a position of high respect in the family symbolically, but their position is still not equal to that of the men. The first-born daughter of any household in Tonga is regarded as a 'gift of god'. Yet, women are seriously under-represented in politics and absent in decision-making processes (Likiliki, 2008).

Unlike Fiji, where funds are mainly channelled through the civil society sector, allocation of aid and development funds in Tonga are aligned with the Paris Declaration and the principle of country ownership, meaning aid and development funds are channelled to the government of Tonga and to the Ministry of Finance primarily, being the focal point for donors within the kingdom. 
To understand the complexities of country ownership and to observe the mechanics of Paris Declaration, I approached the Ministry of Finance, shared my research questions and sought the Ministry's participation and permission to closely observe and examine the country ownership procedures and the aid and development systems. The staff at the Ministry of Finance indicated interest in the question of ownership and enabled me to meet a range of relevant officials from the Aid Effectiveness Division. The officials at the ministry were highly supportive because I was told that the question of ownership is an important question for Tonga because of its past and very challenging to ensure, given the dominance of China and Australia and New Zealand interests and the politics involved. The staff even arranged for me to meet with the Minister of Finance, Lisiate Akolowho, who then engaged in this research, and authorised and encouraged the testing of the Ownership Index, while very frankly admitting that there is no capacity within the ministry and that the ministry will not even function without donor funding.

I began the research by closely examining and observing the role of the World Bank, the Asian Development Bank (ADB), and UNDP, who maintain large and luxurious offices at the heart of Ministry of Finance in Nukualofa. Meetings with the World Bank, ADB and UNDP representatives were highly Informative. Siosaia Faletau, who is the representative for both ADB and the World Bank, stated that the Tongan Government has been successful in coordinating donors, and:

\footnotetext{
Reform of the aid structure (strengthening of the Paris Principles) in Tonga has resulted in receiving all of the allocated budget-support from all the major donors since 2012, which is a rarity in the region. (S. Faletau, Interview, July, 2013)
}

According to Faletau, Tonga is unique in the sense that it is the only country in the Pacific that has succeeded in coordinating all allocated aid from one government department, being the Ministry of Finance:

Tonga is an excellent example of how the Paris Declaration can be safe guarded, but how each principle needs further reflection, as the strategies adopted mixed with foreign political interferences have not made aid more effective as expected (S. Faletau, Interview, July, 2013) 
The officer responsible for coordination and allocation of funds to the CSOs at the Ministry of Finance, Mr. Malaki Kaufusi, mentioned that there is a lack of country ownership in general in the design and allocation of donor funds in Tonga:

Donors have their own, often uncompromising, criteria and it is very challenging for the Ministry to appropriately consult with the CSOs and other stakeholders and to especially align community needs with donor conditions. (M. Kaufusi, Interview, July, 2013)

The task of aligning and meeting everyone's needs is very challenging given the diversity of the priorities for each stakeholder. China, Australia, New Zealand, the EU, the World Bank, and ADB each work very closely with Ministry of Finance. According to the UNDP Country Representative, Milika:

Due to lack of capacity and lack of time, the senior staff at the Ministry of Finance have no choice but to negotiate development priorities with donors on behalf of the people and sometimes even neglect community needs to meet donor priorities. (M. Tuita, Interview, July, 2013)

The Principal Economist and the Aid Effectiveness Advisor at the Ministry of Finance, Natalia Palu Lātū, frankly admitted that:

Foreign funding finances more than $50 \%$ of Tongan Annual Budget (2013/14), and hence ensuring ownership of development becomes essential in this context when half of the national budget has strings attached to donor funding. Donors have their own goals and interests and they must be met if funds are to be allocated. (N. Palu Lātū, Interview, July, 2013)

Aid and development in the context of Tonga is:

Only as good as the decisions made by the ministers and the staff. It is the ministers who ultimately make the final decisions in regards to development aid and they are under pressure and under resourced and 
simply incapable to make everyone happy. (N. Palu Lātū, Interview, July, 2013)

The staff at the Ministry of Finance in general expressed frustration over the processes and the 'soft power' of the donors and especially the lack of appropriate consultations with the stakeholders before identification of development plans;

Donors have their own priorities. The challenge is dealing with donors like China who tend to ignore National Development Plans and national priorities. Sometimes the Chinese Officials target one minister in particular, build diplomatic ties and side-step the entire 'county ownership' agenda through one official. (N. Palu Lātū, Interview)

According to Palu Lātū, the government of Tonga does its best to align its priorities with donor criteria. Donor meetings are held annually and donors are invited to present their criteria and state their areas of priority. Tongan officials present from each ministry then coordinate and draft their annual plan accordingly:

Civil society and other stakeholders are unfortunately consulted at the very last moment. It is simply impossible to inform and to consult everyone and to arrive at consensus as deadlines are always looming. (N. Palu Lātū, Interview)

At the Ministry of Finance, the staff deal heavily in correspondence with the donors on behalf of the stakeholders, while according to Mr Kaufusi:

Most Government officials are disconnected from the grassroots and uninformed of the civil society challenges. (M. Kaufusi, Interview, July, 2013)

Each of the government departments are expected to do their own planning in consultation with their own stakeholders, especially the CSOs, but:

The ministries are lacking capacity and make last-minute plans. They often fail to reach out to their constituencies, and tend to hire consultants from donor countries who speak donor technical language to write up their 
project proposals. This way they know they will be able to secure donor funding. Equally CSOs are always challenged by drafting of their own project proposals. (M. Kaufusi, Interview, July, 2013)

To understand the complexities of the aid and development industry, I visited as many completed development projects implemented by ADB, World Bank, UNDP, and other major donors, including China, Australia and New Zealand, as I could. I talked to the project beneficiaries and concentrated especially on local CSOs and talked to the women and youth on the islands. These visits and conversations with project beneficiaries were highly informative as they opened my eyes to the challenges the people are facing on the islands of the Pacific and potential strategies that can be adopted to cultivate self-determination and ownership of development change. What became immediately obvious was the question of sustainability, as projects often fail when local knowledge is neglected and ownership of the outcomes ignored. Solutions are often offered by the external 'experts' and donors, rather than identified by the people.

To capture the pulse of Tongan civil society, I approached the Civil Society Forum of Tonga (SCFT), which is the umbrella organisation for all CSOs in Tonga. According to Siale Ilolahia, the Director of SCFT:

The sector lacks capacity in different areas, but it is strong enough to target the shortcomings of the government of Tonga and address issues of common concern. (S. Ilolahia, Interview, July, 2013)

According to the SCFT Director, who guided this research and was instrumental in unearthing the findings, the sector's main challenges are general lack of capacity and lack of resources, as well as a lack of dialogue and accountability standards.

CSOs are under resourced in Tonga and in a major competition with one another to secure funding. Due to competition, some CSOs have developed areas of expertise as a strategy to avoid rivalry. There is lack of alignment and harmonisation between the CSOs, while they do their best to meet donor criteria, instead of addressing the priorities of the communities. (S. Ilolahia, Interview, July, 2013) 
Finally, the most important challenge neglected by almost all CSOs, as identified by the Director of the CSFT, is "lack of accountability standards downwards to the people".

Consultations downwards with the project beneficiaries are limited, costly and lacking inclusive approaches that value process and permit especially women and youth to voice their concerns. As a result;

CSOs in Tonga lack capacity to ensure that all their development projects are sustainable, lasting, maintained and protected by the people in the long term. (S. Ilolahia, Interview, July)

Most of the local CSOs who participated in this research expressed the importance of their engagement with the SCFT and how, over the years, SCFT has been successful in bridging the gap between national CSOs and Ministry of Finance for accessing funding, and provides regular up-skilling, workshops and information dissemination. As an umbrella body, SCFT plays a key role in aligning and harmonising the work of CSOs in Tonga with the government and connecting the local to the global debate.

According to the Director of SCFT, the other challenge the sector is facing is lack of adequate and appropriate consultation by the Tongan Government, with the local CSOs and other national actors in formation of development policy as:

Government consultations are made at the last minute. Officials visit the SCFT Office for an hour or two and hold a conversation with the SCFT Director or send a draft policy and demand feedback as soon as possible (S. Ilolahia, Interview)

To further investigate this seemingly shallow engagement, I also met with SCFT Board members, and transnational CSOs in Tongatapu including the Red Cross officials and Drew Havea, who is the chair of the SCFT. According to Drew, the more authentic the consultations and discussion between the stakeholders, the more effective the development outcomes, but this important and obvious factor is frequently neglected:

Development aid, to be effective, must be depoliticised. However, aid is normally allocated and distributed based on political interests of the 
donors and that is why development results are often ineffective and lack ownership by the project beneficiaries (D. Havea, Interview, August, 2013)

Debate and consensus is lacking amongst CSOs as to how ownership is defined, how it is to be translated into policy, and how it is to be promoted, as there are currently no policies, rules or regulations amongst CSOs in Tonga (or Fiji) that would ensure appropriate consultation with project beneficiaries or demand equal standards of accountability upwards to the donors and downwards to the people;

There is a need for agreed terms and guidelines on accountability that can guarantee appropriate consultation, accountability downwards to the people and ownership of development outcomes by the people. (D. Havea, Interview, August, 2013)

The enabling environment of civil society in Tonga can benefit from greater attention as the relationship between the civil society and the government is not always easy. Whilst resistance is common, and competition prevails, cooperation is strong. As the case studies will reveal in the following chapters, civil society in Tonga has been particularly effective in connecting the global to the local. The sector has managed to inform the communities, and introduce a range of new ways of cohabitation and living to the people, such as goal setting, and inclusion of women in decision-making, which have been highly positive although in contrast to the usual norms and traditional ways of life previously assumed common.

\section{Conclusion}

Close examination of global, regional and national CSOs was informative and demonstrated that civil society has, indeed, a unique role in bringing together stakeholders, building and sustaining partnerships and playing a complementary role in assisting governments to deliver development aid. As discussed in detail in this chapter, this is mainly due to the scale of the CSOs and their accessibility, flexibility, and grounded relationships.

Civil society is well positioned to cultivate ownership of change by the people, but, although most CSOs have some sort of consultation plan for partnership and engagement with communities, none of the CSOs examined in Fiji and Tonga, large or small, have a written policy or an overall strategy to promote ownership of results from the start by the project 
beneficiaries. Research also revealed that CSOs have become reactive in general, rather than proactive, actors because of their dependence on donor funding.

As the case studies in the next three chapters will reveal, a good starting point is cultivating more accountable and durable partnerships with the project beneficiaries. CSOs can safeguard their legitimacy, ensuring that the people, especially women, are engaged from the start, and that the project beneficiaries are informed and encouraged to reflect and to take ownership of the outcomes and the ultimate results. By building stronger and more authentic and inclusive partnerships with the communities, civil society can cultivate development change that the people would want to maintain and protect over time. 


\section{Chapter 6}

\section{Mainstreaming of Rural Development Innovation Tonga (MORDI)}

\section{Introduction}

This chapter presents a case study examining the strategies adopted by MORDI that have translated into high levels of ownership of development aid. Observing MORDI facilitated the understanding of the complexities of ownership and provided the opportunity to identify, test, and compare the ingredients of ownership towards formulation of a potential guideline aimed at cultivating ownership of development aid and an Ownership Index for partial documentation of the levels of ownership through stakeholder discussion, analysis, and comparison. In addition, analysis of MORDI revealed other important factors that assist or hinder cultivation of ownership of the results by the people, which will be discussed in this chapter.

\section{Presenting Hunga}

There is a remote village on an island in the Vava'u group in the heart of the Pacific Ocean called Hunga. The village is on top of a hill. A steep road links the village to the waterfront. According to the Tonga Census of 2011, there are 52 households on the island with 241 residents, making Hunga one of the most remote island communities in the world.

The people of Hunga have struggled with access to the sea for generations due to the volcanic nature of the island and have only one pathway to the waterfront. According to community elders, the original pathway was muddy and unwalkable for generations, particularly when it rained. People struggled to bring their goods up and down the road. This chapter tells their story of self-determination, and how the people of Hunga decided to take ownership of their problems, and took the decisions necessary to lead the changes they desired.

The only humanitarian organisation active in Hunga today is MORDI and, similar to other civil society organisations (CSOs) in Fiji and Tonga, MORDI has no particular written policy 
for promoting ownership, but has managed to cultivate ownership within the communities that it has worked with. This is mainly through fostering authentic and accountable participation with the community, which has translated into ownership of the outcomes over time by the people. The aim of this case study is to understand the actions and policies MORDI adopted that have resulted in manifestation of self-determination and ownership of change by the people. Examining MORDI and its partnerships has been critical for extracting the ingredients of ownership and for understanding its complexities.

The Ownership Guidelines and the Ownership Index were formed and modified as research advanced. The interviews with stakeholders helped the untangling of the meaning of ownership and were highly informative. The index, in addition, proved to be a practical tool for partial documentation of the levels of ownership felt by stakeholders for further analysis and discussion between the partners.

\section{Background}

MORDI is primarily funded by the International Fund for Agricultural Development (IFAD), an agency of the United Nations Development Program (UNDP), which was formed following the 1974 World Food Conference, and focuses on country-specific solutions. IFAD's presence in Tonga dates back to 1983. In June 2004, IFAD supported a regional programme in Tonga to contribute to sustainable, improved livelihoods of vulnerable communities, especially youth and women, living in remote rural areas of Pacific Island Countries (PICs) guided by the Millennium Development Goals (MDGs), which became the beginning of a new very active and dynamic CSO called MORDI in the years that followed. The director of MORDI (Soane Patolo, also the founder) and his staff are all Tongan and MORDI is renowned for its solid engagements with Tonga's rural island communities.

The first and most obvious trend observed in the work of MORDI, and the two other case studies that follow in Chapters 7 and 8, reveal the importance of process, dialogue, and building of partnerships that are accountable as means for cultivating and achieving ownership of the development projects by the community. Analysis of the concept of ownership in development aid is naturally more feasible post hoc, when development projects are completed: 
Because valid assessments of 'ownership' of development aid can only be made with the passage of time. (Professor Wadan Narsey, USP, Interview, July 2013)

Hence, this case study, as well as the case studies examined in the following two chapters, concentrate on completed development projects only, as a method to unearth the ingredients of ownership as concluded development projects facilitate a more meticulous examination and analysis of the phenomenon of ownership.

\section{How MORDI Works}

While conducting research on the question of ownership and searching for the best examples of community-led development, MORDI was referred to me by numerous development experts as an excellent example of civil society partnership and engagement with community. MORDI is renowned for its accountability and network of partnerships it has managed to build over the years with communities and other stakeholders including the government of Tonga.

Thus, I embarked on exploring MORDI and its work from a range of diverse standpoints. I spent many hours talking to the MORDI Director Soane, the staff, particularly Samsoni Alamoti (MORDI's Senior Advisor and community facilitator), and MORDI board members, as well as the community members who have benefited from MORDI projects. I conducted semi-structured interviews and used the Ownership Index while interviewing the abovementioned actors. I observed MORDI from different perspectives and sought the standpoint of its funders as well as the project beneficiaries.

MORDI is mainly active in the most remote islands of the Pacific, specifically in the Lulanga island group of Ha'apai, the Motu, and Vava'u group, but its main office is in Tongatapu, where I based this research and spoke with MORDI staff and board members. One of the board members of MORDI, Dr. Seu'ula J. Fua, was instrumental in providing a behind-thescenes perspective, and in helping me understand the work of MORDI and the complexities 
of cultivating ownership, as well as the nuances of Tongan culture, such as the intricacies of conducting appropriate talanoa ${ }^{12}$.

A number of community members stated how, in their view, perhaps only a handful of CSOs, such as MORDI, manage to authentically connect with the people at the grassroots and align the needs of the people with the priorities of donors and governments, while making sure that it is the project beneficiaries that are leading the process. One research participant suggested that MORDI is an excellent example of how CSOs are best situated in aligning the needs of the people with the priorities of donors and government of Tonga:

MORDI has been very successful in promoting ownership of development aid and increasing the sustainability of its development work and accountability because it has promoted transparency and community engagement in decision-making while safeguarding process, which has naturally resulted in cultivation of authentic partnerships and higher levels of ownership of the outcomes by the people. (Natalia, Interview, July 2013)

MORDI projects are sustainable because:

MORDI has managed to build strong partnerships both with the communities it works with and with the government, ensuring that women and youth are present and that all stakeholders are engaged and their voices heard. MORDI has succeeded in promoting ownership because it encourages the communities to inclusively engage in decision-making from the start and to identify development challenges and their appropriate solutions. (Dr. Seu'ula J. Fua, Interview, August 2013)

MORDI has consistently worked from a set of fundamental principles, of which the first and most important has been ensuring an authentic partnership. On numerous occasions, I

\footnotetext{
12 talanoa is a Tongan word which means: speaking broadly about nothing, and some scholars (David Robinson \& Robinson, 2005; Vaioleti, 2006b) argue that it is a more culturally appropriate tool for research in the Pacific Islands than Western approaches, as it has synergy with Pacific people's way of life and culture. However, talanoa was not adopted as a method for this research because women and youth are not allowed to speak when talanoa is taking place in traditional settings.
} 
asked MORDI Director, Soane, to describe to me in detail the process of partnership MORDI emphasises, how partnership theories are translated into action and what activities are taken by MORDI that lead to ownership of the results by the project beneficiaries.

As it stands, according to Soane, MORDI does not have an explicit written policy for promoting ownership, while it has effectively incorporated classical partnership strategies in its work. These strategies have helped MORDI engage with the communities it works with more successfully. Through these partnerships, potential project beneficiaries in the communities have voiced their problems and identified the solutions they see fit, which has resulted in people making the commitment to maintain and protect the outcomes. In the next section, I will explore what these strategies actually are and how they are put into practice within the communities.

\section{Partnership towards Ownership}

Although there is a lack of policy in general within the civil society sector on the question of ownership of results, review of the work of MORDI reveals that participatory processes are a very effective tool for engaging with the community and do often result in cultivating ownership of the outcomes by the project beneficiaries in the long term. Almost all research participants commented on how participatory methods are amongst the best tools for influencing project results and ensuring sustainable change, but further research revealed that unfortunately not all CSOs in Tonga and in Fiji actually have a formal policy on participation either.

The approach adopted by MORDI is the Participatory Learning and Action (PLA) plan, which outlines how MORDI should engage with its project beneficiaries. The PLA strategy used by MORDI ensures the community is engaged and consulted and that women and youth are involved in making the decisions. The following are some of the organisational principles of MORDI which are unique amongst CSOs in Tonga and Fiji:

- emphasis on self-reliance;

- grassroots planning;

- bottom-up dialogue for policy formation; 
- linking local action with policy reform; and

- 'learning' approach for implementation of activities.

Further research revealed that the MORDI principles and participatory approaches are very much aligned and inspired by the thinking and writing of Robert Chambers (2007) who has identified language and lack of clarity of the meaning of technical words and concepts in aid and development discourse as problematic. Words such as 'partnership', 'empowerment', 'ownership', 'participation', 'accountability' and 'transparency' are very good examples of this ambiguity - these words are used often in the aid and development arena today, but tend to be unclear and imprecise as to what they actually refer to in policy and practice. These words are new concepts within the discipline and did not exist in the language of aid and development before the 1970s. Chambers claims that in fact it is the civil society that has "disseminated, and innovated" (Chambers, 2013, p. 98) these terms in an attempt to make aid and development more effective.

As discussed throughout this thesis, the language (discourse) of development aid is both the problem and the solution because, as Chambers stresses, sometimes "new words are coined and used by the actors and often by the 'powerful' to legitimise power (action), to maintain dominance, and to camouflage and conceal realities by sanitising power" (Chambers, 2005, p. 119). Inspired by Chambers, Soane and his staff at MORDI talked about the importance of partnership, and referred to the delicate task of language, "balancing the relationships of power", and ensuring change that is people driven and how challenging and delicate it can be:

People must identify the problems and the solutions and engage in making the decisions throughout the development process as development projects unfold. Otherwise, development results will not be sustainable. (Soane, Interview, August 2013)

This engagement, building of partnerships and cultivation of ownership by CSOs within the communities necessitates thorough reflection by the people themselves on identification of priorities and the change needed, which they would want to maintain and protect over time. 
It was interesting to note how community members talked about engaging in a PLA process as a positive experience on its own:

The fact that the traditional forms of decision-making are revised through the participatory methods, their effectiveness questioned and that everyone in the community, including the women, are invited to think about the changes that they would want to see, is an effective and much required transformation. (T. Haukinima, Interview, August 2013)

All of the research participants, especially the MORDI staff, talked about the importance of inclusive decision-making and how, in their experience, project outcomes are more sustainable when decisions are made inclusively, and when women and youth are invited to contribute and engage in identifying the change needed. According to Soane, this is the first time in some of the communities that decisions have been made in a participatory way, as the old traditional decision-making systems are still intact across Tonga:

The elders, however, are watchful and doubtful of the participatory processes where women and the youth are involved in decision-making. (Soane, Interview, August 2013)

Participatory decision-making is a new experience for the majority of the island inhabitants. Community residents admitted that the PLA and the whole engagement of women in decision-making through the process adopted by MORDI is an important task on its own, as it introduces a new standpoint in approaches towards decision-making and cultivates a higher level of ownership over time. Dividing the population into different groups, and giving voice to women and youth is a major shift in decision-making within the Pacific context, because of the crucial role women play towards ownership of development outcomes in the long term. As it will be observed, the engagement of women from the start does increase the level of ownership as development projects unfold. Cultivating ownership takes time and careful consideration and engagement of all stakeholders.

According to Soane, ownership can be cultivated through ensuring and reviving the dialogue between the project implementers and the project beneficiaries throughout the project 
cycle. It is crucial to understand the dynamics and complexities of participation, but observing the work of other CSOs revealed that there is no 'one remedy' for participation or a consensus on how it is to be achieved - what fosters participation more than any other factor is sustaining the dialogue throughout the project cycle:

CSOs need to seriously take the 'process' of development into consideration and be cautious of the 'voice' of the community at each phase of the development project-cycle, which will result in greater accountability, and sustainability of development outcomes. (P. Poulsen, Interview, July 2013)

As observed in the community of Hunga, members of the community often do not know the exact causes of the problems they are facing, or the best solutions to challenges they are facing (see Table 6.1). This can create serious obstacles for the community and in reality it means more work for the CSOs that aim to promote ownership, because it is the responsibility of the governments (donors) and the CSOs to better inform their partners.

Often, the most difficult part of participatory planning is:

Keeping everyone in the community informed and listening to everyone and making sure that community members 'voice' their concerns. (Dr. Seu'ula J. Fua, Interview August, 2013)

The goal is to avoid the automatic and blind acceptance of external solutions, and to initiate the habit of reflection on the change needed, on the possible solutions, and to start a dialogue:

Participatory approaches for engagement with the communities are complex, always different and depend on each context. (Soane, Interview, August 2013)

Research revealed that inclusive engagement has a direct impact on project outcomes and their sustainability but it is also difficult to ensure that the community members are always properly represented, or that they all agree on development 'goals' for the community or the 'solutions' adopted. 
These are numerous obstacles for promoting ownership, but the solution, as with everything else, is continuous persistence on dialogue between stakeholders. (Dr. Seu'ula J. Fua, Interview, August 2013)

Members of the target community do not always have the experience of engaging in a participatory process. The process must be clearly explained to them prior to the consultations. They need to understand the theory and assumptions and must hear of past practices in order to engage more fully. Some participants may need new skills. This is where CSOs can play a major role, taking into consideration the cultural sensitivities, the cultural context, and the history of the community, while aligning the community needs with their own criteria:

CSOs need to learn more about local culture and context, the power dynamics within the community, and the political and social issues of the community before they can tailor any development intervention. (Dr. Seu'ula J. Fua, Interview, August 2013)

Forming a consensus within the community and with a development partner can be very challenging but it is also the foundation of sustainable change and effective development. It is essential that CSOs understand the context and the culture of the communities they work with and that they facilitate inclusive decision-making and dialogue between stakeholders carefully:

There are always those individuals within the community who 'know' what is right for the community. Who value old traditional structures and do not see change as positive. They can make a participatory process very difficult. Handling this situation can take both tact and toughness. Engaging and ensuring authentic participation of all the actors in the process requires perseverance and continuous dialogue. (Soane, Interview, August 2013) 
The other important challenge in a participatory process, according to Dr. Seu'ula J. Fua, is ensuring that the right people within the community are present, and that they are properly engaged because:

Lack of appropriate representation can cause mistrust, and can tilt ownership and complicate the end results. (Dr. Seu'ula J. Fua, Interview, August 2013)

There is little debate today as to whether participation is important or not. As Soane emphasised, ensuring a fair and just representation and inclusive engagement towards an accountable participation is not an easy task. However, experience in the field reveals that development is more effective when there is trust, when development actors are seen as accountable, and when partners maintain dialogue at each stage of the development process and when everyone is given a voice and listened to.

The additional quasi-quantitative data obtained with the support of the Ownership Index presented in Figure 6.1 below is the result of qualitative assessments conducted by research participants and partially captures the levels of ownership felt by MORDI staff in comparison to the level of ownership felt by the project beneficiaries at the other end of the spectrum. As discussed in Chapter 2, the data gathered with the help of the Ownership Index is partial, but it does help in capturing an estimate of the levels of ownership felt throughout the project cycle for further analysis and discussion between the stakeholders. The feeling of the stakeholders and the levels of ownership felt cannot, however, be solely relied on. The index is an additional tool for partial measurement of the impact for further analysis and discussion between the partners, and has a dual purpose: it can be useful for project implementers for implementing development projects that are community driven and can serve the community as a simple and practical gauge for evaluating development results.

\section{Ownership Index}

The Ownership Index enabled partial measurement of the feeling of the stakeholders and their perception of ownership of development outcomes at each phase of the development process. Interviews and qualitative assessments of the individual ownership measures at 
each phase of development projects stimulated discussions and helped to capture and document MORDI's performance and facilitated assessment amongst development results evaluated.

The partial measurement of the levels of ownership captured by the index permitted diagnosis of the development project at each stage which proved to be highly informative. For example, as shown in the Figure 6.1 below, the partial measurement for the Problem Indicator and the Solution Indicator of the project as well as the Finance and Implementation phases of the MORDI Hunga Road project in particular, show large differences. This means more discussions must be had at each of these phases, and that the index does have the potential to serve as a tool to document perception of the stakeholders for further discussion. The difference of perception captured is not very high for the case of MORDI compared to the level of discrepancy in numerous other projects implemented by other CSOs examined with the help of the index. This observation would not have been possible to detect and document without the aid of the Ownership Index.

As the case of MORDI and the following case studies will reveal, the complexities and the challenges that the community and the CSOs feel at each phase of development project are complex. These complexities throughout the process were explored with the help of the semi-structured interviews, but more deeply with the qualitative assessments. I asked the project beneficiaries and the MORDI staff to discuss the details of the development project at each stage of the process in detail, the lessons learnt, and the challenges they faced, which were documented with the support of the index. The Ownership Index thus proved to be an additional and pragmatic tool for documenting these qualitative assessments and recording of an estimation of the feelings and perceptions of ownership of the stakeholders. 


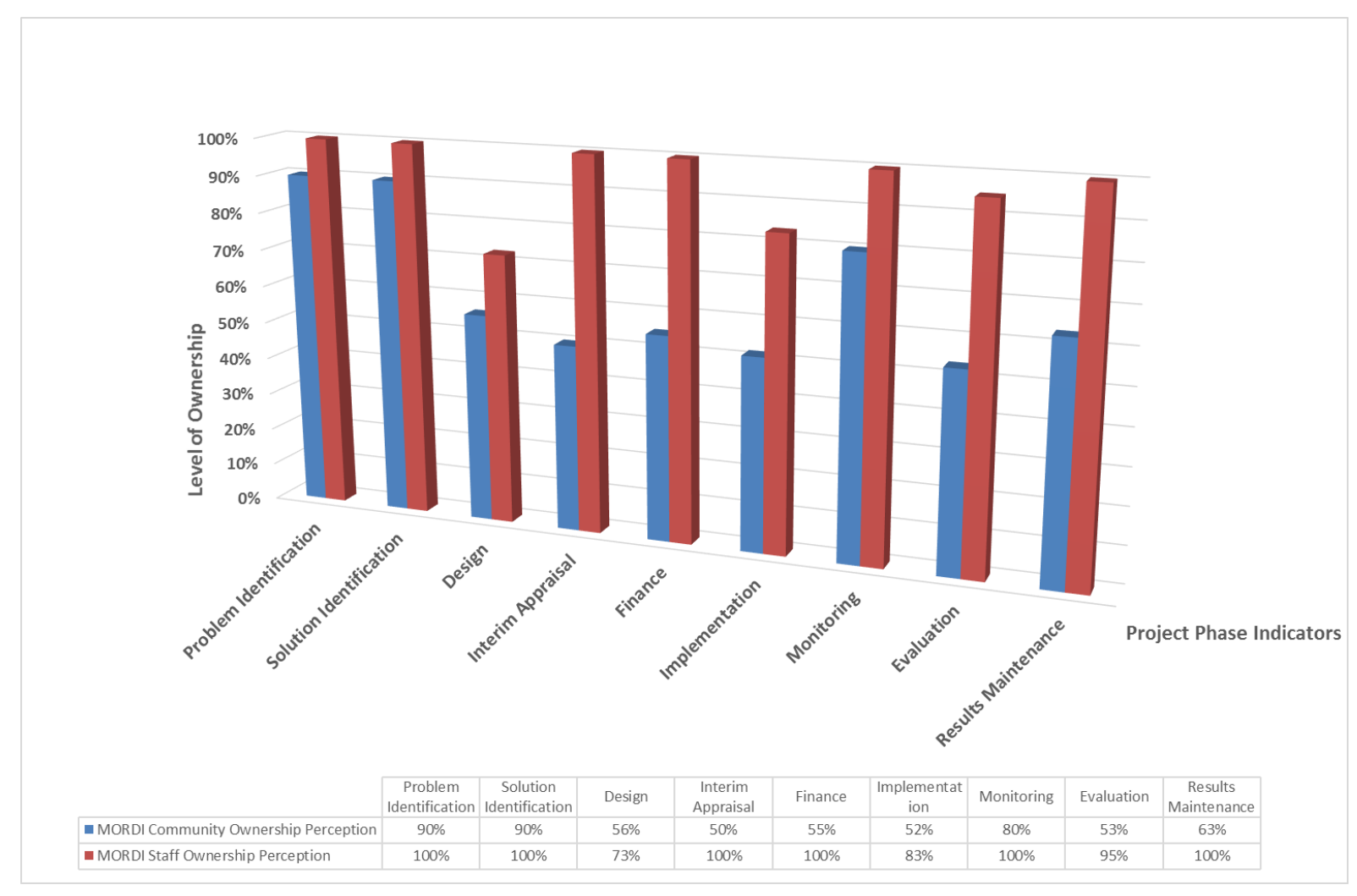

Figure 6.1 - Perceived Levels of Ownership

\section{Project Commencement}

To ensure sustainability of projects, MORDI pays ample attention to initiating engagement and works with all stakeholders, including the government, very closely before the selection and start of the development project. MORDI works with the elders and traditional and church leaders from all the different denominations within the community. To partner with the community and to implement a development project, MORDI informs and invites everyone to preparatory workshops.

The Community Facilitators (CF) working with MORDI and the Town Officers (TO) representing the government each take charge of engaging with the community and informing the stakeholders. They ensure the participation of the community leaders and elders, as well as the women and youth, and make sure that everyone is heard during the meetings and that MORDI intentions are clarified:

Inclusive representation and making sure that everyone within the community is present and engaged when the important development 
decisions are being made is essential for sustainability and Ownership of development results. (Soane, Interview, August 2013)

To identify development priorities, the community is informed in advance of the one-day workshop and the visit of the MORDI staff. The night before each PLA workshop the CF prepares all that is required. For Hunga the CF sought assistance from the TO and a team of volunteers was formed on the island to help organise MORDI's visit.

'Kava'13 was also prepared and served but only for the men, as is the practice in Tonga. (Soane, Interview, August 2013)

It is a tradition in Tonga for all functions to begin with an opening prayer. After the opening prayer, the CF (Alamoti) conducted an opening speech to introduce MORDI, how the PLA seminar would function and its objectives. Then he emphasised the importance of the PLA outcomes and inclusive decision-making and divided the community into three groups: the youth, the women, and the men, and asked each group to identify the problems and the solutions to their problems in Hunga (Ownership Index indicators M1 and M2).

However, the MORDI Director admitted that sometimes the community cannot be divided into appropriate groups. Ensuring inclusive decision-making and everyone's participation is not an easy task, Soane elaborated:

Some communities tend to see development CSOs as unreliable external actors and are doubtful of their intentions, so the men of the community get together and make the decisions for the community before the PLA sessions and on the day of consultation simply present their list of demands, such as the case of the community of Ovaka. (Soane, Interview, August 2013)

\footnotetext{
13 Kava is a plant common throughout the islands of the South Pacific. The roots of the plant are used to produce a drink with sedative and anaesthetic properties which brings about a relaxed sensation to the body and mental clarity. Tongans respect the plant and place a high importance on it. In both Tonga and Fiji, a formal kava ceremony will often accompany important social and political events.
} 
It is difficult for CSOs to argue with community leaders, like those in Ovaka, and perhaps demand a revision of the decisions, making sure that women are heard in the process. According to MORDI staff, in remote communities the decision-making structures are more traditional, so women are expected to support the decisions made by the men of the community. Additionally, not all the members of the community have the interest or the time to engage with CSOs.

A certain level of flexibility is required. Sometimes people participate, but say nothing, as they are afraid of the consequences of expressing their thoughts. These challenges are more obvious in the remote islands. Lack of proper consultation with youth and women naturally influences the level of ownership of development results in the long-term.

\section{Identification of the Problems and the Solutions}

Identifying the problem and the appropriate solution (development project) within the community can have a direct impact on development effectiveness and constitute the first two indicators of ownership that must be seriously taken into consideration if ownership is to be cultivated. The three case studies examined revealed that the most effective development projects are those projects that the beneficiaries have been inclusively engaged from the start in identifying the problems as well as the solutions. The higher the level of participation and project beneficiary engagement at these two stages, the higher their level of ownership of the project outcomes.

The sooner the people are brought into the 'tent', so to speak, and asked to think about the change (development) needed in the community and the solution, the higher the level of ownership of development results. Respect for process is a key aspect of development effectiveness, and must be taken into consideration. Close examination of MORDI's work reveals that the high levels of ownership cultivated are a direct result of partnership with the community from the start and encouragement of the project beneficiaries to engage in identification of the changes needed.

The case of Hunga visibly demonstrates that if the community is properly engaged in identification of the change needed and development projects then there is a strong chance 
that the community will remain engaged throughout the process and maintain and protect the outcomes. The story of Hunga is particularly interesting because, according to Soane, more than $70 \%$ of the community members came together, including the women and the youth of the community, before the project was chosen, to identify the changes needed. This factor played a key role as development progress unfolded within the community and after the project was completed, because the majority of the participants who engaged in making the decisions ended up maintaining and protecting the outcomes.

People were eager in Hunga to bring about change they felt was long overdue so were proactive in their lead and identifying the problems and solutions. At the first PLA meeting held in Hunga in partnership with MORDI, some 19 problems were listed (see Table 6.1) on the first day, but after careful study of the list and long discussion, the people of Hunga decided to first address the most important problem they were facing, which was the main road in their community. Instead of scattering their forces they thought it best to actually focus their resources and first address and resolve the most important problem in their community with the support of MORDI. It is important to note, according to Alamoti, that although women were present and were encouraged to voice their concerns, it was mostly the men that engaged and did the talking.

Women are encouraged to speak out, but this is not always the case because they are not used to it customarily, and because, out of their love, women tend to support the decisions made by the men and the youth of the community. (Alamoti, Interview, August 2013)

The value of PLA is that it invites the women and the youth of the community to the tent and encourages them to think and to talk about the changes they would like to see. People, through this method, are encouraged to make decisions, especially women, and engage with the plans and processes over time and hence consciously, and at times unconsciously, begin to feel that they 'own' the change and the development that is taking place within their community, because it is their own decision. At least, this is what is hoped for, but naturally the consultations are not always a success. Challenges are always present and: 
A participatory process does not always end with rosy outcomes, but it has other positive consequences, such as people reflecting and talking about the changes they like to see. In the process, people also learn about other forms of decision-making and are often encouraged to take action towards the change they desire. (Alamoti, Interview, August 2013)

The more people engage in decision-making, the more they influence the outcomes and feel the commitment and the desire to maintain and protect the results:

With PLA, a new paradigm and a new way of thinking and making decisions is introduced; one in which the old traditional systems of decision-making are challenged and, instead, women and youth are invited and involved in making decisions. (Dr. Seu'ula J. Fua, Interview, August 2013)

This kind of decision-making is not the way things are usually done on the islands of Tonga, or elsewhere in the South Pacific, and all sorts of disagreements occur, but maintaining the discussions and the dialogue is important in ensuring sustainability of the projects over time and fostering ownership:

Making people understand the need for their involvement in decisionmaking is vital. Convincing the men that the women must be engaged is especially challenging. Informing the women and the youth so they can make the best decisions for their own future is another challenge. At the same time, this whole coming together of the community is a success on its own, because it is not every day that women, community leaders, church leaders and youth come together to make decisions. (Dr. Seu'ula J. Fua, Interview, August 2013)

According to the research participants, PLA workshops conducted in Hunga enabled people to benefit from different perspectives, identify shared problems, and develop shared solutions. Identifying the 'why', the 'what', and most importantly the 'how' of development 
projects by the community has made all the difference for the sustainability of the projects implemented by MORDI:

Project beneficiaries must be heard and engaged from the start if ownership is to be cultivated. Everyone must think and speak about the change they want to see. The hierarchy of traditional power is complex. Hence it is vital to ensure that everyone is genuinely involved and that all 'voices' are heard, especially women. (Dr. Seu'ula J. Fua, Interview, August 2013)

Over the years and based on experience, MORDI has focused more on bottom-up methods for development aid, encouraging the project beneficiaries to engage more and lead change. Observing the outcomes of a diverse range of projects implemented by MORDI and speaking to the MORDI staff and project beneficiaries about the lessons learnt, shed ample light on the importance of accountability downwards to the people, authentic participation, and an enabling environment - all important factors and essential characteristics for cultivating ownership.

After the community has identified the problem, the facilitators embark on helping the community to identify the solution. The brainstorming sessions are always useful. According to Soane and Alamoti, some issues that appeared to be repeatedly mentioned in the long list of problems in the community of Hunga were merged under a single over-arching title. For instance, issues such as lack of water tanks, no water pumps, and poor water supply systems were all merged into No Ground Water Pump System (see 6.1 \#17). Other problems such as lack of pig-fencing were also identified and added to the list of community needs:

After completing the first stage, the problems identified were reviewed by everyone and prioritised. It was remarkable to note how prioritisation of the problems signified the shift in the mind and vision of the community, and helped the people to beter plan and make the necessary decisions. (Alamoti, Interview, August 2013) 
According to Alamoti, a simple matrix has been adopted by MORDI over the years, based on experience, whereby all the problems identified are compared with each other. This technique gives equal opportunities to the participants, either in gender-specific groups or in single community groups, to thoroughly assess solutions to every single problem. MORDI encourages lively debates, and consensus amongst the participants over significant issues is mediated by MORDI. This means that the whole group shares a common understanding of the issues at hand. The frequency with which each problem occurs is recorded horizontally and vertically to a matrix, which gives a total score (frequency of occurrence) for each problem. According to MORDI staff, normally the problem with the highest frequency of occurrence is given the highest rank. Where several problems have equal scores, the groups are given another chance to decide which problem should receive higher ranking over another.

The majority of the people of Hunga engaged in formulating specific development plans. This was necessary and is the usual strategy for MORDI to engage with each community, encouraging each group to envisage their challenges and possible strategies to address the needs and solutions. There were specific issues in Hunga, as elsewhere when PLA is conducted, which had to do with different groups wanting different things. For example, women as a group, initially sought household fencing, bathrooms, and better toilets, while the youth indicated the need for training in art and having a proper sports facility. Selecting development priorities is not easy given the diversity of the needs of each group. As a result, MORDI formulated criteria to rank the problems identified by different groups in the community.

The methodology used by MORDI is as follows: common problems and concerns raised in all three groups (women, youth and men) are considered the highest-ranked community concerns. Issues raised both by women and youth are given the second highest ranking. Issues raised in common by women and men's group become the third priority. Next are issues raised by youth and men's groups and finally issues ranked by men's group only.

Interviews with community members revealed later that women of Hunga did not feel comfortable voicing some of their concerns and primarily thought about what the men and 
the youth of the community want, while neglecting their own needs. At the same time, women constitute $50 \%$ of the population and they play a key role in maintenance and protection of development outcomes, as the three case studies in this research revealed. Therefore, the more women are engaged and the more they reflect on and express the changes they would want to see and maintain, the higher the overall level of ownership of results. However, one serious limitation to the development process is that women tend to avoid expressing their desires due to traditional norms. Consultation with women is intricate because women tend to remain silent and align their needs with the men and the youth of the community, which means that they feel no ownership of the change in the long term. Interviews revealed that it is especially important to engage women very early in the process, making sure that they are involved from the start, listened to, and encouraged to reflect and to 'voice' the 'change' they desire.

The women of the community must be informed and encouraged to voice their concerns and engage in decision-making if they are to own the development results. In some communities, MORDI conducts a separate consultation with women only. The challenge is to create participatory processes and an enabling environment where women can freely and willingly talk about the challenges they are facing and the solutions they believe are appropriate without the fear of being judged by the men of the community.

Another issue that often surfaces when working with rural communities such as Hunga, according to Soane, is the issue of 'expectation' and how at times the unspoken anticipation of almost a majority of community members is for donors (CSOs) to solve the community's problems. Foreign aid and donor funding is seen as the answer to most problems (see Table 6.1). Hence, most needs identified, as has been the case in Hunga, are immediate needs and there is a lack of consideration for long-term planning to address root causes.

Finally, the most common issue raised by the community members of Hunga was that a partnership cannot be built over one or two days and that project implementers (CSOs) must engage more often with the communities throughout the development process. Often CSOs engage with their project beneficiaries at the start of the partnership, but their presence fades as the project advances: 
Development results are effective when there is a dialogue between the partners throughout the development process (Alamoti, Interview, August 2013)

\section{Community Development Plan (CDP)}

After the first day of debate, Alamoti, who was acting as the CF, articulated that the ultimate challenge for him on this day was to write up all the concerns raised by the people and to formulate an overall Community Development Plan (CDP). With the help of the CDP, the community then identified the cause of the problems and their potential solutions.

The output column of the PLA showed that building a good road was the most important issue of concern for everyone in Hunga, which according to the community members was the beginning of a very interesting journey of community-driven change. Furthermore, the final issue discussed on the first day was funding and the potential partners for assistance in order to achieve the community objectives. Looking back, Alamoti said:

What was remarkable to note on the day MORDI brought the community together in Hunga for the consultation was how lively the dialogue was; and how everyone, including the women and youth, participated and shared their ideas and the elders listened. (Alamoti, Interview, August 2013)

Each group created a chart on the day of consultation. At the end of the day all the charts were hung on the walls by the MORDI staff. The details were later translated into English for the purpose of sharing with potential donors. As

A simple and community driven development plan was thus amalgamated from identification of the needs as seen in Table 6.1, which compiles the list of all problems identified by the people of Hunga. 
Table 6.1 - Problems and Solutions Identified by the Community

\begin{tabular}{|c|c|c|c|c|}
\hline \multicolumn{2}{|c|}{$\begin{array}{l}\text { LIST OF PROBLEMS } \\
\text { (prioritised) }\end{array}$} & \multirow{2}{*}{$\begin{array}{l}\text { CAUSES } \\
\text { Lack of Funds }\end{array}$} & \multirow{2}{*}{$\begin{array}{l}\text { POSSIBLE } \\
\text { SOLUTIONS } \\
\text { Seek External } \\
\text { Funding }\end{array}$} & \multirow{2}{*}{$\begin{array}{l}\text { POSSIBLE OUTCOMES } \\
\text { Transportation Made } \\
\text { Easier }\end{array}$} \\
\hline 1 & Poor Road & & & \\
\hline 2 & $\begin{array}{l}\text { No Market (for selling } \\
\text { handicrafts) }\end{array}$ & Lack of Funds & $\begin{array}{l}\text { Seek External } \\
\text { Funding }\end{array}$ & More Income \\
\hline 3 & Poor Power Supply System & Lack of Funds & $\begin{array}{l}\text { Seek External } \\
\text { Funding }\end{array}$ & $\begin{array}{l}\text { Able to Use Heavy Duty } \\
\text { Electrical Appliances Such } \\
\text { as Refrigerators, TV, } \\
\text { Washing Machines, and } \\
\text { Iron. }\end{array}$ \\
\hline 4 & No Life Saving Boat & Lack of Funds & $\begin{array}{l}\text { Seek External } \\
\text { Funding }\end{array}$ & Less Risk of Death \\
\hline 5 & Poor Household Fencing & Lack of Funds & $\begin{array}{l}\text { Seek External } \\
\text { Funding }\end{array}$ & Village More Attractive \\
\hline 6 & No Cement Stove & Lack of Funds & $\begin{array}{l}\text { Seek External } \\
\text { Funding }\end{array}$ & Efficient Cooking \\
\hline 7 & Poor Bathrooms/Toilets & Lack of Funds & $\begin{array}{l}\text { Seek External } \\
\text { Funding }\end{array}$ & Healthier Living \\
\hline 8 & No Lawn Mower & Lack of Funds & $\begin{array}{l}\text { Seek External } \\
\text { Funding }\end{array}$ & More Attractive Village \\
\hline 9 & No Mat Weaving House & Lack of Funds & $\begin{array}{l}\text { Seek External } \\
\text { Funding }\end{array}$ & Work Made Easier \\
\hline 10 & Lack of Technical Skills & Lack of Funds & $\begin{array}{l}\text { Seek External } \\
\text { Funding }\end{array}$ & $\begin{array}{l}\text { Revenue For The } \\
\text { Community }\end{array}$ \\
\hline 11 & Lack of Sport Facilities & Lack of Funds & $\begin{array}{l}\text { Seek External } \\
\text { Funding }\end{array}$ & $\begin{array}{l}\text { Sources Of Income To } \\
\text { Support Livelihoods }\end{array}$ \\
\hline 12 & $\begin{array}{l}\text { Lack of Revenue Generating } \\
\text { Activities }\end{array}$ & $\begin{array}{l}\text { Early School } \\
\text { Dropouts }\end{array}$ & $\begin{array}{l}\text { Seek External } \\
\text { Funding }\end{array}$ & $\begin{array}{l}\text { Revenue For The } \\
\text { Community }\end{array}$ \\
\hline 13 & $\begin{array}{l}\text { Difficulties in Transportation } \\
\text { of Heavy Cargo }\end{array}$ & Lack of Funds & $\begin{array}{l}\text { Seek External } \\
\text { Funding }\end{array}$ & Workload Made Easier \\
\hline 14 & No Proper Fishing Tools & Lack of Funds & $\begin{array}{l}\text { Seek External } \\
\text { Funding }\end{array}$ & Income Increases \\
\hline 15 & Shallow Causeway & Lack of Funds & $\begin{array}{l}\text { Seek External } \\
\text { Funding }\end{array}$ & $\begin{array}{l}\text { Transportation Made } \\
\text { Easier }\end{array}$ \\
\hline 16 & $\begin{array}{l}\text { Deteriorated Boundary } \\
\text { Fencing }\end{array}$ & Lack of Funds & $\begin{array}{l}\text { Seek External } \\
\text { Funding }\end{array}$ & Crops Protected \\
\hline 17 & $\begin{array}{l}\text { No Ground Water Pump } \\
\text { System }\end{array}$ & Lack of Funds & $\begin{array}{l}\text { Seek External } \\
\text { Funding }\end{array}$ & $\begin{array}{l}\text { Community Living } \\
\text { Standard Improved }\end{array}$ \\
\hline 18 & Poor Pig Fencing & Lack of Funds & $\begin{array}{l}\text { Seek External } \\
\text { Funding }\end{array}$ & $\begin{array}{l}\text { Clean and Attractive } \\
\text { Community }\end{array}$ \\
\hline 19 & $\begin{array}{l}\text { No Emergency Rescue } \\
\text { Facilities }\end{array}$ & Lack of Funds & $\begin{array}{l}\text { Seek External } \\
\text { Funding }\end{array}$ & Safer Community \\
\hline
\end{tabular}


Analysing the problems and solutions identified by the community (Table 6.1), it is interesting to note how all the causes of the community problems are associated with "lack of funds", and how the solution to all the problems addressed by the community members is to "seek external funding". Numerous conclusions can be drawn based on the chart above: most importantly how both the people of Hunga (at least while engaged in a PLA) and the CSOs in general view donor funding as the first and the last solution to community problems instead of actually nurturing ownership of development challenges and questioning how an individual or the community can self-actualise, make use of available resources (although limited) and to activate community capacities and potentialities.

Therefore, a major challenge for development CSOs such as MORDI, is to encourage the communities to think and to tackle the root causes of their problems themselves, and to find their own solutions to their challenges. The chart above highlights a common side effect that reflects lack of self-sufficiency, which, as revealed in this research, is an international development side-effect, because aid, no matter how effectively delivered, fosters a culture of dependence.

Some community members were sceptical of the MORDI workshops and the PLA process overall. They said that more time was needed and more lasting engagement. They felt that a one-off consultation does not constitute an authentic partnership. More time and engagement is needed to understand the culture and the indigenous knowledge. Most importantly, MORDI ignores the strengths of the community and the PLA process is simply concentrated on the problems that the community is facing.

According to one of the MORDI staff engaged in the process, majority of CSOs and donors in general place too much stress on how to obtain external assistance and the 'problems' within the communities they work with, while they should also help the communities they work with to identify their own strengths, instead of their weaknesses, and to build on their assets, no matter how insignificant those assets are to start with:

There is no doubt that starting with the positive, asking people 'what works'? What they consider their 'strength', rather than 'what are your problems', can be more effective. (F. Mauitau, Interview, July 2013) 
Starting a partnership on the positive and building on the strengths of the community can potentially be very effective and this idea often surfaced. Many research participants argued that this is MORDI's main weak point. Soane, however, in response stated that this is something that MORDI management is thinking about and over time will ensure greater emphasis on the community's strengths.

\section{Funding, Design and Appraisal}

After the CDP was completed the young residents of Hunga came together and thought about possible solutions to fund the construction of the road. As a result of discussions held they decided to build a social networking website for the community to raise funds and to keep overseas families and friends up to date with their objectives. The youth on the island created a website, along with the details of the community's development plans and a barometer of the money collected for building the road.

It was not easy at first, but then persistence paid off and the community was motivated:

The community was divided and there were some sceptics, the core of the community who had engaged in the initial PLA were persistent and successful in raising their share, tapping into their own savings, and family members living abroad. The fact that the community decided, instead of being offered a development plan, made a difference. It is being involved in making of the decisions that cultivates the seed of 'ownership' of development outcomes. (Alamoti, Interview, August 2013)

Because not all communities have the capacity, funding and technical expertise to complete their development objectives, CSOs like MORDI play an important role:

Informing and empowering the communities to identify the changes needed and to take the decisions towards desired goals while making sure that the dialogue is ongoing throughout the development project is a major responsibility for CSOs. (S. Fua, Interview, August 2013) 
Providing a portion of the funding required for the project, MORDI then encouraged and helped the community in their pursuit for further funding for the rest of the project costs. MORDI only partially funds development projects, motivating the communities to fund their own projects as much as they can:

Encouraging people to contribute financially makes them care more about the project outcomes and makes development more sustainable as it fosters value for money, sense of responsibility and greater sense of 'ownership'. (Soane, Interview, August 2013)

In the case of Hunga, MORDI contributed $25 \%$ of the total estimated funding, and the community was obliged to secure the rest from other sources. In collaboration with MORDI, a team was formed to follow up the development goals. The team drafted a proposal in Tongan along with community elders. In general, MORDI assists the communities it works with to design their development plans, making sure that all project benefits, impacts, and costs are objectively estimated and that the project proposal meets the donor standards. At the same time, MORDI ensures and emphasises the importance of the community lead of the design and the search for funding. According to Soane;

Every phase of a development project is important, securing funding, design etc. Projects are more sustainable, however, when people participate throughout the process at each phase and lead. The more people are engaged, the more effective the outcomes. (Soane, Interview, August 2013)

With the help of MORDI staff, the development proposal was then translated into English and made more technical and appealing to donors. This started the quest for funding to construct the much-needed $1.5 \mathrm{~km}$ concrete road. According to Soane;

On an island where the average income is about US\$58 per month, the community of Hunga raised US\$100,000 from their own savings and from relatives living abroad. The community also reached out and submitted 
their plan to as many donors and potential funders as they could. (Soane, Interview, July 2013)

At first they were rejected, but their persistence paid off. To their surprise, amongst all the donors, the faraway government of India embraced their appeal and indicated concern for their condition and offered financial support towards completion of the road on their remote island. This was surprising and motivating according to one community member.

MORDI board members reflected on the enduring nature of the change that took place in Hunga over the years, and recalled how the community was empowered through the process. The initial success and the fact that they managed to secure the funding for their first development plan stimulated by MORDI gave significant leverage to the community to accomplish more and instigated a solid partnership between MORDI and the community.

Most of the CSOs examined in Fiji and Tonga write the project proposals for their partners because it is difficult to engage people in the design of the projects, especially in writing the proposals for donors, addressing the more technical aspects of development projects. However, MORDI is among very few CSOs in the South Pacific that engages with the communities while designing and writing development projects. As will be highlighted in Chapter 9, design of the development projects is generally an area of weakness and there is a greater need overall for CSOs to encourage the people to engage in writing of the project proposals:

Drafting the project proposals and then the Project Approval Documents has become very complicated in recent years, and the communities are often left out of the discussions around the log frames and other technical aspects of the project design. (Soane, Interview, July 2013)

A characteristic of ownership identified while examining MORDI and the other case studies in Fiji and Tonga is the role of the community leaders. Leaders within each community play a key role in informing and engaging the people in decision-making and the development process, thus cultivating ownership of change over time. Even the best designed 
development projects, according to Soane, can fall apart if the community leaders are incompetent. It is the community leaders that must:

Inform, ensure and encourage everyone to participate, which is a method for cultivating shared responsibility towards common goals. (Dr. Seu'ula J. Fua, Interview, August 2013)

Community leaders are key players in cultivating ownership. They must make sure that partnerships are accountable and that people are appropriately represented, informed and capable to think independently about development results that they would want to maintain and protect over time.

\section{Who Implements, Monitors and Evaluates}

During the few months that the road was being built everyone in the community contributed in some way or another. If the contribution was not financial, it was in the form of labour, and often it was in both forms. Women, especially, participated in building of the road by feeding and taking care of the men as they worked. (Soane, Interview, July 2013)

According to numerous research participants, partnerships, especially when they are accountable and constantly revived throughout the development project cycle, can be crucial and directly influence the level of ownership of development outcomes.

Research revealed that greater community engagement is needed when a project is advancing, during the monitoring, and particularly during evaluation of the project outcomes. Ownership can be promoted strategically throughout the project cycle and monitoring stages if people are invited to discuss their challenges as projects progress. That way, people are able to steer and influence development outcomes.

What works best must be identified by the project beneficiaries. Efforts should be made by project implementers to ensure all stakeholders are included in the dialogue. If budget permits, a person or a team can be established to work solely on monitoring the project and ensuring appropriate engagement with the community towards changes desired by the 
project beneficiaries. According to the NLU Director in Tonga, this approach is unheard of in Tonga or any other South Pacific Island state as:

CSOs normally struggle financially and can hardly make the ends meet and never have enough funding to conduct appropriate monitoring of their projects. Equally, there is never appropriate consultation made with the project beneficiaries when CSOs or donors conduct end of project evaluations, which are normally conducted by external consultants. (S. Ilolahia, Interview, July 2013)

There is plenty of room to improve the engagement of the project beneficiaries in the process. Among other factors evaluations must take into particular consideration the level of ownership of the projects by the communities and how ownership of projects can be enhanced. Soane admitted that:

Establishing an effective and efficient monitoring and evaluation system is a major challenge for MORDI and it is the weak point of the majority of CSOs. (Soane, Interview, July 2013)

The case of MORDI shows how cultivating ownership requires new ways of thinking, working, and changing of the firmly held mind-sets and already established practices. The MORDI case study also reveals how it takes leadership, initiative, strategy, and especially time to revive ownership through calculated interventions throughout the development process. The partial measurement of ownership felt and captured by the Ownership Index assisted in documenting stakeholder perspective, revealing that the more robust the project beneficiaries' engagement with the development process at each phase, the higher the level of ownership of the results by the people.

Soane admitted that MORDI lacks capacity and resources to actually engage the communities more in monitoring and evaluation projects. At the same time almost all research participants within the community emphasised the importance of monitoring and of strengthening partnerships towards greater ownership of development projects as 
projects advanced. Equally, it is essential to conduct a thorough evaluation and to ensure inclusive engagement of the project beneficiaries:

The project beneficiaries must be particularly involved in monitoring and especially evaluation as their perspective and input can be crucial for greater effectiveness of future development projects. (Alamoti, Interview, August 2013)

At the same time, it is important to recognise that capturing the lessons learnt and monitoring and evaluation of projects are not in themselves magic wands that can be waved to ensure ownership; they are not the ultimate solution, but like other indicators of ownership highlighted by the Ownership Guidelines and the Ownership Index, are important points of intervention throughout the project cycle that can influence project outcomes, and contribute to cultivating ownership, making development aid more effective and sustainable.

\section{Who Maintains and Protects?}

The community of Hunga today maintains and protects the outcomes of the road project, which indicates their ownership of the development outcomes. A road committee action group has been created with the task of maintaining and repairing the road when need be. The committee has been successful in raising further funds from the island residents and relatives living overseas through their online social networking and their website. The community today preserves a specific bank account for the purpose of maintenance and protection of the road. According to Soane, a year after the road was built a reunion was held in Hunga:

Approximately some 300 community members returned to Hunga to celebrate the road which was a unique occasion. Most had contributed financially to development of Hunga. During this reunion, they commented on the extent of changes that they had observed on the island. They were inspired by what their own community has achieved. (Soane, Interview, August 2013) 
Observing and analysing MORDI, and how it engages with the communities it serves was informative because it helped to illuminate the complexities of ownership throughout the development project cycle. However, the interviews with community members and MORDI staff also exposed additional complex cross-cutting concerns. These issues must be taken into consideration in addition to the Ownership Guidelines and the Ownership Index if ownership is to be actively cultivated and for development results to be sustainable and maintained by the community. These cross-cutting themes are presented in the following subsections and referred to as Characteristics of Ownership.

\section{Women and Empowerment}

The first and arguably most important question that constantly surfaced during the interviews was the question of women and their participation in decision-making and the role they play in cultivating, maintaining and protecting development outcomes. Women in the Pacific are particularly polite and often silent. They normally avoid speaking out during traditional community meetings, especially on the more remote islands of the Pacific where traditional values are still predominant. According to Dr. Seu'ula J. Fua, the most obvious challenge for MORDI and other CSOs in general is to ensure women are given their voice, especially during traditional talanoa sessions and in the presence of the elders when decisions are being made:

The most obvious constraint that hinders the participation of women in decision-making is religion and tradition. Old values are still upheld by the society. These values are often based on old biblical interpretations which are still prevalent and must be reformed. (Dr. Seu'ula J. Fua, Interview, August 2013)

Special attention must be paid to raising awareness about women's rights. Women must be particularly encouraged to break their silence and to voice their concerns at the village meetings, making sure that they are aware of the consequences of the decisions that are being made and the expected development outcomes. It is also essential that the men of the community are properly educated and made aware of the importance of women's rights: 
Men must be educated on women's rights issues and they must learn to 'listen' to the women of the community. Young girls, especially, must be educated, given 'voice' and empowered to participate in decision-making if development is to be effective, lasting and sustainable. (Dr. Seu'ula J. Fua, Interview, August 2013)

Community planning and development will be more effective and sustainable when women are informed and appropriately engaged during each stage of the development process:

Social barriers of respecting 'tapu'14 and 'elders' etc, will be less restrictive as time advances, and this will hopefully allow women to engage more and to lead change. (Alamoti, Interview, August 2013)

The ultimate challenge for the women of the Pacific today (as well as elsewhere in the world) is confronting the old religious and traditional values. As in other regions of the world, old values impede, obstruct and hinder equality and must be revisited and reformed.

A term often used by research participants when talking about women's rights and challenges was 'empowerment', which is another loaded development term, and used constantly in development discourse (Chambers, 2013). Eager to understand how the concept is translated into policy and practice within the Pacific context, I asked every research participant, especially those working with the CSOs to elaborate further on what the term meant to them and to their work and observed that it has become another buzzword and has a very broad connotation in practice. Some scholars argue that the term "empowerment, similar to other technical development terms such as 'ownership', 'accountability' or 'sustainability' is unscientific" (Mikkelsen, 2005, p. 30), because there is no one way it can be achieved, and there is no agreement amongst stakeholders as to what it really means and how it is best promoted. In addition, there is the problem of language and the challenge of translating of the concepts.

\footnotetext{
${ }^{14}$ Tapu is a Polynesian concept denoting something holy or sacred, with "spiritual restriction" or "implied prohibition"; it involves rules and prohibitions. The English word taboo derives from this later meaning and dates from Captain James Cook's visit to Tonga in 1777.
} 
The term 'empowerment' is fashionable today and is used by most of the development leaders and CSOs. Some research participants argued this 'empowering' of the individuals and the communities is another way ownership of change can be cultivated. The case study presented in Chapter 8 will delve further into the concept of empowerment and will reveal how it can actually lead to ownership, but ultimately empowerment is about the capacity to take action, or enhanced decision-making, especially in a context where power for decisionmaking has been denied, for which the only solution is active "participation and representation of the group (disempowered) in political, social, and economic change" (Mikkelsen, 2005, p. 210).

The term 'empowerment' today is used broadly by all manner of donors and CSOs in Fiji and Tonga and, similar to the concept of ownership, it can benefit from further clarification. Interviews and research in general revealed that the term 'empowerment' today in Fiji and Tonga broadly refers to a range of development needs such as access to information and better participation, and often refers to the strengthening of the capacity of the individuals and organisations to work for common interests. However, it is women and especially young girls who must be particularly empowered, as they are constantly marginalised while they play a key role in shaping the future.

According to Dr. Seu'ula J. Fua, the introduction of Christianity to the Pacific Islanders has been positive overall, but it has also resulted in adoption of sometimes passive approaches, especially in the lives of women. The sense of empowerment and self-determination has vanished in the psyche of men and particularly women on the Pacific Islands with the introduction of Christianity over time, and has been replaced by a general inclination to 'accept the will of god' and the belief in destiny. This is also evident with other religious societies elsewhere in the world;

Submission to god and his 'will', has taken the place of self-determination. This is mainly due to the impact of religion, which is complemented by a sense of living in the day-to-day, and accepting the 'will' of god, with little planning or self-determination. (Dr. Seu'ula J. Fua, Interview, August 2013) 
Thus, 'empowerment', as understood from the interviews and from observation of the work of MORDI in the communities, is a social process of developing the collective capacities of people, especially women and young girls, so that they can take action, voice their concerns, participate in decision-making and bring about change they consciously desire and would want to maintain and protect over time.

\section{Donor Criteria}

Finally, the last issue that surfaced while examining MORDI was the unavoidable condition and the necessity for aligning community needs with the donor criteria and 'marrying' (so to speak) of the community needs and donor criteria for being eligible to receive donor funding.

Triangulation of the interviews with research participants at different levels of aid and development hierarchy (donors, CSOs, and community members) provided a better understanding of the dynamics of the stakeholder engagement. Interviews with MORDI funders (IFAD), MORDI staff and MORDI project beneficiaries was informative and provided various perspectives on development challenges, in particular, indicating that development aid has been historically a top-down process, but that approaches to decision-making and development aid planning are changing:

IFAD today aims to enable the poor to determine, to participate and to benefit from their own thinking, planning and decisions when possible. (S.

Tubuna, Interview, July 2013)

In a document, IFAD (Anríquez \& Stamoulis, 2007) admits that most development projects in the past were designed with minimal input from project beneficiaries and the poor themselves. Instead, IFAD as an extended arm of the UNDP with technical expertise primarily used its own 'expert judgement' and experience to decide on project features for developing partner countries.

During implementation, historically and habitually IFAD candidly admits that "beneficiaries were generally treated as passive recipients" (IFAD, 2012, p. 11). Some of the needs of the people were so obvious that many CSOs would engage in assisting the communities without 
proper inclusive consultations with the potential project beneficiaries or any consideration for the ownership of development outcomes in the long term. In most cases, assumptions were made based on obvious needs.

Recent changes and mainly the Paris Principles of Aid Effectiveness, although only demanding country ownership, have influenced donor approaches. Therefore, UNDP and its branches, such as IFAD, and CSOs that work with t hem, such as MORDI, are progressively changing practices and are reflecting on building more authentic participatory processes where people are more engaged in decision-making. A number of research participants emphasised this shift towards people, and the emphasis on engagement with project beneficiaries that was previously unheard of:

CSOs should explore local knowledge becuase people (potential project beneficiaries) have the answers to their problems themselves. Exploring the local knowledge is however not easy and requires trust, legitimacy and accountable partnerships. (Dr. Seu'ula J. Fua, Interview, July, 2013)

As observed in Chapter 3, the global discussion has shifted from how to improve the Aid Effectiveness Agenda and systems and obligations around country ownership and the transfer of funds between the governments to a more detailed exploration of options on the ground and amongst the people for improving development effectiveness. This includes the role of the people, how decisions are made and the accountability of the CSOs that are collaborating with them at the grassroots.

\section{Conclusion}

The MORDI case study provided an opportunity to reveal how promoting and cultivating ownership of aid by the project beneficiaries can result in more effective and sustainable development results. Examining MORDI helped to identify, and verify the ingredients of ownership. It also helped to generate a better understanding of the complexities of ownership and how it can be partially measured. The case of the MORDI clearly indicates that development projects that are 'owned' by the project beneficiaries are more effective and sustainable over time and that ownership of development outcomes can be deliberately 
woven into the project cycle, producing results that people feel they 'own' and commit to maintain and protect over time.

The MORDI case study reveals that development projects are much more sustainable when people take ownership of the development process and are engaged inclusively in decisionmaking from the start, and when local intelligence and ideas are explored and included rather than superimposing of external ideas onto local problems.

Most importantly, the case of MORDI highlights the important question of accountability, leadership, legitimacy of development actors and the important role of women in decisionmaking at each phase of the project cycle, and how taking these characteristics into account can progressively create a culture of self-determination, independence and eventually ownership of development change.

Civil society, as observed in the case of MORDI, is capable of connecting to the grassroots, unearthing local diverse knowledge, perspectives, and aligning community demands with national development policies and donor criteria. Civil society is equally expected to uphold accountable partnerships, to be legitimate and to lead governments and the private sector in promoting accountability, which means cultivating ownership of change and development outcomes that the people would commit to maintain and protect over time. 


\section{Chapter 7}

\section{Ola Fou}

\section{Introduction}

This second case study examines another civil society organisation (CSO) active in the South Pacific called Ola Fou (meaning "New Life"), which is renowned for upholding indigenous values and being community driven. Observing Ola Fou facilitated further analysis of the concept of ownership. As it will be observed in this chapter, Ola Fou has been effective particularly in encouraging the communities it has worked with to use art, especially photography as a tool for self-determination and cultivation of development results that people would want to maintain and protect over time. Analysis of Ola Fou further revealed other important factors and characteristics of ownership that assist or hinder the cultivation of ownership of development results which will be discussed in detail in this chapter.

\section{Presenting Ola Fou}

Parallel to other case studies, all available online documents and evaluation reports were thoroughly examined before research in the field was initiated. Documents available for review included both primary and secondary sources. Most of the documents reviewed were generated by Ola Fou or were developed by external reviewers or agencies ${ }^{15}$ and given to me by the Ola Fou staff. Once in the field, I talked to as many Ola Fou project beneficiaries as possible. I encouraged research participants to talk about their understanding of ownership, what it means to them, the policies and practices in place and the challenges of ensuring ownership in their view.

\footnotetext{
15 Links to the documents examined:

a) http://www.praxispacific.org/olafoupasifika

b) http://www.aid.govt.nz/media-and-publications/development-stories/july-2013/ola-fou-youth-agents-change
} 
In general, Ola Fou tends to implement small scale development projects, such as building a wooden bus stop, building a water tank or starting vocational training for single mothers in a community. Tracing these small development projects and how their outcomes have come to be owned by the people provided an excellent opportunity to observe and understand how ownership can be promoted and cultivated.

\section{The Context}

The percentage of young people in both Fiji and Tonga is significantly larger than all other population groups and they are facing numerous challenges. Ola Fou is among very few Civil Society Organisations (CSOs) that are addressing the challenges the youth are facing. In Fiji and Tonga, the 15-24 year age group accounts for more than one-third of the adult working age population. This sheer weight of numbers and the particular challenges that the youth are facing creates pressures on the governments of Fiji, Tonga and other Pacific Island states, but they "do not have the capacity to appropriately address the concerns of the youth, especially the challenges they are facing in the area of education and unemployment" (Ware, 2004, p. 2) and this is one reason the work of Ola Fou is valued.

The Pacific Islands are facing some radical challenges environmentally and socially and these have a direct impact on the lives of the youth. In most cases, the youth in Fiji and Tonga are making their way from far-away remote islands to the main cities to find jobs and educational opportunities.

The common obstacles the islanders are facing, such as climate change, are bringing the people into closer proximity. On the other hand, customary influences and traditional structures are going through a transition. The physical and spiritual challenges of the Pacific youth are exacerbated by low levels of education, and limited economic and social opportunities. In short, there are very few opportunities for upward mobility or room to improve living standards (Curtain \& Vakaoti, 2011).

Hence, most of the Pacific youth want to leave their islands as soon as they get older, as they face frustrations in various areas and seek greater opportunities. The work of Ola Fou targets these youths and encourages them to identify and act on the changes they 
themselves desire. Therefore, the aim of this study was to understand how Ola Fou addresses these issues and promotes self-determination and ownership of change.

\section{Background}

Ola Fou is an initiative aimed at developing youth and community workers from churches and villages across the Pacific and is funded mainly by the New Zealand Ministry of Foreign Affairs and Trade (MFAT) and other donors, primarily TEAR Fund New Zealand and Australia. Ola Fou has a reputation of being organic and well connected to the communities it serves and has successfully managed to align its work and thinking with the indigenous Pacific culture and context. Originally it was founded based on the Youth Empowerment Strategy (YES) Pasifika, which is an adaption of the Youth Development Strategy Aotearoa, and is informed by best practice (Pitanoe, Korocowiri, Martin, \& Davidson, 2012).

Over time Ola Fou has become an indigenous South Pacific CSO which, like MORDI, engages with Pacific youth based on participatory approaches. Ola Fou staff trains youth living across six of the South Pacific Islands including Fiji and Tonga. The youth selected are nominated by their communities. Once under the Ola Fou wing, they are taken through a journey of selfdetermination and conscientisation, which will be discussed further in this chapter.

Ola Fou is led by a group of indigenous Pacific Islanders who understand and recognise the diversity of Pacific cultures and the diversity of people's needs, and focuses primarily on developing indigenous ways and tools to address development challenges. There is a strong theoretical grounding to Ola Fou, which makes Ola Fou stand out amongst other CSOs. Ola Fou is interesting to observe, particularly from an ownership viewpoint, because it encourages the project beneficiaries to think, to take action and to lead the entire development process.

Since 2006, some 150 youth in the six Pacific Islands countries of Solomon Islands, Vanuatu, Papua New Guinea, Samoa, Fiji, and Tonga have been trained by Ola Fou. These 'youth leaders' (from now on referred to as alumni) are active development leaders and practitioners in their own right. Some are still working for Ola Fou as trainers, while others, after graduation, have moved on to greater opportunities. The value of their knowledge 
derives from the training they received from Ola Fou and their experience of engagement with communities to instigate and complete development projects identified by the communities themselves.

Ola Fou youth leaders are trained in development project management skills, research approaches, evaluation methodologies, financial management and stakeholder engagement. By concentrating first on themselves and their own personal development the alumni learn to use their skills to promote their own personal wellbeing (physical, social, spiritual, and mental health). They then receive training in counselling, negotiating, and teaching and are assessed on their ability to apply these techniques in their communities.

In other words, Ola Fou trains individuals (mainly youth) who then go back to their own communities to instigate positive change and to initiate development projects identified by their own community. Emphasis is placed on the development of mentoring skills, communications and leadership. The approach adopted by Ola Fou helps Pacific youth develop the necessary skills and confidence to engage with the communities and to ask the right questions, instigating change from within the communities.

What makes Ola Fou different from other CSOs is the practical component to the training programme. Interactive, participatory models of learning as well as practical skills are widely used alongside the theories of knowledge with the aim of raising the level of each individual's consciousness. Ola Fou trained staff then take their practical skills to the community settings. Most assignments involve undertaking community-level activities, such as bringing together the youth of the community to identify a need or an expected goal, and to lead the process of change, primarily guiding the engaged community members to lead relying on local knowledge and resources within the communities.

During my research in Fiji and Tonga, I met with Ola Fou staff and students and visited some of the communities that Ola Fou has been involved with. The aim was to understand what ownership of development and change means and how it is cultivated in the context of their work, and to assess the impact of their completed projects and understand and measure the level of ownership of the projects they have completed. These discussions with a variety of 
Ola Fou youth leaders and community members resulted in a series of observations on ownership and how it can be cultivated, which I will share in this chapter.

\section{Why Ola Fou?}

As evidence reveals and as argued throughout this thesis, development aid is more effective if the questioning, the thinking, the identification of the problems and the solutions are determined by the individual or the community and the potential project beneficiaries rather than offered as solutions by external actors.

Ola Fou is a particularly interesting case study because it endorses this thinking strongly and concentrates on self-determination, encouraging the people within the communities to look within, to think carefully about the change they desire and to make their own development goals and plans. This way, Ola Fou brings about change that is desired and maintained by the individuals and the communities it serves in the long-term, or in other words, cultivates ownership of development outcomes. Ola Fou is innovative, it is using new tools and unconventional and indigenous strategies, making sure that people reflect carefully on the changes they want to see, maintain and protect in the long term. One of the Ola Fou alumni who played a key role in guiding this research stated:

Citizen-driven approaches are more sustainable and effective because they reflect what is needed by the individual or the community rather than imposition of outside agendas. (A. Waqetia, Interview, July 2014)

To understand how Ola Fou achieves this goal, I conducted interviews with Ola Fou project managers in Suva and Nukualofa, spoke with the alumni and spent ample time in the communities with the project beneficiaries on the islands. I also attended Salt Society meetings in Suva where I met many of the Ola Fou alumni who come together in these meetings to discuss their achievements and future plans. Salt Society members welcomed me to their group, endorsed my research and talked about the importance of ownership in their view and details of their work, the development projects they have implemented in the past, and how they think ownership is cultivated over time. 
Salt Society meetings are organised monthly by Ola Fou. These meetings allow the youth leaders to exchange ideas, to give each other support, and to plan for the future. Eleven of the Ola Fou alumni indicated strong interest in participating in this research, and assisting me in understanding the mechanics of their work and how ownership is cultivated.

The research participants were encouraged to tell their stories of partnership in detail throughout the development project cycle and to talk about the specifics of the development process and the different stages from start to finish, given Ola Fou has no explicit policy on promoting ownership. I engaged with both the Ola Fou staff and community members and sought their perspectives as to how ownership was promoted (if at all) and the challenges they faced. The Ownership Index served as a practical tool in the process as it assisted me in capturing and illustrating the complexities of ownership at work at each phase.

\section{How Ola Fou Promotes Ownership}

As highlighted in Chapter 6, leadership is an important factor when it comes to the development effectiveness of CSOs and can make all the difference. Ola Fou is another example of how the success of a CSO is often dependent on the person who runs the organisation and how effective one individual can be. The founder of Ola Fou, Lloyd Martin, has worked with Pacific youth for more than 20 years. Lloyd established Ola Fou in 2006, after many years of work with Māori youth in New Zealand, and since has been active in six Pacific Island countries. Lloyd is inspired by the thinking and philosophy of Paulo Freire (Freire, 1968), and uses the camera and photography in addition, as a tool to cultivate change and promote self-determination.

Each year since 2006, Ola Fou has selected a group of 30 willing individuals with the guidance of their own community and through a rigorous process and has brought them together in carefully designed workshops that last up to 16 months. During this period, participants learn through their training to think and to define the world around them from their own perspective. As Paulo Freire encourages (Freire \& Freire, 2004), they learn to question the nature of their own historical and social situation. They learn to think, to ask

important questions, and to envision the change they desire, thus enabling themselves to 
act as proactive facilitators of positive change within their community. Freire argues that to achieve critical consciousness and to create lasting positive change, individuals must learn to reflect within, to think, to ask questions, take decisions, act and to determine and be the owner of their own actions and labour (Freire, 1968, p. 183), as change will only be meaningful and sustainable when the individual or the community takes ownership of the process.

This viewpoint and philosophy has been adopted by Ola Fou and shapes the theoretical foundation of the organisation. The training offered by Ola Fou is grounded in action-based learning, whereby youth leaders learn together to tackle issues on their own, while reflecting on their actions at each stage. Participants learn through actual actions and practice rather than through traditional instructions. According to the Ola Fou Programme Manager:

Ola Fou training varies depending on the country and the context, but Freire's philosophy of questioning is its backbone and simply aims to raise the individuals' capacity to think independently, to question, and to take the decisions needed to shape her 'own' destiny. (J. Martin, Interview, July 2013)

\section{Method: Conscientisation towards Ownership}

This section discusses in detail the strategies Ola Fou has adopted to assist the youth of the South Pacific. The question of youth and their needs is a key issue both in Fiji and in Tonga. To address this issue, Ola Fou has amalgamated a series of approaches, such as the innovative method of 'conscientisation', 'citizen interaction' and 'participation', while upholding traditional Pacific knowledge at the heart of its approach. But what are these methods exactly, and how do they help Ola Fou cultivate ownership of development aid?

Ola Fou is amongst a very few CSOs in the South Pacific that uses the concept of conscientisation as a tool and a guideline for development. The English term "conscientisation" is a translation of the Portuguese term conscientização, which translates as "consciousness raising" or "critical consciousness". The term is based on observations 
made by Brazilian educator, Paulo Freire and is best summed up in two words: 'action' and 'organisation' (Mies, 1973, pp. 1764-1767).

As people amplify their power to perceive and respond to suggestions and questions arising in their context and increase their capacity to enter into dialogue, not only with other men but with their world, they become transitive. Transitivity of consciousness makes us 'permeable'. It leads us as humans to replace our disengagement from existence with almost total engagement (Freire, 1973b, p. 17).

Ola Fou, in line with Freire's thinking, envisions an ideal education as learning that inspires the learners to think, to ask questions, to take decisions, to organise and to take action towards their own desired development change. In this framework, Ola Fou encourages self-determination. It aims to awaken the individual's capacity to the potential of their own choices and give them the ability to envision the change, instead of being directed. Conscientisation therefore involves encouraging the individual to look within and to see the world from their own perspective. It encourages the individual to engage in a dialogue, to use language effectively and to connect the self to the world through language and through questioning. This process of self-reflection, engagement with the world through language and posing the questions instead of being reactive is what conscientisation refers to, and how Freire generally believed we can best connect to the world around us and become part of the process of changing the world (Freire, 1973b).

This is not a new phenomenon, as Eastern Schools of thinking, such as Buddhism, already highlighted the importance of self-knowledge. Philosophers over the centuries have encouraged their students to develop an impulse and willingness to stand back, think and question. "Know thyself" was the Delphic maxim, according to the Greek periegetic writer, Pausanias (10.24.1), and inscribed on the forecourt of the Temple of Apollo at Delphi:

Know thyself, and know what you want is the kind of education that has been discouraged in the Pacific. Various factors have contributed to the docility of the people in the Pacific Islands, mainly lack of education that would encourage critical thinking, but also the 'culture of silence' inspired 
by Christianity which offers all the answers and the 'right' path, as all religions do. (A. Waqetia, Interview, July 2013)

One of the main challenges of the people of the South Pacific, according to Waqetia and other research participants, is the predominance of the culture of silence ${ }^{16}$ in which citizens are passive in the face of the ultimate truth offered by religions, as well as conventional and traditional norms, and abide as they are told without questioning.

\begin{abstract}
Community members, especially women and youth, are expected to respect the traditional values and norms without questioning. Doubt and questioning of the norms and biblical interpretations is seen as disrespectful to the church and thus thinking and questioning is discouraged. (J. Madraiwiwi, Interview, July 2013).
\end{abstract}

Along these lines of thinking, and from this standpoint, Ola Fou encourages individuals to inform themselves, to reflect, to question the nature of their historical and social situation, and to identify their own priorities while reflecting on the changes they would like to see in their world. In other words, Ola Fou promotes self-reflection and questioning which can result in commitment to creating change that is wanted, maintained, and protected over time by the individual and the community. In this fashion, the goal of Ola Fou is to encourage the communities it works with to think, to question and to decide on the change needed:

Encouraging the communities to think critically, and to identify the changes they want to see is Ola Fou's goal. So many ideas surface when Ola Fou brings the community together and encourages the people to reflect and to contemplate about the changes they like to see. (J. Martin, Interview, July 2013)

\footnotetext{
${ }^{16}$ The term 'culture of silence' was coined by Paulo Freire and describes cultures that accept apathy. A conspiracy of silence, or culture of silence, describes the behaviour of a group that, by unspoken consensus, does not speak. The practice may be motivated by positive interest in group solidarity or by such negative impulses as tradition or fear of political repercussion or social ostracism. It differs from avoiding a taboo subject in that the term is applied to more limited social and political contexts rather than to an entire culture.
} 
Speaking to Ola Fou alumni was interesting as through their training they have developed a critical awareness of their social reality through reflection and belief in action:

Action is fundamental because it is action alone that will change the reality. Ola Fou hence concentrates on learning that uncovers real problems, actual needs and encourages the individuals to think and to take action towards the changes desired. (J. Martin, Interview, July 2013)

\section{The Camera as the Instrument of Change}

The main tool used by Ola Fou to initiate change is the camera. With the help of the camera, Ola Fou encourages and inspires individuals to identify and take photographs of the strengths and weakness of their communities and ultimately what they want to see changed. The photographs permit and steer debate within the community. The photos point to the issues that need to be addressed and they allow an opportunity for reflection and prompt change that is desired, owned and sustained by the community. This method of identifying development goals is inspired by traditional methods of Participatory Photography (Gotschi, Delve, \& Freyer, 2009).

Community members engaged with Ola Fou are taught to use the camera, and they are invited to go back to their communities to photograph what they would like to see changed. The photos taken then help initiate debate amongst the community members and reflection on priorities. The camera is used in this way as an instrument of expression and empowerment for each individual, and gives a voice to the community members who traditionally have had no say. The camera becomes the truth-telling, and the "all-knowing machine" (Sontag, 1977, p. 10) with the capacity to motivate the individuals and the community to identify what they want changed and to transform themselves and their community through art.

The 'truth', so to speak, is captured with the camera and shared. The photos taken by the community members highlight the reality of the community viewed by each individual's standpoint and the changes needed from the community's perspective. The camera becomes a critical instrument for capturing the perspective of each individual. Today we rely 
on the lens and the photos in a range of sciences. Photos taken by satellites give us a completely new point of view. With the help of x-rays or microscopes we can see beyond what our naked eyes viewed previously. A photograph reveals reality. Even our existence as individuals is validated with our photograph as "no passport or identity card is validated without a photograph" (Sontag, 1977, p. 116).

Potential project beneficiaries are encouraged to reflect on the change they desire and to photograph it. Each photograph in this process becomes a question posed:

Photographs are powerful tools of communication, and they offer the chance for the individual or the community to identify the change they seek. The camera in this process becomes the tool by which the much needed change is framed. (A. Waqetia, Interview, July 2013)

The camera and the function of photography are used by Ola Fou to revive Freire's concept of conscientisation and the general notion of reflection on the self and the importance of questioning. Thus, through photography people are engaged and collectively embark on identifying and framing development projects that they would want to maintain and protect over time.

\section{How Ola Fou Works}

Ola Fou works with a number of stakeholders within each community, such as churches, NGOs, community groups, and the government. In this way, Ola Fou ensures that it is the people within the communities who choose the potential candidates and the Ola Fou Youth Leaders.

While in Fiji and Tonga, to better understand the details of the process and how Ola Fou works, I reached out, explained my research and engaged 11 of the Ola Fou alumni who were interested in the question of ownership in this research. I conducted semi-structured interviews, inquired about their experience and listened carefully to their development stories. 
I visited numerous Ola Fou completed development projects on different islands and met with the communities. The alumni were proud to share their stories of engagement and they felt strongly that they owned the development outcomes. Other stakeholders, especially community members, spoke of the Ola Fou youth leaders with respect for their achievements, although some of the youth talked about how they were doubted throughout the process by some of the community members.

To initiate engagement during the first few sessions, the Ola Fou alumni inform and educate the community based on their own knowledge, mainly focusing on the importance of questioning and self-determination. Each of the Ola Fou youth leaders over time forms a support group and networks within the community they work with. In line with Freire's thinking, Ola Fou alumni tend to bond with the communities they serve as they believe that learning and transformation can only take place when an authentic relationship exists between the teacher and the learner;

Authentic partnerships can only grow where there is trust, mutual goals, empathy, respect and a genuine belief by both parties that they can learn from each other. It has been Ola Fou's goal to train leaders who are keen to learn as much from the people they work with as they are able to teach them, which over time ensures a truly mutually beneficial exchange of knowledge. (J. Martin, Interview, June 2013)

Once the alumni have cemented a partnership with the community, the cameras are distributed to those community members who are keen to participate. They are encouraged to take the cameras home, to first reflect on the issues that they want to see changed, and to take photos in the following days. The camera, through this method, becomes the tool for sustainable development and cultivating lasting change.

Photography is a powerful tool for engagement, ad self-actualisation. Using the camera, Ola Fou encourages the people to think about their development goals, and the change they like to see in their community and to frame the change needed in a photograph. (A. Waqetia, Interview, July 2013) 


\section{Ownership Index Analysis}

As with the other case studies, the Ownership Index was used as an additional tool in this case study to document the assessment of the stakeholders, to arrive at a more precise diagnosis of the development results and to capture an estimate of the levels of ownership felt at each stage of the project cycle for comparison and further analysis. The Ownership Index, as described in Chapter 2, assisted in partial measurement of the levels of the ownership 'felt', both by the project implementers and the project beneficiaries at each stage of the development process for in-depth triangulation.

This capturing of the data at each phase of the development process and from both sides of the spectrum, although partial, permitted a more detailed diagnosis of the variances in the perception of the Ola Fou staff compared to the community members, highlighting the discrepancies and areas in which stakeholders can improve engagement more precisely.

The information obtained, compared to other development projects examined and data gathered, revealed that taking ownership into consideration from the start, as Ola Fou does, and reviving the question at identified points of interval as development projects advance, does improve and increase sustainability and effectiveness of development results.

As it can be observed below in Figure 7.1, the Ownership Index also permits the calculation of an overall partial rating of ownership, which for the case of Ola Fou is $71 \%$. Documentation of the level of ownership per project allows more detailed comparison with other projects. The data gathered is an approximation and partial, as highlighted and discussed in Chapter 2, but the data obtained, based on qualitative assessments, permits formulation of a diagnosis to enable stakeholders to highlight the problematic phases of the development cycle and areas that need greater and immediate attention. 


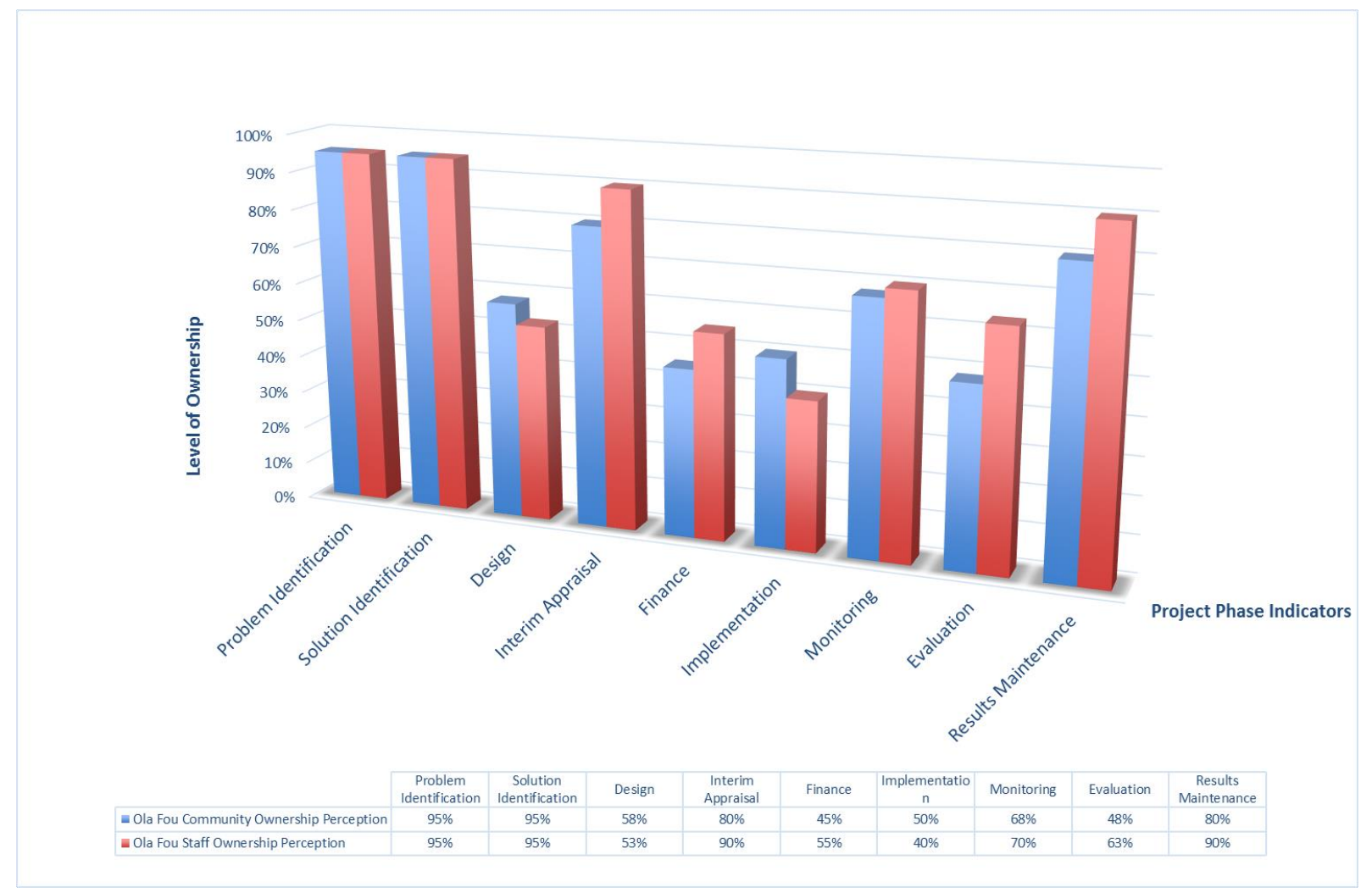

\section{Figure 7.1 - Ola Fou Perceived Levels of Ownership}

The data obtained above, with the support of the Ownership Index, is useful as it permits comparison and detailed analysis, and documents observations of the development process. It is interesting to note, for example, how highly ranked the first two indicators are in the case of Ola Fou projects compared to other case studies, showing solid engagement by the people in Problem Identification and Solution Identification which are naturally related directly to the end results. The camera seems to give a strong voice to the community members for identification of the problems and the solutions, all strongly contributing to cultivation of ownership in the long term. From the partial data gathered above and based on the qualitative assessments, we can more precisely conclude where the problems are and that there are some issues with the Finance, Appraisal, and especially Monitoring and Evaluation stages of the process and that these matters need to be discussed further by the stakeholders.

As with other case studies examined, community members interviewed indicated that they feel a greater level of ownership of development projects implemented by Ola Fou compared to other development projects they have been engaged with in their community 
because they were involved from the start in identification of development goals and actively and inclusively joined the development process throughout the project cycle.

Interviews and qualitative assessments revealed that the women of the community are neglected and not always invited to the initial meetings to identify development goals or engage in other stages of the development process more actively which fosters disparity, indifference and lack of ownership of development results. The complexities and the challenges for cultivating ownership are multifaceted but lack of women's engagement is a priority and needs immediate attention.

In the following sections, I will present the more detailed stakeholder reflections and observations gathered through qualitative interviews which were primarily relied on throughout this research, and permitted the deciphering of the mechanics of ownership and understanding of its complexities at work.

\section{Identification of the Problems and the Solutions}

The responsibility of the Ola Fou youth leaders is to help the community inclusively select the most important issue amongst the problems identified by the community members with the help of the camera. Ola Fou staff are trained to facilitate debate and are familiar with different methods of participation. With the help of the photos they start the debate within the community and encourage the community members to speak out, to debate and to identify the one project or problem the community would want to focus on. Identification of development goals by the community and ensuring consensus on expected results is a delicate task, and the youth leaders play a crucial role in the process, ensuring that everyone is given a voice.

This can be difficult as there is the barrier of traditional norms, and not all community members are interested and keen to participate. At the same time, given that this is a new approach and a process of self-exploration through the camera, community members, especially the youth, do tend to want to participate, as it provides them an avenue for and selfactualisation. (J. Martin, Interview, July 2013) 
To initiate engagement with the community:

Ola Fou alumni discuss and highlight the importance of critical thinking and questioning. (L. Lewa, Interview, July 2013)

The community members are informed and taught about the Ola Fou participatory photography method before they are sent back into their communities with cameras to photograph and to identify what they appreciate in their community but more importantly what they would like to see changed. The camera, as observed through the index, is very effective during this stage.

Once they have completed their assignment, which sometimes takes a week or two, the group convenes again. At this time, they look at the photos and talk about the pros and cons of living in their community and the kind of changes that the participating members would like to see. Each person takes the time to explain why they took the picture, the strengths of the community they have observed and especially the problems they have identified. These meetings sometimes last a long time and the debate is heated and interesting. Ola Fou at this stage provides strong support.

According to one of the Ola Fou alumni:

The sharing of the pictures and the participation that normally occurs before the projects are identified can be at times emotional. The process of questioning is very revealing both at the individual level and at the community level. (L. Lewa, Interview, July 2013)

For some community members, this is the first time they have engaged in a participatory process and the first time they have openly discussed the challenges they are facing in their community and how these challenges can be resolved. The camera is a political tool. It gives voice to women or other community members who are marginalised and permits them to voice their concerns and identify the changes they want to see. The camera facilitates collaborative intervention, and encourages individuals to share their vision and think critically about the issues affecting their communities and the potential solutions. 
Since 2006, using this method, Ola Fou has successfully helped and encouraged numerous communities around the Pacific Islands to identify development projects and the changes that they want to maintain and protect. However, according to Lite, one of the Ola Fou graduates and current alumni, the main challenge is:

Ensuring continuous participation of the community in the entire development process and through each phase. (L. Lite, Interview, June 2013)

This involves an ongoing debate and dialogue between the stakeholders:

Development projects fail when dialogue stops and people lose interest as projects advance, but it is up to the CSOs and their staff to revive the projects as they advance. (L. Lewa, Interview, July 2013)

The participation process and identifying problems and solutions is not always easy. One of the research participants talked about the pictures she took and the problems she identified in her community, as her photos instigated a very serious and unwanted debate amongst the men of the community and no solution was identified by the community for the problem she addressed. I asked if she could describe what she had photographed and what the photographs meant. She explained how she reflected thoroughly on the problems in her community for a few days and finally decided to photograph the bottles of beer left on the street;

Young men in our small community get together all the time. They drink kava and then drink beer, and then they get really loud and rude, especially towards the women of the community. It makes me sad, particularly when they get violent and start demanding sex and beat us when we don't agree. I don't feel safe in my own home as my man is one of them. I like to change this, so I took a photograph of the bottles and confronted the men at the village community. (Community Member, Interview, July 2013) 
This was not very well received by the men of the community, and according to the research participant, there was first silence and then laughter and condemnation of her photos and nothing was done about the issue.

I am glad that I had the courage to finally talk about it and that I used my photos to express myself. My man is trying to be nicer to me since, but it is hard to change habits. (Community Member, Interview, July 2013)

Another Ola Fou alumna talked about her more positive engagement with her community;

This is a picture of the street corner where all the children come together and play marbles or other games every day. One of the mothers in the community took this photo and talked about how children are wasting their time, and how ideally they should go to school. The men of the community were stunned why they never thought about this idea themselves and everyone supported her idea. (Tema, Interview, July 2013)

Tema was then chosen by the community to be the teacher and she has been teaching the children of the community since. This Ola Fou project is a true success story as the semischool formed by Tema and the support of the community and Ola Fou is now in its fourth year and expanding. Tema has labelled her project the 'Literacy Hour' and over the years she has become one of the most effective alumni and an Ola Fou success story. Her involvement with the different communities in Fiji through Ola Fou has resulted in numerous positive development projects, always encouraging the communities to speak out and to point to the positive changes they would like to see in their community.

Finally, Ola Fou Team Leader, Toeapi Anitelu, talked about how alumnus, Willy G. N., helped his community identify the change they desired, which, although a small project, created major friction within the community. This project was interesting as a camera and photos were not involved. One of the youth in his village simply made a drawing with crayons and drew everyone's attention to a potential bus shelter. He drew the rain coming through the roof of their current shelter, the muddy ground and people standing in the rain because the shelter was too small, too old and always wet. 
This drawing and the simple problem it was referring to first appeared too small a project for the community, but a bus stop is what the community identified as the main problem at the end of the discussion and so it had to be addressed. Some within the community felt that time and resources should be allocated to more important and sustainable development projects, but the will of the majority eventually prevailed.

Having made its decision, the community then unanimously pulled together its resources, provided a portion of the funding, and a few volunteers who were familiar with construction started to build the bus stop in their spare time. Further support and funding was then provided by Ola Fou. A group was formed and the project started without external assistance.

The Ola Fou Youth Leader (Willy) who is from the community assisted with the shortcomings on behalf of Ola Fou at each stage of the development process, both financial and technical. Progress was very slow. Some of the community members sourced building supplies (gravel, sand, and cement) cheaply; others contacted relatives in town for further cash and to improve the design and secure the metal poles needed.

By the time the shelter was completed, 55 people within the community had helped in some way or another to build the bus stop. This project was halted numerous times throughout the process, but it was the people within the community that revived it each time:

\section{Everyone got involved and engaged with the process and hence everyone in the community feels they own the bus stop now. Community members talk about the bus stop proudly today and how they perceived the idea and how they went about building it. (Willy G. N. Interview, July 2013)}

I visited the bus shelter with the community members. The shelter is painted, maintained, and well protected by the community and, although small, it is an excellent example of how change and ownership of development results can be cultivated and achieved within a community. People can now stay dry in the shelter when it rains, as they had envisioned. 
The community may be in need of many other basic necessities, but this is the change that they desired. The shelter is perhaps a very small achievement, but it is a development project identified by the community and the community will maintain and protect its outcome. Discussions with the Ola Fou alumni and the community revealed how important it is for the people to engage and lead change. According to Willy, having overcome one obstacle, his community has since embarked on initiating a series of other development projects.

\section{Funding, Design, and Appraisal}

Once the problem and the solution are identified by the community, Ola Fou alumni help the community identify the design for the project, ensuring the community members steadily and inclusively lead the process. Project design is an essential step within the development process, and Ola Fou strategies require and ensure solid engagement of the community. People are encouraged to think about the outcomes that they would want to maintain and protect over time. This is why the community feels ownership of the project results. According to J. Martin:

Those who are to benefit from the development outcomes must especially be involved from the outset in identification of the project, design and the appraisal. The very people who have engaged from the start and throughout the project cycle, will be the very people who will make sure that development results are maintained and protected. (J. Martin, Interview, July 2013)

Creating consensus on design can be a challenging phase for any development project; bringing the community together, ensuring that everyone is given a voice, especially women, and that everyone contributes to the project in one way or another and that the community is leading the process is not easy:

Some participants join at the start, but lose interest as development projects unfold. Ensuring and maintaining a continuous conversation between the partners, and dealing with the failures and challenges as 
projects develop is time-consuming and drains all resources: financial and spiritual. That is why, generally speaking, CSOs prefer to deliver development projects that are tested, proven effective and are more aligned with their own criteria. (J. Martin, Interview, July 2013)

Consultation with community representatives and local stakeholders during the design phase of the Ola Fou projects is conducted based on loose participatory processes. It is also never the same, as the scenarios change each time based on the cultural and traditional context of each community;

Planning and designing primarily with the project beneficiaries and engaging and informing other stakeholders, including other CSOs and the government when possible, is complex, but it is a necessity and it contributes to the sustainability of development outcomes. (J. Martin, Interview, July 2013)

This is especially so for the women of the community who often feel pressured due to traditional norms to maintain silence. Therefore, CSOs need to be alert at every stage of the process and to revive and renew the development process constantly, making sure that the participation is accountable and that it is the community that is leading the process.

As has been argued throughout this thesis all the development phases and ownership indicators are critical and must be taken into consideration for the overall ratio of ownership to increase. The key to cultivating ownership is in improving the dialogue, raising the average level of engagement at each phase of the development process and making sure that the development process is as inclusive as possible. The more the community engages at each phase the more the community owns the results, especially when women are engaged. At the same time, it is important to note that:

Good ideas for change and development projects are often rare within the communities. People in the communities who are under pressure cannot always think of the right solutions and are in need of, and welcome, expert 'outsider' opinion and especially new ideas. (L. Lewa, Interview, July 2013) 
Ola Fou encourages community representatives to identify and lead the mapping process, ensuring that all of the community goals are incorporated in the design and that chaos is avoided in the long term. Ola Fou ensures that stakeholders are clear about what they would like to achieve and how. However, comparative analysis of the three case studies indicates a low level of ownership in Design for all three case studies, which is directly related to lack of appropriate engagement of the women of the community in the process, as it will be discussed in Chapter 9 .

The design of the project directly influences the financing of the projects; hence Ola Fou often designs the details of the projects and writes the project proposals for the community (as other CSOs examined do), making sure that the project proposal meets donor criteria for funding. Ola Fou engages and encourages the community it works with to explore possible funding options. In addition, Ola Fou demands contribution from the community in every way possible: financial and in-kind, community skills building, and related areas to help ensure sustainable community engagement and benefits. According to J. Martin:

The more the people contribute to the development process, be it physically, financially or spiritually as the project is advancing, the more

effective and sustainable the outcomes. (J. Martin, Interview, July 2013)

\section{Who Implements, Monitors and Evaluates?}

Ola Fou is an indigenous grassroots CSO that has a people-driven approach to change and is relevant to the Pacific cultural context. What makes Ola Fou different in comparison to other CSOs is the level of the community participation.

The community members trust Ola Fou because they are engaged in dialogue, because they are listened to and because they feel that they are leading the process. This dialogue is not a one-off interaction. It is revived at each phase of the process. Research revealed that persistence in dialogue is a key factor for effectiveness of development outcomes and over time translates to accountability and ownership of development results. With the guidance of the community, Ola Fou tweaks the projects as they progress and makes sure that the projects advance towards results that the community desires to maintain and protect. 
Interviews within communities that have engaged with Ola Fou revealed that Ola Fou has a subtle but consistent monitoring approach to the projects. Persistent and inclusive monitoring through each phase of the project cycle allows the outcomes of the development projects to be more aligned with the expected results:

Appropriate, accountable and constant monitoring is an important factor and directly contributes towards the sustainability of development results.

(A. Waqetia, Interview, July 2013)

Ensuring everyone voices their concerns as projects advance, especially women, youth and those who are going to benefit directly enhances the level of ownership of the project outcomes. Ola Fou alumni talked about how challenging it is to actually facilitate a just and inclusive consultation, and how slow the communities are sometimes in arriving at consensus as the projects advance.

Initiating a partnership is easy. The challenge is maintaining the partnership, the ongoing dialogue, and agreeing on expected results. (Lite, Interview, July 2013)

Finally, reflecting on her experience, Lite mentioned how, in her view, the secret of lasting development outcomes is:

Making sure that the women of the community are informed and that they are engaged in identification and implementation of the development projects. (Lite, Interview, July 2013)

The value of the work of Ola Fou is in it being community driven. The Ola Fou alumni are often selected amongst the youth, so it is the alumni and the community themselves that want and desire the outcomes, so they focus on the projects and become more attentive as projects advance. This also has to do with the fact that size and scale of Ola Fou development projects are relatively small. Ola Fou sets out a timeline for completion of the development projects it engages with, but it is flexible in general and does not have written policies on ownership or policies on exit strategies. 
Finally, Ola Fou projects have been assessed over the years by external experts. As with other CSOs examined, it is interesting to note the low-level rating for Monitoring and Evaluation. The reasons for this are often the lack of capacity of CSOs such as Ola Fou, as well as lack of available funding to make sure that thorough monitoring and evaluation is conducted and that the project beneficiaries are consulted and that their views and experiences are heard and captured.

\section{Who Maintains and Protects}

Ola Fou has an indisputably new approach to development and maybe this is why its projects are effective and sustainable and its influence is growing so rapidly across the South Pacific. Completed Ola Fou projects are certainly maintained and protected by the community because, as the Ownership Index reveals, people are engaged with the process at each phase. The last measure of the Ownership Index, being the Results Maintenance perception of the community, indicates an above-average level of ownership at $80 \%$, which is simply an indication of development effectiveness and value for money as these projects (although small) are highly effective and sustainable.

Engaging local staff, mobilising the community to think and identify changes that they desire with the help of photography, and ensuring that it is the people that are in charge of the change during each development phase, are not conventional approaches, but seem to produce highly effective results as these simple methods encourage people to take ownership of the process. Research thus reveals that the more people engage in the process, the more they feel that they own the product.

The Ola Fou staff and the community members that engaged with this research were all very inspiring. It was particularly interesting to notice the bond and the solid partnership between the Ola Fou alumni, and the community members. Since 2006, numerous community development projects have been instigated by Ola Fou. All of these projects have been identified by the communities, and have been completed by the project beneficiaries themselves. 
The list of successful projects implemented by Ola Fou is long and their success is due mainly to Ola Fou's approaches:

Small development projects have sometimes a very powerful impact on the community. This is particularly obvious when projects are identified and implemented by the community itself. Through the process of participation, the individuals who engage, and identify the change they desire and implement the projects awaken to their own capacities. (J. Martin, Interview, July 2013)

The successful completion of projects and people's desire to maintain and protect the development outcomes demonstrates that the communities themselves often hold the answers to the development challenges they face. This was also observed with MORDI. People need to be educated and encouraged to think, to question, and to take the decisions and actions that will shape their lives. Careful analysis of the work of Ola Fou and its approach reveals that:

Engagement with the development process leads to greater levels of ownership of change over time and in the long term could contribute to greater self-determination and reduction in dependence on foreign aid. (Amani, Interview, July 2013)

As with MORDI, research on Ola Fou revealed additional characteristics of ownership that are relevant and must be taken into consideration. They are briefly mentioned in the next section.

\section{Donor Funding and Influence}

It was often mentioned by research participants that organic and effective CSOs like Ola Fou often change over time. First, they are community driven and focused on the needs of the people they serve. As time advances and when they are in need of more funding for survival, they have no choice but to align their thinking and policy more with the donors. 
Ola Fou is an interesting example. Youth leaders and groups across the Pacific were all invited by Ola Fou in October 2009 to participate in a robust conversation in which the first youth code of ethics was prompted by Ola Fou. According to an evaluation conducted by New Zealand's Ministry of Foreign Affairs and Trade (MFAT) in 2012, "Ola Fou has pioneered development work in the Pacific, which is the first of its kind".

Ola Fou is growing and to secure greater funding to reach out to a greater number of youth and communities in the region it has no choice but to align its policies more with the donors. (J. Martin, Interview, July 2013)

Ola Fou has also aligned its work with a number of other Pacific regional strategies such as the Pacific Plan on Strengthening Regional Cooperation and the Human Security Framework for the Pacific:

To begin with, Ola Fou approach and strategy was more loose, spontaneous and more community driven, but over time we have realised that we have no choice to align our strategies with that of the donors, if we want to obtain funding and survive as an organisation. (J. Martin, Interview, July 2013)

The more renowned Ola Fou has become because of the impact of its work, the more funds are being allocated by donors and as a result Ola Fou is becoming more constrained by donor criteria and policies, as it has no choice but to abide with donor criteria and align its thinking more closely with that of donors:

But this alignment in thinking has its disadvantages too and is changing the organisational thinking and the organic nature of the organisation and the way Ola Fou works with the communities. (J. Martin, Interview, July 2013)

Donors on the other hand are quite open about the need for CSOs they fund to align their thinking with their policies. According to a report on Ola Fou commissioned by MFAT in 2013, "Ola Fou alumni are graded on the outcome of their engagement with their 
community, and higher grades are given to projects which align more with the New Zealand Government priorities ${ }^{17 \prime \prime}$.

A closer look at Ola Fou's website and online policies indicates that Ola Fou aims to appeal to donors. An example is MFAT's 'value for money' strategies. A good indication of this donor influence on Ola Fou is the inclusion of 'economic development' in annual planning and reports, and changes to the Ola Fou course curricula (2014). This simple inclusion of the term 'economic development' makes Ola Fou more aligned with MFAT's objectives:

Ola Fou has no choice but to abide with donor expectations and donor criteria if it wants to grow as an organisation and help more youth across the South Pacific. Funding will not be secured otherwise and the work of Ola Fou will remain marginal, influencing the lives of very small number of youth on the islands. (J. Martin, Interview, July 2013)

The challenge for Ola Fou and its funders, as for other CSOs hence, is aligning community needs with donor criteria, and finding a balance, making sure that it is not the donor policies and criteria that dictate their interaction with the people.

Accountability downwards to the people is an important issue but there are currently no consensuses amongst CSOs as to how accountability is to be conveyed and no requirements for the CSOs researched in Fiji and Tonga to demonstrated downward accountability to the people they serve, while almost all CSOs are faced with robust donor criteria:

There are no strict rules or regulations for Ola Fou or any of its partners to demonstrate downwards accountability to the people, and reports are mainly prepared for donors. (J. Martin, Interview, July 2013)

There is no consensus amongst CSOs on any codes of conduct to demonstrate accountably downwards to the project beneficiaries in Fiji and Tonga yet. However, Ola Fou is a relatively young CSO and is among a handful of organisations that is perceived as being accountable

\footnotetext{
${ }^{17}$ Evaluation Report for Ola Fou Pasifika Youth Development Programme. Commissioned by the New Zealand Ministry of Foreign Affairs and Trade for the New Zealand Aid Programme. January 2013
} 
to community members. According to the research participants, Ola Fou is considered to be an accountable organisation primarily because the community selects its youth leaders and development projects and because of Ola Fou's indigenous and home-grown nature. Close observation of its work and speaking to Ola Fou staff and project beneficiaries revealed that Ola Fou has managed to maintain the trust of the communities it works with. This is because its staff, the Youth Leaders, are from the communities they serve and because it demonstrates transparency in decision-making through dialogue and collaborates strongly with the community throughout the development process, making sure that it is the communities that are taking the decisions and leading the agendas.

Ola Fou builds ownership of change from the grassroots and cultivates development through an ongoing dialogue where people contribute towards the projects in every way they can, including financial, and voice their concerns and influence the decisions taken. According to the Ola Fou Team Leader:

Ola Fou maintains a solid and transparent partnership with stakeholders throughout the project cycle, making sure that everyone is listened to and involved in decision-making during each phase of the development process.

Transparency in decision-making is the key to Ola Fou's success and why Ola Fou is perceived as accountable. (A. Toeapi, Interview, July 2013)

\section{Women and Ownership}

Research has established that educating girls is the most effective way to ensure sustainable development and lasting positive change: "female education creates powerful povertyreducing synergies and yields enormous gains. It is positively correlated with increased productivity, higher earnings, and most importantly improved societal health and wellbeing" (Tembon \& Fort, 2008, p. 17). Yet, as observed in Fiji and Tonga, not enough attention is being paid to engaging women in development.

Women hold a very distinct place in almost all aspects of society, but:

Patriarchy is still the norm in almost all of the South Pacific Islands, and although women are becoming more active in the development scene, 
there is a massive gap in women's presence in decision-making, and especially in politics, which is particularly alarming. (A. Taufe'ulungaki, Interview, August 2013)

Education is the most critical tool for empowering women, but, according to UNICEF, among children not attending school there are twice as many girls as boys, and among illiterate adults there are twice as many women as men (Unicef, 2011).

Consequently, the limited number of Ola Fou women youth leaders is an issue that was raised by the Ola Fou alumni who participated in this research. Lite, Tema, and other Ola Fou alumni especially stressed this gap and hoped that women would engage more with Ola Fou in the future and play a greater role in all walks of life;

Women can play an essential role in development but they lack education and confidence. The more the women of the community are informed, educated and encouraged to engage, the more effective and sustainable will development outcomes be, and the higher the level of ownership and overall effectiveness of the development results. (L. Lewa, Interview, July 2013)

Ola Fou has more male than female graduates. Ola Fou women alumnae are few and outnumbered, and this is one of the weak points and challenges for Ola Fou. To be more effective, Ola Fou is reflecting on how to change this reality and how to engage a greater number of women. When asked for the reasons behind women's lack of engagement, the Ola Fou alumni blamed the Church and the traditional interpretation of the scripture and the traditional norms and values.

Ofa G. Likiliki, the director of Women and Children Crisis Centre (WCCC), who participated in this research is an outspoken activist on this issue. She summed up the situation:

Historically and customarily, women in the Pacific and youth are normally excluded from decision-making processes. Decision-making is hierarchical and old-fashioned. Women and the youth are not invited to speak and if present tend to remain silent. (O. Likiliki, Interview, July 2013) 
However, women of the South Pacific are educating themselves. According to Ofa:

What is disturbing today is that there are still no firm laws in Tonga that would criminalise violence against women, although it is one of the most concerning issues. The churches hardly ever speak out on the issue of violence against women, which indicates lack of informed leadership, and the influence of traditional norms, and the need for educating the men. $(0$. G. Likiliki, Interview, August 2013)

The Ola Fou alumni engaged in this research also spoke of the need for reform of the old ways of thinking and felt that greater attention must be given to women's rights. They all indicated that they hope to see a greater number of women as leaders in the future:

The challenge for the Pacific women is to reform the old ways of thinking without offending the traditional values, the church, the elders, and old structures of power. (Lite, Interview, July 2013)

Women need to engage more robustly in development aid projects from the start and must be involved in decision-making. At the same time, the men of the communities must be better informed and educated on women's rights issues. In Chapter 9, I will further elaborate on the challenges women are facing and will present a more detailed analysis of the information obtained on the role of women with the help of the Ownership Index.

\section{Conclusion}

The self-reflection and questioning process, called "conscientisation", adopted by Ola Fou, has a wide range of positive implications on development interventions, which tend to promote self-actualisation and cultivation of ownership of results by the project beneficiaries. The distinct strategy of 'questioning', or so-called "conscientisation", adopted by Ola Fou promoted change from within and encourages and inspires community members to reflect on their development priorities and to think and identify the challenges and the solutions and how they might take action. This approach as the case of Ola Fou reveals tends to cultivate self-determination and ownership of development process by the project beneficiaries and more sustainable and more effective development outcomes. 
Observing the work of Ola Fou was inspiring as it revealed how 'art' can be used to empower the community and to prompt positive change. At first glance, the change instigated with the help of the camera, especially the small scale of Ola Fou development projects, may seem insignificant, but these projects, inspired by self-reflection and creative photography, should be judged based on their sustainability, their effectiveness, and their impact on the individuals and the community over time.

The work of Ola Fou clearly demonstrates that there is a direct correlation between the community ownership of the development process and sustainability and effectiveness of development results. Examining Ola Fou also revealed that development outcomes are particularly more effective when women of the community are properly informed and engaged, and when partnerships are accountable and the dialogue ongoing throughout the development cycle. It is this inclusive, accountable and ongoing dialogue that strengthens partnerships over time and cultivates ownership and development results that are maintained and protected by the project beneficiaries.

Thus, the challenge is to make sure that the women of the community are given voice and properly engaged in decision-making throughout the development process, and to promote and ensure accountability towards greater legitimacy while making sure that it is the project beneficiaries themselves that inclusively identify and agree on development goals which in return leads to greater levels of ownership and more effective and sustainable development results. What was particularly inspiring and interesting to note is how the alumni trained by Ola Fou and the project beneficiaries who participated in this research articulated their hope and desire to shape their own destiny, to take charge of their community development, and to 'own' the development process as a result of the process of "conscientisation" promoted by Ola Fou. 


\section{Chapter 8}

\section{Pacific Community Network (PCN)}

\section{Introduction}

The Pacific Community Network (PCN) is renowned for being a community driven organisation in Fiji, and has partnered with numerous disadvantaged groups in Fiji over the last decade. This last case study will examine the work of PCN, its effectiveness in cultivating ownership of development results and how it promotes accountable partnerships, while encouraging the people at the grassroots to engage, act and to commit to take the lead towards development change that they want to maintain and protect over time. The interviews and the qualitative assessments conducted for this case study with the community members and development leaders were highly revealing and provided an opportunity to understand the mechanics of ownership and how it can be cultivated. As with other case studies examined, the analysis of PCN revealed further relevant complexities that hinder or assist cultivation of ownership of the results by the people which will also be discussed in this chapter.

\section{The Context}

Sprawling, informal slum cities are called by different names in different corners of the world. In the French territories of the South Pacific they are called bidonvilles, in India they call them basti, in Mexico barrios marginales, and in Peru pueblos jovenes. In the South Pacific they are sometimes referred to as squatter settlements. They all have one thing in common: they are usually the poorest of the society and the most disadvantaged people, and their homelessness a primal response to a diverse range of external pressures.

The population of the world and the Pacific is progressively moving from rural island villages and settlements to more active hubs and centres of trade. Poverty and inequality continues to be a major challenge. There is pressure on the capitals of both Fiji and Tonga as the populations of the main islands continue to grow, with at least 15 percent of the population living in informal and squatter settlements (Butcher-Gollach, 2015). 
Squatter and informal settlements now cater for approximately $40 \%$ to $50 \%$ of the urban populations residing in the larger Pacific towns and cities. People are being increasingly attracted to urban areas in the likelihood of finding a better life for themselves and their families. In Suva alone, it is estimated that up to some $45 \%$ of the population is living in squatter settlements (Jones, 2012).

According to Fiji's Ministry of Housing and Environment, the term 'squatter' is used loosely to include all spontaneous or informal settlements that have substandard and unauthorised structures and a lack of basic services. To understand the complexities at work, I spoke with the PCN staff and visited as many squatter settlements as I could and interviewed the residents during my field research in both Fiji and Tonga. Rain, floods and lack of basic needs, such as electricity or drinkable water, are just few of the obvious obstacles that the residents are facing.

Having heard about the work of the PCN and how it has managed to empower and enhance the lives of the people living in the squatter settlement, I visited these settlements which have benefited from engagement with PCN and spoke with the elders, as well as the women and youth of the community. Through their eyes I focused on development projects already completed to better understand the anatomy and the complexity of ownership, and how it is promoted by PCN. I spoke with the PCN Director and PCN staff, and read all the existing documents and PCN publications. As with the other case studies, the semi-structured interviews backed up with qualitative assessments conducted with the Ownership Index enabled me to better understand the ingredients and complexities of ownership and the role CSOs can play in promoting and cultivating the principle.

\section{The Situation}

Squatter settlements are a problem in both Fiji and Tonga. Viti Levu and Tongatapu have various squatter settlements. To observe and better understand the situation I visited numerous squatter settlements but concentrated mainly on Lagilagi, Wailoko, Tukutonga, Popua and Sopu, which are especially affected by seasonal flooding. In both Fiji and Tonga, squatter settlements consist of squatters from outer islands living on government land, often next to rubbish dumps or other undesirable locations, such as swamp lands. According 
to UNICEF, the majority of the residents of the squatter settlements in Tonga do not have access to agricultural land for growing food crops or the skills and experience to obtain regular employment and a reliable source of income; most depend on fishing. They are also affected by the increasing cost of living in the main islands and they are facing numerous other challenges as a consequence of urbanisation (UNICEF, 2012).

It became apparent from interviews and research in the slums of the South Pacific that life goes on for the residents despite the diverse range of challenges that they face, especially those caused by poverty. Poor housing is a major index of slum conditions. Most of the homes in the squatter settlements of Fiji are built with wood, usually on poles. I was told by the residents that in the rainy season water blocks the pathways and the entire settlement is often mud-covered. Toilets are public, the homes are damp, improperly heated, and there is no such thing as privacy in its Western context, although some of the residents have worked harder and have made their dwelling more habitable and private. It is important to note that while "slum settlement" refers to the condition of a settlement, "squatter settlements" in the context of Fiji and Tonga refers to the legal status of the settlement. Interviews with community members revealed that the situation is bleak. One of the outspoken community elders mentioned how:

These settlements have become a breeding ground for crime, drugs, and other social issues while the youth are often frustrated by lack of opportunities and long to move away. (A. Oke, Interview, August 2013)

The limited financial resources of the people living in the settlements means that many children fail to complete school. Almost two-thirds of children in Fiji who drop out of school do so due to poverty (Petersen et al., 2012) and live in the slums with their families who are low-income earners. Casual workers, in particular, cannot meet the costs of educating their children. For low-income families with several children, the costs can be overwhelming.

The available statistics for Fiji, Tonga and the rest of the South Pacific Islands are varied and not entirely reliable. Research and evidence, however, points to a large growth of squatter settlements across the South Pacific Islands in recent years. Apart from the rural/urban drift and the increasing cost of urban rents, much of the mushrooming of existing squatter 
settlements is attributed to numerous problems, but mainly to lack of available and affordable land and increase in population. What is happening in the towns and cities of the Pacific Islands is symptomatic of what is happening in other parts of the world. A combination of unemployed and self-employed live in the slums. Some of the slum dwellers work in the cities, but the wages some of them make are so low that they are literally squeezed in to the squatter/slum conditions. According to various sources, roughly $80 \%$ of the residents in squatter settlements live below the poverty line (Barr, 2005; Narsey, 2006).

Squatter residents are neglected and excluded from the general life of their society. They face a long list of challenges, but the biggest problem they face is evacuation from their homes. Almost all of the squatter residents who participated in this research feared and talked about being evacuated someday. At the same time, they spoke about their dreams and how they hoped to own land someday and build schools for their children. The situation of those living in squatter settlements is well captured in a study called Youth, Mental Stress and Violence in Fiji: "Often a family of eight will live in one or two rooms. In some areas 5080 makeshift homes are built in the same area. Many boundary disputes arise over small garden plantations, so that some people live in a continual state of tension with their neighbours. Hygiene and sanitation is poor. Government and CSOs are not active in these areas. Living conditions are so poor that outbreaks of diarrhoeal and dermatological disease are common" (FSPI, 2012, p. 38).

The study goes on to address the situation of children and how many children do not have access to health clinics or schools, and go on to experience the health conditions and social exclusion determined by their position on the social gradient: "Children witness all of their parent's behaviours, including sexual activity, abuse, and arguments. They observe their fathers returning home drunk. Marriages are under stress from the lack of family resources and the absence of services" (Ibid, p.40).

Despite the stress of living in these conditions, the statistics indicate that every year more and more people, especially youth, are moving to the urban areas of the South Pacific in search of better opportunities. When visiting the more rural and remote areas, however, it became apparent for me that not everyone was keen to move to the big cities. Some of the 
elders on the remote islands alleged that it is mainly the youth who leave for greater opportunities:

Here on the remote islands, the inhabitants are privileged. The ocean is generous and feeds us, and the coconut trees and our crops are just an additional blessing. The nature is kind to us. We have enough to survive, although people always want more. We take care of one another, our land, and take responsibility for what we own. (R. Kumari, Interview, July 2013)

Poverty in the South Pacific is undeniable despite the occasional argument to the contrary. Poverty in the South Pacific is a different kind of poverty compared to the rest of the world, however, and is caused by numerous factors such as lack of appropriate systems of education, lack of sympathy for and understanding of women's rights, natural disasters, small internal markets and, most importantly, geography and the remoteness of the islands (UNICEF, 2012). Despite these obvious factors, some of the research participants claimed that Pacific Islanders are labelled "poor" by foreign researchers because:

They are being pressured by rich neighbouring countries and international financial institutions to become consumers, create a dynamic market, sign trade agreements and make commitments to further open their economies to foreign goods and services. They are labelled poor because they are compared to Western economic standards and do not have the capacity to purchase expensive imported goods. (A. Leveni, Interview, July 2013)

The conditions of life, poverty, and especially life in squatter settlements in the South Pacific, is complex, diverse and beyond the scope of this research, but before describing the work of PCN it was important to briefly draw a picture of life in general and to share some of the local perspectives and the questions that surfaced during the interviews with squatter residents, especially in regards to the question of poverty and its definition within the Pacific context. The next section explores how PCN connects with the people living in these most disadvantaged communities, and how it promotes partnership and works with the communities towards effective development results that are maintained and protected by the communities. 


\section{Why PCN?}

Rapid population growth is affecting most of the South Pacific Islands. The main islands of the Pacific are often overcrowded, which has a direct impact on every aspect of life but especially people's health (Davis, 2011). It is a real struggle for the governments of Pacific Island states, such as Fiji and Tonga, to provide and secure sustainable housing for displaced populations (Campbell, 2010, p. 38), and in the midst of all these challenges PCN is one of very few CSOs active within the squatter settlements. It is also the only CSO that encourages the people themselves to deal with their challenges.

The landscape of poverty is very diverse in the urban areas in both Fiji and Tonga, especially in the big cities such as Suva, Nadi, Loutoka, Labasa, and Tongatapu. Both Fiji and Tonga are urbanising rapidly. Some of the families living in the squatter settlements have some source of income. Despite their living conditions, they are not destitute as the sense of kinship and unity of the community is strong in the South Pacific; people always share and care for one another. In short, no one is dying from poverty or hunger, but they are poor in the much broader sense of the word and mainly as a result of lack of access to education, human rights issues, especially women's rights, and female representation in key political decisionmaking positions.

The work of the PCN is interesting because PCN promotes empowerment through partnership in the communities, which often results in effective development and ownership of development outcomes by the people. Examining the work of PCN seemed necessary and logical since the catchphrases of 'ownership', 'empowerment' and 'partnership' are constantly used by PCN and are strongly encouraged, even though PCN has no explicit or written policy that would elaborate on what the concept of ownership means in policy and practice and how it is to be cultivated.

Therefore, in this chapter, as with the other two case studies examined, I will discuss the details of the development process and how the residents of squatter settlements engaged with PCN at each stage of the development process and how ownership of development outcomes were cultivated over time. 


\section{PCN Background}

PCN works on the understanding that squatter residents should not be evicted, rather people within the squatter settlements should be informed and empowered to take charge and work towards improving their conditions. To this end, PCN provides workshops, informs, educates, and empowers people to understand their own situation and to make the necessary decisions to bring about positive change.

The formation of PCN was the result of workshops on social analysis organised from 2004 to 2006 by the Ecumenical Centre for Research Education and Advocacy (ECREA) in Fiji to inform and empower community members. These workshops brought community members together so that they could discuss and identify their own problems and the appropriate solutions. To understand the complexities of the process, I approached ECREA first and met with its Director, S. Rakabi. I also met with the ECREA board members who all engaged with and informed this research before I started my research and interviews with the PCN staff, and at the grassroots with the residents of the squatter settlements.

PCN is a branch of ECREA that grew out of the collaboration of empowered community members who attended workshops offered by ECREA over the years. The workshops are renowned for the methods used, their power to educate, and their capacity to encourage people to reflect, unite and take action towards the development change they desire. These workshops are held within the squatter settlements mainly and they have been effective in engaging and empowering the residents of diverse communities around Fiji, helping people to form networks with the goal of identifying the problems and finding the solutions.

Over the years and inspired by the workshops, some 32 communities across Viti Levu came together and the number kept growing until there were about 75 communities in the LamiSuva-Nausori corridor. This union of squatter settlements eventually formed the foundation of the PCN. A constitution was drawn up and approved for PCN, as that is a requirement in Fiji for registering any non-profit organisation. PCN became an independent organisation in 2010. One of the PCN founders Kevin Barr participated in this research: 
PCN has become a unique squatter settlement movement across Fiji and is represented in 160 of the 230 squatter settlements throughout Fiji. PCN has been very effective from the start in aligning and working with all of the stakeholders. (K. Barr, Interview, June 2014)

The residents of the squatter settlement have used PCN to bring together different settlements, to give voice to the residents and to reach out to the city councils and the government of Fiji. Thus, PCN was selected as a case study for this research because it is founded on the principles of 'partnership' and 'empowerment' towards positive change, which in the long term has resulted in ownership of development results.

\section{How PCN Works}

To engage with the communities, PCN starts with a series of workshops which are aimed to make people think about their situation and to speak about the challenges they are facing in their community. These workshops are aimed at moving people out of the 'culture of silence' to which they have been accustomed so that people can begin to 'stand on their own feet', so to speak, reflect on their situation and solve their own problems. The motto PCN uses for this process of empowerment is named:

Stand up and walk; Stand up and talk. (K. Barr, Interview, June 2014)

The workshops offered by PCN have been ongoing and have provided opportunities for the community members that attend to think, reflect and examine their situations. Research participants said that they were asked during the workshops to think about the change they desire, and the actions they have to take. At the workshops, participants are asked to reflect on their lives, to clearly identify their goals and decide on the necessary and immediate action needed.

The workshops have been designed and improved over the years by PCN staff and to some extent resemble the approaches adopted by other effective grassroots organisations, such as Ola Fou. The objective of PCN is to 'awaken' the participants, promote a sense of "conscientisation", as referred to in Chapter 7, and to demand that the community members identify the important questions (development priorities) and find the expected 
solutions, while designing and planning the expected outcomes. PCN aims to ensure that the community and individuals are reminded of their inner capacities to take charge and to lead the development process. The workshops encourage community members to be proactive, instead of waiting for hand-outs and aid from external donors:

PCN empowers people by encouraging the people to think about their problems and what they want to change. To pose questions, to identify goals and to take the necessary immediate steps towards their desired goals. (S. Kautoke, Interview, June 2013)

According to Sameula Wlawi (Director of PCN), empowerment is the core philosophy of PCN; it is a simple remedy to put into practice and it is not as vague or complicated as it is commonly perceived to be:

An individual or a community is empowered when capable to think, to articulate the questions and the answers, and to take action self-reliantly.

(S. Wlawi, Interview, June 2013)

Empowering the individuals within the communities is a key factor in the work of PCN and how it encourages change that is owned by the communities.

Interviews with Kevin Barr, founder of PCN, and other staff revealed that empowerment is defined in the work of PCN as the people's capacity to:

- think (for oneself);

- gain knowledge;

- engage in dialogue (articulate the problems and solutions);

- make decisions;

- organise (towards expected results);

- partner towards positive change; and

- keep results in mind.

Previous research revealed that ownership is demonstrated by the community when the expected results are outcomes that the community wants to maintain and protect. This 
approach is not written down and formally accepted as policy for cultivating ownership by the PCN, but the evidence of its work reveals that empowerment towards partnership has actually resulted in eventual ownership of the change:

People of the Pacific especially the indigenous Pacific Islanders remain passive, inactive and dependent, relying on others to make decisions for them. To create lasting and effective change, they must identify first what they want. People must 'own' their dreams and decisions, and take the necessary steps towards them. (J. Madraiwiwi, Interview, July 2013)

According to Barr, who drafted the initial workshop on empowerment for PCN:

When people are empowered, they can then participate and take actions, and even if they fail, they will stand up again because they know where they are going. When people are empowered, they become fully engaged with life. (K. Barr, Interview, June 2014)

The formula used by PCN to engage with the community is simple according to Barr:

\section{Empowerment $\rightarrow$ Participation $\rightarrow$ Change}

The empowerment approach adopted stands out because it is not concerned with doing things for the people, but always enabling and motivating them to take the much-needed decisions and the necessary actions themselves. The way things are, is not the way they could be:

When an individual or a community realises this fact and the importance of decision-making, action and process, then positive change has occurred. People and communities who have understood this fact have ownership of their lives because they have determined and taken action towards shaping their 'own' destiny. (K. Barr, Interview, June 2014) 


\section{METHOD: Participatory Development}

Today almost all development actors unanimously view participation as an effective tool for development, but as discussed in Chapter 4, the concept is broad and still unclear as there is no one way to form partnerships and no consensus as to how partnership can be most effective. Towards the end of last century, however, and at the end of the Cold War, the World Bank did, for the first time, announce that in the context of development aid "popular participation is important to the success of projects economically, environmentally and socially" (Feeney, 1998, p. 12).

Participation has since been valued within the aid and development arena. Today it has become a common term within the discipline and is used by all manner of aid and development agencies. It is interesting to note, as observed in the previous two case studies, that participation if taken into consideration does have various positive side effects, including ownership of development results. In fact, it seems that the concept of "participation can be the solution to every problem" (Mansuri \& Rao, 2012, p. 116); but what needs ample reflection and further discussion is how participation can be more accountable, inclusive and lasting.

"The term 'participation' is considered by many to be empowering, regardless of the actual activity undertaken" (Cleaver, 1999, p. 598). Although it is admired in literature and spoken about constantly by practitioners the civil society sector in Fiji or Tonga has no rules or regulations today binding civil society actors to ensure accountable participation for development policy and design when dealing with the people they serve:

There are [sic] no consensus amongst CSOs as to how participation is to be conducted, and there is no 'blueprint' for participation and no one 'methodology' for CSOs to follow. (K. Barr, Interview, June 2014)

Research revealed that most policies adopted by CSOs in Fiji and Tonga vary in how participation is defined and put into practice. Participation varies depending on the situation, the context (culture), the priority of each CSO, the project and specific stakeholder characteristics and needs. CSOs that participated in this research elaborated on how 
participation is an effective tool, but that there is no one way to ensure it when implementing development projects as it varies depending on funding, donor requirements and the context of the community. Working in a participatory manner requires planning, innovation, creativity, and flexibility over the project cycle, and those factors are not always easy to secure.

At the same time, development experience and evidence over the decades reveals that authentic participation makes development aid more effective and helps prevent development aid from being a handout and an entirely top-down process. True participation gives meaning to lives as "participation is a fundamental human right" (Steiner, 1988, p. 77); and it enhances the capacity of individuals to take action towards expected results with the help of others, facilitating positive social change (Fowler, 2013).

Thus, PCN is aware of the magical powers of participation and strongly emphasises the importance of participation as a method of directly influencing the outcome of development results while making sure that the development projects implemented are primarily identified by the communities and that the potential project beneficiaries are all engaged in the process.

\section{The Process}

Analysis of the work of PCN, as well as the close examination of the other case studies examined, revealed that the absence of project beneficiaries in decision-making, especially women of the community and lack of appropriate participatory processes leads to recipients of the aid feeling uncommitted to the project outcomes in the long term.

The Housing Project in the squatter settlement of Lagilagi (Jittu Estate), which took some nine years to complete, and the building of Paterson Drive in the Wailoko squatter settlement, which took six years of perseverance in partnership between PCN/ECREA and the community, were chosen as case studies for detailed examination of the work of PCN to help understand the complexities of ownership at work and how 'empowerment' or 'participation' can bring about change that is desired, maintained and protected by the community. 
Talking to PCN staff and project beneficiaries as well as analysing development projects completed by PCN (and other CSOs) reveals that ownership of development is directly related to the process and the level of dialogue and engagement between the CSOs and the project beneficiaries.

An active community resident engaged with the building of the Paterson Road in Wailoko squatter settlement claimed:

What makes PCN different is that it creates a space for dialogue, and brings the community together to discuss future plans and maintains an inclusive and long-lasting dialogue with the community making sure that the community is informed and leading the development process. (K. Busby, Interview, July 2013)

Interviews and analysis of the complexities of ownership confirmed the importance of dialogue through the process, but also the need for a range of other factors such as flexibility, adaptability and, most importantly, accountability of CSOs to the project beneficiaries, which will be further discussed in Chapters 9 and 10. Decision-makers must be informed. Women and youth in the community must be engaged and appropriately represented at the table with a clear understanding of the situation. Respect for the process and successive inclusive decision-making at each phase will no doubt ensure the outcomes desired by the people.

\section{Ownership Index Analysis}

It is important to note again that the case studies selected for detailed analysis and presented here are among CSOs that stand above the average in terms of their capacity and ability to connect with project beneficiaries. They are selected among the most effective CSOs observed in Fiji and Tonga and have managed to implement development projects that are sustainable, and maintained by the project beneficiaries. They are organisations that are accountable in their partnerships both upwards to their donors, but especially to the communities they serve, and have managed to encourage the people to lead the process. Thus, the qualitative assessment of the work of PCN reveals a partial overall 
ownership rating of $71 \%$ (Figure 8.1 below), which is within the same range as with the other two case studies.

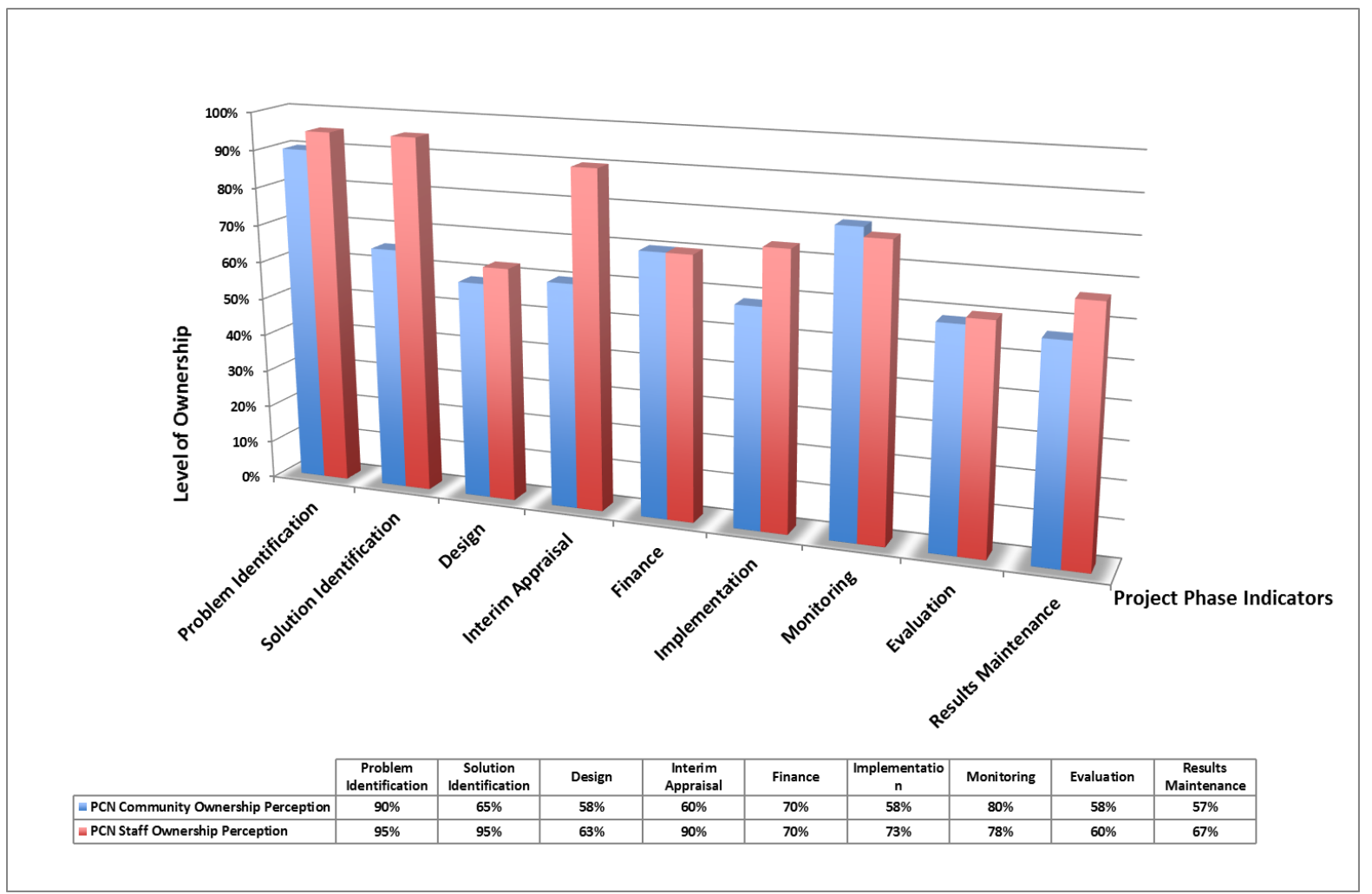

\section{Figure 8.1 - Perceived Levels of Ownership}

As discussed in Chapters 2, 6 and 7, the data gathered above is partial and is based on qualitative assessments conducted by the research participants within the community and the staff working with PCN. The data in Figure 8.1 above indicates a relatively high degree of overall ownership because the project beneficiaries have been strongly engaged in decisionmaking at each phase of the development project from the start, influencing the outcomes and thus raising the overall level of ownership. As a result of an inclusive and consistent partnership over time, the projects PCN has implemented are owned by the community and ownership is estimated to be within the margin of 70 or $75 \%$. By examining and carefully observing each partial measure of ownership captured above we can better understand and analyse the development process. It is interesting to note the high levels of ownership felt in certain areas such as Problem Identification, relatively high levels of ownership in the Monitoring phases, along with full ownership reported by the CSO staff for the Solution 
Identification and Interim Appraisal phases. In contrast, there are shortcomings during the Evaluation and Community Reporting phases.

The variance between the community and CSO staff measures of ownership in the Interim Appraisal, Finance, and Implementation phases, although partial, indicates some disagreement between the perspective of the community members and the PCN staff in these areas. As was revealed in the interviews, the PCN staff (as noted in the two other case studies) tended to report inflated levels in these areas.

The qualitative assessments highlighted the strengths and weaknesses of the process, although the information obtained is partial, and clearly demonstrated areas in the development cycle that need greater attention. For example, a perceptual difference of $30 \%$ for the Interim Appraisal, and 15\% for Implementation on the Ownership Index reveals that PCN staff and project beneficiaries should come together to discuss the cause of this point of difference and agree on measures to address the breakdown in understanding and communication.

The Ownership Index effectively identifies the strong and weak points of the development process. It highlights the points that are in need of greater discussion and the need for better agreement to improve the ownership rate over all. The causes of the variance cannot be determined from the quasi-quantitative data gathered, as discussed in Chapter 2, but measuring ownership helps identify areas that require further dialogue between the partners and further careful consideration and research.

\section{Identification of the Problems and the Solutions}

Planning is often done 'for' the people, not 'with' them. This is not the case with PCN. According to Kevin Barr, who has worked within the aid and development arena in Fiji for 30 years:

Change is more effective and sustainable only when initiated through accountable partnerships and directed by the community and when all stakeholders are willingly and inclusively engaged in the dialogue from the start. (K. Barr, Interview, July 2013) 
Dialogue is a necessity and essential to ensure authentic partnership as development projects advance. The literature, field research and interviews with stakeholders verified that there is no doubt that "the result of better dialogue is greater partnership and shared responsibility" (Fowler, 2000a, p. 7). PCN promotes dialogue and encourages inclusive engagement of partners in decision-making processes, making sure that all voices are heard within the community:

People must be first informed, awakened to their own potential and then they must be authentically and accountably engaged in the process. Once people are informed, they will inevitably become engaged. (K. Barr, Interview, July 2013)

Community residents who participated in this research emphasised the importance of time and process and how vital it is for CSOs to maintain the dialogue with stakeholders throughout the process, instead of simply conducting a one-off consultation with the communities at the start. Development CSOs must make sure that the communities they serve are informed and inclusively engaged in decision-making at each stage of the development process.

At all stages of the development process, $\mathrm{PCN}$ encourages people within the community to lead the change needed, while making sure that other stakeholders, such as responsible government officials, are also invited and involved, from which the communities can potentially benefit. Over the years, PCN has conducted numerous workshops and inclusive consultations with the community members of Wailoko and Lagilagi, who kindly agreed to participate in this research. According to the project beneficiaries who engaged in this research, PCN has managed successfully to inform the community members and align their needs with donor criteria. PCN has engaged, informed and invited other stakeholders to the table too: people such as University of the South Pacific (USP) academics, donors, CSOs and Fiji Government officials in an attempt to harmonise and align development aid efforts and to make the project outcomes more effective and sustainable.

The Lagilagi squatter settlement is an excellent example of successful partnerships that have effected change, driven and maintained by the project beneficiaries. The broad 
collaboration and attempt to address the problem of squatter settlements in Lagilagi was initiated in 2005 with the help of Dr Graham Hassall. At the request of PCN, Dr Hassall (currently an Associate Professor at Victoria University of Wellington, but teaching at the USP at the time) initiated the dialogue. Dr. Hassel encouraged an inclusive dialogue and brought together different development practitioners, community representatives and government officials to address the issues people are facing in the squatter settlements and to find support for positive change. As a result, a series of workshops were held by USP. Stakeholders (community members, PCN staff, and government officials) were invited to brainstorm and to find solutions for some of the problems identified by the community. At a PCN workshop the community of Lagilagi identified a need to improve their living conditions and potentially build new homes in their settlements.

These early workshops held by Dr Hassall were followed by numerous meetings between stakeholders over the years, which helped the people inform and empower themselves and to lead and plan the change they desired. In time, they even inspired other initially reluctant stakeholders such as the government of Fiji to support their initiatives.

The ongoing workshops held by PCN over the years helped the people identify their own strengths and learn about each other. The workshops offered by PCN helped inform the people living in the squatter settlements and establish a framework for an integrated, collaborative approach to foster change from within the communities: first, by exploring the strengths of the community, and then by identifying the changes desired by the people, while highlighting the importance of authentic participation, broad stakeholder consultation, accountability, and planning for continued dialogue towards identifying solutions.

Research participants within both communities talked about how the process required persistence and motivation over the years. The potential was there, but PCN, especially Kevin Barr and Dr Graham Hassall, played a key role as the 'instigators' and constantly brought the stakeholders and the communities together. The elders, the youth, and the women were invited and everyone was engaged, according to the research participants. One community needed a road and desired to be connected to the rest of the island. The 
other community could see the potential of actually improving their own living conditions by improving the quality of their settlement and potentially even building their own homes. How all this was to be achieved was the big question. It was with the help of PCN workshops and consultations with community members that both communities eventually formulated their plans and, with persistence, initiated the development projects. PCN has been especially effective in empowering and encouraging the people within the communities to lead and to identify the desired goals and specific steps to be taken towards completing the projects:

Reminding the people within the communities (squatter settlements) that they need to carefully reflect on the change they desire and that they must engage, take decisions and act at each phase of the project if they are keen to see outcomes they desire. (K. Barr, Interview, July 2013)

Development projects implemented by PCN are effective because PCN is accountable downwards to the people and remains constantly engaged with the communities it serves. PCN makes an effort to bring everyone within the community together, and empowers the people by simply encouraging them to think and to talk about the changes they want to see and to reflect on the potential actions they must take.

As with the other case studies, examining the PCN projects revealed that the more project beneficiaries are engaged with the development process at each phase, the more effective and sustainable the project outcomes are in the long term, because when people are involved they tend to influence and shift the process towards outcomes they desire. This is the most effective way to cultivate ownership of change.

As argued throughout this thesis and as revealed in the review of the literature, CSOs are in a valuable position to align and work closely with the people making sure they are in tune with the needs of the people and that their project beneficiaries are engaged, which makes development aid more sustainable in the long term (Botes \& van Rensburg, 2000, p. 51). 


\section{Funding, Design and Appraisal}

Over the years, PCN has encouraged the people in the communities it works with to contribute to development projects in every way possible - if not financial, then by physical labour:

Given it is the people themselves that identify the change they want to see, and the projects are community aspirations, it seems only natural that the community members contribute to the project no matter how small their contribution. (K. Barr, Interview, July 2013)

Community members who participated in this research talked about how once people have invested in a project be it financial or conceptual, they tend to follow up with the progress, and want to participate with the process even more:

Project beneficiaries who contribute towards a development project financially, no matter how small, and through sweat equity, tend to immediately feel ownership of the development process. (K. Barr, Interview, July 2013)

When development goals are identified by the people, and when the people contribute financially and physically to the projects, the individual and the community becomes determined to make sure that the project succeeds. According to the research participants, PCN played a key role in engaging the community and bringing together all stakeholders. According to a community member:

It is PCN that made us reflect on the change we want to see and made us realise that we can do what we want and create the change we need in the community. It is PCN that aligned the community needs with donor criteria, government policy, and secured a portion of the funding needed for the project but it was the people that ultimately lifted the project off the ground and followed up and pushed the process forward because it was their own idea. (S. Wlawi, Interview, June 2013) 
To build the road for example, the squatter community of Wailoko contributed what they could financially, although the amount was minimal. According to Wlawi, this very small contribution from their very limited savings had a "physiological impact" as the community now had its savings at stake. People provided their labour, or what PCN calls the 'sweat equity', during the construction of the houses and did everything they could to safeguard the results. The engagement in the process made members of the community value the outcome and some of the community members learnt new skills in the process:

The road was built because members of the community got engaged and persisted. In addition, some 20 people from the community who were engaged and trained as block-layers and as carpenters during the project have now found other jobs and have a profession for life. (S. Wlawi, Interview, July 2013)

It is PCN policy and it was agreed by the community that they must contribute in every way possible, financially and with labour, and the community did as they had promised because they desired the outcomes. Over time the community contributed financially and with their sweat equity, all of which contributed to cultivation of ownership. While PCN encourages the community to donate financially, the PCN staff drafted project proposals with the help of the community members and stakeholders and approached potential donors.

The majority of the funding for completing projects in both Wailoko and Lagilagi was eventually obtained from overseas donors. However, as observed in the other case studies, the community contribution towards the development process, although minimal, raised the level of their engagement, their desire to complete the project and, most importantly, their overall level of ownership.

The success of PCN in promoting ownership of change within the communities it works with is indisputable, as it has managed to bring together as many stakeholders as possible within the communities to address community challenges, while it has equally encouraged the project beneficiaries themselves to lead the processes and bring about the change that they desire. 
Some community members talked about their positive experience of attending the PCN participatory sessions:

PCN promotes participation and inclusive decision-making and always makes sure that women, youth, and community elders are all present and listened to when important decisions are made within the community, which is why their development projects are so effective and the community feels ownership. (T. Waqa, Interview, July 2013)

I paid numerous visits to both squatter settlements and on each occasion the residents demonstrated their pride in what they had accomplished and expressed how they now felt confident in taking their accomplishments even further. What was remarkable to note is how squatter residents who are engaged with the PCN talked about other development projects they have in mind, as they now know they can create change and implement other development projects if they reflect, unite, and identify the development change that they want to maintain and protect over time.

\section{Who Implements, Monitors and Evaluates?}

Visiting the squatter settlements and speaking with the project beneficiaries in the community, the youth, the women and the elders, as well as speaking with the PCN program officers who assisted the community in implementing the projects, was very valuable as it provided a chance to observe the development process closely and analyse the factors that impede or promote ownership;

\footnotetext{
Squatter residents securing a housing project on a land they have occupied is unheard of. They have, however, now, after 10 years, built 152 houses for the squatter residents, and have inspired many other communities. ( $\mathrm{S}$. Wlawi, Interview, July 2013)
}

This achievement has encouraged other squatter settlements across Fiji and has brought new life to the Lagilagi community. Equally, according to the research participants, the completion of Paterson Drive seems to have given a new life and energy to the community as the residents were inspired by their own achievement. Today, Paterson Drive connects 
the remote settlement to Suva and has had a major impact on the lives of the people, especially during the rainy season.

Speaking to community members, it became obvious that another element that has contributed to the high level of ownership in both communities is that the residents contributed their labour to the process. In Wailoko the community residents themselves offered to build the road. It did take some six months to build a small road, but everyone in the community contributed to the project;

The community owned the project from the start all the way to the end. The road was a need identified by the community, so everyone in the community participated and contributed to the project. The elderly, the youth and the women all participated. Women especially were very helpful in the whole process as they not only contributed to the building of the road but also took care of the men and cooked the meals for everyone. (S. Kautoke, Interview, July 2013)

Almost all research participants talked about the opposition and the divisions they faced throughout the process and how all obstacles were eventually resolved by persistence and respect for dialogue and accountable partnership.

The Patterson Road and Lagilagi Housing projects are both monitored today by locally formed committees. These committees were formed at the start of the project and have played a major role. They have been particularly successful in bringing together the diverse needs of the members and aligning donor criteria with that of the community residents.

Close examination of CSOs in Fiji and Tonga reveals one area of weakness within the civil society sector, which is monitoring and evaluation. Monitoring that is inclusive throughout the process is especially lacking - monitoring that gives voice to the community members, especially women, and emphasises dialogue and sharing of information and perspectives.

According to the research participants, project evaluations are all too often conducted without robust inclusive engagement of the project beneficiaries. Another major challenge for PCN and other CSOs observed is reporting and sharing of the findings and evaluations 
conducted. The staff at CSOs almost unanimously complained about the complex matrix of reporting requirements by donors and how they lack the resources and the capacity to produce these reports; yet, they spend a disproportionate amount of their time trying to satisfy donor requirements, while seldom going back to the communities to share their findings with the project beneficiaries after a project is completed:

Almost all CSOs in Fiji report to their donors who do not always read the reports in detail. CSOs feel greater obligation to their funders than they do to the local communities they serve. Therefore, the heavy demands to keep the donors satisfied for continued funding has shifted the focus of CSOs and has paralysed the capacity of civil society to better connect and engage with the local communities they serve. ( $\mathrm{H}$. Khan, Interview, July 2013)

\section{Who Maintains and Protects?}

The qualitative assessments revealed a low estimate of ownership of Results Maintenance by the Lagilagi community. The partial estimation of the community ownership is at $56 \%$, although there is a high combined rating of ownership (Figure 8. 1). This is because squatter residents who move into these homes are required to financially contribute to the new homes over the coming years and to cover at least one-third of the cost of the homes within the next 12 to 15 years.

Interviews revealed that this has had a direct impact on the ownership of the outcomes felt by the community members because if residents fail to make the payments, they would need to move out of their homes and allow other residents to move in. A few of the research participants mentioned how they own nothing, but they feel they own the idea. They have strata title ${ }^{18}$ and the land on which their new homes are built on is supervised and managed by PCN (to prevent selling off).

\footnotetext{
${ }^{18} \mathrm{~A}$ form of co-ownership of property and land in Fiji and some of the other island states of the South Pacific. Under this scheme land is subdivided into two or more 'stratas' or cubic (spaces), with individual owners acquiring title to individual
} 
However, in spite of the low level of Results Maintenance, the overall level of ownership is high and the development projects have had a major impact on the lives of the project beneficiaries. The overall level of ownership by the community is high because the people, in collaboration with PCN, created the change and they are keen to maintain and protect the outcomes. They have successfully mobilised and have engaged inclusively from the start, each phase of the project contributed to making their vision a reality. In this way, PCN has succeeded in motivating the community to lead the development process. It is not PCN that decided for the communities or suggested a development need; rather, PCN empowered and encouraged the project beneficiaries to think and identify the changes needed and to take the necessary actions required.

The process is the product. The squatter residents engaged with PCN were transformed physically and psychologically through their partnership with PCN. To many people's surprise squatter residents determined the changes they desired, and made their aspiration a reality.

Finally, it is important to note how PCN, like other effective CSOs, has been active in engaging, aligning and harmonising all of the stakeholders while implementing development projects, especially raising the awareness of the responsible government departments which has resulted in greater sustainability of the project results. The next section presents some other observations made while examining the work of PCN, which are worthy of contemplation if cultivation of ownership is to be taken into consideration.

\section{Democratic Decision-making}

Donors, the church, the state, and the traditional structures each have their own different agendas, and tend to influence the decision-making structures. The big question for civil society in the South Pacific, as elsewhere in the world, is how to inform and engage the project beneficiaries on the islands in decision-making throughout the development process

spaces, lots or 'units' (in substance, a space within the confines of a wall, floor and ceiling) and undivided rights to the common areas. 
and align their needs with donor criteria while bypassing the politics of development aid, traditional structures and old methods of decision-making.

The question of ownership is directly related to the questions of decision-making, control and power. Civil society is in an excellent position to establish new systems and inclusive approaches for decision-making that could lead to development projects that are more desired and owned by the people and therefore more effective and sustainable.

As highlighted in previous chapters, research participants, especially the women and the youth within the communities, complained about the existing decision-making processes, and expressed their concerns:

There is dire need for more democratic decision-making processes and greater accountability of civil society downwards to the people. Women must be present at the decision-making tables and better engaged if ownership of the results by the community is anticipated. (L. Lewa, Interview, July 2013)

There is plenty of room to improve participation and to reform the traditional ways of life especially when it comes to the engagement of women in decision-making processes, and addressing their needs. Women play a crucial role in the ownership of development aid and CSOs are in a strong position to promote and to ensure engagement of women throughout the development process especially during the identification and monitoring of the projects as well as the evaluation phases of the development projects, as the case studies in this research indicate. Women of the community must be informed and encouraged to get involved in decision-making processes; otherwise, half of the population's valuable insights and capacity is neglected.

Similar to the other two case studies, interviews with research participants and close observation of different development projects implemented by PCN unearthed data that had to be triangulated. The case studies assisted in unearthing the ingredients of ownership, but also other characteristics of ownership which will be discussed in detail in Chapter 9. These characteristics must be seriously taken into consideration by CSOs, if ownership is to 
be actively cultivated and for development aid to be sustainable and maintained by the project beneficiaries.

\section{The Role of the Governments}

The PCN case study revealed that CSOs are well positioned to organise, align and bridge the needs of the community with the donor criteria and that governments can especially play a critical role in supporting the efforts of the CSOs on the ground, and to safeguard the development process and outcomes. Examining the PCN also reveals that development outcomes are more sustainable, particularly when governments are informed and engaged from the very start of the development process. This way they can better engage and assist the process when development projects originated by CSOs terminate. Partnerships are always varied and further reflection is needed as to how each partnership can be improved; but what is observable and evident is that development outcomes are sustainable when all responsible stakeholders are engaged, informed and when partnerships are accountable and inclusive.

There is, however, ample room to improve the relationship between the CSOs and the governments and to advance the enabling environment of the CSOs as well as their accountability. The starting point could be the recognition of CSOs by governments as independent, legitimate and accountable development actors and the start of a more inclusive dialogue, and accountable partnerships as well as improved consultation processes for drafting of development plans. As the case studies demonstrated, the enabling environment for CSOs and their accountability is in serious need of enhancement, which is a critical factor that must be considered if CSOs are to be more effective. This however is not easily achieved and relationships between the governments and the civil society is often complicated, as discussed in Chapters 3 and 5.

There is ample room to improve the accountability of CSOs. Development is complex and therefore requires an enabling environment where governments are supportive of development interventions by CSOs, but also demand greater accountability and engagement from the CSOs. (S. Ilolahia, Interview, August 2013) 
Civil society holds a special and critical place as it is squeezed between the people at the grassroots and the governments, but this in-between position also brings about plenty of opportunity and responsibility. Knowing that people in general, especially project beneficiaries, and governments are increasingly interested in the question of accountability and effectiveness. Civil society can be proactive in this front, take control of the agenda, approach stakeholders on these issues especially governments and ensure that their accountability and effectiveness as a sector are measured by standards they deem appropriate. How this is done is naturally dependent on the context, but as the case of the PCN reveals, this approach can have long lasting impact.

Finally, it is important to reiterate that the case of PCN and other case studies examined for this research clearly reveal that effectiveness of development aid is dependent on the quality of the partnership of the stakeholders, but especially on the accountability of the partners towards promotion of sustainable development change that addresses the root causes as well as the symptoms of poverty and injustice and that governments can play a critical role in upholding these factors.

\section{Conclusion}

Analysis of the work of PCN and the communities it works with clearly indicates that the key factor in promoting and cultivating ownership is identification of the problem and the solution by the community. Stakeholders, especially women, must be properly engaged in decision-making throughout the development process. The more inclusive the process and the dialogue, the stronger the partnerships and more effective and sustainable the results. Stakeholders must be able to have a say and to tweak the projects as they advance towards changes that they want to maintain and protect over time.

Participation is a strong remedy for effective development and it is not a new concept, but it is not always effective (Cooke \& Kothari, 2001). However, the PCN case study reveals that participation can be an effective strategy when appropriately conducted and can result in multiple positive outcomes if it is conducted inclusively, especially when partners are accountable. The more accountable the partners, and authentic and continuous the 
dialogue, the more effective the development outcomes and the greater the level of ownership of development results by the community.

Close observation of PCN also demonstrated that commitment to fostering ownership requires an enabling environment in which CSOs can freely engage and empower the people and that CSOs need to rethink their relationships and to develop approaches that show greater accountability both upwards to their donors and governments, but also downwards to the people they serve. Accountability must be looked at as a strategy as governments will be more supportive, funding will be more easily secured by donors and aid and development outcomes will be more effective and sustainable if civil society demonstrates greater accountability.

Finally, as seen in the other case studies, women must be authentically involved in decisionmaking throughout the development process to ensure the effectiveness of development results. Without inclusive and accountable participation, development aid will inevitably be unsustainable and ineffective in the long term. 


\section{Chapter 9}

\section{Comparative Analysis and Additional Findings}

\section{Introduction}

This chapter presents the comparative analysis of the case studies, and argues that the working definition of ownership developed in this research is pragmatic and that it is possible to identify the variable indicators that formulate ownership and feasible to cultivate and measure the principle. This chapter will also present the characteristics of ownership that civil society, in particular, must take more seriously into consideration as research highlighted the fact that these issues are talked about, but not suficantly incorporated into policy and practice. These characteristics were observed through the case studies and have a direct relation to the core proposition of this thesis, namely that ownership of development aid is directly related to effectiveness and sustainability of development results.

\section{Background}

The multiple-case study method employed helped identify patterns and common themes (Yin, 2014) related to ownership, which effectively contributed to understanding of the phenomenon of ownership and constructing of the arguments. As argued throughout this thesis, the aid and development effectiveness discourse has promoted the principle of ownership with the clear implication that greater ownership means more effective development (Theisohn \& Lopes, 2013). The research findings indicate that this is an important theory and it has major implications, as argued in Chapter 4, essentially based on the rationale that development aid requires 'buy-in' (Chambers, 2014), and responsibility from those who are to benefit from aid and the development interventions. However, the current research found no concrete definition or consensus amongst stakeholders as to what 'ownership' of development aid means in policy and practice, especially within the civil society sector (CSOs) or how it is to be cultivated and potentially measured. 
Research also revealed that CSOs have the potential and are in an ideal position to cultivate ownership using the definition offered for ownership in this thesis, as well as the Ownership Guidelines and the Ownership Index to promote and cultivate ownership of development results by the project beneficiaries. As demonstrated in the case studies, some CSOs have adopted strategies (mainly through accountable partnerships) that can translate into ownership of development aid over the project cycle. However, there is no consensus on these strategies and further research and debate among stakeholders is needed to better understand ownership and how it can be cultivated.

Research showed that each community already has the capacity to create positive change, but that this capacity must be harnessed. What is currently lacking are programmes that encourage people to address their own problems and to take action towards the goals they themselves have identified. Evidence demonstrates that it is strategies and interventions, as such, that cultivate ownership, and that civil society can play an important role in this process and tap into the local knowledge, experience and skills, encouraging the communities to be more autonomous, responsible for their own development goals and active, making sure that it is the project beneficiaries at the grassroots who are more inclusively engaged in determining the objectives and leading the development process.

The three case studies analysed, confirmed the ownership definition offered in this research as the community or the individual's commitment and capacity to maintain and protect development outcomes, and clearly demonstrated that ownership of results can be preempted and incorporated into project design and cultivated over time. The case studies also revealed that the ingredients that formulate ownership are obvious and that they can be measured and that these particular variables of ownership can be nominated as indicators to better facilitate the tracking of the development progress and stimulate discussions.

In addition, research revealed that there are other dimensions to ownership that are not as obvious which are referred to here as Characteristics of Ownership which will be further discussed in this chapter. These Characteristics of Ownership need to be seriously taken into serious consideration especially by CSOs if ownership is to be cultivated:

- authentic participation, particularly the role of women; 
- accountability;

- transparency;

- leadership; and

- the enabling environment for CSOs.

Cultivating ownership through accountable and inclusive partnerships is about being equally engaged with and responsive to both the donors and to the project beneficiaries. The key challenge is ensuring a balanced, inclusive and accountable engagement while creating an enabling environment where the voices of the people are not overshadowed by the interests of the more powerful stakeholders.

\section{Analysis of the Case Studies}

As observed through the case studies, ownership has numerous components and that these components or indicators of ownership are all equally important and can be measured. Mainstreaming of Rural Development Innovation Tonga (MORDI), Pacific Community Network (PCN), and Ola Fou were selected deliberately for this research because amongst the CSOs closely examined in Fiji and Tonga they demonstrated the highest levels of partnership with the project beneficiaries and have successfully encouraged the communities they work with to actually identify the development change they desire and have thus effectively promoted ownership of development aid.

The assumption made in this research was that if the indicators of the index showed that the CSOs adopted for this research (which are amongst the best) struggle with certain aspects of ownership, such as the Design or Monitoring of the projects, or if they are effective because they get the recipients to identify development projects, then other CSOs are likely to have similar concerns.

The Ownership Index proved to be useful for making such analysis because it served as a 'talking point' and facilitated comparison of development results and detailed diagnosis of the development process and its phases. The information obtained provided an opportunity for discussion and learning about the obstacles and how CSOs can potentially improve in aligning the needs of the people they serve with those of the donor criteria, while ensuring 
that people are leading the process. In addition, it permitted gathering of more detailed data and documentation of results for comparison.

Average ownership ratings, for example, were attained using the information gathered from the three projects (see Appendix 8). Based on the average ownership ratings, the areas that partially highlight low rating in engagement can be used as talking points and can be offered greater attention in the future.

The information obtained with the help of the index, although partial, provides a picture of areas the community should be more involved with during future project cycles and areas that could be targeted for improvement. The data also reveals how involved different actors were in the project cycle, how they perceived the engagement, and how they could better contribute and influence the outcomes in the future. If women, for example, were not as involved in one area and a breakdown occurred in the project, it could be noted and discussed by the CSOs or by the community.

The gathering of the data through qualitative assessments with the support of the index offers a picture, especially to development practitioners, and highlights areas in which the CSO or the communities must be more engaged in future. A low rating of a certain segment of the index identifies the need for more attention and dialogue between stakeholders. Delving more deeply into the source data allows identification of the reasons for the low rating and the under-involved actors and these can be brought to the decision-making table. Areas with discrepancies imply a breakdown in understanding, highlighting the fact that the CSO and community need to come together to better align their expectations and improve their strategies and approach.

\section{Comparing Ownership of Development Results}

The interviews and case studies all indicated that the principle of recipient ownership of development aid can be defined and broken down into relevant ingredients and thoughtfully measured. The qualitative assessments that were conducted with the support of the Ownership Index revealed that high or low partial ratings of ownership could be recorded for future analysis, compared with other projects and used to determine the 
effectiveness of interventions at each phase. The partial ratings of ownership documented present a source of data for more careful diagnosis of the development results and opportunity for further analysis and discussion between stakeholders.

The Ownership Index goes hand in hand with the Ownership Guidelines, which will be discussed in detail in Chapter 10, and permits recording of the progress of development projects and the results achieved. Based on the data obtained, questions could be posed such as, how can partnership be enhanced in the low rating areas? Observations can be made and issues can be taken into account and dealt with. The Ownership Index and the ratings it produces although an estimate of the overall ownership are useful because they highlight the weak points within the development process and indicate that partnerships are effective or more attention is needed and in which phase of the development process precisely.

Measuring ownership and documenting the process is highly beneficial if it is not politically motivated and simply conducted to rate the feeling of ownership. The low rating of ownership, although partial, obviously points to an area in need of improvement. By digging into the individual ownership measures and constituent survey answers, CSOs are best situated to discuss the problem with the community, to identify the factors contributing towards low ownership and work with the community to determine the best strategy for increasing ownership, thus enhancing the sustainability of the development outcomes. By delving more deeply into the source data obtained through the index, the under-involved people/groups can be identified by the CSOs. Ownership ratings very clearly provide an opportunity for greater dialogue, while they also record the process for further analysis and facilitate comparing and equating the development outcomes and their effectiveness.

The interviews and qualitative assessments discussed throughout this research reveal that the women of the community are not properly engaged with the development processes in all case studies examined. This trend indicates a greater need for more emphasis and consideration of appropriate strategies that would bring the women of the community to the decision-making tables, making sure that project beneficiaries are inclusively invited to 
reflect on development outcomes that they would want to maintain and protect in the long term.

The ratings obtained and recorded with the support of the Ownership Index help in dissecting the development project cycle and improving strategies that can better influence future development outcomes and ensure more accountable partnerships and eventually greater ownership of development results. The challenge however is to be aware of and watchful of political motivations that tend to influence the ownership ratings. The Ownership Index is an effective tool; but what needs to be avoided and seriously taken into consideration is human error.

The Ownership Guidelines, and the Ownership Index are analytical and practical development tools for cultivating ownership and for identification of strengths and weaknesses of development partnerships towards development outcomes that project beneficiaries would want to maintain and protect over time.

If partnerships are accountable, the dialogue lasting and women of the community properly engaged, the ownership ratings will be fairly closely grouped and the level of ownership of development outcomes will be high. Otherwise, ratings are scattered, indicating divergence and lack of ownership of development results.

\section{Ownership Inflation}

An observation made through the qualitative assessments and the comparative analysis of the case studies is the difference between the ownership reported by the staff of CSOs and the ownership felt by the project beneficiaries through qualitative assessments. This amounts to a probable 'inflation' of ownership as reported and recorded by CSO staff compared to the levels of ownership felt by the communities. Research also revealed that some CSOs tend to inflate the ownership ratings of the community to win the confidence of their donors and to secure funding for future projects. This rosy reporting is common amongst CSOs and donors in general, and development results achieved are often exaggerated compared to the reality on the ground. 
This observation was facilitated with the help of the Ownership Index formulated for this research which enabled the recording and analysis of the perception of ownership of the development results at both ends of the spectrum (project implementers vs. project beneficiaries) which were then triangulated (See Appendix 9). Interviews and the data gathered reveal that community-reported ownership and CSO-reported ownership is different, showing that, in both PCN and MORDI's cases, for example, the CSOs have reported higher levels of ownership than the community has. This was the same scenario across most of the other case studies examined in the field. Interviews with the community members revealed that CSOs tend to claim to know the issues and challenges within the community and speak on behalf of the community, but do not always consult methodically with their project beneficiaries, especially with the women of the community. Interviews also revealed that CSOs are often more active in areas other than what the community has identified as priority, because they are delivering projects funded by donors and meeting donor criteria.

Amongst the CSOs examined, inflation of ownership is much less pronounced in the case of Ola Fou which reflects the awareness of the staff according to the project beneficiaries. Interviews revealed that this is mainly due to the fact that Ola Fou Youth Leaders are nominated by the community and selected based on merit and are aware of the issues within the communities they represent. Ola Fou Youth Leaders are often young, ambitious and are chosen from within and by the communities they represent which has a direct impact on development results because the Youth Leaders have to keep face and because they are, after all, serving their own community.

Most CSOs examined tend to avoid publishing or even debating development failures and tend to inflate development results as a strategy to maintain image and secure funding in the future. The large difference between the levels of ownership felt by the project implementers and project beneficiaries implies the need for greater alignment, harmonisation of development activities and strengthening of accountability systems, as well as the necessity of a more robust dialogue between stakeholders. 


\section{Characteristics of Ownership}

The semi-structured interviews and the qualitative assessments conducted while examining the case studies revealed a wealth of information on the question of ownership as observed, and helped the identification of the Nine Indicators of Ownership as research advanced. At the same time, other issues surfaced around the question of ownership which are harder to pinpoint and assess, but are essential and must be taken into consideration if ownership is to be cultivated. These important features are referred to as characteristics of ownership and are cross-cutting themes that must be seriously taken into consideration when cultivating ownership of development aid, namely the urgency and need for discussions around 'accountability', especially downwards to the people, as well as the need for further clarification on meaningful and authentic 'partnerships' and the dire need for healthier 'enabling environments' which must be highlighted, and carefully incorporated into the development process.

\section{Authentic Participation, and the Critical Role of Women}

Development thinking over recent decades has "shifted from a focus on things, to a focus on people" (Wrighton \& Overton, 2012, p. 245), and accountable participation has become one of the main pillars of sustainable development. Project beneficiaries must be shifted to the centre of the aid and development agenda and people must be appropriately informed, and inclusively involved in decision-making processes at each phase of the development process to influence and shape the expected development results as projects advance to make sure that the process is evolving towards outcomes that they would want to maintain and protect.

A key finding for this research is that partnerships can result and translate into ownership of development results by the project beneficiaries, especially when women are properly engaged and when partnerships are accountable. Partnerships, however, must be consistent, ongoing and genuine. Without accountable partnerships that are lasting and without inclusive dialogue throughout the development process, project outcomes will be skewed and unsustainable (Blewitt, 2014). When partnerships are accountable, CSOs (donors) openly invite stakeholders to the table and will constantly prompt the project 
beneficiaries at each phase of the development cycle to keep the end results and the question of maintenance and protection of the outcomes in mind. Partnerships are accountable when CSOs (donors) take the question of ownership of the outcomes into consideration at each phase and ensure that the stakeholders are invited to direct the projects towards the end results that they desire as they develop.

The case studies examined and observed meticulously for this research clearly demonstrated that accountable participation is an essential characteristic of ownership and can highly influence development outcomes, and that partnership strategies, when authentic, although varying in form and structure, can bring about development change that is wanted and maintained by the project beneficiaries. Candid and ongoing dialogue through the development process and "ensuring decisions are made inclusively by informed stakeholders is at the core of any effective partnership" (Cooke \& Kothari, 2001, p. 76).

At the same time, as discussed in Chapter 4, it is important to keep in mind that "partnership is a standard buzzword" (Ahmad, 2006, p. 629), and there is no consensus amongst the CSOs as to what partnership means in practice and in policy and how it is to be safeguarded. Most CSOs and donors often use the term 'partnership' without demonstrating the obligations in their work.

In most development projects, 'participation', similar to the term 'ownership', of development aid has become part of the rhetoric, and a political value to which institutions refer to for different reasons and mainly use the term because it is fashionable and because they want to secure funding. Participation, as with the concept of ownership, tends to be more of a way of talking rather than doing, and as it stands "it is not a verifiable methodology, but simply a global value" (Cooke \& Kothari, 2001, p. 31) within the modern aid and development discourse.

The case studies highlighted the challenges but also the benefits of ensuring authentic participation within the community, although 'the term 'community' is broad and can sometimes include people speaking different languages and practicing different faiths (Narayan, Chambers, Shah, \& Petesch, 2000)." What the case studies revealed clearly is that participation is another policy ideal, but it brings together different perspectives and 
interests at each segment of any development process and arriving at consensus is not easy, but when achieved can be highly rewarding and have a direct impact on sustainability and ownership of development outcomes.

'Participation', as a development term, has been highly contested and considered by some as another fuzzy word similar to the concept of 'ownership', both of which are "like the Trojan Horse, and arrive with the promise of a gift but only further dispose the poor from their locally mobilised resources" (Miraftab, 2004, p. 98). Participation purports to be a simple and necessary concept, yet it is a very complicated task and it must be handled carefully, because if not accurately defined in policy and in practice it "can be restraining and perpetuate certain sets of power relations" (Cooke \& Kothari, 2001, p. 11) and hence influence a range of issues, most importantly the effectiveness and sustainability of development outcomes and the ownership of development results.

The case studies, however, revealed that genuine and accountable partnerships that value and maintain ongoing dialogue cultivate ownership organically. They also revealed that there are various approaches to ensure partnership and that there is no one approach that can be agreed on and adopted. Observations from the case studies revealed that participation enhanced effectiveness, particularly when it was renewed at different phases of the development cycle through inclusive dialogue and when project beneficiaries were reminded that the project results belonged to them, that they needed to reflect about the outcomes desired, and that they must voice their concerns and shape the process towards development results that they want to maintain and protect over time. CSOs can play an important role in this process and genuinely align the needs of the people with donor criteria as projects advance. Consequently, the more accountable the CSOs, the more genuine and inclusive is the level of participation and the dialogue between the partners throughout the project cycle, and thus greater the level of ownership of the project outcomes by the project beneficiaries.

All evidence indicates that participation is an imperative factor within the aid and development arena and its effectiveness as a method can hardly be challenged (Blackburn, Chambers, \& Gaventa, 2000; Chambers, 1993; Gaventa, 2004b; Hickey \& Mohan, 2004; 
Tadesse et al., 2006). Partnerships are important because they are the essence of the development process and it is the process that shapes the product:

Consistent, and accountable participation throughout project cycle encourages development outcomes that are desired, maintained and owned by the project beneficiaries. (J. Martin, Interview, August, 2013).

The mapping of a perfect process for participation is still, however, blurred, and depends on the stakeholders and the context of participation, but the cases studied in this research revealed very clearly that women's participation and accountability are the two key factors. Persistence and continuity of an inclusive dialogue, despite challenges that might occur in the process, is a key factor that can strongly influence the outcomes. Through participation, project beneficiaries are often reinvigorated and heartened to think, to identify their own priorities and to shape their own destinies. Ensuring authentic and accountable participation is highly challenging, but as the case studies revealed, accountable participation is a proven and effective pathway for ensuring sustainability and effectiveness of development results that are desired by the people.

Women in the traditional settings of the South Pacific are, however, expected to abide by decision-making processes that are male-dominated (George, 2012; Wright, 1999). Decisions are typically made by the men of the community and women tend to maintain silence, as that is culturally and traditionally the norm. In Tongan society, for example, "men are the head of the family and there is a traditional family expectation that women should assume a subordinate role and submit to their husbands" (Fairbairn-Dunlop \& Lievore, 2007, pp. 24, 28).

Research, however, revealed that women play a vital role in cultivating ownership of development outcomes that are sustainable and effective, and that lack of women's presence and appropriate engagement in decision-making is an issue in the Pacific that needs to be addressed immediately. The women who participated in this research talked about how they are not consulted by the men for identification of development goals and that in general there is a lack of women's presence when it comes to the making of important decisions. 
Women are seldom consulted properly by the men when development goals are being identified. This has always been the norm on the islands of the Pacific and this is why development results are not as effective, or sustainable. (L. Lewa, Interview, July, 2013)

At the same time, women who participated and informed this research highlighted the fact that they are often in tune with what the men of the community want and tend to place their own priorities after the concerns of the men of their community:

Women are often present at the meetings on the islands, but they are not speaking their minds because of old traditional values and their upbringing. (L. Lewa, Interview, July, 2013)

Research revealed that this has a direct impact on the ownership of development results. Appendix 10 exhibits an estimate of the perception of ownership felt by the women of the community after the projects were completed in comparison to the levels of ownership of the outcomes perceived by the staff of implementing agencies. This diagram was formulated based on the information obtained in response to Measure 16 of the Ownership Survey, posed to both the Project beneficiaries and to the project implementers (see also Appendix 4 and 5).

Of the three CSOs examined, women's engagement was only reported as being high by MORDI staff. This high rating from MORDI is a reflection of inflation of the perception of ownership by the MORDI staff. When interviewed, community members reported that the MORDI staff have a much higher perception of the ownership of development projects by the women of the community than is actually the reality within the community, and that CSOs, as well as other stakeholders, must address this problem immediately and further contemplate on how to boost and enhance women's engagement.

Many women who participated in the research spoke about how being present and 'apparently' participating in a community meeting does not mean that women will actually speak their mind and truly participate as there are cultural norms and unspoken rules that dominate the structure of the Pacific communities, and that in general the culture of silence 
dominates. All of the case studies examined for this research revealed that the low level of women's engagement in decision-making has negatively affected the overall level of ownership of development outcomes. However, of the three CSOs, Ola Fou Alumni were more aware of the problem (see Appendix 10) and admitted the challenge they were facing and how they are seeking greater participation of women in decision-making and identification of development goals.

The case studies, especially interviews with the women of the community, revealed that the first two phases of development projects are particularly important and that women must be present in identification of the problems and their solutions in the community and that their presence is critical and necessary throughout the development process at each phase of the development project.

Close observation of project outcomes and interviews revealed that if women's presence is high during the development process and if they are engaged in decision-making, then there is a greater chance of women following up with the development process more robustly, and, at times when necessary, holding the men accountable and following up to make sure the project is advancing towards agreed goals and the expected results.

In contrast, projects tend to have lower levels of ownership and fall apart when women are excluded from the debate. The more women have a say and the more they voice their concerns from the start, the more sustainable the outcomes. The numerous projects and case studies examined in the context of the South Pacific with the support of the Ownership Index reveal a worrying variance, indicating that the levels of ownership reported by women are insufficient and often inflated by most project implementers, which has a direct impact on the effectiveness of development results and that this characteristic of ownership and the role women play has a direct impact on the sustainability of development outcomes and the commitment of the communities to maintain and protect the development outcomes.

\section{Accountability and Ownership}

The data collected from close examination of the civil society sector in both Fiji and Tonga reveals that accountability standards are vague, especially downward to the project 
beneficiaries. Accountability cannot exist without answerability especially financial and proper procedures and accounting practices; in other words, an absence of transparent accounting within the civil society arena equals an absence of accountability.

Unfortunately, there is no consensus yet within the civil society sector or amongst donor governments as to what accountability means in practice, reporting and sharing of information (Boomsma et al., 2010). CSOs claim to be in tune with community needs, but in practice and in reality they are restrained and controlled by their donors and funding strings (Ebrahim, 2003; Nancy \& Yontcheva, 2006). What became apparent, especially as research advanced, is the need for and lack of downward accountability to the people. The "accountability structures are tilted towards the donors" (Peruzzotti, 2011, p. 62), which is the main reason why most development outcomes are not as sustainable as they should be. If development aid is to become more effective and if ownership is to be cultivated, ample attention must be paid to reporting structures and especially to accountability downwards and ideally a shift in thinking to bring about "change in power relations within the organisations" (James, 2002, p. 146).

Research revealed that accountability is a major issue, but:

Accountability is not a question that CSOs like to talk about, as they are already under-resourced and face numerous challenges and fear that further accountability procedures will complicate their work even further. (H. Khan, Interview, July, 2013)

As demonstrated through the case studies, and as argued throughout this research, enhancing accountability, especially downwards to the people will have many positive impacts and can make aid and development more effective and sustainable because it means that aid and development actors are engaging the project beneficiaries more robustly with the development process. Accountability between partners is demonstrated in two ways; CSOs have to demonstrate accountability to the project beneficiaries as well as their donors and funders, but "in practice accountability downwards is rare, and weak" (Chambers, 2013, p. 210). 
As observed through the case studies and highlighted through the literature, accountability has a direct psychological connection to 'ownership' (Pierce \& Jussila, 2011). Hence it seems to be obvious that the shortcut to more effective development is focusing on accountability, and that aid and development is about quality, not quantity, and that "accountability is a responsibility" (Eyben, 2008, p. 9) and should be the most obvious priority for the CSOs.

If the people are to take charge of their destiny, and if ownership cultivated to make development aid more sustainable, then accountability of the CSOs, especially towards their project beneficiaries, must be moved to centre-stage, but this is not easily achieved because it demands "change of mind-sets and behaviours" (Chambers, 2013, p. 78), and requires that CSOs disempower themselves to empower the people.

Research revealed that one of the main difficulties with the accountability procedures is the fact that accountability is a culturally diverse phenomenon and it means different things to different people. This is particularly apparent within the context of the South Pacific Islands but CSOs are in an excellent position to become more proactive and discuss the topic further, especially with their project beneficiaries, because they are theoretically the watchdogs and frequently demand accountability from the governments and the private sector:

To gain the confidence of the donors, the governments and the people, civil society must 'walk its own talk' and take the lead in defining, promoting, and ensuring accountability. (Lord Fakafanua, Interview, August, 2013)

CSOs examined for this research admitted that they had strings attached to them by the donors that directed their moves, and that:

There are no agreed standards, shared policies, or codes of conducts in Fiji and Tonga for accountability of CSOs downwards towards the project beneficiaries. (F. Seu'ula, Interview, August, 2013)

It was also stated that CSOs have no choice in general but to focus on their own accountability standards upwards to their donors based on their dependence on donor 
funding, and that there are currently no rules or regulations within the civil society sector that demand downward accountability to the people.

The challenge, therefore, is identifying the strategic ways in which CSOs can improve their accountability downwards to their project beneficiaries, because the absence of genuine accountability standards and how they can be improved and strengthened downwards to the people is simply the biggest impediment to effectiveness of development aid and it is surprising that donors are not addressing this issue more vigorously.

The question of accountability, especially to project beneficiaries, was raised by almost all of the research participants during the examination of the role of civil society in promoting and cultivating ownership of development aid in the Pacific Islands examined for this research. The issue of accountability downwards to the people is sensitive and challenging, but largely ignored and overlooked by the civil society and very few CSOs promote or uphold the debate. Research revealed that CSOs are not willing to admit or share information on failed development projects, and that they avoid identification of their areas of weakness. In short, CSOs rarely admit failure as admittance to failure can directly influence their funding.

Accountability demands courage and transparency, but because of a range of different issues, particularly their dependence on donor funding, CSOs lack the courage to be transparent. If taken into consideration appropriately, accountability can be a vital tool for more effective development and promotion of ownership as both "accountability and ownership are key to sustainable development" (Theisohn, 2013, p. 21). Civil society's lack of proactivity and the 'dodging of the bullet' of accountability provides the critics of civil society the leverage that is gaining ground. At the heart of this critique is the contention that "responsible donors are primarily accountable to the people" (Theisohn, 2013, p. 11), but the situation is challenging because CSOs depend on donor funding for survival while "donors tend to play god" (James, 2002, p. 148).

Accountability standards are hence tilted upwards and towards the donors. Civil society with all its potential has not been as effective as it can be, because it has not been accountable to those it seeks to benefit and because the aid and development agenda is short-sighted. What became clear, however, during the course of this research on the 
question of ownership is that accountability downwards to the people is essential, and that CSOs must concentrate on accountability downwards to the communities that they serve as well as aligning their work with donor demands.

It is important to note that the concept of accountability is beyond the scope of this research, while considerable research was conducted on the question as research progressed. The literature on the topic is sadly narrow, but here are few suggestions for

further reading: (R. Gray, Bebbington, \& Collison, 2006; Jacobs \& Wilford, 2010; Jordan, 2005; Jordan \& van Tuijl, 2006; Kaldor, 2003; Kaler, 2002; Lloyd, 2005; Mfunwa, 2006; Seidenfeld, 2001; Tomlinson, 2011). Further enquiry and debate between the stakeholders is needed to better understand the complexities of accountability and the essential role it plays in cultivating change that is community driven and sustainable.

\section{Transparency}

Countless CSOs examined for this research did not share financial details of any of their development projects and strongly refused to share particulars of their project finances. In the interest of this research, the CSOs who participated referred to their annual reports as evidence of their transparency and accountability. MORDI, Ola Fou, and PCN each have selfregulatory systems in place to demonstrate accountability to their stakeholders, but the problem with this approach is that the lessons learnt and the mistakes (if any) are not shared widely and failures are simply veiled instead of openly being shared with stakeholders.

Interviews, as well as close examination of the work and financial reporting of CSOs examined for this research, revealed that CSOs aim to target donor priorities and carefully balance donor criteria with their own obligations to the communities they serve, and that some CSOs are aware that:

Lack of transparency in decision-making and finances downwards to the people means lack of accountability in partnerships, which over time translates into ineffective and unsustainable development aid. (Barr, Interview, July, 2013) 
To enhance their roles as mediators and to lead and build greater trust and accountability, CSOs could consider becoming more transparent, share information more generously and introduce more robust measures such as open door strategies to external reviews. As discussed in Chapter 4, ownership and its characteristics, especially transparency, which is viewed as accountability, can have a major impact on development results if taken more seriously into consideration, but research in the Pacific reveals both accountability and ownership principles are still vague concepts in policy and practice, and are a challenge to ensure, especially within the civil society arena. Their implications must be discussed and their role and influence understood for development aid to become more effective and sustainable.

Transparency fosters greater accountability (Lisk, Besada, \& Martin, 2013) and accountability fosters greater ownership as argued throughout this research. By demonstrating transparency, development actors can demonstrate greater accountability, and civil society is very well placed to lead this agenda, set examples of robust accountability structures and oblige both governments and the private sector to become more transparent. Financial transparency, sharing of information and lucidity in decisionmaking throughout the development process can have a direct impact on communities as they will be able to better understand, engage and influence the development agenda:

Transparency, both financial but especially transparency in decisionmaking strengthens 'partnerships' and encourages stakeholders to engage more with the development 'process' and safeguard ownership of development change. (D. Havea, Interview, August, 2013)

Transparency is seen as directly related to accountability within the aid and development literature (Kaufmann, 2009; Steer, Wathne, \& Driscoll, 2009; Tujan Jr, 2012), but research reveals that transparency is not as valued and demonstrated in practice amongst development actors. Research also revealed that transparency, especially in decisionmaking, at each phase of the development process is an important dimension of accountability and an essential characteristic of ownership that needs to be seriously taken into consideration if development aid is to become more effective and sustainable. 
The case of the PCN reveals that transparency can lead to ownership of change and bring about public trust, which is crucial for building the legitimacy of civil society and fostering partnerships, especially if civil society is demanding accountability from government and the private sector. Only if decision-making processes are fully transparent and trust is created, will appropriate accountability be possible and ownership of desired change cultivated.

It was suggested by both Soane, MORDI Director, and Barr, the founder of PCN, that there is lack of transparency within the civil society in regards to funding transactions, but especially when it comes to development project failures, as failures are not welcomed or talked about within the aid and development industry. This flaw is naturally caused by CSOs fear, and desire to secure future funding and maintain a positive reputation in the face of the donors and the communities that they serve. Accountability is often talked about by CSOs, but is only valid when it is verified. CSOs can gain the trust of both the people and their funders if they demonstrate transparency and enhance their accountability as mediators between donors and the people, (Unerman, O'Dwyer, Gray, Bebbington, \& Collison, 2006). According to Tonga's Clerk of the Legislative Assembly:

Transparency and accountability cannot be forced on to the civil society. Instead, a culture must be nurtured that truly values and promotes these concepts as ideals. (G. Pale'o, Interview, August, 2013)

Most CSOs, however, are quick to demand transparency from governments and the market (Essia \& Yearoo, 2009). They blame the governments and private sector for lack of accountability and transparency, yet they have failed so far in improving their own approach. It is time for CSOs to reconsider their policies and ensure greater transparency, which, as research reveals, can make development aid comprehensively more effective and cultivate ownership of development aid. As it will be further discussed in this next section, transparency is an essential pillar of accountability and a strong characteristic of ownership and vital for cultivating change that is maintained and protected by the people over time. 


\section{Leadership}

Another characteristic of ownership and an issue that constantly surfaced in interviews was the question of 'leadership' and its relation to ownership amongst both donors and governments at the regional level and also within the civil society sector and especially within the communities:

Ownership is synonymous with leadership. An effective and an accountable leader will reflect about the question of ownership of development results and will make sure that people are informed, consulted and engaged with the progress of development plans from the start. (Alamoti, Interview, August 2013)

It was interesting to note how effective CSOs and successful communities in both Fiji and Tonga have outspoken and knowledgeable directors in charge, and how their organisational leadership has had a major influence on the outcome of their development work. However, as observed with MORDI, there are no succession plans in civil society and for the directors of the CSOs examined, and when they move on to their next job, in most cases they tend to take their institutional knowledge with them:

Often with the change of the leadership there is a massive loss of expertise in civil society, for rarely the experience and lessons learnt of the CSOs are documented internally. (S. Ilolahia, Interview, August, 2013)

MORDI proved to be a good example of this as the community members and the staff referred to Soane as the pillar of the MORDI success.

The most important asset of any organisation is its leader (Alamoti, Interview, August 2013)

According to Alamoti and numerous other research participants "it is due to the diligence and work standards of its general manager (Soane) that MORDI has consistently demonstrated disciplined financial and project management". It is assumed that community representatives and civil society leaders are appropriately and democratically elected, and 
that they represent and speak on behalf of everyone (Gaventa, 2004a, 2004b; Pallas, 2013; Tadesse et al., 2006), but this is far from the reality in practice:

Some civil society leaders have remained in the same position for so long. They are leaders who understand how to connect with donors and how to align community needs with donor criteria. (S. Ilolahia, Interview, August, 2013)

Some civil society leaders in Fiji have stayed at the helm of the same organisation for some 20 years, and have no succession plan for the leadership of the organisation they lead. As a result, they often become disconnected from the communities they serve and begin to demonstrate a lack of downward accountability to the people. Leaders as such tend to be much more aligned in thinking and approach with their donors and their criteria instead of the people they serve. As discourse around accountability is escalating the question of leadership must be taken further into consideration (L. David Brown \& Moore, 2001).

Research in both Fiji and Tonga showed that leadership is an essential characteristic of ownership, but that it is not a common practice within the civil society sector to consider succession plans for civil society leaders. In fact, it is unheard of, as local CSO leaders in some cases are the founders of the organisations they lead and strongly identify with the organisations they have formed and represent:

Civil society leaders as such, following the effective initial establishment of their organisation, cannot let go of the organisations they have formed. They have secured funding and have shaped their institution over time; and hence cling on to their position, their organisation, and have what is known as the 'Founder's Syndrome'. (R. Yee, Interview, June, 2013)

Research, however, revealed that the success of development aid depends greatly on the role and the sphere of influence of the community leaders, their accountability, and the strategies that they adopt to ensure effective and sustainable change over time:

The more legitimate, accountable, informed, and connected the leaders are, the more they engage with the people they serve and the more they 
ensure that the decisions made are inclusive, and that the women and the marginalised groups in the community are properly engaged and that the decision made are community-driven. Development change, as such, is change that is sustainable and 'owned' by the people. (J. Madraiwiwi, Interview, August, 2013)

Good leaders are very few and they are in touch with the pulse of the community. As observed in Fiji and Tonga however, the focus of development aid is often on finding technical and Western solutions to local problems (Cracknell, 2000), starting with foreign expert diagnoses of what is wrong in the community, to recommendations of good development projects by external consultants, to assistance toward transplanting good development practices. Uneven results arising from this approach suggest that addressing development problems includes, but goes beyond, technical solutions, and that the people within each community should be the instigators of change themselves.

When people have leadership that promotes a sense of ownership and engages them in bringing about change that they desire, then people are likely to be more committed, and development outcomes are more successful, effective, and sustainable (Goleman, 2003).

Successful development programs have numerous characteristics and a range of questions must be taken into consideration. Leadership, both communal and organisational, however, is a weighty and influential factor and can have a major implication on development results and the ownership of the outcomes. Accountable leadership brings the right people together and ensures collaboration between all stakeholders toward achieving a complex set of desired objectives (Gurdjian, Halbeisen, \& Lane, 2014).

Leadership never takes place in a void, but always in a particular context and in relation to expected results and what the people truly want. Thus, it must be highlighted as it was observed through the case studies examined for this research, that leaders can play a key role in cultivating ownership. A complex, yet direct, relationship exists between leadership and ownership of development aid and this characteristic of ownership, both organisational and communal (leadership) is a critical factor that must be taken into consideration for safeguarding the effectiveness, quality, and sustainability of development outcomes. 
Interviews with community members, however, revealed that people are not always properly informed or engaged in decision-making processes;

The more informed the people are, the better decisions they can make. Most people lack 'ideas' and do not even know what they want for themselves or for their community. Majority of people want the answers to be given to them. They want the path to be easy and identified for them, while they fear change, and often cling on to the old traditional ways. (A. Waqetia, Interview, August, 2013)

Making the right decisions at each phase of the development process is essential, and leaders can play a vital role in this process. Leaders, both within the communities, on behalf of project beneficiaries, and within civil society as project implementers, are responsible for development results and must ensure that fair and just methods are adopted and that decisions made have a positive and sustainable impact on the future of the community.

There are, however, different decision-making structures in Fiji and Tonga that directly influence development project outcomes. The first is through traditional structures, such as the vanua in Fiji, as referred to in Chapter 4. These traditional pathways for leadership are hereditary and the decisions made in this fashion, although apparently accepted by the community, are often contested, especially by the more educated women of the community and the youth (Douglas, 1979; Gaventa, 2004b).

Many of the research participants complained about the importance of leadership and the challenges they are facing within their own communities, most importantly the puzzling decision-making systems that they have to deal with:

An individual today in Fiji or any other South Pacific island is subservient to three decision-making authorities; the first is the vanua and old traditional structures, which still dominate and particularly ignores the voice of the women and youth in decision-making. The second is the government, which is often not democratic, and the third dominant structure that profoundly influences all aspects of life including the way decisions are 
taken, being the religious authorities which are predominantly the church.

(A. Waqetia, Interview, July, 2013)

Amongst CSOs examined, Ola Fou is the one organisation which is addressing the question of leadership and is aiming to reform decision-making structures by strongly engaging the youth while promoting a new form of leadership across the South Pacific: one which emerges democratically within the community, works for the community and maintains power based on merit and results achieved. Research revealed that this pathway to leadership is highly effective and stems out of self-determination and the capacity to think, question, envision and ensure that everyone in the community, especially women and youth, are given a voice and that they are involved in decision-making processes.

Current structures of leadership lack the capacity to take appropriate decisions for the good of the majority and drain the people's energy financially and spiritually. Majority of the people do as they are told and give all that they have to the traditional chiefs, to the church, and to the corrupt governments and wait for others to improve their lives but they neglect the role they can play themselves. (L. Lewa, Interview, July, 2013)

Thus, through a delicate range of subtle and mainly indigenous approaches, some CSOs, like Ola Fou, are addressing the importance of leadership, and the need for just and inclusive decision-making structures. Effective CSOs as such are making sure that the people are awakened to their potential and realise that they can actually lead the development they seek, and that they do not need to always rely on external help.

Effective leaders are thus partners who succeed in instilling in the minds of each person in the community that they are capable to determine the change desired and to take ownership of the development process. Each community and development scenario is, however, different and there is no one leadership strategy that can fill the existing void. However, what research on the question of ownership revealed, as discussed, is that leadership is directly related to development aid which is more effective, sustainable and desired by the people. 


\section{The Enabling Environment}

The last but not least important characteristic of ownership is the enabling environment of civil society. CSOs over the years, despite their shortcomings, have managed to successfully bridge the gap between donors (governments) and the vulnerable people at the grassroots (Foley \& Edwards, 1996; Van Rooy, 2013). Civil society has succeeded to manoeuvre around obstacles and challenges often imposed by the governments. Civil society, however, must secure its lawful and legal position more strongly and to ensure that it is a legitimate and 'just' mediator who is accountable and trusted by all stakeholders, because CSOs in the context of development aid are in an ideal position to cultivate partnerships between governments and the communities and to promote change that is desired by the people (OECD, 2009).

Research participants who work with the CSOs in both Fiji and Tonga often paint a very limiting, enabling environment and highlight the challenges that civil society, in general, is facing as a sector, and how governments need to better recognise their important role and improve the enabling environment so that the sector can play a more effective and independent role.

Close inspection of CSOs for this research undertaken at the National Umbrella Organisations of Fiji and Tonga and in collaboration with the regional umbrella organisation for CSOs in the Pacific was very helpful. It revealed some not very obvious facts about the constantly changing, enabling environment of the CSOs in the region, the pressure from the governments and the lack of satisfactory sharing of information.

The enabling environment of CSOs in both Fiji and Tonga, for example, is dependent on a complex set of conditions, which include political factors, internal laws and regulations and administrative factors affecting the way in which CSOs work with stakeholders - mainly with their donors, governments and the people. But overall the civil society sector in the Pacific could benefit from further research on how to improve its effectiveness and development results on the ground and within the communities it serves, as "there is hardly any detailed information available on CSOs in the Pacific" (Pegus, 2013, p. 12). 
Analysing the work of CSOs revealed that development CSOs have a complex enabling environment, especially in Fiji, because they tend to be more political and speak out against human rights abuses and so have a very challenging relationship with the government. Some CSOs in Fiji have been very open and active about human rights abuses during the past ten years (Merry, 2009). They are using foreign donor funding to voice their concerns, which has made them suspicious in the eyes of Fiji's military regime, and has made their enabling environment very limited, since they are seen to be advancing political agendas that are set by foreign governments (Fisher, 1998, p. 110).

Despite the challenging environment, CSOs have become more active and effective during the past decade. There is a lack of harmony and alignment within the sector, however, and this factor tends to make the enabling environment for civil society even more difficult. According to the director of the Fiji civil society umbrella organisation Fiji Council of Social Services (FCOSS):

There is pressure on the civil society by the government of Fiji, and CSOs are in general ignored and often dismissed as unaccountable. The fact that civil society in Fiji lacks alignment in their activities, and does not address the big question of accountability has worsened the situation and has made the enabling environment of the CSOs even more restraining. $(\mathrm{H}$. Khan, Interview, June, 2913)

Another research participant in Fiji equally summed up the enabling environment of CSOs in Fiji as frustrating:

CSOs have to abide with government rules on one side and have to align activities with donor criteria to secure funding on the other side. The risk of questioning donor or government policies, equals the risk of being shut down or financially excluded. (A. Singh, Interview, July, 2013).

The challenges that civil society is facing are numerous. The situation is not as perplexing in Tonga, but it is the funding that influences the accountability structures all the same, and as 
a result it is the people that feel the pressure, and end up being driven by donor agendas instead of pursuing the changes they desire.

The government of Tonga affiliates much more strongly with civil society than does the government of Fiji, and the relationship between the stakeholders is much more functional in Tonga. What is, however, primarily lacking is inclusive dialogue - especially consultation with stakeholders for design of development policy.

The Ministry of Finance of the Kingdom in Nukualofa, which is the focal point for donors in Tonga lacks capacity and conducts consultation with the civil society always at the last minute and normally simply shares development plans and policy with the Civil Society Forum of Tonga (CSFT) only a week or two before the policy is adopted which makes these consultations tokenistic as discussed in Chapter 5.

Several research participants in Tonga talked about how CSOs are more aligned in thinking with the donors and ironically better understand the challenges of the Tongan government than the communities they serve. According to the Director of the Tonga NLU:

To secure funding, CSOs in Tonga have no choice but to align their activities and their thinking with donors. (S. Ilolahia, Interview, August, 2013)

According to llolahia there is a lack of genuine and sincere dialogue on aid and development issues in Tonga between the stakeholders. There is ample competition for donor funding and participatory structures for consultation with the project beneficiaries are weak. Partnerships are especially weak between the CSOs and their project beneficiaries, which makes the situation complex and the people suffer as a result;

There is lack of harmonisation, alignment and sharing of information within the civil society sector, and CSOs all compete with one another to secure donor funding. (S. Ilolahia, Interview, August, 2013)

The National Emergency Management Office (NEMO) is the centre for humanitarian responses in Tonga and works in collaboration with national and international nongovernmental organisations in Tonga and across the Pacific. The Director of NEMO, Mr Aho, 
participated in this research, and discussed the enabling environment of civil society in the South Pacific and the challenges CSOs are facing:

"Politics of funding skews ownership of development results. Money influences partnerships. While donor funding is the salvation for CSOs. The continued dependence on donor funding means that the manipulation of agendas takes place. CSOs, as a result, are becoming more detached from their project beneficiaries and more aligned with the objectives of their donors. At the other end, donors change focus and policy often, and demand CSOs to follow suit in order to be qualify for further funding. (L. Aho, Interview, August, 2013).

Research in the context of the South Pacific thus reveals that donors and governments must proactively engage with the civil society and improve the enabling environment of CSOs especially the legal, financial conditions, and accountability mechanisms.

\section{Conclusion}

As observed through the case studies and discussed in this chapter, ownership of development aid is an important political question which has a direct impact on the effectiveness and sustainability of aid and development results.

The problem, however, is the multiple interpretations of the term 'ownership and an absence of consensus amongst the stakeholders on a solid definition for the concept within the aid and development arena, as discussed throughout this thesis. Research, nevertheless, revealed that the phenomenon of ownership is definable, although complex, and that there are a range of ownership variables that can be observed, cultivated and measured as well as a series of characteristics that, if taken into consideration, will ensure and safeguard sustainability of development results and bring about ownership of development change by the people.

Observing the case studies revealed that ownership is the result of careful reflection, accountable partnerships and persistence in dialogue throughout the development process. The case studies examined demonstrated the practicality of the definition of ownership 
offered in this research and the usefulness of taking ownership methodically into consideration at each stage of the development process.

Research reveals that cultivation of ownership of development aid by the project beneficiaries is in fact an operational and a practical remedy for safeguarding more effective and sustainable development aid. The more involvement and engagement people have in identification of the development goals and decision-making as development unfolds, the more they are capable of bringing about change in their communities that they would want to maintain and protect.

Research also revealed that the principle of ownership is an end in itself, and not just a condition of successful development aid. The case studies revealed that the integration of local knowledge, especially authentic participation of women, is vital for ensuring ownership and sustainability of development outcomes. Project beneficiaries must all be listened to and engaged at each phase of the development process as projects advance because they play a major role in maintaining and protecting the development outcomes in the long term.

Thus, research and the case studies observed and analysed in the context of the Pacific reveal that the ownership definition offered in this research, the Ownership Guidelines and the Ownership Index formulated have the potential to serve practitioners especially within the civil society arena as a practical tool to promote, and cultivate ownership of development aid and to make development aid more sustainable and effective. An enabling environment, however, is a prerequisite where all the project beneficiaries are engaged, empowered (especially women) and accountably partnered with, towards implementation of development outcomes that are maintained and protected by the people.

Development aid is effective and sustainable when project beneficiaries determine and identify the change they desire and when they take charge of their own development agenda and become self-reliant. This can only be realised when cultivation of ownership and upholding of its ingredients and characteristics are seriously taken into consideration. 


\section{Chapter 10}

\section{Conclusion}

\section{Introduction}

In this concluding chapter, I will summarise the main findings and arguments that have been triangulated and rendered into conclusions. This chapter will highlight the philosophy and the new definition offered for ownership, present the Nine Indictors of Ownership unearthed, and will deliberate on the importance of the variables of ownership identified. The Ownership Index, and the Guidelines formulated for this research will also be discussed as well as the critical role civil society can play in cultivating ownership by way of taking these variable indicators of ownership into consideration. Final conclusions are then made as to how this research contributes to the aid effectiveness debate, and development results that project beneficiaries would want to maintain and protect.

\section{Significance of this Study}

This study is important because it offers a new and practical definition for ownership and presents new tools to cultivate and to measure ownership of development aid. This thesis highlights the Nine Indicators of Ownership which were identified through close examination of the case studies that are measurable and that serve as a practical scaffolding that hold the ownership definition offered intact and support the cultivation and assessment of ownership of development aid. As a result, what this thesis offers is essentially a starting point for what can become an applied strategy for promoting, cultivating and assessing ownership of development aid by the project beneficiaries.

This thesis contributes to a range of bodies of literature within the social sciences, such as public policy, development practice, and promotion of human rights. Most notably it contributes towards the largely overlooked debate around how aid can become more effective (Chambers, 2014; Collier, 2010; Hughes, 2003; Sen, 2001): and especially the role that project beneficiaries and people at the grassroots can play. The aid and development industry is not as effective as it can be (Blackburn et al., 2000; Chambers, 2013; Kaldor et al., 2003) and there is ample room to improve the effectiveness and sustainability of 
development aid (Pegus, 2013; UNDP, 2012). The important question is how aid and development industry can become more effective and sustainable, and how the sector can promote greater accountability downwards to the people, especially to the project beneficiaries and cultivate change that people desire and would want to maintain and protect over time.

\section{Philosophy}

Research on the question of ownership in development aid, as well as the literature, reveals that "development results are more effective when the process of development is organic verses when development is intentional" (Baaz, 2005, p. 37). Delivery of development aid can be very complex, but unfortunately this distinction is neglected and lost in the contemporary development context.

The aid and development industry is multifaceted today, because there is a need for intentional intervention and development practice to create order out of social disorder (Crush, 1995); but most development processes today are far away from being organic. "Development proceeds through different stages" (Baaz, 2005, p. 40). Steps must be taken willingly and inclusively according to the pace of the people and in the direction identified by the people, through accountable partnerships and appropriate inclusive dialogue to avoid a variety of problems over time and to ensure ownership of development outcomes. Yet, this is not the case in most development situations observed in the Pacific.

Development results examined for this research revealed that steps are sometimes taken too fast, consultation with the project beneficiaries in certain stages of development process often skipped, and that people are not always appropriately listened to, engaged in monitoring, evaluation, or invited inclusively and methodically to think and reflect at each stage on the long term changes needed and the development outcomes that they would want to maintain and protect over time. The question is how project beneficiaries can be better informed and encouraged to lead and determine the change they desire.

As observed in Chapters 7 and 8, development can be highly effective when it is organic, when the 'process' is seriously taken into consideration and especially when the people are invited to think for themselves, identify their own problems and the solutions for their 
problems and to engage in a long-term dialogue as development process unfolds. What is essential is for people to reflect and to identify the change they desire and to actively participate in the process. To achieve this, situations must be created where donors engage with their partners and listen more judiciously and create conditions where partner knowledge and feelings and understanding are taken more seriously into account. Donors must primarily educate and inform partners and assist them in thinking critically about the changes that they would want to maintain and protect over time.

It is interesting to note how the few CSOs that are renowned for their solid partnership and connection to the communities seem to be inspired by the philosophy of Paulo Freire. This may be due to the fact that underneath Freire's apparent activist approach lies a deep respect for the poor and the oppressed people and an admiration for their own understanding and standpoint of the world they inhabit. Freire believed that we can 'know' the world and that we can change it through a process of reflection, and dialogue. Freire argued that the act of knowing involves a dialectical movement that goes from action to reflection and from reflection upon action again (Freire, 1973a), but that all this must be driven by the free and informed individual.

What is apparent is that the world, the society and the individual are not fixed. We are constantly changing. There is no fixed state of being. Equally, there is no one fixed truth, or pathway. We are constantly changing, and evolving physically and spiritually. Evidence reveals that the so-called truth is thus a 'process', and it is relative and dependent on where we stand and how we are taught to see and perceive the world (Nietzsche, 1887/1992). Once our perception and our so-called 'truth' is unveiled, it is open to transformation (Heidegger \& McNeill, 1943). This transformation and so-called 'becoming' is achieved in part and shared through the power of language and words (Wittgenstein, 1921). It is possible to imagine a new and different reality. Communicating a new reality and creating a new world, however, is dependent on how we use language and the power of words (Wittgenstein et al., 1969) as language can be used to oppress or to free the individual. People must think for themselves, understand and identify their own path. People then can use language to share their understanding, experience and objectives. Instead, people are often taught to follow, and are conditioned to view the practices and behaviours of a certain successful individual or group as correct. To become whole, complete and correct, the 
individual and the community is encouraged to simulate already tested and approved practices and to imitate instead of innovate.

To counter this perception and to cultivate lasting and self-actualised effective development that is 'owned' by the people, individuals and communities around the world must be better educated, informed, and encouraged to self-actualise and learn to tap into their own resources and imagination. People everywhere must be encouraged to reflect and to take charge of their own development challenges and take ownership of change that they would want to maintain and protect over time.

The philosophy of ownership demands robust thinking, self-reflection and selfdetermination. It demands that the individual and the community arrive at naming the desired goals and objectives and the accurate use of words and language as discussed in Chapter 4. Robust dialogue is the next pillar of sustainability in this process and a must. Development aid, will not last when it is dictated, when words, ideals, goals and development projects are projected onto the individual and the community and carried out mechanically and autocratically. Instead, effective development is achieved when the consciousness is cultivated and when the individual is awakened (Freire, 1968).

Thus, philosophically speaking, potential project beneficiaries must be invited to explore their own reality and encouraged to identify the change and the development they seek, instead of implementing external solutions offered. Ideally, aid and development actors will help their partners realise that the world is a transformable place, rather than an inescapable equilibrium, and that every individual is capable to think, imagine, and shape the world and its so-called reality. This method and thinking is often criticised as utopian, but it can be highly gratifying. The important elements that must be taken seriously into consideration is the prominence of questioning, self-reflection and self-determination, which cultivates individuals who are both objects but also subjects of the world, and who lead their own development and ensure change that they desire, and would want to maintain and protect over time.

Ownership of development results, as argued throughout this research, can be achieved and benefits will be lasting and effective when people think about the change they desire, when they identify their 'own' goals and the development they want to see and when they take 
the necessary actions. This very ability to look within and to reflect on change needed, to ask questions, and to imagine, plan and act towards expected development results shapes the world based on reason, and brings about change that is maintained and protected over time.

\section{A New Definition for Ownership}

This research unearthed a detailed analysis of the question of ownership of development aid from a 'bottom-up perspective' with a focus on the role of the people throughout the development process and their engagement with development actors. Through the use of the case studies, the anatomy of ownership was deconstructed. Examination of the case studies demonstrated that ownership is directly dependent on inclusive decision-making and insertion of ownership as a desired outcome into the development process from the start, which would permit revival of ownership (maintenance and protection of the outcomes) at different stages of the development process, while taking into consideration a range of other factors (the characteristics of ownership discussed in Chapter 9).

Close analysis of the case studies and how ownership is being cultivated by seemingly highly effective CSOs revealed that ownership is not as complex and multifaceted as it is made out to be within the international aid and development discourse and that it can be defined. Ownership of development aid by the project beneficiaries has obvious ingredients and these ingredients can be carefully detected and observed as variable indicators and injected into the development process. Research also revealed that ownership can be partially measured and that strategies can be adopted, such as application of the Ownership Guidelines with the support of the Ownership Index to promote, cultivate and assess ownership by the project beneficiaries and that simply put: Ownership occurs when people commit, and have the capacity to maintain and protect development outcomes.

By taking this new working definition into consideration donors and especially CSOs (because of their proximity to the project beneficiaries, and ties to the donors) can engage and invite the project beneficiaries to influence the project outcomes throughout the development process. Examining the case studies adopted revealed that positive change, and development that is owned by the people can be formulated systematically and incorporated into the development plans, but that it is often neglected. 
Ownership of development outcomes must be encouraged and promoted and can be cultivated by ensuring that it is the communities and ultimately people at the grassroots themselves that determine and identify the development changes needed and that the project beneficiaries are involved and engaged in aligning, adjusting and tweaking the projects as they advance towards results that they would want to maintain and protect.

Cultivation of ownership and the consultative process introduced in this thesis is heavily constructed on accountability downwards to the people and puts a great deal of decisionmaking power in the hands of the project beneficiaries and demands that the project implementers reflect and consult with stakeholders at each phase of the development progress. As observed in this research, this is because ownership of development aid is best cultivated over the life span of a development project and through accountable partnerships that value 'process' and respect 'dialogue'. The process thus is the product from this standpoint.

Ownership of development aid results cannot be cultivated through one single point of intervention. Ownership is not a one-stop phenomenon -a box to tick, or a step to take. The case studies showed that safeguarding ownership of development results is an extended nonlinear 'process' and must be harnessed at the start and rejuvenated through progression as development unfolds.

As the case studies revealed, adaptable, flexible, accountable engagement with the community is a simple and excellent approach that translates into ownership of development outcomes, but engagements and partnerships must be ongoing, fair and inclusive. Partners, especially women in the communities, must participate in decisionmaking and provide an input to the design, implementation and monitoring of the development projects as they progress. The end result will not be what the community desired otherwise and thus development outcomes will not be sustainable and as effective as they can be.

The potential project beneficiaries must be invited to the decision-making tables at each phase of the project cycle and asked to provide input, keeping the question of ownership (namely the maintenance and protection of outcomes) in mind at each stage of the 
development project cycle. As discussed in Chapter 9, opinions of relevant groups and stakeholders in the community must be incorporated if high ownership rating is expected.

Case studies also revealed that dialogue throughout the development process is an essential ingredient for lasting partnerships and a powerful tool for "achieving strong social values of equity and justice" (Fowler, 2013, p. 231), but that the dialogue must be ongoing and that project beneficiaries especially women must be properly engaged in development process for the outcomes to be effective and sustainable. Greater dialogue among stakeholders can and will enhance partnership and foster ownership, but CSOs must 'listen' to the people, and make sure that their interactions are slanted towards the project beneficiaries instead of donors as they are currently (Ebrahim, 2010; Jacobs \& Wilford, 2010; Kaldor, 2003; Kaler, 2002).

Close examination of the case studies also revealed that each indicator and point of intervention throughout the project cycle is significant on its own, and hence no particular priority is given to any one single Indicator of Ownership as discussed in Chapter 2. The higher the engagement between the partners and the greater the involvement of project beneficiaries in decision-making, the greater the overall ratio of ownership of the outcomes. Project beneficiaries in this process and viewed through this lens play the lead role and effectively instigate, catalyse, and support initiatives to promote change that they would want to maintain and protect over time.

\section{The Role of Civil Society}

Listening to the people is at the heart of development effectiveness and the first step on the path of rethinking approaches and shifting of the current paradigm for ensuring more effective development aid. Civil society is in an ideal place to do that, as it is often well connected to the grassroots and able to give voice to the people and cultivate change that is people-driven and therefore more sustainable. However, Civil Society Organisations (CSOs) must first become more accountable (M. Edwards \& Gaventa, 2014) and transparent with their partners to be able to play their role more effectively (Tomlinson, 2011).

Civil society has often been at the forefront of change in the Pacific Islands region: "Civil society, in the context of the Pacific, has demonstrated its capacity to stand against 
injustice" (Fraenkel, Firth, \& Lal, 2009, p. 82). Human rights principles, women's rights, minority rights (Tsutsui \& Wotipka, 2004) are all profound universal changes and shifts in thinking and paradigms that have been initiated within the sphere of civil society.

Civil society today is a major player and provider of essential services in the Pacific Islands. The sector is an influential advocate for marginalised groups and is a knowledgeable advisor on public policy. CSOs that were examined for this research in the Pacific revealed that they have become important players within the communities that they serve. CSOs are filling gaps that government services do not address and at times experimenting with innovative approaches and philosophies. At the same time, the data gathered revealed that available information on CSOs in the Pacific context is scant, undocumented and constantly changing and that there is ample room to improve the accountability of CSOs downward to the people: namely, the ownership of development aid by their project beneficiaries.

Careful examination of civil society in the Pacific, especially Fiji and Tonga, and the review of the literature indicates that CSOs have the advantage of being "aware of the issues of interest to donors, as well as the people" (Thörn \& Moksnes, 2012, p. 28). This places the sector in an ideal position to promote ownership of change and safeguard more effective and sustainable development aid. Hence, it is essential for CSOs to pause, reflect and take into consideration how they can better play their role as mediators and take advantage of their position and cultivate self-determination and development change that the people would want to maintain and protect in the long term.

In theory, people maintain power over governments and politicians by their vote. In democratic societies where the rule of law prevails, people who are not content with the ruling government can show their strength by voting the ineffective governments out of office. Government's legitimacy and power is therefore justified by the power of the people's vote. According to Article 21 of the Universal Declaration of Human Rights: "The will of the people is the basis of the authority of government" (Donnelly, 2013, p. 218).

Similarly, within the market and the private sector, businesses are penalised by unsatisfied consumers. Consumers exercise power over the market by their power to purchase. If they are not happy with the quality of the goods they have purchased, they have choices: they can return the purchased item, stop buying from that particular supplier and turn to the 
next provider (Labrecque, vor dem Esche, Mathwick, Novak, \& Hofacker, 2013). Consumers today have power over the market and people can influence products and prices (Rezabakhsh, Bornemann, Hansen, \& Schrader, 2006).

The story of civil society is a different one. CSOs are frequently key actors in development, especially in the poorest communities of the world. However, the accountability of CSOs downwards to the people is skewed and weak because CSOs are not dependent on the people they serve, rather they are dependent on their donors, and feel obliged to demonstrate accountability upwards to their benefactors because of the funding structures. Project beneficiaries at the grassroots have thus become unable to hold CSOs or donors accountable. Holding CSOs accountable is challenging because CSOs obtain their funding from one sector of society and deliver their services to another sector. Therefore, benefactors/clients cannot vote them out of office as it is the case with governments or stop purchasing their products as we can do with the products offered by the private sector (Ebrahim \& Weisband, 2007).

This complex relationship translates into project beneficiaries holding little power to question or influence the work of the CSOs involved in their communities, as they rarely hold control over them. The need to safeguard funding diverts the accountability of CSOs from their primary beneficiaries given their limited resources and forces them to be liable to their funders rather than to the people they are to connect with and are being assisted, and this odd and unique arrangement influences the balance of power, accountability of the CSOs and the ownership and sustainability of development outcomes.

According to the Institute of Development Studies (2006), "current accountability mechanisms are inefficient and detrimental to both donors and recipients" (p.3). Donor rules and procedures seem to influence every act of CSOs. In some instances "donors become part of the establishment of the recipient organisations by means of their rules and procedures and 'colonise' the CSOs" (Eyben, 2006, p. 167). Unless development CSOs counter their resource dependence, they will fail to win the cause of the people they aim to serve and will be abandoned by the people over time (Jacobs \& Wilford, 2010).

Observing the civil society of the Pacific revealed that CSOs are in a challenging position: their hands are tied because of their dependence on donor funding and their focus is spread 
between meeting the standards of accountability of their donors and meeting the needs of the communities they serve. However, by taking small steps towards greater accountability systems, CSOs can change practices and better meet the needs of both their project beneficiaries and their funders. This will have a dual impact on their work. It will make them more trustworthy in the eyes of their donors and will bring greater resources and will attract more funding while it will also give CSOs greater legitimacy in the communities that they serve.

Research on the civil society in the Pacific revealed that the first and most important area civil society must address is in fact the question of their accountability downwards to the people. This can have a range of diverse and positive effects and must be immediately addressed and talked about. By addressing the questions of accountability sooner rather than later, CSOs can automatically resolve a series of interrelated issues that they are facing: namely sustainability and ownership of their development interventions. Demonstrating greater accountability will naturally increase the trust of their funders and they will be regarded more favourably by the people. As with remedies for more effective development there are no blueprints. "The process of development is unpredictable and it is often fluid and so demands flexible and adoptive procedures" (Groves \& Hinton, 2013, p. 219) but the question of accountability of CSOs, especially downwards to the people, is an obvious first step as observed through the case studies in the Pacific and requires immediate attention.

Accountability structures are losing ground. It is becoming more and more apparent to any researcher that the upward accountability of civil society to development funders takes priority over downward accountability to the project beneficiaries and there are ample justifiable reasons for that but this challenge is directly influencing the effectiveness and sustainability of development aid and ownership of results in the long term. Addressing the questions of 'to whom', 'for what', and 'how' CSOs are accountable is the essence of development effectiveness and the crux of ownership of development aid.

What is interesting to note however is how accountability is the most important question within the aid and development arena today and also the question least cherished. Accountability, is the shortcut to effectiveness of development aid and the ultimate challenge that must be immediately talked about and improved if development aid is to 
become more sustainable and effective. In the face of this obstacle, CSOs seems to have two clear choices: they can ignore the question of accountability, especially downwards to the people, as majority of CSOs have so far, and continue with their current approaches until eventually external accountability codes of conduct are enforced on them by their governments; or they can lead the process, and set new standards of accountability proactively and lead the private sector, donors and governments on the accountability front. To be more effective, CSOs of tomorrow can be proactive and target and strengthen their own accountability and partnership downwards to the people first and thus enhance ownership of change and enhance sustainability.

As it has been highlighted already by numerous scholars, the continued existence of CSOs and their capacity depends on their very ability to demonstrate greater accountability as many have already alluded to (L. David Brown \& Moore, 2001; Carothers, 2014; Ebrahim, 2003). The principle of ownership, as demonstrated throughout this thesis, is heavily dependent on downwards accountability of CSOs to their project beneficiaries, and lasting and accountable partnerships between the CSOs and the people they serve.

Cultivating accountability is a pillar of ownership and ensuring lasting and sustainable development aid. The ownership working definition offered, as well as the guidelines and the index presented in this research aim to address this problem and can promote development outcomes that the people would commit to maintain and protect over time. Hence, it is important that development partners take these factors into account, evaluate their partnerships and make sure that their partnerships are genuine and primarily constructed on the basis of accountability and transparency. In addition, CSOs should promote development activities that their project beneficiaries would want to maintain and protect and not be under "the influence of funding or the dynamics of other invisible dimensions' of power" (Groves \& Hinton, 2013, p. 10) that lead the aid and development industry.

\section{Ownership Guidelines}

As the case studies confirmed, ownership is definable, desirable as an outcome to ensure effectiveness and must be taken into consideration prior to project identification and methodically cultivated and revived throughout the development process. 
Taking the different ownership indicators into consideration at each stage of the process and documenting the levels of ownership can be an effective strategy to enhance partnerships through dialogue towards ownership of project beneficiaries as a desired outcome and increase sustainability and effectiveness of development results. This will foster an environment where development projects and results are identified, maintained and protected by the people. However, as highlighted in Chapter 9, it is essential to maintain high levels of flexibility and to discuss the question of ownership, being the question of maintenance and protection of development outcomes from the very start and to tweak, regulate and adjust as development projects unfold.

The following are the Nine Indicators of Ownership and points of intervention for cultivation and assessment of ownership that form the bases of the Ownership Index and the Ownership Guidelines:

\section{Indicator One: Who Identifies the Problem?}

Members of the community must identify the change they desire in their community. The case studies revealed that 'who' identifies the needs of the community and the idea behind the development project can have a major influence on development results. Development aid is more effective and sustainable if the project beneficiaries identify the desired outcome, and when they select, acknowledge and buy into the process from the start (Groves \& Hinton, 2013; Narayan et al., 2000). The more the people are engaged in identifying the development projects, the more they feel ownership towards the project outcomes. However, communities are normally diverse and development actors must make sure that everyone within the community is properly engaged in the process, especially women and youth, as they play a critical role in maintaining and protecting the outcomes (Campbell \& Teghtsoonian, 2014; Groves \& Hinton, 2013). Thus, it is the responsibility of the CSOs (donors) to establish accountable and lasting partnerships, making sure that everyone is properly represented and given voice in the decision-making processes through each phase of the development. 


\section{Indicator Two: Who Identifies the Solution?}

Project beneficiaries must be encouraged to identify the solutions to the problems they have identified. Identifying the needs of the people for them does not resolve their problems permanently. People must think for themselves and be encouraged to question and self-actualise (Freire, 1973b). Development is ineffective when solutions are prescribed and offered on a platter. A focus on ownership of development aid demands that project implementers ensure that project beneficiaries are informed and engaged, especially women, in identification of the solutions. Planning must be done inclusively with the community (Berkes, 2004) and not for the community. Ideally solutions and the details of the plans are imagined and identified by the community (Angeles \& Gurstein, 2000) unless the answers require technical expertise, in which case the experts must be first sought within the community (A. Cornwall \& Brock, 2005). When people are involved in identifying the solutions and making decisions, they learn more and tend to take greater responsibility for the outcomes (Hickey \& Mohan, 2004). Development results are unsustainable when project beneficiaries are not appropriately engaged and listened to when solutions are identified (Mansuri \& Rao, 2012). Cultivating ownership requires promotion of accountable participation and education. People and the communities engaged must learn about the importance of self-determination by posing important questions (Freire, 1970), that lead towards development results that they would want to maintain and protect.

\section{Indicator Three: Who Designs?}

Project beneficiaries must be engaged in the design of the development plans. People who engage in designing the projects feel a greater sense of ownership over time (Rondinelli, 2013). It is important to recognise the limitations of outsider (CSOs) knowledge and deepen understanding of local knowledge, practices and norms (Chambers, 2014). It is critical that development actors (CSOs) tap into and ensure integration of the local knowledge and culture during development projects (Fukuda-Parr \& Lopes, 2013). Designing successful development projects depends on inclusive and accountable partnerships where women and youth are given voice and are invited to decision-making tables. Successful development projects should not be used as blueprints for designing future development projects in other communities. Design must be mutually conceived, culturally appropriate 
and inclusively agreed on by stakeholders through the process (Chambers, 1993; Groves \& Hinton, 2013; Rondinelli, 2013). How this is done depends on the context and on the actors involved. The formation of a body of elected community members who are responsible, knowledgeable and capable to engage and bring the essence and the knowledge of the community into the development process is instrumental for cultivation of ownership.

\section{Indicator Four: Who Conducts the Appraisal?}

Appraisals are critical as they provide the opportunity for the community to envision and influence the expected outcomes before the project is implemented, making sure that the project design is in line with the needs and the expected results of the community (Groves \& Hinton, 2013). Appraisals are the last chance communities have to influence the development plans before the project initiates. Ensuring that people, especially women and youth, are well aware of development plans and are able to tweak the projects can have an impact on the long-term effect of projects. Prompting ownership requires constant reflection, questioning and discussion between partners throughout the development process. Appraisals are often non-existent or mismanaged, while research revealed that they are central, especially to human resource management, the feasibility of development projects and the long-term development results. Appraisals help the project beneficiaries identify issues neglected in design and permit revision of the expected outcomes. Finally, project appraisals allow the potential project beneficiaries to calculate the project's viability and encourage the people to envision and become responsible for the results from the start.

\section{Indicator Five: Who Funds?}

Some form of contribution from the project beneficiaries, even if minimal, is necessary and important. People must be informed and prompted to reflect on ways they can potentially fund the projects themselves. The impact of the project beneficiary investment in a development project no matter how minimal is sometimes very challenging and perhaps not so obvious or possible at first, but the community must be encouraged to engage and to identify how it can contribute to the process (Finsterbusch \& Van Wicklin, 1989). Identification of community strengths and potential resources is the most effective option. This option is not always assessed. If this option is not possible, then people must be 
encouraged to potentially explore alternative ways to contribute to the project. Community contribution does not have to be only in the form of cash. Contribution can be in other forms, chiefly labour. In short, all options must be considered before external funding is provided. Finally, accountability for and transparency of the funds must be stressed and ensured as they are key factors for safeguarding partnerships and fostering ownership. Funding is unfortunately often the ultimate impediment to sustainability, and dependency on funding can eventually compromise the project results. Encouraging the community to reflect on innovative financing can sometimes have surprising results.

\section{Indicator Six: Who Implements?}

Project beneficiaries must be engaged and involved in implementing development projects in their community. Implementation is another excellent point for intervention and cultivation of ownership. This is the stage at which the project becomes visible to the entire community (Crawford \& Bryce, 2003). This is the stage at which the project becomes visible to the entire community. Supporting actions are needed and options are numerous and depend on the context. However, what is essential at this stage is the awakening of the community to the importance of the process and their capacity to become further engaged and involved in implementing the project. This phase also consists of reviving partnerships and rule-making for administration of results as projects advance. Aside from funding and capacity, factors impacting implementation are the enabling environment of CSOs, their level of accountability and the strength of partnerships they have formed with the community (Tomlinson, 2011). Other important factors are the inclusive engagement of the community, ensuring that women are informed and engaged with the implementation phase. If project beneficiaries are properly involved at this stage, then they are able to strongly influence and effectively take over and lead the process and make sure the project is advancing towards outcomes that they would want to maintain and protect.

\section{Indicator Seven: Who Monitors?}

Project beneficiaries must be engaged in monitoring the projects. The question of "who will maintain and protect the outcomes", is directly related to ownership of development aid, and must be revived at each monitoring phase and the project beneficiaries must be encouraged to reflect on the 'why', the 'what', and the 'how' of the development outcomes 
as development projects advance. Evidence and research indicates that monitoring is crucial but often neglected and poorly done. Accountable partners ensure solid and robust monitoring as monitoring does help improve the expected results and is a chance for the community to voice their concerns (Bourguignon \& Sundberg, 2007). The dynamics of the evolution of a development project are not always obvious to outsiders and implementers. This is one of many reasons why CSOs should strongly engage project beneficiaries during the monitoring phase, making sure that women are particularly involved and are given a voice (George, 2011; Likiliki, 2008).

\section{Indicator Eight: Who Evaluates?}

Evaluations must include the project beneficiaries as they are best able to judge the project outcomes, whether they feel they own the results or not, and evaluate the challenges they faced as the projects advanced. Genuine ownership evaluations conducted jointly by the implementing organisations and the project beneficiaries are valuable as they identify the barriers to potential ownership of results by the project beneficiaries throughout the project cycle. Evaluations can provide the chance for stakeholders to voice their concerns, speak out and submit their critical reflections. Once a clear understanding has been gained, appropriate changes can be devised for future development projects (Degnbol-Martinussen \& Engberg-Pedersen, 2003). Project evaluations must capture barriers and failures as well as successful outcomes, and the lessons learnt must be shared with the project funders and especially with the project beneficiaries and other CSOs.

\section{Indicator Nine: Who Maintains and Protects?}

Ownership is best cultivated through development interventions that are formed out of a complex labyrinth of interactions before and during the development process, characterised by accountable partnerships in constant and changing interaction with each other. Ownership of the results must be treated as an input by the potential project beneficiaries at each phase of the development project and the direction of the project revisited and discussed with the community at each stage of the project cycle, making sure that the project is developing towards change and results that the community would want to maintain and protect. Ownership can be cultivated systematically and gradually based on a simple, flexible and practical formulation. The key constituent for cultivating ownership is 
thus keeping in mind the end results from the start and the questions concerning the 'maintenance' and 'protection' of development outcomes before the development projects are identified, designed and implemented. Accordingly, ownership of development aid is the result of a lasting dialogue and accountable partnership in the context of a healthy enabling environment. A development aid project implemented is 'owned' by the community when the development outcomes are maintained and protected by the project beneficiaries after the end of the project cycle. 
Table 10.1 - Effect of Ownership on Development Results

\begin{tabular}{|c|c|}
\hline \multicolumn{2}{|c|}{ DEVELOPMENT RESULTS } \\
\hline WITHOUT CONSIDERATION FOR OWNERSHIP & WITH CONSIDERATION FOR OWNERSHIP \\
\hline Problems are identified for the people & People identify the problems \\
\hline pre-planned solutions & solutions identified jointly with people \\
\hline pre-determined design & design integrates local knowledge \\
\hline informed consultants conduct appraisal & $\begin{array}{l}\text { project beneficiaries are engaged during the } \\
\text { appraisal }\end{array}$ \\
\hline donors fund the project & $\begin{array}{l}\text { project beneficiaries contribute towards the } \\
\text { funding (labour or financially even though minimal) }\end{array}$ \\
\hline donors implement & $\begin{array}{l}\text { project beneficiaries are engaged in } \\
\text { implementation }\end{array}$ \\
\hline Staff or external monitoring & project beneficiaries are engaged in monitoring \\
\hline evaluation made by project funders & project beneficiaries are engaged in evaluation \\
\hline focus on reporting to the donors & $\begin{array}{c}\text { focus on reporting to the project beneficiaries as } \\
\text { well as donors and other stakeholders }\end{array}$ \\
\hline donors maintain and control results & results maintained and protected by people \\
\hline focus on expected results & $\begin{array}{l}\text { focus on process and dialogue } \\
\text { towards lasting change }\end{array}$ \\
\hline
\end{tabular}

Successful cultivation of ownership of development aid with the support of the Ownership Guidelines and the Index presented in this research depends on the degree to which project beneficiaries are engaged in the dialogue and their capacity to influence decision-making structures. Often complex interactions within the community or between the project 
implementers and project beneficiaries can seriously affect the level of the ownership of development results. Effective development occurs when stakeholders are at the table and when partners engage in the dialogue and when consensus is achieved between the partners. As observed through the case studies, the distribution of the ownership of development results is influenced by the level of partnership and capacity of the partners to agree on different and conflicting sets of interests as development projects unfold.

\section{Dialogue Towards Ownership}

Promoting self-determination and ownership primarily requires self-questioning, effective communication between the partners and, most importantly, it requires stakeholders 'listening' to one another. This is, in fact, the over-riding challenge that CSOs face in practice in their attempt to promote ownership. Research participants who work with CSOs constantly talked about their communication challenges with governments, their donors and their project beneficiaries. Equally, at the community level, people, especially women spoke of their frustrations with the CSOs and their desire to be better engaged in the dialogue and the decision-making processes.

Case studies revealed that communication between all stakeholders must be wider than just funding and that joint analysis for identification of development goals and solutions are imperative to cultivate ownership. Research also revealed that communication and maintaining of an ongoing dialogue - an inclusive talanoa in the Pacific context - is the key foundation for authentic partnerships. Safeguarding ownership of development outcomes requires ongoing professional friendships, trust and understanding which all lead to greater accountability, legitimacy and cultivation of development change that is more sustainable.

Each interaction and partnership varies considerably in terms of breadth and closeness, and so does the level of eventual ownership of development projects as a result. These variations are mainly due to the degree to which partners are involved in dialogue and policy discussions before and during the 'development process'. The case studies revealed that the degree to which partners/stakeholders are involved in dialogue and policy discussions, particularly before and during the project cycle, indicates the level of ownership of development outcomes. The case studies revealed that project beneficiaries feel ownership of development outcomes and results when stakeholders are more closely linked 
when partners talk and listen to one another at each phase, and where there is a deep understanding of the situation and consultation with those involved, especially women and youth. Talanoa, meaning the lasting dialogue, is the Pacific approach and a practical method to ensure sustainability of outcomes and ultimately ownership of development change.

Talanoa is a practical tool and it is the backbone of cultivating ownership, and building cultural capital and bringing forth conscientisation (Freire, 1970) as observed through the case studies. It is through inclusive talanoa that people can articulate their needs, their dreams and shape their own future. It is through dialogue that understanding is arrived at, knowledge is shared and consensus arrived at.

\section{Flexibility and Process}

The new definition offered in this research for 'ownership' of development aid and the Ownership Guidelines and the Index formulated are simple but pragmatic tools, as the case studies have revealed. They are tools and approaches that can effectively challenge the current status quo and address the need for greater engagement of the project beneficiaries and increase ownership of development outcomes, which in return will have a direct impact on sustainability and the effectiveness of development results. As observed in the case studies, ownership is the result of, and directly related to, a series of decisions made through the development process, and the level of ownership of project results is directly related to the 'who' deciding the 'what' of the development aid. Who initiates and identifies the needs (e.g., who is in charge of identifying the change needed)? Who finds the solutions (e.g., who decides what the development project should be)? Who designs and implements? Who monitors? Who evaluates? In this sense, as observed, ownership refers to an individual or the community's capacity to influence the outcomes of the projects as projects advance towards desired development change that is maintained and controlled by the project beneficiaries.

The variable indicators of ownership observed and presented in this research have the potential to instigate a shift, especially in civil society's approach towards cultivating greater ownership of development aid by the people. The ownership definition and the indicators highlighted for cultivating ownership, however, are not a blueprint. They are suggested, rather than prescribed, and they are heavily dependent on partnerships that are 
accountable and in a healthy, enabling environment, as observed through the case studies. Therefore, ownership is cultivated, nurtured, and refined through a series of decisions made as the development project advances. The more accountable and robust the partnership and the more inclusive the dialogue as the project is advancing, the more sustainable and effective the outcomes.

It is never too soon to encourage and promote ownership of change by the people. In fact, as observed through the case studies, the question of ownership must be raised and discussed even before the project is identified or designed. The sooner the question of ownership is posed and discussed, the greater the ratio of ownership. Grounded in observations made in the field, it is safe to conclude that ownership of development results is best promoted and cultivated at the start of the partnerships between the CSOs and the communities they serve. Potential project beneficiaries must be invited to reflect on both the change desired and on the question of the sustainability of the project outcomes and the ownership of development results. This highlighting of the need for the community to identify the change needed and the need for the project beneficiaries to take charge of the outcomes from the start is critical to ownership of development results. Potential project beneficiaries must be invited to reflect on the maintenance and protection of the outcomes which will in the long-term as the case studies in this research have revealed will translate to ownership of development aid.

Finally, it must be stressed here that it is difficult to predict and control development processes and outcomes, because development often tends to be chaotic and messy. This is why this research highlights and encourages the need for taking the ownership of change and its complex web of variable indicators and characteristics into consideration, and puts forward a systematic method to promote self-determination towards results that are desired, maintained and protected over time. That is precisely why it is essential for development partners to maintain high levels of flexibility (Chambers, 2014) and to encourage self-actualisation instead of offering solutions.

The more partners are able to 'listen' to one another and to adapt and adjust as development projects advance, the more effective the outcomes will be. This is especially the case for the civil society, as the sector must hold on to the pulse of the communities 
they serve and be able to organically incorporate the changes desired by the people (Eyben, 2013) as development unfolds.

'Good' development which is 'owned' by the people demands that partners are flexible and persistent in dialogue as projects advance. Listening to, and incorporating project beneficiary wishes as projects are evolving can make all the difference to the outcomes and can ensure change that is desired and that the people would commit to maintain and protect because they are working towards development change that they desired. Typically, an unwillingness to change from either side comes from a desire to control circumstances, but, when cultivating ownership, partners must constantly keep the end results in mind, making sure that the process and ultimately the development project is advancing towards change that the communities want.

Hence, development results, as observed through the case studies in this research, are most effective when partners 'listen', engage in constant dialogue, and are flexible and adaptable during each phase of development process. Development results are effective and sustainable when project implementers seriously take into consideration and include the demands of the project beneficiaries throughout the development process, keeping the outcomes in mind, and show their willingness and ability to adjust to the needs of the community as projects unfold.

\section{Final Conclusion}

As observed in this research, 'recipient ownership' is directly related to the effectiveness of development results as hypothesised in this thesis: namely that development aid is more sustainable and effective when the project beneficiaries, especially women, are included fully in decision-making early on, and encouraged to determine the change they desire, while keeping in mind the question of 'maintenance' and 'protection' of the outcomes.

Research revealed that cultivating ownership of development results by the project beneficiaries is complex and demands taking into account a number of factors from the start, but the decisive pillar of effective development aid and lasting change is accountability, which is directly related and results in ownership of development outcomes. Ownership of development aid can only be constructed and achieved gradually, which 
means constant dialogue between accountable partners, as well as flexibility and persistence in discussion at each phase of the development process towards commonly identified desired results, while accepting the uncertainty, doubt and flux of the partnerships.

The key factors that have a direct impact on cultivating ownership and ensuring effectiveness of development results are persistence in dialogue, before and throughout the project cycle, and respect and emphasis on process, keeping in mind that the development process is indeed the development product itself. Women, especially, play a critical role and must be appropriately engaged in decision-making from the start and they must be properly informed and empowered to engage and influence the process. The capacity of partners must be strengthened, and stakeholders must be encouraged to voice their concerns at each stage of the development process while taking into consideration the critical question of maintenance and protection of results.

Finally, development aid must become less political and ambiguous, and technical development terms must become more precise in terms of policy and practice. Development discourse must be carefully unpacked. Development terms must be properly translated and partners and stakeholders must be accurately informed and engaged. The time has come to capture a sharper picture of the meaning of the key words and concepts within the constantly evolving discipline of development aid and to clearly define and translate key technical concepts into partner languages within the discourse (Alejandro Leal, 2007; Chambers, 2013; Cooke \& Kothari, 2001), namely 'ownership' of development aid, because, as observed in this research, there is ongoing confusion and a lack of consensus amongst stakeholders as to what ownership means and how it can be embedded in policy and practice, while evidence clearly reveals that cultivating ownership plays a key role in nurturing effective and sustainable development change. The language used within the aid industry is an essential tool, and it must be properly and justly employed, because it has a direct impact on development results. New technical terms and development concepts will mean nothing to partners unless technical terms and development concepts are properly defined, discussed, translated and understood. 
Political motivations and the imbalance of wealth and power supports the view that the people at the grassroots in the Pacific have lost a good measure of control of the discourse and ownership of their own development process. Civil society in the Pacific at the same time reveals to be an important actor and could play a crucial role in cultivating ownership of development - 'assisted self-determination' is not a contradiction in terms. However, research and review of the existing mechanisms and strategies in the Pacific indicates that CSOs and other major development actors have few clear policies for promoting, and cultivating the principle of ownership of development outcomes by the project beneficiaries; indeed, there are no consensuses on vital key related issues, such as how CSOs can strengthen accountability downwards to the people - and certainly no consensus on how to measure such key aspects of development aid.

As a result, very few development projects are owned and driven by the local communities when donor funding terminates and ownership of development outcomes is more of a policy ideal than an actual policy intact. Equally, very few projects have benefited from unbiased scrutiny to determine their effectiveness and development results are often grossly inflated, and there is a dire need for greater accountability fundamentally downwards to the people and more inclusive decision-making, as women are still not properly engaged in decision-making processes. Improving the effectiveness of development aid and the impact of the dollars spent on the ground is an urgent problem, which can be addressed in major part through addressing the difficult question of ownership of development results and especially accountability through more inclusive dialogue. This facilitates a simple approach, namely nurturing development aid that the project beneficiaries identify themselves and that they would want to maintain and protect over time.

Development aid is effective when it is no longer needed. Thus, what must be encouraged is self-determination and a kind of development assistance that is grounded in accountable partnerships that cultivate self-actualisation and sustained change that people would want to maintain and protect. Ultimately, it is my hope that this research will contribute to understanding how development aid might help the communities of the Pacific Islands shape their own sustainable future and that it plays a part in establishing a new era when there will be no dependence on foreign aid. 


\section{References}

Ahmad, M. M. (2006). The 'partnership' between international NGOs (non-governmental organisations) and local NGOs in Bangladesh. Journal of International Development, $18(5), 629-638$.

Alejandro Leal, P. (2007). Participation: the ascendancy of a buzzword in the neo-liberal era. Development in practice, 17(4-5), 539-548.

Andrews, T. (2012). What is social constructionism. Grounded theory review, 11(1), 39-46.

Angeles, L., \& Gurstein, P. (2000). Planning for participatory capacity development: The challenges of participation and North-South partnership in capacity building projects. Canadian Journal of Development Studies, 21(S1), 447-478.

Anheier, H. (2013). Civil Society:" Measurement, Evaluation, Policy". London: Routledge.

Anheier, H. K., \& Seibel, W. (1990). The third sector: Comparative studies of nonprofit organizations (Vol. 21): Walter de Gruyter.

Anheier, H. K., \& Toepler, S. (2009). International encyclopedia of civil society. Washington, D.C: Springer.

Anríquez, G., \& Stamoulis, K. (2007). Rural development and poverty reduction: is agriculture still the key. Electronic Journal of Agricultural and Development Economics, 4(1), 5-46.

Assessment, M. E. (2005). Millennium Ecosystem Assessment Findings: Millennium Ecosystem Assessment.

Atidegla, A. C. (2011). Challenges for Democratic Ownership and Development Effectiveness. Development Effectiveness: Civil Society Perspectives on Progress since Paris, 45.

Atwood. (2011). The road to Busan: pursuing a New consensus on development cooperation. Global Economy and Development, 21. 
Avey, J. B., Avolio, B. J., Crossley, C. D., \& Luthans, F. (2009). Psychological ownership: Theoretical extensions, measurement and relation to work outcomes. Journal of Organizational Behavior, 30(2), 173-191.

Baaz, M. E. (2005). The paternalism of partnership: A postcolonial reading of identity in development aid: Zed Books.

Babbie, E. (2013). The basics of social research: Cengage Learning.

Baker, M. (2011). In other words: A coursebook on translation. London: Routledge.

Baliamoune-Lutz, M., \& McGillivray, M. (2011). State fragility: Concept and measurement. Fragile states: causes, costs, and responses, 33-42.

Bandler, R. (1985). Using your brain for a change: Neuro-linguistic programming: UT: Real People Press.

Bandura, A. (1994). Self-efficacy. London: Wiley Online Library.

Bank, W. (2002). Goldin, I., Rogers, H., \& Stern, N. Retrieved from http://siteresources.worldbank.org/DEC/Resources/roleofdevelopment.pdf

Banks, N., \& Hulme, D. (2012). The role of NGOs and civil society in development and poverty reduction. Brooks World Poverty Institute Working Paper, 171.

Barr, K. J. (2005). Globalisation And The Economy.

Belk, R. (1988). Possessions and Self. London: Wiley Online Library.

Bendell, J. (2005). In whose name? The accountability of corporate social responsibility. Development in practice, 15(3-4), 362-374.

Berg, B. L., \& Lune, H. (2004). Qualitative research methods for the social sciences (Vol. 5): Pearson Boston.

Berkes, F. (2004). Rethinking community-based conservation. Conservation biology, 18(3), 621-630. 
Bernhard, M. (1993). Civil society and democratic transition in East Central Europe. Political Science Quarterly, 307-326.

Bhim, M. (2010). FIJI: Democracy disabled due to uninformed citizenry. Pacific Media Watch.

Blackburn, J., Chambers, R., \& Gaventa, J. (2000). Mainstreaming participation in development. Retrieved from http://ieg.worldbank.org/Data/reports/mnstream.pdf.

Blewitt, J. (2014). Understanding sustainable development: Routledge.

Boomsma, R., O'Dwyer, B., \& Georgakopoulos, G. (2010). The shaping of NGO accountability: aligning imposed and felt accountabilities in Oxfam Novib.

Booth, D. (2011). Aid, institutions and governance: what have we learned? Development Policy Review, 29(s1), s5-s26.

Booth, D. (2012). Aid effectiveness: bringing country ownership (and politics) back in. Conflict, Security \& Development, 12(5), 537-558.

Botes, L., \& van Rensburg, D. (2000). Community participation in development: nine plagues and twelve commandments. Community Development Journal, 35(1), 41-58.

Bourguignon, F., \& Sundberg, M. (2007). Aid effectiveness: opening the black box. The American economic review, 316-321.

Brown, L. D. (2008). Creating credibility: Legitimacy and accountability for transnational civil society. London: Kumarian Press.

Brown, L. D., \& Moore, M. H. (2001). Accountability, strategy, and international nongovernmental organizations. Nonprofit and Voluntary Sector Quarterly, 30(3), 569-587.

Browne, S. (2006). Aid and influence: do donors help or hinder? London: Routledge.

Buiter, W. H. (2007). 'Country ownership': a term whose time has gone. Development in practice, 17(4-5), 647-652. 
Burbules, N. C., \& Smeyers, P. (2002). Wittgenstein, the practice of ethics, and moral education. Philosophy of Education Archive, 248-257.

Burr, V. (1998). Overview: Realism, relativism, social constructionism and discourse. Social constructionism, discourse and realism, 13-26.

Butcher-Gollach, C. (2015). Planning, the urban poor and climate change in Small Island Developing States (SIDS): unmitigated disaster or inclusive adaptation? International Development Planning Review, 37(2), 225-248.

Cahill, A. (2008). Power over, power to, power with: Shifting perceptions of power for local economic development in the Philippines. Asia Pacific Viewpoint, 49(3), 294-304.

Campbell, M. L., \& Teghtsoonian, K. (2014). Aid effectiveness and women's empowerment: Practices of governance in the funding of international development. Signs, 40(1).

Carothers, B. (2014). Accountability, Transparency, Participation, and Inclusion: A New Development Consensus? Carnegie Endowment for International Peace, Think Tank, 42. Retrieved from http://carnegieendowment.org/2014/10/20/accountabilitytransparency-participation-and-inclusion-new-development-consensus

Chambers, R. (1993). Challenging the professions: Frontiers for rural development. London: Intermediate Technology Publications Ltd (ITP).

Chambers, R. (1994a). The origins and practice of participatory rural appraisal. World development, 22(7), 953-969.

Chambers, R. (1994b). Participatory rural appraisal (PRA): Challenges, potentials and paradigm. World development, 22(10), 1437-1454.

Chambers, R. (2002). Participatory workshops: a sourcebook of 21 sets of ideas and activities: Earthscan.

Chambers, R. (2005). Words, power and the personal in development. Language and Development: Africa and Beyond, 119.

Chambers, R. (2013). Ideas for development. London: Routledge. 
Chambers, R. (2014). Rural development: Putting the last first: Routledge.

Cheah, I., \& Phau, I. (2012). A confirmation bias approach to country of ownership cues.

Chomsky, N. (1986). Knowledge of language: Its nature, origin, and use. London: Greenwood Publishing Group.

Clark, J. (1995). The state, popular participation, and the voluntary sector. World development, 23(4), 593-601.

Clayton, A., Oakley, P., \& Taylor, J. (2000). Civil society organizations and service provision: United Nations Research Institute for Social Development.

Cleaver, F. (1999). Paradoxes of participation: questioning participatory approaches to development. Journal of International Development, 11(4), 597-612.

Cobb, P., \& Yackel, E. (1996). Constructivist, emergent, and sociocultural perspectives in the context of developmental research. Educational psychologist, 31(3-4), 175-190.

Cohen, J. L. (1994). Civil society and political theory. New York: Mit Press.

Cohen, J. M., \& Uphoff, N. T. (1980). Participation's place in rural development: seeking clarity through specificity. World development, 8(3), 213-235.

Collier, P. (2010). The bottom billion and what we can do to help Fairness in International Trade (pp. 3-8). London: Springer.

Comaroff, J. L., \& Comaroff, J. (1999). Civil society and the political imagination in Africa: Critical perspectives. Chicago: University of Chicago Press.

Cooke, B., \& Kothari, U. (2001). Participation: The new tyranny? : Zed Books.

Cornwall, A. (2007). Buzzwords and fuzzwords: deconstructing development discourse. Development in practice, 17(4-5), 471-484.

Cornwall, A. (2008). Unpacking 'Participation': models, meanings and practices. Community Development Journal, 43(3), 269-283. 
Cornwall, A., \& Brock, K. (2005). What do buzzwords do for development policy? A critical look at 'participation', 'empowerment' and 'poverty reduction'. Third world quarterly, 26(7), 1043-1060.

Cornwall, A. B. (2005). Beyond Buzzwords: "Poverty Reduction", "Participation" and "Empowerment" in Development Policy Retrieved from http://www.unrisd.org/80256B3C005BCCF9/\%28httpAuxPages\%29/F25D3D6D27E2 A1ACC12570CB002FFA9A/\$file/cornwall.pdf

Correll, D. (2008). Can Aid be Effective without Civil Society? The Paris Declaration, the Accra Agenda for Action and Beyond.

Corry, O. (2010). Defining and theorizing the third sector Third sector research (pp. 11-20): Springer.

Cracknell, B. E. (2000). Evaluating development aid: issues, problems and solutions: Sage.

Crawford, P., \& Bryce, P. (2003). Project monitoring and evaluation: a method for enhancing the efficiency and effectiveness of aid project implementation. International Journal of Project Management, 21(5), 363-373.

Crewe, E., \& Harrison, E. (1998). Whose development. An ethnography of aid, 23-65.

Crocombe, R. (2001). The South Pacific. Suva: University of the South Pacific Suva.

Crush, J. (1995). Power of development: Psychology Press.

Curtain, R., \& Vakaoti, P. (2011). The State of Pacific Youth Report 2011: Opportunities and Obstacles: Suva, Fiji. UNICEF, SPC.

d'Souza, D., \& Wills, A. C. (1998). Catalysis: Objects, Components, and Frameworks with UML (Vol. 223): Object Technology Series. Addison-Wesley.

De Haan, A. (2009). How the aid industry works: an introduction to international development. Sterling, VA: Kumarian Press.

de Tocqueville, A. (1835). Democracy in America (Vol. 147). Boston: Digireads. com Publishing. 
Degnbol-Martinussen, J., \& Engberg-Pedersen, P. (2003). Aid: understanding international development cooperation: Zed Books.

Denscombe, M. (2010). The Good Research Guide: For Small-Scale Social Research Projects: For small-scale social research projects: McGraw-Hill International.

Devarajan, S., Dollar, D., \& Holmgren, T. (2001). Aid and reform in Africa: Lessons from ten case studies. New York: World Bank Publications.

Di Vinadio, T. B., Sinha, P., \& Sachdeva, P. (2012). Strengthening Inclusive Ownership Through Capacity Development.

Dichter, T. (2012). Time to stop fooling ourselves about foreign aid: A practitioner's view.

Dijkstra, G. (2011). The PRSP approach and the illusion of improved aid effectiveness: Lessons from Bolivia, Honduras and Nicaragua. Development Policy Review, 29(s1), s110-s133.

Dollar, D., \& Svensson, J. (1998). What explains the success or failure of structural adjustment programs? World Bank Policy Research Working Paper(1938).

Donnelly, J. (2013). Universal human rights in theory and practice. New York: Cornell University Press.

Douglas, B. (1979). Rank, power, authority: A reassessment of traditional leadership in South Pacific societies*. The Journal of Pacific History, 14(1), 2-27.

Drever, E. (1995). Using Semi-Structured Interviews in Small-Scale Research. A Teacher's Guide: ERIC.

Dundes, A. (1984). Sacred narrative: readings in the theory of myth. New York: Univ of California Press.

Ebrahim, A. (2003). Accountability in practice: Mechanisms for NGOs. World development, 31(5), 813-829.

Ebrahim, A. (2010). The many faces of nonprofit accountability. The Jossey-Bass Handbook of Nonprofit Leadership and Management, 101-123. 
Ebrahim, A., \& Weisband, E. (2007). Global accountabilities: Participation, pluralism and public ethics (Vol. 23): UK: Cambridge University Press.

Edgren, G. (2003). Donorship, ownership and partnership: Issues arising from four Sida studies of donor-recipient relations: Swedish International Development Cooperation Agency.

Edigheji, O. (2005). A democratic developmental state in Africa. A Concept Paper.

Edmond, R. (1997). Representing the South Pacific: Colonial Discourse from Cook to Gauguin: Cambridge University Press.

Edwards. (2009). Civil society. London: Polity.

Edwards, Foley, M. W., \& Diani, M. (2001). Beyond Tocqueville: civil society and the social capital debate in comparative perspective: Upne.

Edwards, M., \& Gaventa, J. (2014). Global citizen action. London: Routledge.

England, K. V. (1994). Getting Personal: Reflexivity, Positionality, and Feminist Research*. The Professional Geographer, 46(1), 80-89.

Ernst, M. (1994). Winds of Change: Rapidly growing religious groups in the Pacific Islands.

Essia, U., \& Yearoo, A. (2009). Strengthening civil society organizations/government partnership in Nigeria. International NGO Journal, 4(9), 368-374.

Etzioni, A. (1991). The socio-economics of property. Journal of Social Behavior and Personality, 6(6), 465-468.

Eyben, R. (2006). Relationships for aid: Routledge.

Eyben, R. (2008). Power, mutual accountability and responsibility in the practice of international aid: A relational approach. London: Institute of Development Studies.

Eyben, R. (2013). Building Relationships in Development Cooperation: Traditional Donors and Rising Powers. 
Eyben, R., \& Savage, L. (2013). Emerging and submerging powers: imagined geographies in the new development partnership at the Busan Fourth High Level Forum. The Journal of Development Studies, 49(4), 457-469.

Fairbairn-Dunlop, P., \& Lievore, D. (2007). Pacific Prevention of Domestic Violence Programme: Tonga Report. Wellington: Victoria University of Wellington.

Farrelly, T., \& Nabobo-Baba, U. (2014). Talanoa as empathic apprenticeship. Asia Pacific Viewpoint, 55(3), 319-330.

FCDP. (2014). Design Document. Retrieved from http://aid.dfat.gov.au/Publications/Pages/4629_5522_7515_7549_8631.aspx

Feeney, P. (1998). Accountable aid: local participation in major projects. Oxford: Oxfam.

Feeny, S., \& Donahue, J. (2014). Foreign aid delivery: modes and modalities in the Pacific. Development in Difficult Sociopolitical Contexts: Fragile, Failed, Pariah, 89.

Fenner, D. E. (2006). The aesthetics of research methodologies in the social sciences. International Journal of Applied Philosophy, 20(2), 311-330.

Ferguson, J. (2005). Bridging the gap between research and practice. Knowledge Management for Development Journal, 1(3), 46-54.

Finsterbusch, K., \& Van Wicklin, W. A. (1989). Beneficiary participation in development projects: Empirical tests of popular theories. Economic Development and Cultural Change, 573-593.

Fioramonti, L., \& Kononykhina, O. (2014). Measuring the Enabling Environment of Civil Society: A Global Capability index. VOLUNTAS: International Journal of Voluntary and Nonprofit Organizations, 1-22.

Fisher, J. (1998). Nongovernments: NGOs and the political development of the third world. West Hartford, CT: Kumarian Press

Flyvbjerg, B. (2006). Five misunderstandings about case-study research. Qualitative inquiry, $12(2), 219-245$. 
Foley, M. W., \& Edwards, B. (1996). The paradox of civil society. Journal of democracy, 7(3), $38-52$.

Foresti, M., Booth, D., \& O'Neil, T. (2006). Aid effectiveness and human rights: strengthening the implementation of the Paris Declaration. ODI report to the DAC.

Foucault, M. (1982). The subject and power. Critical inquiry, 777-795.

Fowler, A. (2000a). Introduction beyond partnership: getting real about NGO relationships in the aid system. IDS bulletin, 31(3), 1-13.

Fowler, A. (2000b). NGDOs as a moment in history: beyond aid to social entrepreneurship or civic innovation? Third world quarterly, 21(4), 637-654.

Fowler, A. (2013). Striking a balance: A guide to enhancing the effectiveness of nongovernmental organisations in international development. New York: Routledge.

Fox, J. A., \& Brown, L. D. (1998). The struggle for accountability: The World Bank, NGOs, and grassroots movements. Chicago: MIT press.

Fraenkel, J. (2013). Fiji. Diminishing Conflicts in Asia and the Pacific: Why Some Subside and Others Don't, 13, 169.

Fraenkel, J., Firth, S., \& Lal, B. V. (2009). The 2006 military takeover in Fiji: a coup to end all coups? Canberra, Australia: ANU E Press.

Freire, P. (1968). Pedagogy of the oppressed. London, UK.: Bloomsbury Publishing.

Freire, P. (1970). Cultural action for freedom. Boston: Harvard educational review.

Freire, P. (1973a). Education for critical consciousness (Vol. 1): Bloomsbury Publishing.

Freire, P. (1973b). Education for critical consciousness. New York: Continuum.

Freire, P., \& Freire, A. M. A. (2004). EPZ pedagogy of hope: Reliving pedagogy of the oppressed. London, UK.: Bloomsbury Publishing. 
FSPI. (2012). Youth, Mental Health and Violence in Fiji, Situation Analysis Retrieved from https://fspiblog.files.wordpress.com/2011/08/fiji-masculinity-mental-health-andviolence.pdf

Fukuda-Parr, S., \& Lopes, C. (2013). Capacity for development: new solutions to old problems. New York: Routledge.

Fulu, E., Warner, X., Miedema, S., Jewkes, R., Roselli, T., \& Lang, J. (2013). Why do some men use violence against women and how can we prevent it? Quantitative findings from the United Nations multi-country study on men and violence in Asia and the Pacific. Bangkok: UNDP, UNFPA, UN Women and UNV.

Gaventa, J. (2004a). Representation, community leadership and participation: citizen involvement in Neighbourhood Renewal and local governance. Neighbourhood Renewal Unit Office of Deputy Prime Minister, February.

Gaventa, J. (2004b). Representation, community leadership and participation: citizen involvement in Neighbourhood Renewal and local governance. Paper prepared for the Neighbourhood Renewal Unit Office of Deputy Prime Minister.

Gellner, E., \& Hamilton, H. (1994). Conditions of liberty: Civil society and its rivals: Hamish Hamilton London.

George, N. (2011). Pacific women building peace: a regional perspective. the contemporary pacific, 23(1), 37-71.

George, N. (2012). Situating women: Gender politics and circumstance in Fiji. Canberra: ANU E Press.

Gilbert, C. L., \& Vines, D. (2006). The World Bank: structure and policies (Vol. 3). Boston: Cambridge University Press.

Goleman, D. (2003). What makes a leader. Organizational Influence Processes (Porter, LW, et al. Eds.), New York, ME Sharpe, 229-241.

Gotschi, E., Delve, R., \& Freyer, B. (2009). Participatory photography as a qualitative approach to obtain insights into farmer groups. Field Methods, 21(3), 290-308. 
Gramsci, A. (1995). Further selections from the prison notebooks: University of Minnesota Press.

Gray, D. E. (2013). Doing research in the real world. London: Sage.

Gray, R., Bebbington, J., \& Collison, D. (2006). NGOs, civil society and accountability: making the people accountable to capital. Accounting, Auditing \& Accountability Journal, 19(3), 319-348.

Griffith, T., \& Ferrari, G. (2000). Plato: 'The Republic': Cambridge University Press.

Groves, L., \& Hinton, R. (2013). Inclusive aid: Changing power and relationships in international development. London, UK: Routledge.

Gupta, A., \& Ferguson, J. (1997). Discipline and practice: "The field" as site, method, and location in anthropology. Anthropological locations: Boundaries and grounds of a field science, 100, 1-47.

Gurdjian, P., Halbeisen, T., \& Lane, K. (2014). Why leadership-development programs fail. McKinsey Quarterly, 1, 121-126.

Gurtner, B. (2010). La crise économico-financière et les pays en développement. International Development Policyl Revue internationale de politique de développement(1), 201-227.

Gusterson, H. (1998). Nuclear rites: A weapons laboratory at the end of the Cold War. London: Univ of California Press.

Hanafi, H. (2002). Alternative conceptions of civil society: A reflective Islamic approach. Alternative conceptions of civil society, 171-189.

Hann, C. M., \& Dunn, E. (1996). Civil society: Challenging western models. London: Psychology Press.

Hansen, H., \& Tarp, F. (2000). Aid effectiveness disputed. Foreign Aid and Development: Lessons Learnt and Directions for the Future, 103-128.

Harcourt, W. (1994). Feminist perspectives on sustainable development. London: Zed Books. 
Harding, S. G. (2004). The feminist standpoint theory reader: Intellectual and political controversies: Psychology Press.

Hartsock, N. C. (1998). The feminist standpoint revisited and other essays.

Haskell, J., Linds, W., \& Ippolito, J. (2002). Opening spaces of possibility: The enactive as a qualitative research approach. Paper presented at the Forum Qualitative Sozialforschung/Forum: Qualitative Social Research.

Hauck, V., \& Land, T. (2011). Fostering democratic ownership.

Hayman, R. (2009). From Rome to Accra via Kigali: 'aid effectiveness' in Rwanda. Development Policy Review, 27(5), 581-599.

Haynes, J. (1999). Power, politics and environmental movements in the Third World. Environmental Politics, 8(1), 222-242.

Hegarty, D. (2013). 1. A Changing Oceania. Politics, Development and Security in Oceania (7), 3.

Heidegger, M., Gray, J. G., \& Wieck, F. D. (1968). What is called thinking? (Vol. 8). New York: Harper \& Row New York.

Heidegger, M., \& McNeill, W. (1943). On the essence of truth.

Heinrich, V., \& Fioramonti, L. (2007). CIVICUS Global Survey of the State of Civil Society: Comparative Perspectives (Vol. 2). Johannesburg: Kumarian Press.

Hickey, S., \& Mohan, G. (2004). Participation--from tyranny to transformation?: Exploring new approaches to participation in development. London: Zed Books.

Higgs, J., Horsfall, D., \& Grace, S. (2009). Writing qualitative research on practice: Sense Publishers Atlanta^ eGA GA.

Howard, M. M. (2003). The weakness of civil society in post-communist Europe. London: Cambridge University Press. 
Hsu, J., Pitt, C., Greco, G., Berman, P., \& Mills, A. (2012). Countdown to 2015: changes in official development assistance to maternal, newborn, and child health in 2009-10, and assessment of progress since 2003. The Lancet, 380(9848), 1157-1168.

Huang, P. C. (1993). " Public Sphere"/" Civil Society" in China?: The Third Realm between State and Society. Modern China, 216-240.

Huffer, E. (2006). Regionalism and cultural identity: Putting the Pacific back into the plan. Globalisation and Governance in the Pacific Islands (1), 43.

Hughes, H. (2003). Aid has failed the Pacific. Issue analysis, 33.

Huntington, S. P. (1993). The third wave: Democratization in the late twentieth century (Vol. 4): University of Oklahoma press.

IFAD. (2012). The Evolution of IFAD's Gender Approach. Retrieved from http://www.ifad.org/pub/other/ruralwomen/3.pdf

Jacobs, A., \& Wilford, R. (2010). Listen First: a pilot system for managing downward accountability in NGOs. Development in practice, 20(7), 797-811.

James, R. (2002). People and change: exploring capacity-building in NGOs. Washington DC: INTRAC.

Janus, H., Klingebiel, S., \& Mahn, T. C. (2014). How to Shape Development Cooperation? The Global Partnership and the Development Cooperation Forum. Paper presented at the The Global Partnership and the Development Cooperation Forum (March 10, 2014). Briefing Paper, German Development Institute.

Jennings, R. (2000). Participatory development as new paradigm: the transition of development professionalism. Prepared for the Community Based Reintegration and Rehabilitation in Post-Conflict Settings Conference, Washington DC. Washington, DC, 49.

Jiang, W. (2000). The relationship between culture and language. ELT journal, 54(4), 328334. 
Jiobu, R. M., \& Lundgren, T. D. (1978). Catastrophe Theory A Quasi-Quantitative Methodology. Sociological Methods \& Research, 7(1), 29-54.

Johnson, R. B., \& Onwuegbuzie, A. J. (2004). Mixed methods research: A research paradigm whose time has come. Educational researcher, 33(7), 14-26.

Jones, P. (2012). Searching for a little bit of utopia-understanding the growth of squatter and informal settlements in Pacific towns and cities. Australian Planner, 49(4), 327338.

Jordan, L. (2005). Mechanisms for NGO accountability. GPPi Research Paper Series (3).

Jordan, L., \& van Tuijl, P. (2006). NGO accountability: Politics, principles and innovations. London: Routledge.

Jump, L. (2013). Beneficiary feedback mechanisms. Retrieved from http://scholar.google.co.nz/scholar?q=Beneficiary+feedback+mechanisms\&btnG=\&h $\mathrm{I}=e n \& \mid r=l a n g \_e n \& a s \_s d t=0 \% 2 C 5$

Kahn, C., \& Winton, A. (1998). Ownership structure, speculation, and shareholder intervention. The Journal of Finance, 53(1), 99-129.

Kaldor, M. (2003). Civil society and accountability. Journal of Human Development, 4(1), 527.

Kaldor, M., Anheier, H., \& Glasius, M. (2003). Global civil society: Cambridge Univ Press.

Kaler, J. (2002). Responsibility, accountability and governance. Business ethics: A European review, 11(4), 327-334.

Kang, S. H. (2012). Transformation of global governance. Busan Partnership for Effective Development

Cooperation Fourth High Level Forum on Aid Effectiveness.

Kaufmann, D. (2009). Aid effectiveness and governance: the good, the bad and the ugly. Development Outreach, 11(1), 26-29. 
Keppel, G., Morrison, C., Watling, D., Tuiwawa, M. V., \& Rounds, I. A. (2012). Conservation in tropical Pacific Island countries: why most current approaches are failing. Conservation Letters, 5(4), 256-265.

Kiely, R. (1999). The last refuge of the noble savage? A critical assessment of post-development theory. The European Journal of Development Research, 11(1), 30-55.

Kim, E. M., \& Lee, J. E. (2013). Busan and beyond: South Korea and the transition from aid effectiveness to development effectiveness. Journal of International Development, 25(6), 787-801.

Kindornay, S., \& Samy, Y. (2012). Establishing a legitimate development co-operation architecture in the post-Busan era.

Knack, S., Xu, L. C., \& Zou, B. (2014). Interactions among donors' aid allocations: evidence from an exogenous World Bank income threshold. World Bank Policy Research Working Paper (7039).

Kohler, J., \& Huber, J. (2006). Higher education governance between democratic culture, academic aspirations and market forces (Vol. 5). London: Council of Europe.

Labrecque, L. I., vor dem Esche, J., Mathwick, C., Novak, T. P., \& Hofacker, C. F. (2013). Consumer power: Evolution in the digital age. Journal of Interactive Marketing, 27(4), 257-269.

Lal, B. V. (2013). Fiji: Sailing in Uncharted Seas. The Round Table, 102(5), 481-482.

Law, J. (2004). After method: Mess in social science research: Routledge.

Lawson, M. L. (2010). Foreign aid: international donor coordination of development assistance.

Lawson, S. (1996). Tradition Versus Democracy in the South Pacific: Fiji, Tonga and Western Samoa. London: Cambridge University Press.

Leckie, J. (2002). 9 The complexities of women's agency in Fiji. Gender politics in the AsiaPacific region, 156. 
Lerner, J. S., \& Tetlock, P. E. (1999). Accounting for the effects of accountability. Psychological bulletin, 125(2), 255.

Lewis, D. (2001). Civil society in non-Western contexts: Reflections on the 'usefulness' of a concept: Centre for Civil Society, London School of Economics and Political Science.

Likiliki, O. G.-L. (2008). Advancing Women's Representation in Tonga. Retrieved from http://www.forumsec.org/resources/uploads/attachments/documents/Report_4__Advancing_Women_s_Representation_in_Tonga_143_-_2081.pdf

Lim, L. L. (2011). Building an Asia-Pacific youth employment coalition: reviewing past policies and the way forward: ILO.

Lincoln, B. (1999). Theorizing myth: narrative, ideology, and scholarship. Chicago: University of Chicago Press.

Linnekin, J. (1990). The politics of culture in the Pacific. Cultural identity and ethnicity in the Pacific, 149-173.

Lisk, F., Besada, H., \& Martin, P. (2013). Regulating extraction in the global South: Towards a framework for accountability. Background Research Paper submitted to the High Level Panel on the Post-2015 Development Agenda, May.

Llewellyn-Fowler, M., \& Overton, J. (2010). 'Bread and butter' human rights: NGOs in Fiji. Development in practice, 20(7), 827-839.

Lloyd, R. (2005). The role of NGO self-regulation in increasing stakeholder accountability. One World Trust, 1-15.

Malcolm, N. (1989). Wittgenstein on language and rules. Philosophy, 64(247), 5-28.

Mansuri, G., \& Rao, V. (2012). Localizing development: does participation work? Washington, DC World Bank Publications.

Martini, J., Mongo, R., Kalambay, H., Fromont, A., Ribesse, N., \& Dujardin, B. (2012). Aid effectiveness from Rome to Busan: some progress but lacking bottom-up approaches or behaviour changes. Tropical Medicine \& International Health, 17(7), 931-933. 
Mati, J. M. (2008). Taking the Pulse of Civil Society Worldwide: Insights from the CIVICUS Civil Society index project (2003-2007). Paper presented at the 8th conference of the International Society for Third Sector Research, Universitat de Barcelona, Barcelona, Spain July.

Mawdsley, E., Savage, L., \& Kim, S. M. (2014). A 'post-aid world'? Paradigm shift in foreign aid and development cooperation at the 2011 Busan High Level Forum. The Geographical Journal, 180(1), 27-38.

May, T. (2011). Social research: McGraw-Hill Education (UK).

McAfee, N. (2000). Habermas, Kristeva, and citizenship: Cornell University Press.

McGhie. (2013). New Zealand's Approach to Fiji. Retrieved from http://pen.org.nz/articles\%2Bindex/New+Zealand\%27s+Approach+to+Fiji

McKeown, T. J. (2004). Case studies and the limits of the quantitative worldview. Rethinking social inquiry: Diverse tools, shared standards, 139-167.

Merry, S. E. (2009). Human rights and gender violence: Translating international law into local justice. Chicago: University of Chicago Press.

Mfunwa, M. G. (2006). Strengthening internal accountability in the context of programmebased approaches in sub-Saharan Africa. German Development Institute. Retrieved from http://edoc.vifapol.de/opus/volltexte/2011/3076/pdf/4_2006.pdf

Mies, M. (1973). Paulo Freire's Method of Education: Conscientisation in Latin America. Economic and Political Weekly, 8(39), 1764-1767. doi:10.2307/4363063

Mikkelsen, B. (2005). Methods for development work and research: a new guide for practitioners. New Delhi, India: Sage.

Miles, M. B., Huberman, A. M., \& Saldaña, J. (2013). Qualitative data analysis: A methods sourcebook: SAGE Publications, Incorporated.

Miraftab, F. (2004). Public-Private Partnerships The Trojan Horse of Neoliberal Development? Journal of Planning Education and Research, 24(1), 89-101. 
Mohan, G. (2000). Structural adjustment: Theory, practice and impacts. London: Psychology Press.

Mohanty, M. (2008). A Handbook of Non-state Actors (NGOs and CSOs) in Fiji (Suva, The University of the South Pacific, Development Studies Programme).(2007)."The third sector and social development in small Pacific Island countries: constraints and opportunities in Fiji Islands". Development Problems and Prospects in Pacific Islands States, 229-244.

Morriss, C. (2009). The Pacific plan and gender: Policies, programs, and (has there been any) progress. Social Alternatives, 28(4), 19-23.

Mulligan, K. (1997). The essence of language: Wittgenstein's builders and Bühler's bricks. Revue de Métaphysique et de Morale, 193-215.

Nancy, G., \& Yontcheva, B. (2006). Does NGO aid go to the poor? Empirical evidence from Europe: International Monetary Fund.

Narayan, D., Chambers, R., Shah, M. K., \& Petesch, P. (2000). Voices of the Poor: Crying out for Change: New York: Oxford University Press for the World Bank.

Narsey, W. (2006). Just living wages for Fiji: lifting workers out of poverty: ECREA.

Negin, J. (2010). Sector-Wide Approaches for health: lessons from Samoa and the Solomon Islands. Health Policy and Health Finance Knowledge Hub Working Paper(4).

Nietzsche, F. (1887/1992). On the genealogy of morals and ecce homo: Vintage.

Nowaczyk, M. (2011). Implementing and Monitoring the Paris Declaration. Development Effec veness: Civil Society Perspec ves on Progress since Paris, 134.

O'Leary, Z. (2004). The essential guide to doing research. Chennai, India: Sage.

O’Driscoll, M. P., Pierce, J. L., \& Coghlan, A.-M. (2006). The psychology of ownership work environment structure, organizational commitment, and citizenship behaviors. Group \& Organization Management, 31(3), 388-416. 
ODI, I. o. D. S. (2014). Rising Powers in International Development Programme. Retrieved from http://www.ids.ac.uk/idsresearch/rising-powers-in-international-developmentprogramme

OECD. (2009). Partnering with Civil Society. Retrieved from http://www.oecd.org/dac/peer-reviews/partneringwithcivilsociety.htm

Olckers, C., \& Du Plessis, Y. (2012). Psychological ownership: A managerial construct for talent retention and organisational effectiveness.

Oliver, D. L. (1989). The Pacific Islands. Hawai'i: University of Hawaii Press.

Olson, D. H. (1977). Insiders' and outsiders' views of relationships: Research studies. Close relationships: Perspectives on the meaning of intimacy, 115-135.

Open Forum. (2011). Open Forum for CSO Development Effectiveness second Global Assembly. $\quad$ Retrieved from http://csoeffectiveness.org/IMG/pdf/ga_report_full_final_24-7-11.pdf

Open Forum and BetterAid (Producer). (2012, November 6th, 2014). Post-Busan Global CSO $\begin{array}{llll}\text { Meeting } & \text { Documentation } & \text { Retrieved }\end{array}$ effectiveness.org/IMG/pdf/cebu_documentation_report-2.pdf

Pallas, C. L. (2013). Transnational Civil Society and the World Bank: Investigating Civil Society's Potential to Democratize Global Governance: Palgrave Macmillan.

Palys, T. (2008). Purposive sampling. In L. M. Given (Ed.), The Sage encyclopedia of qualitative research methods (pp. 697-698). Los Angeles: Sage.

Patterson, D. (2006). Wittgenstein on Understanding and Interpretation (Comments on the work of Thomas Morawetz). Philosophical Investigations, 29(2), 129-139.

Pegus, C.-M. (2013). The State of Civil Society Report Retrieved from Johannesburg: http://civicus.org/eei/downloads/Civicus_EEI\%20REPORT\%202013_WEB_FINAL.pdf

Peruzzotti, E. (2011). The Workings of Accountability: Contexts and Conditions. From Inertia to Public Action, 122. 
Petersen, S., Mavoa, H., Swinburn, B., Waqa, G., Goundar, R., \& Moodie, M. (2012). Healthrelated quality of life is low in secondary school children in Fiji. International journal of pediatrics, 2012.

PIANGO. (2014). Strategic Plan 2013-2015. Retrieved from http://www.piango.org/PIANGO/plan/strategic-plan.html

Pierce, J. L., \& Jussila, I. (2011). Psychological ownership and the organizational context: theory, research evidence, and application. Northampton, MA: Edward Elgar.

Pierce, J. L., Kostova, T., \& Dirks, K. T. (2003). The state of psychological ownership: Integrating and extending a century of research. Review of general psychology, 7(1), 84.

Pierce, J. L., \& Rodgers, L. (2004). The psychology of ownership and worker-owner productivity. Group \& Organization Management, 29(5), 588-613.

Pieterse, J. N. (2011). Discourse analysis in international development studies. Journal of Multicultural Discourses, 6(3), 237-240.

Pihama, L., Cram, F., \& Walker, S. (2002). Creating Methodological Space: A Literature Review of Kaupapa Maori Research. Canadian Journal of Native Education, 26(1), 3043.

Pitanoe, E., Korocowiri, S., Martin, L., \& Davidson, J. (2012). YES (YOUTH EMPOWERMENT STRATEGY) PASIFIKA: THE FORMATION OF A MODEL FOR PASIFIKA YOUTH DEVELOPMENT.

Poverty, E. (2014). A New Global Partnership for Ending Poverty and Reducing Inequality. Rethinking Partnerships in a Post-2015 World: Towards Equitable, Inclusive and Sustainable Development, 9.

Power, P. F. (1986). The South Pacific Nuclear-Weapon-Free Zone. Pacific Affairs, 455-475.

Pretty, J. N. (1995). Participatory learning for sustainable agriculture. World development, 23(8), 1247-1263. 
Ravuvu, A. (1988). Development or dependence: The pattern of change in a Fijian village. Suva: editorips@usp.ac.fj.

Ravuvu, A. (1991). The facade of democracy: Fijian struggles for political control, 1830-1987. Suva: editorips@usp.ac.fj.

Reanda, L. (2001). Human Rights and Women's Rights: The United Nations Approach. Human Rights Quarterly, 3(2), 11-31.

Reuter, T., \& Reuter, T. A. (2006). Sharing the Earth, Dividing the Land: Land and territory in the Austronesian world: ANU E Press.

Rezabakhsh, B., Bornemann, D., Hansen, U., \& Schrader, U. (2006). Consumer power: a comparison of the old economy and the Internet economy. Journal of Consumer Policy, 29(1), 3-36.

Riddell, R. C. (2007). Does foreign aid really work? Oxford: Oxford University Press.

Riddell, R. C. (2014). Does Foreign Aid Really Work? An Updated Assessment. An Updated Assessment (March 2014). Development Policy Centre Discussion Paper(33).

Ritchie, J., Lewis, J., Nicholls, C. M., \& Ormston, R. (2013). Qualitative research practice: A guide for social science students and researchers: Sage.

Ritzer, G., Zhao, S., \& Murphy, J. (2001). Metatheorizing in sociology: The basic parameters and the potential contributions of postmodernism Handbook of sociological theory (pp. 113-131): Springer.

Roberts, J. (2001). Dialogue, positionality and the legal framing of ethnographic research.

Robinson, D. (2012). Law and civil society in the South Pacific Retrieved from http://www.vanuatu.usp.ac.fj/sol_adobe_documents/world/icnl/Klingelhofer2.htm

Robinson, D., \& Robinson, K. (2005). " Pacific ways" of talk: Hui and talanoa. Retrieved from

Rogers, G. A. J., Filmer, R., Lawson, G., Bramhall, J., \& Clarendon, E. H. (1995). Leviathan: contemporary responses to the political theory of Thomas Hobbes. 
Rondinelli, D. A. (2013). Development projects as policy experiments: An adaptive approach to development administration: Routledge.

Sachs, W. (2010). Development Dictionary, The: A Guide to Knowledge as Power. London: Zed Books.

Sahlins, M. (2013). Culture and practical reason: University of Chicago Press.

Salamon, L. M., \& Anheier, H. K. (1997). Defining the nonprofit sector: A cross-national analysis: Manchester University Press.

Saldaña, J. (2012). The coding manual for qualitative researchers: Sage.

Schank, R. C., \& Abelson, R. P. (1995). Knowledge and memory: The real story. Knowledge and memory: The real story. Advances in social cognition, 8, 1-85.

Schopenhauer, A. (1844). The world as will and idea (Vol. 2): Library of Alexandria.

Secretariat, C. (2014). Small States: Economic Review and Basic Statistics, Volume 17 (Vol. 17): Commonwealth Secretariat.

Seidenfeld, M. (2001). The psychology of accountability and political review of agency rules. Duke Law Journal, 1059-1095.

Sen, A. (2001). Development as freedom: Oxford University Press.

Sienkiewicz, S. (1999). Ethnic relations in Fiji: Peaceful coexistence and the recent shift in the ethnic balance. Retrieved, May, 9, 2007.

Siggelkow, N. (2007). Persuasion with case studies. Academy of Management Journal, 50(1), 20-24.

Skaaning, S.-E. (2010). Measuring the rule of law. Political Research Quarterly, 63(2), 449460.

Smillie, I., Helmich, H., Randel, J., \& German, T. (2013). Stakeholders: Government-NGO partnerships for international development: Routledge. 
Smith, A., Reitsma, L., Van Den Hoven, E., Kotzé, P., \& Coetzee, L. (2011). Towards Preserving Indigenous Oral Stories Using Tangible Objects. Paper presented at the Culture and Computing (Culture Computing), 2011 Second International Conference on.

Smith, G. H. (1997). The development of kaupapa Maori: Theory and praxis. researchspace@auckland.ac.nz

Snape, D., \& Spencer, L. (2003). The foundations of qualitative research. Qualitative research practice: A guide for social science students and researchers, 11.

Soederberg, S. (2001). The emperor's new suit: The new international financial architecture as a reinvention of the Washington Consensus. Global Governance, 453-467.

Soederberg, S. (2004). The politics of the new international financial architecture: Reimposing neoliberal domination in the global south: Zed Books.

Sontag, S. (1977). On Photography. New York: Picador.

Spratt, C., Walker, R., \& Robinson, B. (2004). Mixed research methods. Retrieved from http://www.col.org/sitecollectiondocuments/a5.pdf.

Steer, L., Wathne, C., \& Driscoll, R. (2009). Mutual Accountability at the Country Level. A Concept and Emerging Good Practice Paper. Centre for Aid and Public Expenditure, Overseas Development Institute.

Steiner, H. J. (1988). Political participation as a human right. Harv. Hum. Rts. YB, 1, 77.

Steinle, A. (2009). Can aid be effective without civil society. Retrieved from http://www.icsw.org/doc/2008_Accra_ICSW_Full_Paper_FINAL_25Aug08.pdf

Sultana, F. (2007). Reflexivity, positionality and participatory ethics: Negotiating fieldwork dilemmas in international research. ACME: An International E-Journal for Critical Geographies, 6(3), 374-385.

Swain, P. M. (1999). Civil society and development: Pacific Island case studies: a dissertation presented in fulfilment of the requirements for the degree of Doctor of Philosophy in Development Studies at Massey University, Palmerston North, New Zealand. 
Tadesse, E., Ameck, G., Christensen, C., Masiko, P., Matlhakola, M., Shilaho, W., \& Smith, R. (2006). The people shall govern: A research report on public participation in policy $\begin{array}{lll}\text { processes. } & \text { Retrieved from }\end{array}$ http://www.gsdrc.org/go/display\&type=Document\&id=2012.

Tashakkori, A., \& Teddlie, C. (2010). Sage handbook of mixed methods in social \& behavioral research: Sage.

Teddlie, C., \& Tashakkori, A. (2009). Foundations of mixed methods research: Integrating quantitative and qualitative approaches in the social and behavioral sciences: Sage Publications Inc.

Tembon, M., \& Fort, L. (2008). Girls' education in the 21st century: gender equality, empowerment, and economic growth: Washington, DC: World Bank.

Tester, K. (1992). Civil society (Vol. 11): Routledge London.

The Pacific Island Forum Secretariat. (2014). Retrieved from http://www.forumsec.org/pages.cfm/about-us/

Theisohn, T. (2013). Ownership Leadership and Transformation: Can We Do Better for Capacity Development. New York: Routledge.

Theisohn, T., \& Lopes, C. (2013). Ownership Leadership and Transformation: Can We Do Better for Capacity Development: Routledge.

Thörn, H., \& Moksnes, H. (2012). Global civil society-beyond the "good" and the "bad". Global Civil Society: Shifting Powers in a Shifting World, 3.

Tomlinson, B. (2011). Strengthening Broad-Based Inclusive Ownership and Accountability: A Synthesis of Key Findings and Cluster A Messages for the Working Party on Aid Effectiveness and High Level Forum 4. Draft Report Submitted to The Swiss Agency for Development and Cooperation, Black Rock Consulting, February.

Tongco, M. D. C. (2007a). Purposive sampling as a tool for informant selection. (1547-3465). Retrieved from 
http://scholarspace.manoa.hawaii.edu/bitstream/handle/10125/227/I1547-346505-147.pdf.

Tongco, M. D. C. (2007b). Purposive sampling as a tool for informant selection.

Topp, L., Barker, B., \& Degenhardt, L. (2004). The external validity of results derived from ecstasy users recruited using purposive sampling strategies. Drug and alcohol dependence, 73(1), 33-40.

Tsutsui, K., \& Wotipka, C. M. (2004). Global civil society and the international human rights movement: Citizen participation in human rights international nongovernmental organizations. Social Forces, 83(2), 587-620.

Tujan Jr, A. (2012). Civil society-new power in aid and development? Global Civil Society: Shifting Powers in a Shifting World, 27.

UNDP. (2004). United Nations and Civil Society. Retrieved from http://www.un.org/en/civilsociety/

UNDP. (2012). A Capacity Development Plan for CSOs in the Pacific Retrieved from http://www.asia-

pacific.undp.org/content/rbap/en/home/library/democratic_governance/A_Capacit y_Development_Plan_for_CSOs_in_the_Pacific/

Unerman, J., O'Dwyer, B., Gray, R., Bebbington, J., \& Collison, D. (2006). NGOs, civil society and accountability: making the people accountable to capital. Accounting, Auditing \& Accountability Journal, 19(3), 319-348.

Unicef. (2011). The State of the World's Children 2011-Executive Summary: Adolescence an Age of Opportunity: Unicef.

UNICEF. (2012). Children in Fiji, An Atlas of Social indicators.

USAID. (2012). Country ownership and organizational capacity building. Retrieved from http://www.msh.org/sites/msh.org/files/as2_techbrief4_final.pdf

Vaioleti, T. M. (2006a). Talanoa research methodology: a developing position on pacific research. 
Vaioleti, T. M. (2006b). Talanoa research methodology: A developing position on Pacific research. Waikato Journal of Education, 12, 22-34.

Van Dyne, L., \& Pierce, J. L. (2004). Psychological ownership and feelings of possession: three field studies predicting employee attitudes and organizational citizenship behavior. Journal of Organizational Behavior, 25(4), 439-459.

Van Rooy, A. (2013). Civil society and the aid industry. London: Routledge.

Vanderbeck, R. M. (2005). Masculinities and fieldwork: widening the discussion. Gender, Place \& Culture, 12(4), 387-402.

Vogl, C. R., Vogl-Lukasser, B., \& Puri, R. K. (2004). Tools and methods for data collection in ethnobotanical studies of home gardens. Field Methods, 16(3), 285-306.

Wallace, T., Bornstein, L., \& Chapman, J. (2007). The aid chain: Coercion and commitment in development NGOs. Kampala: Practical Action Pub.

Walsh, D., \& Downe, S. (2005). Meta-synthesis method for qualitative research: a literature review. Journal of advanced nursing, 50(2), 204-211.

Wang, J.-F., Wu, C.-H., Hsieh, S., Liou, S., \& Chen, B.-W. (2014). Detection, Measurement, and Enhancement of Happiness. The Scientific World Journal, 2014.

Ward, R. G., \& Kingdon, E. (2007). Land, custom and practice in the South Pacific: Cambridge University Press.

Ware, H. (2004). Pacific instability and youth bulges: the devil in the demography and the economy. Paper presented at the Australian Population Association, 12th Biennial Conference, Canberra.

Wesley-Smith, T. (1995). Rethinking Pacific Islands Studies. Pacific Studies, 18(2), 115-136.

Whelan, K. K., Huber, J., Rose, C., Davies, A., \& Clandinin, D. J. (2001). Telling and retelling our stories on the professional knowledge landscape. Teachers and Teaching: theory and practice, $7(2), 143-156$. 
Williamson, J. (2000). What should the World Bank think about the Washington Consensus? The World Bank Research Observer, 15(2), 251-264.

Williksen-Bakker, S. (1990). Vanua-a symbol with many ramifications in Fijian culture. Ethnos, 55(3-4), 232-247.

Wittgenstein, L. (1921). Tractatus Logico-Philosophicus (trans. Pears and McGuinness).

Wittgenstein, L., Anscombe, G. E. M., Wright, G. H., Paul, D., \& Bochner, M. (1969). On certainty (Vol. 174): Blackwell Oxford.

Wolfensohn, J. D. (2005). Voice for the World's Poor: Selected Speeches and Writings of World Bank President James D. Wolfensohn, 1995-2005 (Vol. 889): World Bank Publications.

Wood, B., Betts, J., Etta, F., Gayfer, J., Kabell, D., Ngwira, N., . . Samaranayake, M. (2011). The Evaluation of the Paris Declaration, Phase 2. Final Report. Copenhagen: Danish Institute for International Studies.

Wood, J., \& Winston, B. E. (2005). Toward a new understanding of leader accountability: Defining a critical construct. Journal of Leadership \& Organizational Studies, 11(3), 84-94.

Wood, J. A. A., \& Winston, B. E. (2007). Development of three scales to measure leader accountability. Leadership \& Organization Development Journal, 28(2), 167-185.

World Bank, S. O., Natalia Agapitova and Joy Behrens. (2009). The Capacity Development Results Framework.

Wright, J. (1999). Uses of writing to counter the silence of oppression: Counselling women at USP. Pacific Health Dialog, 6(2), 305-309.

Wrighton, N., \& Overton, J. (2012). Coping with participation in small island states: The case of aid in Tuvalu. Development in practice, 22(2), 244-255.

Yin, R. K. (2010). Qualitative research from start to finish: Guilford Press.

Yin, R. K. (2014). Case study research: Design and methods. London: Sage publications. 
Zipes, J. (2005). To eat or be eaten: The survival of traditional storytelling. Storytelling, Self, Society, 2(1), 1-20.

Zipes, J. (2005). To eat or be eaten: The survival of traditional storytelling. Storytelling, Self, Society, 2(1), 1-20. 


\title{
Appendices
}

\section{Appendix 1 - Consent Form}

\author{
CONSENT TO PARTICIPATE IN RESEARCH
}

Title of project: Ownership, civil society and development effectiveness

I have read and understood the information sheet and I understand that I can request more information at any stage. I am aware that participation is purely voluntary and I can withdraw at any time, refuse to answer any questions, or retract any statements before the $13^{\text {th }}$ February 2014 without disadvantage

I consent to my real name being used in publications.

I have consent from the CEO of the organisation I work for to participate in this research; Name of the organisation I work for (please identify): Name of the CEO (please identify):

I would like to be identified using: (please circle one)

The name of an organisation (please identify):

A code name (please identify):

Other: (please identify):

I understand that the information I give will not be used for any purpose other than those mentioned in the information sheet.

I would like to receive a final report of the findings at the conclusion of the research

$\mathbf{Y} / \mathbf{N}$

If yes, my address is:

And my email address is:

I, . consent to being interviewed and audio recorded by Pedram Pirnia for the purposes of completing a PhD thesis, producing one or more journal articles and presentations at conferences.

Signed

Date 


\title{
Appendix 2 - Information Sheet for Research Participants
}

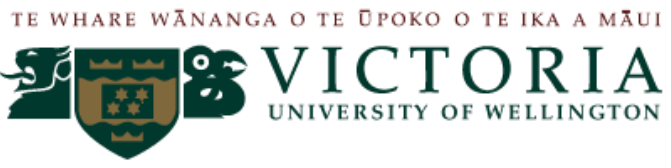

\section{Information Sheet for research}

\author{
Researcher: PEDRAM PIRNIA
}

I am a PhD student in Development Studies at Victoria University of Wellington. As part of this degree I am undertaking a research project leading to a thesis. The project I am undertaking is exploring the meaning of 'ownership' and people's empowerment in relation to development aid from a Pacific perspective.

\section{BACKGROUND}

'Ownership' is a key principle and a critical theme in international development. Behind this research is the idea that 'ownership' may relate directly to sustainable and effective development. Each year millions of dollars are spent around the world on diverse development programmes to improve health, education and other outcomes in developing countries. But very few programmes are owned and driven by the local communities. This need for 'democratic ownership' of the development programmes at the community level, and better development outcomes is an urgent problem.

\section{EXPECTED RESULTS}

This research will put forward strategies for development NGOs to better implement the principle of democratic ownership and will improve the sector's engagement with local communities. This study will assess the impact of development projects implemented by NGOs on the people to understand more deeply some of the prevailing circumstances and conditions that enable or impede the principle of ownership, and will seek to find solutions to enhance ownership of development projects by the local communities. It is hoped that this research will clarify to whom development NGOs are accountable, and how can they improve their 'downward' (i.e. to local communities, not just to donors) accountability?

\section{INTERVIEW FORMAT}

Each interview will be approximately one hour and will be audio recorded if I have your consent. The interview is based on a semi-structured format so the exact nature of the questions has not been determined in advance but will depend on the way that the interview develops. Should the line of questioning progress in a way that makes you uncomfortable you can decline to answer any question(s). Potential participants who do not want to be recorded or named are also welcomed.

\section{CONFIDENTIALITY}

Your participation is completely voluntary and you can leave the interview at any time or retract any statements made before $13^{\text {th }}$ February 2014 without any disadvantage to yourself. All information gathered is confidential and will only be seen by myself and my supervisors. On the attached consent form, you are given the option of using your real name, an organisation's name, or a code name to maintain anonymity (for instance, Participant One). Because of the nature of the case, anyone who is very familiar with it may connect statements to particular groups or stakeholders. However, please be assured that should you use anonymity every effort will be made to make sure you cannot be easily identified. The recording of our conversation will be stored at Victoria University in a password-protected computer for two years after the date of your signature.

\section{ETHICAL APPROVAL}

This study has been reviewed and approved by the Ethics Committee of the Victoria University of Wellington in New Zealand.

\section{DATA USE AND STORAGE}

The data collected will be securely stored in such a way that only myself and my academic supervisors will be able to gain access to it. At the end of the project any personal information will be destroyed, except that on which published results rely. These data will be stored securely for a period of two years. The completed thesis will be submitted for marking to the School of Geography, Environment and Earth Sciences and deposited in the University library. It is intended that one or more articles will be submitted to scholarly journals and that the research may form the basis of conference presentations. You may receive a final report with my findings if you wish.

If you have any questions or would like to receive further information about the project, please contact Prof John Overton, at the School of Geography, Environment and Earth Sciences, Victoria University, P O Box 600, Wellington, NZ 


\section{Appendix 3 - Research Questions}

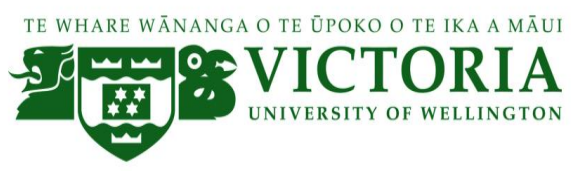

\section{Research Questions:}

\section{Ownership Anatomy}

- How does your organisation define ownership?

- What are the ownership ingredients in your view?

- Does your organisation have a stated ownership policy?

- Are there written guidelines on ownership for your organisation?

\section{Civil Society}

- Your assessment of CSOs in general. Your Strategy? Mission/goal?

- Do you think your organisation is accountable? Who do you report to?

- Can you think of your most successful project and a failed project (OWNERSHIP)?

- How are your projects designed/assessed (external or internal)? Who are the evaluators?

- Is there an Impact Evaluation Report to assess the long-term effects of the project on people and the environment?

- What is the impact of the project on other populations? Indigenous population and women? Children? Environment?

\section{Ownership Structures}

- How and who designs development projects in your organisation?

- Who is consulted before a project is designed? How is the consultation made?

- How is the approach to ownership structured in your organisation?

- Who has the responsibility within your organisation for building strong connections with the local communities and to promote the principle of ownership? Is there a guideline for their interaction with the communities?

- Development Effectiveness Principles? Who has the responsibility within your organisation to connect to the regional and international discourse on ownership?

- Do you have a Strategic Plan? A Code of Ethics or a Code of Conduct? Board of Governance?

- Is there a mention of Ownership in your Code of Ethics or a Code of Conduct?

Processes of ownership

- How do you promote Ownership within your organisation and within the communities?

- To what extent is your organisation autonomous in terms of designing and managing programmes?

- Have there been any assessments of the nature and effectiveness of the Ownership strategies in your organisation?

- Is there an Exit Strategy for your projects?

- Is there a Succession Plan for the governance of your organisation?

\section{Future}

- Will the nature of ownership change over the next five to ten years?

- How can the practice and management of Ownership be enhanced? 


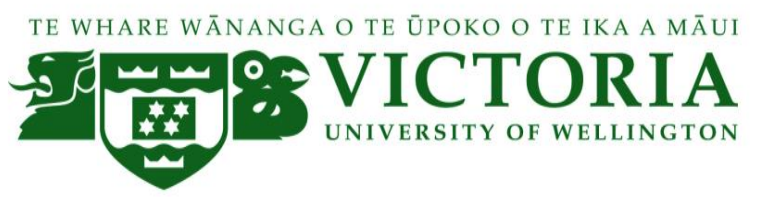

\section{Ownership Index Survey}

\section{Survey for the Implementing Organisation}

- Name of the Organisation:

- Project Name:

- Name of the Project Manager:

- Name and the Title of the person completing this survey:

- Gender and Age (if appropriate)

1. Who identified the problem (the development project):

CSO $\quad$ The Community $\square$ The Government $\quad$ Other (specify please)

$\square$

2. The development project and the idea was imagined by:

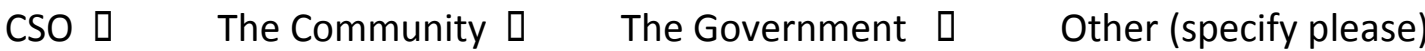

$\square$

3. The CSOs level of engagement in project design?

1------2------3------4------5-----6-----7-----8-----9-----10

(10 indicating high level of engagement)

4. Level of engagement between the CSO, and the community prior to project design?

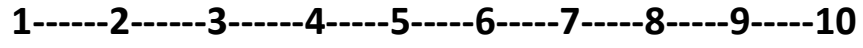

(10 indicating high level of engagement)

5. Level of Government's engagement in project design?

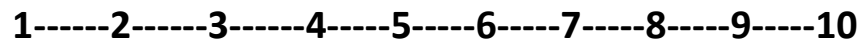

(10 indicating high level of engagement)

6. Community's level of engagement in project appraisal?

1------2------3-------4-----5-----6-----7-----8-----9-----10

(10 indicating high level of engagement) 
7. Community's level of engagement in project implementation?

$$
\text { 1------2------3------4-----5-----6-----7-----8-----9-----10 }
$$

(10 indicating high level of engagement)

8. Government's level of engagement in project implementation?

$$
\text { 1------2------3------4-----5-----6-----7-----8-----9-----10 }
$$

(10 indicating high level of engagement)

9. Level of monitoring by the implementing CSO?

$$
\text { 1------2------3-------4-----5-----6-----7-----8-----9-----10 }
$$

(10 indicating high level of engagement)

10. Community's level of engagement in monitoring of the project?

$$
\begin{aligned}
& \text { 1----2-----3-----4----5-----6----7----8-----9----10 } \\
& \text { (10 indicating high level of engagement) }
\end{aligned}
$$

11. Level of the community's engagement in evaluation of the project?

$$
\text { 1----2-----3-----4----5-----6-----7----8-----9----10 }
$$

12. Level of the feedback (evaluation) to the CSO by the community?

$$
\text { 1------2------3------4-----5-----6-----7-----8-----9-----10 }
$$

(10 indicating high level of engagement)

13. Level of leadership (control) shown by the community in the process?

$$
\text { 1------2------3------4-----5-----6------7-----8-----9-----10 }
$$

(10 indicating high level of engagement)

14. Community's capacity to make decisions in the process?

$$
\text { (10 indicating high level of engagement) }
$$

15. Level of women's engagement with the project design?

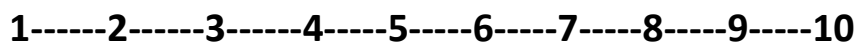


16. Level of women's engagement during the project life cycle?

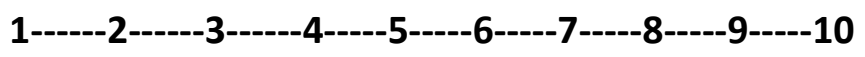

(10 indicating high level of engagement)

17. Level of traditional knowledge attributed to the project by the local community?

$$
\text { 1------2------3------4------5-----6-----7-----8-----9-----10 }
$$

(10 indicating high level of engagement)

18. Level of technical expertise offered by the CSO to the community?

$$
\text { 1------2------3-------4-----5------6-----7-----8------9-----10 }
$$

(10 indicating high level of engagement)

19. Level of transparency (financial) by the implementing agency?

$$
\text { 1------2------3------4-----5-----6-----7-----8-----9-----10 }
$$

(10 indicating high level of engagement)

20. Level of Ownership built into the project by the CSO at the beginning of the project?

$$
\text { 1------2------3------4-----5-----6-----7-----8-----9-----10 }
$$

(10 indicating high level of engagement)

21. Level of community's Ownership of the project at the end?

$$
\text { 1------2------3------4------5-----6-----7-----8-----9-----10 }
$$

(10 indicating high level of engagement)

22. Did the CSO engage with your community after the end of the project? Did they capture and share the lessons learnt?

$$
\text { Yes ? No ? How? }
$$

23. Do you share the information with other communities?

$$
\text { Yes ? No ? How? }
$$

24. Thanks for your participation. Please indicate if you would like to...

a. a) be informed about the findings of this research

b. b) participate in a follow-up survey 


\section{Appendix 5 - Ownership Index Survey: Project Beneficiaries}

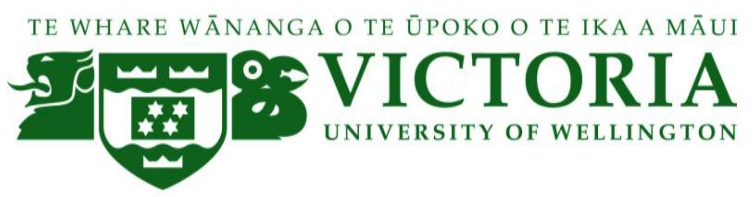

\section{Ownership Index Survey}

\section{Survey for Project Beneficiaries}

- Name of the Person Completing this Survey:

- Name of the Project:

- Implementing Organisation:

- Location

- Gender/Age (if appropriate):

1. Who identified the problem (the development project):

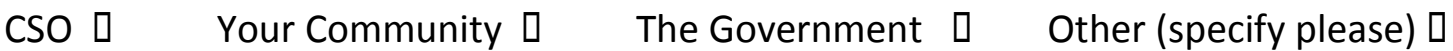

2. The development project and the idea was imagined by:

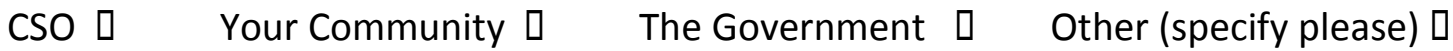

3. Your level of engagement in project design?

$$
\text { 1------2------3-------4-----5-----6-----7-----8-----9-----10 }
$$

(10 indicating high level of engagement)

4. Level of engagement between the CSO, and your community prior to project design?

$$
\text { 1------2------3-------4-----5-----6------7-----8-----9-----10 }
$$

(10 indicating high level of engagement)

5. Level of Government's engagement in project design?

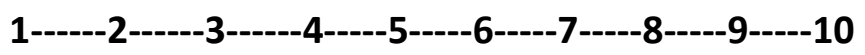

(10 indicating high level of engagement)

6. Your community's level of engagement in project appraisal?

1------2------3------4-----5-----6-----7-----8-----9-----10

(10 indicating high level of engagement) 
7. Your community's level of engagement in project implementation?

$$
\text { 1------2------3------4-----5-----6-----7-----8-----9-----10 }
$$

(10 indicating high level of engagement)

8. Government's level of engagement in project implementation?

$$
\begin{aligned}
& \text { 1------2------3------4-----5-----6-----7-----8-----9-----10 } \\
& \text { (10 indicating high level of engagement) }
\end{aligned}
$$

9. Level of monitoring by the implementing CSO?

$$
\text { 1------2------3------4-----5-----6-----7-----8-----9-----10 }
$$

(10 indicating high level of engagement)

10. Level of the project monitoring by your community?

$$
\text { 1------2------3------4-----5-----6-----7-----8-----9-----10 }
$$

(10 indicating high level of engagement)

11. Level of feedback on evaluation conducted by the CSO?

$$
\text { 1------2------3------4-----5-----6-----7-----8-----9-----10 }
$$

(10 indicating high level of engagement)

12. Level of evaluation and feedback to the CSO by the community?

$$
\begin{aligned}
& \text { 1------2------3------4-----5-----6-----7-----8-----9-----10 } \\
& \text { (10 indicating high level of engagement) }
\end{aligned}
$$

13. Level of leadership (control) shown by the community in the process?

$$
\begin{aligned}
& \text { 1-----2------3------4-----5-----6-----7-----8-----9-----10 } \\
& \text { (10 indicating high level of engagement) }
\end{aligned}
$$

14. Community's capacity to make decisions in the process?

$$
\text { 1------2------3------4-----5-----6-----7-----8-----9-----10 }
$$

(10 indicating high level of engagement)

15. Level of women's engagement with the project design?

$$
\text { 1------2------3------4-----5-----6-----7-----8-----9-----10 }
$$

(10 indicating high level of engagement) 
16. Level of women's engagement during the project life cycle?

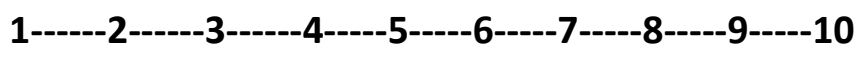

(10 indicating high level of engagement)

17. Level of traditional knowledge attributed to the project by the local community?

$$
\text { 1------2------3------4------5-----6-----7-----8-----9-----10 }
$$

(10 indicating high level of engagement)

18. Level of technical expertise offered by the CSO to the community?

$$
\text { 1------2------3-------4-----5------6-----7-----8------9-----10 }
$$

(10 indicating high level of engagement)

19. Level of transparency of funding by the implementing agency?

$$
\text { 1------2------3------4-----5-----6-----7-----8-----9-----10 }
$$

(10 indicating high level of engagement)

20. Level of Ownership built into the project by the CSO at the beginning of the project?

$$
\text { 1------2------3------4-----5-----6-----7-----8-----9-----10 }
$$

(10 indicating high level of engagement)

21. Level of community's Ownership of the project at the end?

$$
\text { 1------2------3------4------5-----6-----7-----8-----9-----10 }
$$

(10 indicating high level of engagement)

22. Did the CSO engage with your community after the end of the project? Did they capture and share the lessons learnt?

$$
\text { Yes ? No ? How? }
$$

23. Do you share the information with other communities?

$$
\text { Yes ? No ? How? }
$$

24. Thanks for your participation. Please indicate if you would like to...

a. a)... be informed about the findings of this research

b. b)... participate in a follow-up survey 


\section{Appendix 6 - List of Research Participants}

\begin{tabular}{|c|c|c|c|c|}
\hline & Last Name & First Name & Organisation & Position \\
\hline 1 & Aakanisi & Ratu beko & Kava farmer & Community Member \\
\hline 2 & Acton & Ged & Wildlife Conservation Program & $\begin{array}{l}\text { Stakeholder Engagement } \\
\text { Officer }\end{array}$ \\
\hline 3 & Adsett & Neil & Government of Tonga & Attorney General \\
\hline 4 & Aho & Leveni & $\begin{array}{l}\text { National Emergency Management } \\
\text { Office, Government of Tonga }\end{array}$ & Director \\
\hline 5 & Akilisi Pohiva & Samuela & Peoples' Representative Tongatapul & Member of Parliament \\
\hline 6 & Ākolo & Lisiate 'Aloveita & $\begin{array}{l}\text { Government of Tonga, Ministry of } \\
\text { Finance and National Planning }\end{array}$ & $\begin{array}{l}\text { Minister of Finance and } \\
\text { National Planning }\end{array}$ \\
\hline 7 & Barr & Fr Kevin J & People's Community Network Fiji & $\begin{array}{l}\text { Consultant (Coordinator PCN } \\
\text { Housing Project) }\end{array}$ \\
\hline 8 & Blake & Betty & MFF Tonga & Executive Director \\
\hline 9 & Bolabola & Akisi & WWF - Fiji & Advisor \\
\hline 10 & Borg & Mark & $\begin{array}{l}\text { IUCN (International Union for } \\
\text { Conservation of Nature }\end{array}$ & $\begin{array}{l}\text { Strategic Partnership, } \\
\text { Membership \& Project } \\
\text { Development Advisor }\end{array}$ \\
\hline 11 & Brownjohn & Michael & $\begin{array}{l}\text { FCDP (Fiji Community Development } \\
\text { Program }\end{array}$ & Team Leader \\
\hline 12 & Bryce-Favonuku & Dorothy & Tonga National Council of Churches & $\begin{array}{l}\text { Assistant Regional Program } \\
\text { Manager }\end{array}$ \\
\hline 13 & Cakau & Miriama & $\begin{array}{l}\text { Farmer working with the CSO FRIEND } \\
\text { in Labasa }\end{array}$ & Project Coordinator \\
\hline 14 & Casimira & Aisake & $\begin{array}{l}\text { Pacific Conference of Churches (PCC) } \\
\text { Fiji }\end{array}$ & Programme Officer \\
\hline 15 & Choe & Joanne & AusAid & $\begin{array}{l}\text { Counsellor Development } \\
\text { Australian High Commission, } \\
\text { Suva, Fiji }\end{array}$ \\
\hline 16 & Costello-Olsson & Koila & Pacific Centre for Peacebuilding & Director \\
\hline 17 & Davies & Kate & Red Cross & Advisor \\
\hline 18 & Delurey & John & $\begin{array}{l}\text { University of Arkansas, Clinton School } \\
\text { of Public Service }\end{array}$ & $\begin{array}{l}\text { American volunteer on Chiton } \\
\text { Scholarship/ MPS Candidate } \\
2014\end{array}$ \\
\hline 19 & DongJin & Wei & $\begin{array}{l}\text { Immigrant worker from China (arrived } \\
\text { in Tonga 11th May 2013) }\end{array}$ & Community Member \\
\hline 20 & Ernst & Dr Manfred & Pacific Theological College & Director \\
\hline 21 & Fakafanua & Lord & Legislative Assembly of Tonga & Speaker of the House \\
\hline
\end{tabular}




\begin{tabular}{|c|c|c|c|c|}
\hline & Last Name & First Name & Organisation & Position \\
\hline 22 & Faletau & Siosaia & World Bank and ADB & Delegation/Mediator \\
\hline 23 & Famkakonkaetan & Amamaiu & Ministry of Health & Advisor \\
\hline 24 & Feger & Mauitau & $\begin{array}{l}\text { Tonga National Leadership } \\
\text { Development Forum }\end{array}$ & Secretariat \\
\hline 25 & Fua & Dr Seu'ula Johansson & USP Institute of Education & Director \\
\hline 26 & Guttenbeil-Likiliki & Ofa & Women and Children Crises Centre & Director \\
\hline 27 & Hashimato & Yohei & $\begin{array}{l}\text { Japan International Cooperation } \\
\text { Assistance (JICA) }\end{array}$ & JICA Representative To Fiji \\
\hline 28 & Hassan Khan & Mohammed & Fiji Council of Social Service & Director \\
\hline 29 & Haukinima & Tevita & Free Wesleyan Church & Secretary for Finance \\
\hline 30 & Havea & Drew & Tonga Civil Society Forum & Chair of the Board \\
\hline 31 & Hokafonu & Ta'hirih F. & $\begin{array}{l}\text { Tonga Secondary School Leadership } \\
\text { Program PLP/AuzAid }\end{array}$ & $\begin{array}{l}\text { Program Monitor - Consultant } \\
\text { for Education: Secondary School } \\
\text { Principal }\end{array}$ \\
\hline 32 & Hoponoa & Amelia Tipaleli & Tonga Family Health Association & Executive Director \\
\hline 33 & Horoi & Rex & $\begin{array}{l}\text { FSPI Foundation of the Peoples of the } \\
\text { South Pacific International }\end{array}$ & Executive Director \\
\hline 34 & Ilolahia & Siale & Tonga Civil Society Forum & Director \\
\hline 35 & Johansson & L. Aloma & Chamber of Commerce (Tonga) & President \\
\hline 36 & Jupiter & Stacy & Wildlife Conservation Program & Program Director \\
\hline 37 & Jurmo & Paul & PeaceCorps USA & Director \\
\hline 38 & $\mathrm{~K}$ & Sandri & $\begin{array}{l}\text { Foundation for Rural Integrated } \\
\text { Enterprises \& Development }\end{array}$ & Deputy Director \\
\hline 39 & Kara & Pelenatita & Civil Society Forum & Programme Officer \\
\hline 40 & Kaufusi & Malakai H. & $\begin{array}{l}\text { Ministry of Finance, ABD Rep - CSO's } \\
\text { Officer }\end{array}$ & Project Manager MoFNP \\
\hline 41 & Kautoke & Busby S. & Project Beneficiary & PCN \\
\hline 42 & Khan & Ayub & Farmer & EU Aid Project Beneficiary \\
\hline 43 & Kioa & Moana & Tonga National Council of Churches & Project Manager \\
\hline
\end{tabular}




\begin{tabular}{|c|c|c|c|c|}
\hline & Last Name & First Name & Organisation & Position \\
\hline 44 & Koloamatongi & Lola B. & $\begin{array}{l}\text { Tonga National Centre for Women } \\
\text { and Children }\end{array}$ & Trainer \\
\hline 45 & Kuilamu & Ruth & Live and Learn & Programme Manager \\
\hline 46 & Kumar (Reena) & Rup & Indian Woman "farmer" Tavevui & Community Member \\
\hline 47 & Lee & Erica & PIPSO & Research Officer \\
\hline 48 & Leha & Faleata & Salvation Army & Team Leader \\
\hline 49 & Leota & Rev. Siaosi & Anglican Church & Reverend \\
\hline 50 & Lewa & Lite & Ola Fou & Project Coordinator \\
\hline 51 & Lolohea & Vanessa & Tonga National Youth Congress & Director \\
\hline 52 & Iris & Low-McKenzie & AusAid & $\begin{array}{l}\text { Program Manager } \\
\text { Community Development }\end{array}$ \\
\hline 53 & Ma'afu & Amelia & Caritas Tonga & Programmes Coordinator \\
\hline 54 & Mackenzie & Teresa & CCF + ECREA & Board Member \\
\hline 55 & Madraiwiwi & Joni & Ex Vice-President & Ex Vice-President (Fiji) \\
\hline 56 & Maharaj & Neil & FCOSS & Director \\
\hline 57 & Martin & Jessamie & Ola fou & Programme Manager \\
\hline 58 & Misser & Rhema & National Disability Platform & President \\
\hline 59 & Murdock & Janet & UNDP & $\begin{array}{l}\text { Programme Specialist- CPR } \\
\text { UNDP Pacific Centre }\end{array}$ \\
\hline 60 & Nabulivon & Noelene & Women's Major group on SDG/OWG & Consultant \\
\hline 61 & Naidu & Richard & Fiji Law Society & $\begin{array}{l}2006 \text { Unsuccessful Candidate } \\
\text { for Presidency (Lawyer) }\end{array}$ \\
\hline 62 & Niuila & Kalisi & Tonga National Youth Council & data Office \\
\hline 63 & Numia & Alisi & TMP Law & Ex Attorney General (Tonga) \\
\hline 64 & Ofahulu & Rev. Tevita & FWCT & HOD Communication Division \\
\hline 65 & Ofahulu & Rev. Tevita & Free Wesleyan Church & Reverend \\
\hline
\end{tabular}




\begin{tabular}{|c|c|c|c|c|}
\hline & Last Name & First Name & Organisation & Position \\
\hline 66 & Ofee & Grant & Tonga Police & $\begin{array}{l}\text { CEO/ Tonga Police } \\
\text { Commissioner }\end{array}$ \\
\hline 67 & Oke & Aisane & Member of parliament (Tonga) & Member of Parliament \\
\hline 68 & Pale'o & Gloria & Legislative Assembly of Tonga & $\begin{array}{l}\text { Clerk of the Legislative } \\
\text { Assembly of Tonga }\end{array}$ \\
\hline 69 & Palu Lātū & Natalia & Ministry of Finance, Tonga & Advisor, Principal Economist \\
\hline 70 & Parsad & Ayodhya & Farmer & EU Aid Project Beneficiary \\
\hline 71 & Patolo & Soane & TRIP Tonga Rural Innovation Project & $\begin{array}{l}\text { Project Manager - General } \\
\text { Manager }\end{array}$ \\
\hline 72 & Penjueli & Moureen & Pacific Network on Globalisation & Director \\
\hline 73 & Poulsen & Peter & $\begin{array}{l}\text { Ministry of Finance and National } \\
\text { Planning } \\
\text { Nuku'alofa Tonga }\end{array}$ & Economic and Planning Advisor \\
\hline 74 & Puloka & Meleana & Tupou Tertiary Institute & Director \\
\hline 75 & Rabuka & Sitiveni & Ex-Prime Minister & Ex-Prime Minister of Fiji \\
\hline 76 & Rakabi & Sirino & ECREA & Director \\
\hline 77 & Ralifo & Alfred & WWF - Fiji & Regional Organisational Officer \\
\hline 78 & Ratabacaca & Barbara & Save the children, Fiji & Project Manager \\
\hline 79 & Raty & Cabsiga & Farmer & EU Aid Project Beneficiary \\
\hline 80 & Ravumaidama & Tevita & $\begin{array}{l}\text { PCDF Partners in Community } \\
\text { Development }\end{array}$ & Executive Director \\
\hline 81 & Robinson & Leaine & AusAid & Civil Society Liaison Officer \\
\hline 82 & Rokodredre & Cema & SEEP & Community Facilitator \\
\hline 83 & Schuster & Alfred & Pacific Islands Forum Secretariat & $\begin{array}{l}\text { Development Cooperation } \\
\text { Adviser }\end{array}$ \\
\hline 84 & Shackleton & Peter & NZAID & Deputy High Commissioner \\
\hline 85 & Sing & Etika & Rotary Pacific Water & Projects Coordinator \\
\hline 86 & Singh & Artika & Live and Learn & Finance Officer \\
\hline 87 & Singh & Smita & USP Ethics and Governance & USP Professor \\
\hline
\end{tabular}




\begin{tabular}{|c|c|c|c|c|}
\hline & Last Name & First Name & Organisation & Position \\
\hline 88 & Slatter & Claire & $\begin{array}{l}\text { USP Professor of Development } \\
\text { Studies }\end{array}$ & Academic/Activist \\
\hline 89 & Ta'ai & Analena & Apifo'ou College & Teacher \\
\hline 90 & Taai & Torika & Farmer in Labasa & Community Member \\
\hline 91 & Talepapalangi & Palu & Ministry of Finance & Aid Management Advisor \\
\hline 93 & Taufe'ulungaki & Dr. 'Ana Maui & Ministry of Education & Minister \\
\hline 94 & Tauiakitaki & Alamoti & MORDI (Tonga) & $\begin{array}{l}\text { MORDI Board Member and } \\
\text { Advisor }\end{array}$ \\
\hline 95 & Tevi & Fei & IUCN & Project Coordinator \\
\hline 96 & Toeapi & Anitelu & Ola Fou & Team Leader \\
\hline 97 & Tonga & Siketi & Tonga Council of Churches & Advisor \\
\hline 98 & Tora & Lai & $A B D$ & $\begin{array}{l}\text { Economist (Public Finance) } \\
\text { South Pacific Subregional Office }\end{array}$ \\
\hline 99 & Troller & Simone & UNDP & $\begin{array}{l}\text { Governance Specialist Human } \\
\text { Rights \& Civil Society }\end{array}$ \\
\hline 100 & Tsujimoto & Makoto & $\begin{array}{l}\text { Japan International Corporation } \\
\text { Agency }\end{array}$ & Japan's Aid Representative \\
\hline 101 & Tubuna & Sakivsa & IFAD & $\begin{array}{l}\text { Sub-Regional Coordinator, Asia } \\
\text { and Pacific Division, Programme } \\
\text { Management Department }\end{array}$ \\
\hline 102 & Tuiano & Pesalili F. & Ministry of Infrastructure & O.I.C for ENG/Div \\
\hline 103 & Tuita & Milika & UNDP & Country Development Manager \\
\hline 104 & Tully & Anne & World Bank & Pacific Rep \\
\hline 105 & Tuuholoaki & Eva & Tonga Red Cross Society & Secretary General \\
\hline 106 & Vaisima & Fr Aisake & Tue Apifoou College Tonga (Tonga) & Principal \\
\hline 107 & Valemei & Isikeli & UNDP - Pacific Centre & $\begin{array}{l}\text { Programme Assistant - } \\
\text { Democratic Governance }\end{array}$ \\
\hline 108 & Van Brink & John & Tonga Power Limited & Chief Executive \\
\hline 109 & Vea & Viliami "Bill" Paelata & Loss Prevention Management Security & Managing Director \\
\hline
\end{tabular}




\begin{tabular}{|c|c|c|c|c|}
\hline & Last Name & First Name & Organisation & Position \\
\hline 110 & Waqa & Taniela & Farmer & Community Member \\
\hline 111 & Waqetia & Amani & Ola Fou - PRAXIS NZ & Polynesian Coordinator \\
\hline 112 & Waugh & Kevin & Salvation Army & $\begin{array}{l}\text { Captain, Regional Support } \\
\text { Officer, Tonga }\end{array}$ \\
\hline 113 & Wiseman & Garry & UNDP / Fiji Women's crises centre & Manager \\
\hline 114 & Wlawi & Sameula & Tui Road PCN & Community Member \\
\hline 115 & Yabaki & Reverend Akvila & CCF - Fiji & Director \\
\hline 116 & Yavalanavanua & Volau & Wife of the Chief & $\begin{array}{l}\text { Wife of the Chief of the Taveuni } \\
\text { Island }\end{array}$ \\
\hline 117 & Yee & Rodney & Citizens' Constitutional Forum & Programme Manager \\
\hline 118 & Zhiguang & $\mathrm{Xu}$ & Chinese Embassy in Tonga & First Secretary \\
\hline
\end{tabular}




\section{Appendix 7 - Formulas for Calculating Ownership}

\begin{tabular}{|c|c|}
\hline Ownership Measure & Formula for Calculating Ownership \\
\hline $\begin{array}{l}\text { Measure 1: Who Identifies the } \\
\text { Problem (idea)? }\end{array}$ & $\begin{aligned} & \mathrm{M}_{1}=(10 \text { if } \mathrm{S} 1==\text { The Community", or } 5 \text { if } \mathrm{S} 1=" \mathrm{NGO} " \text {, and } \\
&2.5 \text { if } \mathrm{S} 1=\text { other })+\mathrm{S} 5) /(2 * 10)\end{aligned}$ \\
\hline $\begin{array}{l}\text { Measure 2: Who Identifies the } \\
\text { Solution? }\end{array}$ & $\begin{aligned} & \mathbf{M}_{2}=(10 \text { if } \mathrm{S} 2==\text { The Community", or } 5 \text { if } \mathrm{S} 2=" \mathrm{NGO} " \text {, and } \\
&2.5 \text { if } \mathrm{S} 2=\text { other })+\mathrm{S} 5) /(2 * 10)\end{aligned}$ \\
\hline $\begin{array}{l}\text { Measure 3: Who designs the } \\
\text { project (plan for change)? }\end{array}$ & $\mathbf{M}_{3}=\left(S_{3}+S_{5}+S_{6}+S_{16}+S_{21}\right) /(5 * 10)$ \\
\hline $\begin{array}{l}\text { Measure 4: Who conducts } \\
\text { interim appraisals of the } \\
\text { project? }\end{array}$ & $\mathrm{M}_{4}=(\mathrm{S} 7) /(1 * 10)$ \\
\hline $\begin{array}{l}\text { Measure 5: Who finances the } \\
\text { project? }\end{array}$ & $M_{5}=(S 14+S 20) /(2 * 10)$ \\
\hline $\begin{array}{l}\text { Measure 6: Who implements } \\
\text { the project? }\end{array}$ & $\mathbf{M}_{6}=(\mathrm{S} 8+\mathrm{S} 9+\mathrm{S} 14+\mathrm{S} 15+\mathrm{S} 17+\mathrm{S} 19) /(6 * 10)$ \\
\hline $\begin{array}{l}\text { Measure 7: Who monitors the } \\
\text { project? }\end{array}$ & $M_{7}=(S 10+S 11+S 14+S 15) /(4 * 10)$ \\
\hline $\begin{array}{l}\text { Measure } 8: \text { Who evaluates } \\
\text { the project? }\end{array}$ & $\mathrm{M}_{8}=(\mathrm{S} 12+\mathrm{S} 13+\mathrm{S} 14+\mathrm{S} 15+\mathrm{S} 17+\mathrm{S} 18) /(6 * 10)$ \\
\hline $\begin{array}{l}\text { Measure 9: Who maintains } \\
\text { and protects the subject of } \\
\text { the aid? }\end{array}$ & $\mathrm{M}_{9}=(\mathrm{S} 18+\mathrm{S} 21+\mathrm{S} 22) /(3 * 10)$ \\
\hline
\end{tabular}

The Table above shows the formulas used to determine the individual Ownership Measures discussed in Chapter 2. Logic formulas were used for qualitative assessments as discussed and averages were used for numerical answers. All answers were then converted into a percentage for a consistent rating of ownership. Based on the formulas offered above the 'ownership' rating formulae can be described as:

\section{Ownership $=\left(\left(M_{1}+M_{2}+M_{4}+M_{5}+M_{6}+M_{7}+M_{8}+M_{9}\right)\right) / 9$}

Where $\mathbf{O}$ is the Ownership rating, $\mathbf{S}$ is the Survey question, $\mathbf{M}$ the individual Ownership Measure, and the subscript indicates the measure. As individual measures are found to be more or less influential to the final Ownership result, the weight of the final 9 individual measures $(\mathrm{M})$ remains the same. 
The degree of the importance of each measure and its devisers have been selected based on the effect they have on nurturing ownership and each was identified through the survey questions and the semi-structured interviews as research advanced. The individual measures are heavily dependent and calculated based on the answers provided to surveys completed by the project implementers and project beneficiaries (See Appendix 4 and 5). Each survey answer is critical and is also a devisor that informs one of the project cycle Measures, with some measures based on multiple survey answers (devisors).

Each of the final 9 Measures adopted have the potential to skew the final index upwards or downwards and that is why they are all given equal value. For example, if a project has very low ownership in five of the nine measures, average ownership in one measure, and very high ownership in two measures, the final index would show a medium-low level of ownership, even though the community had very little ownership over more than half of the project cycle. The opposite is also true, hiding high levels of ownership.

The ratings are based on the qualitative assessments of the research participants and overall perception of the stakeholders and their interactions, although there is no concrete quantitative aspect to both research and analysis as discussed in detail in Chapter 2. The qualitative assessments and the index does document and capture the essence of ownership for comparison and further analysis based on scores allocated by interviewees to variables. 
Appendix 8 -Average of Perceived Ownership for the Three Case Studies

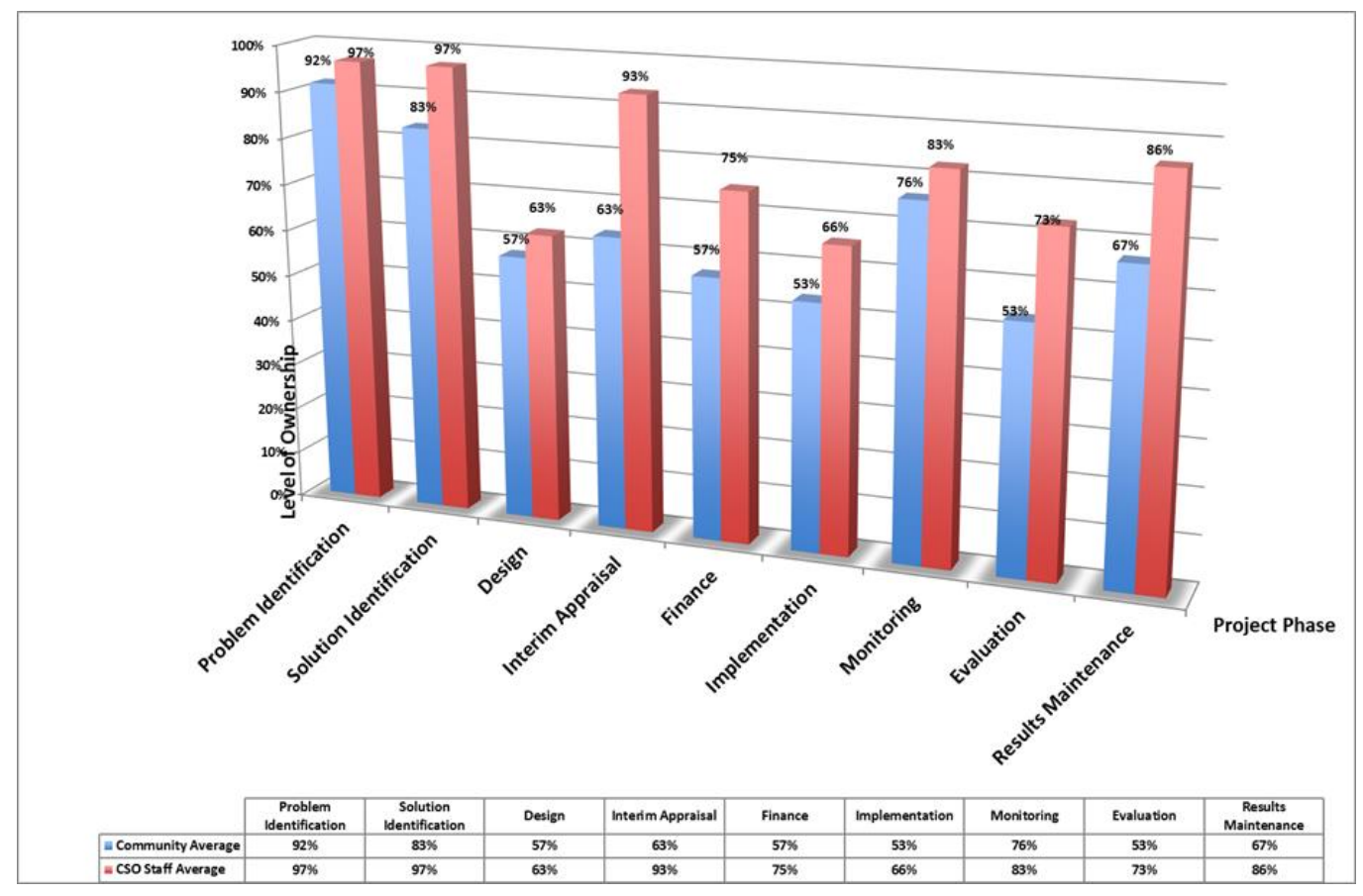


Appendix 9-Perceived Levels of Ownership

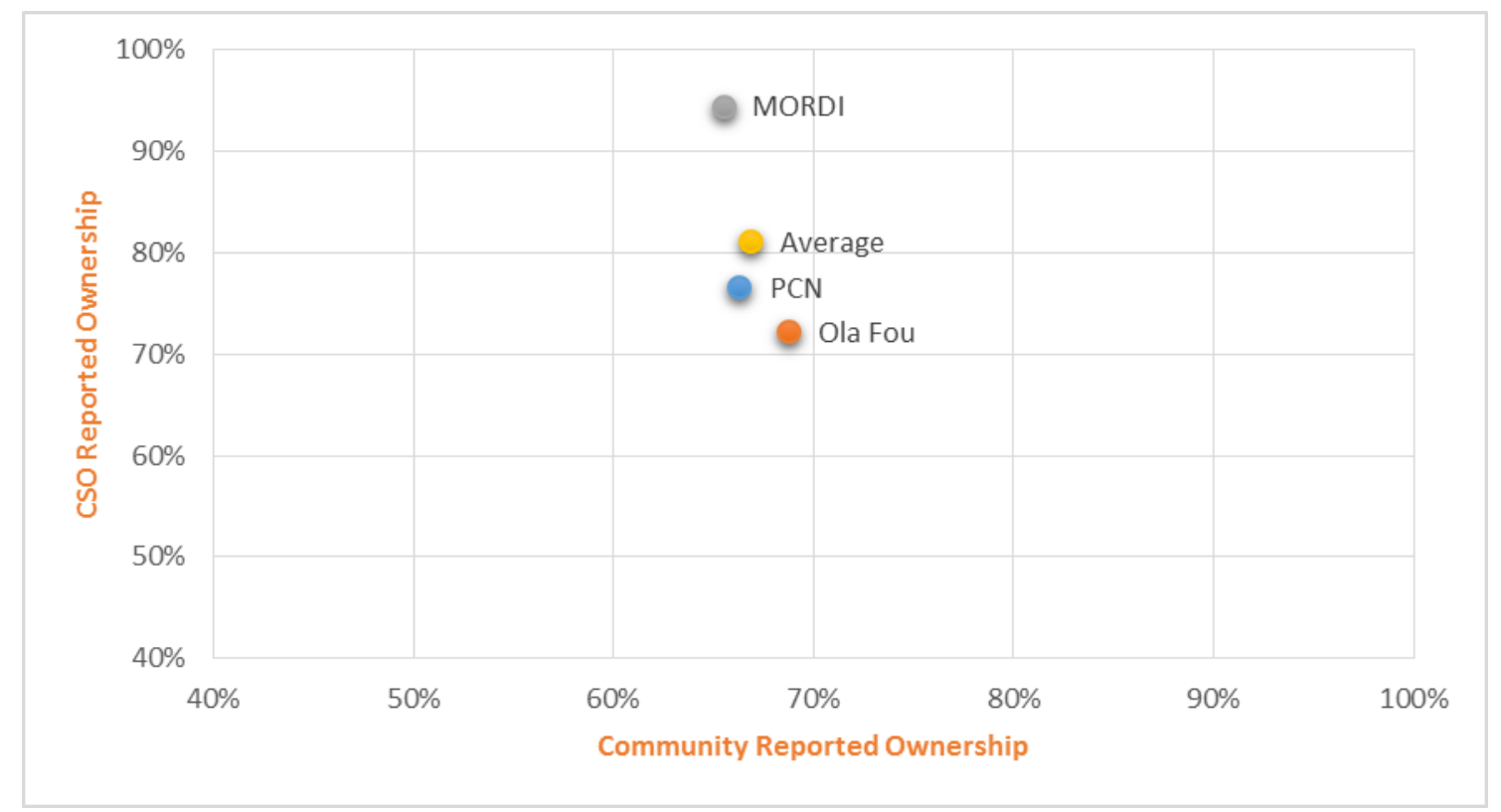


Appendix 10 - The Level of Women's Engagement in Each Case Study

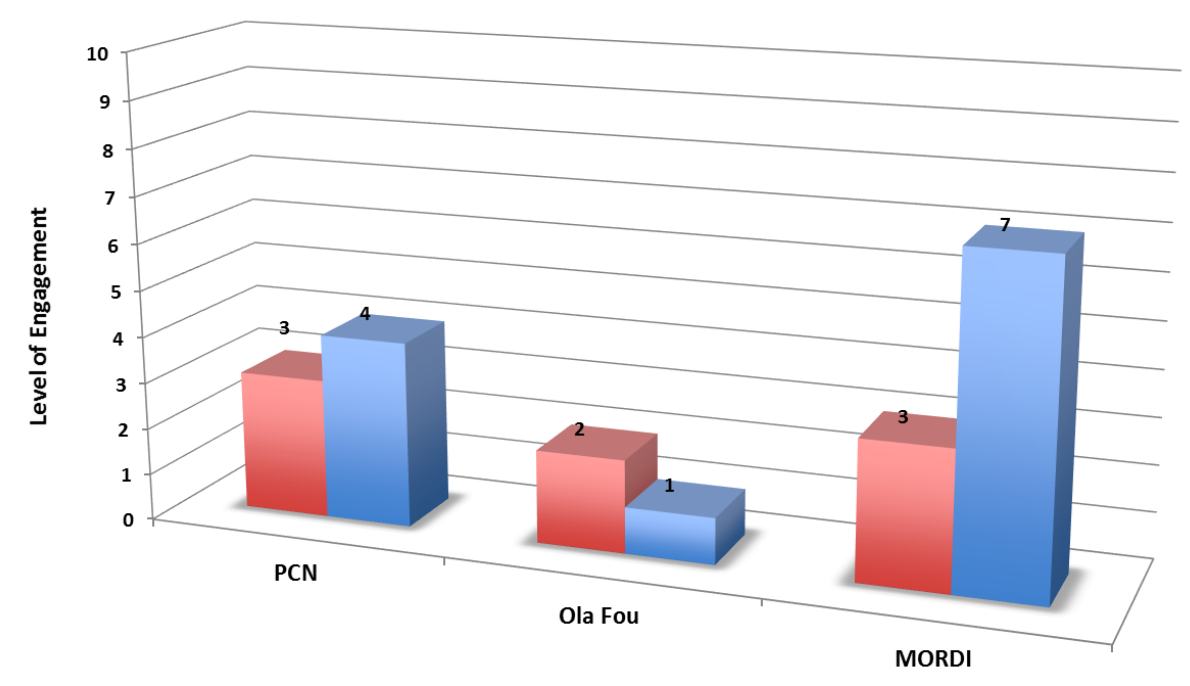

Community $\unrhd$ CSO 